Doctoral Dissertation

\title{
Coordination in Optimality Theory
}

\author{
MikLós GÁsPÁR
}

2005 
Eötvös Loránd University

Faculty of Humanities

Doctoral Dissertation

MikLós GÁsPÁR

\section{Coordination in Optimality Theory}

Linguistics Doctoral School

English Linguistics Program

Supervisor: Dr. Mark Newson

Budapest, 2005 


\section{Supervisor's Signature}

Dr. Mark Newson

\section{Declaration}

I hereby certify that this dissertation is entirely the result of my own work, and that no material is included for which a degree has previously been conferred. I have faithfully, exactly and properly cited all sources made use of in the dissertation.

Date: January 25, 2005

Miklós Gáspár 


\section{Abstract \\ Coordination in Optimality Theory \\ by Miklós Gáspár \\ Supervisor: Dr. Mark Newson}

This dissertation provides an analysis of coordination within a restricted version of Optimality Theory (OT), operating exclusively with alignment and faithfulness constraints. It is shown that this version of OT, which does not assume the existence of syntactic structure, is capable of handling coordination phenomena that have been problematic for previous structureless accounts, while at the same time also avoids the problems encountered by structure-based theories trying to fit coordination into models developed to account for structures occurring elsewhere.

It is standardly assumed in OT that syntactic structure conforming to X-bar Theory axioms is imposed on all the candidates generated from the input by the structure building component of the grammar. I reject this view and contend that it is by eliminating from the grammar historically inherited axioms about X-bar Theory or even the central notion of phrases that we can unlock the real power of OT: the violable constraints that make up the evaluation system are solely responsible for the grammar and grammatical differences between languages.

I show how such an assumption, originally conceived in Newson (2000b), can predict basic word order patterns and can also account for topicalization as well as coordination in a wide variety of language types. As syntactic OT in general, and alignment OT in particular are relatively novel developments within linguistic research, the basic principles of the theory are still being formed. I show that the originally assumed family of predicate alignment constraints alone is not capable of accounting for a variety of data such as SOV language pattern as well as topicalization and focalization in a variety of languages, and introduce a second family of alignment constraints. Contrary to the predicate alignment constraints, which establish the position of an element with respect to its predicate (or, more generally, functor), first and last constraints sanction the placement of elements to the beginning and the end of 
the string, respectively. The interaction of these constraints with each another and with the functor alignment and the faithfulness constraints provides a powerful grammar.

The coordinative conjunction is argued to be a functor, taking the predicates of the propositions it conjoins as its arguments. As a functor, the functor constraints originally developed for the predicate-argument relationship are relevant for the conjunction-conjunct alignment relationship as well.

Central to the analysis of ellipsis is the claim that ellipsis is not only characterized by phonological absence, but by syntactic absence as well. Essentially, ellipsis is treated as a semantic phenomenon: it is up to the semantic component of the grammar to reconstruct elided material missing from all other levels of grammatical description. In the framework adopted semantic interpretation is based on the input of the optimality system. Thus the input is the foundation of ellipsis phenomena - as much as it contains gaps for material that surface as elided. I suggest that semantic reconstruction of missing input material occurs via a higher-order unification process and that the sentence receives interpretation only if this unification process succeeds. 


\section{Acknowledgments}

No acknowledgment can put right the debt I owe my supervisor Mark Newson. Without his probing questions, his comments that pulled the carpet out of entire chapter drafts and his encouraging smile I would not have gotten near to completing this thesis. The basics of the particular Optimality Theoretical framework I have adopted are also due to Mark. But above all he taught me not to accept an assumption just because I have heard it or seen it written countless times and everybody else believes in it. Though the essence of scientific progress is supposed to be questioning old truths and assumptions, rare is the researcher who pursues this basic principle as tirelessly and inspiringly as Mark.

The role of Professor László Varga goes way beyond his role as the director of the $\mathrm{PhD}$ program and the inspiring teacher of many courses during both my undergraduate and graduate studies. It was in one of his Introduction to Linguistics seminars on an early Friday morning in October 1992 that I realized the study of language does not need to be as utterly boring as it had appeared in 12 years of grammar classes. I have been hooked on syntax ever since.

Chris Wilder raised my curiosity in the subject of coordination at a linguistic summer school in Olomouc in 1994. A second-year undergraduate student, I was astonished to find out that there are people making their living out of analyzing the behavior of the three-letter word and. Chris was on the forefront of this research then, and has remained a very influential figure in minimalist ellipsis theories since. His influence on this work will be evident in Chapters 1, 4 and 5.

I would like to thank the audience of the $4^{\text {th }}$ NWCL International Conference on coordination at the University of Salford in 2001 for their critical remarks. Mark and I got bombarded with tough questions - and this clearly hammered home the message that more than average convincing is required when questioning fundamental research axioms. The topic and the outline of this thesis were born that day.

Tamás Décsi has helped me understand the formalisms that underlie the higher order unification algorithms that an earlier version of Chapter 5 were filled with. Though 
my eventual theory took a different turn, the semantic theory in the current version of Chapter 5 could not have been conceived without Tamás's contribution.

Yuko Kitada, a friend for 15 years, has endured many emails and phone calls of questioning regarding Japanese data - and even concluded by the end of one of these sessions that linguistics was a worthy subject.

Doctor Éva Kiss, the supervisor of my M.Sc. thesis in colloid chemistry, has been an important source of inspiration. Spending a year in Doctor Kiss's lab examining the anti-coagulant properties of various polymers has taught me a lot about the trials and tribulations of scientific research and discipline.

Many of my teachers, from Grade 1 through university, have played an indirect, but important role in this work. I was fortunate to have been taught and guided by many remarkable personalities. Attila Villányi has been a role model in more ways than one for the past 15 years. The late Ignéczy Márta néni, Klára Máthé, Sylla Cosineau and Martha Burd have also been very important inspirations.

I would like to thank my boss and colleagues at Pressflex not only for the missed Fridays but also for their patience on many a Monday morning when I showed up at the office more tired than I left at the end of the previous week to spend a weekend with coordination.

Délia and Zalán have shown immense patience and so have Mariette and Pierre, who baby sat and entertained them tirelessly while apa was trying to progress. Marie-Eve has shown a determination that has helped me through many of the harder moments and I hope to return the many sacrifices she has made for this work to get completed.

But above all I would like to thank my parents for putting me through all these years of education, helping me make the right decisions, showing the way when I got discouraged and putting up with some eccentric behavior along the way. As a small sign of gratitude, it is to them that I dedicate this work. 
To my parents 


\section{Table of Contents}

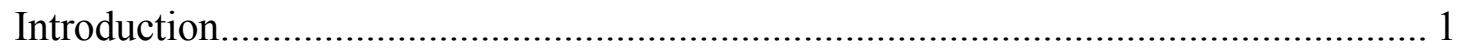

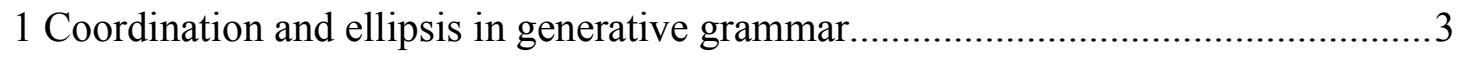

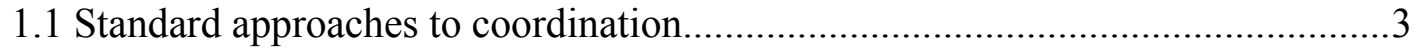

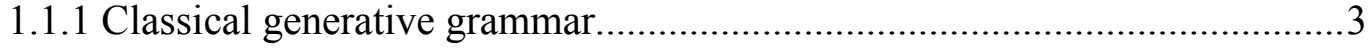

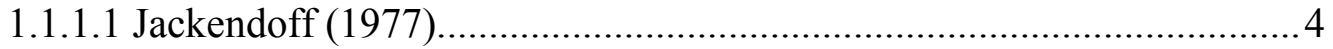

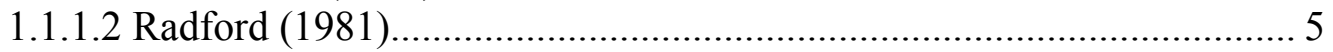

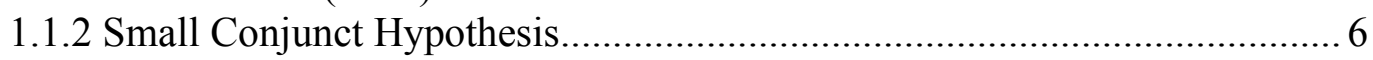

1.1.2.1 X-bar theory and coordination.......................................................... 8

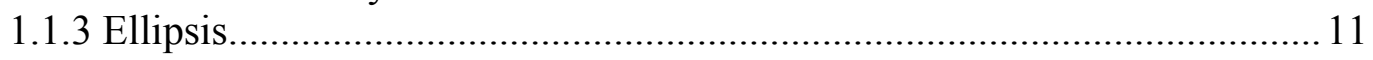

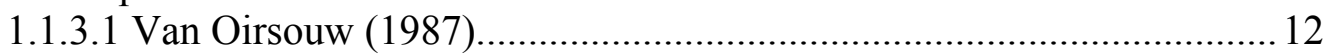

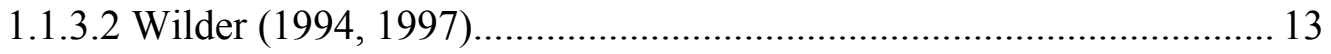

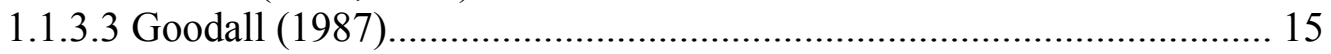

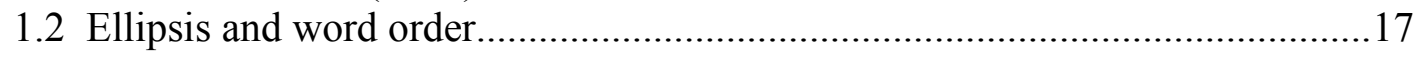

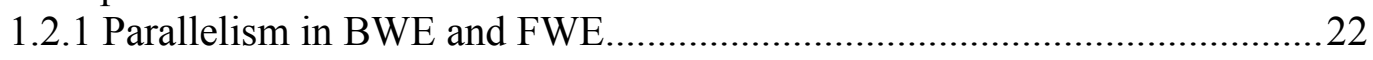

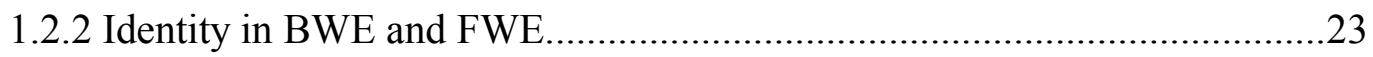

1.2.3 The complementary nature of ellipsis................................................ 26

1.3 Coordination in other "structureless" grammatical theories............................28

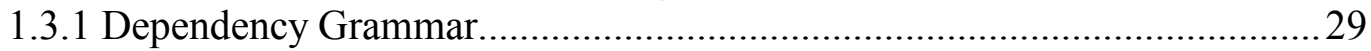

1.3.1.1 Word Grammar....................................................................................

1.3.1.2 Dependency Categorial Grammar................................................... 33

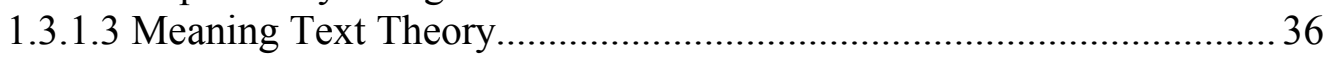

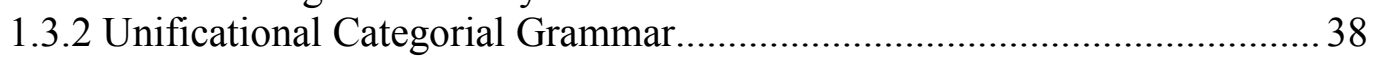

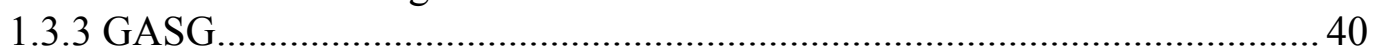

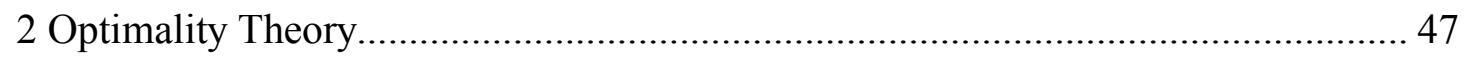

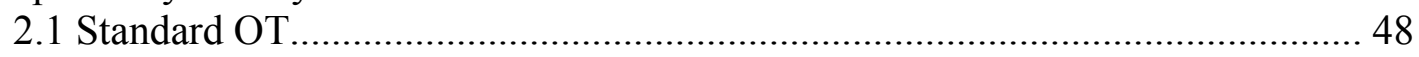

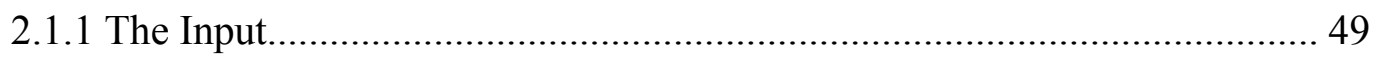

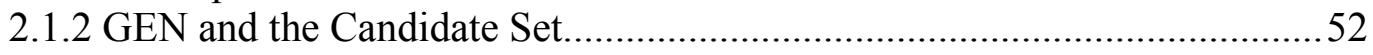

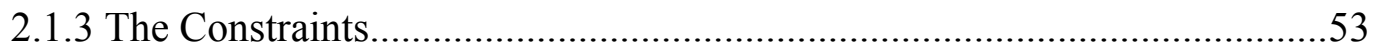

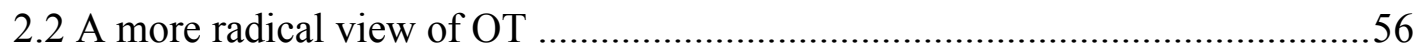

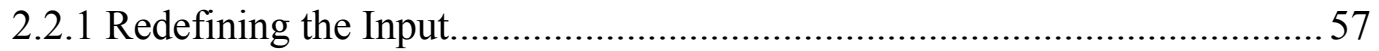

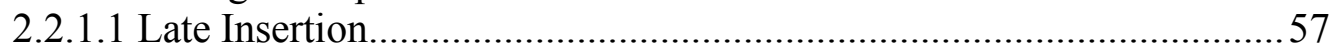

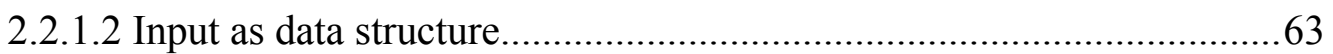

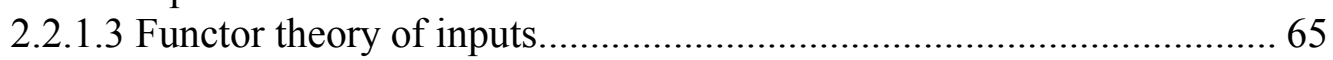

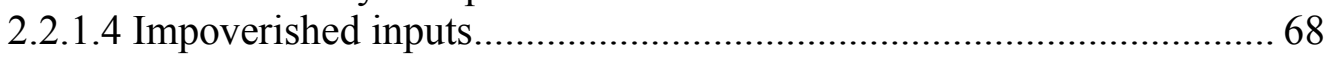

2.2.2 EVAL Revisited: Alignment Syntax..................................................... 70

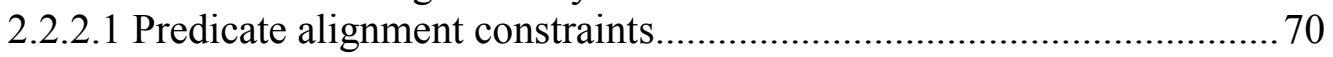

2.2.2.2 Motivation for first/last constraints................................................. 78

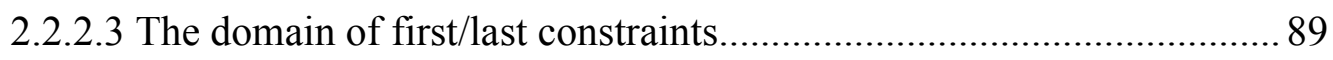

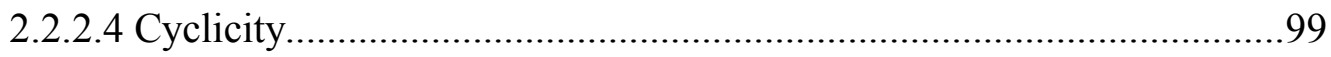

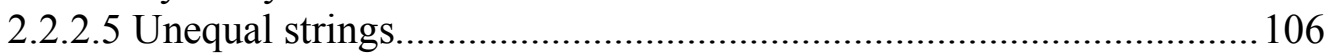

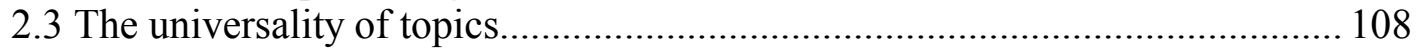

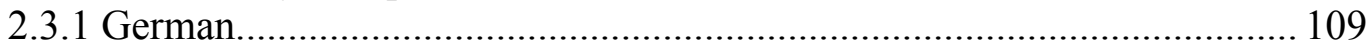

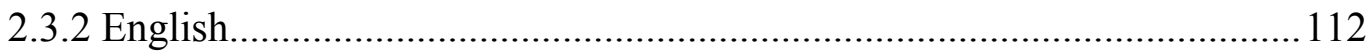

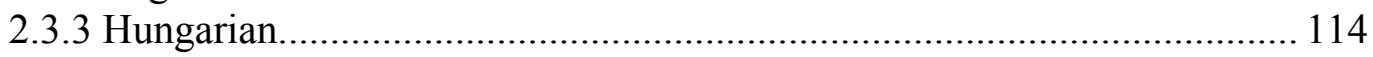

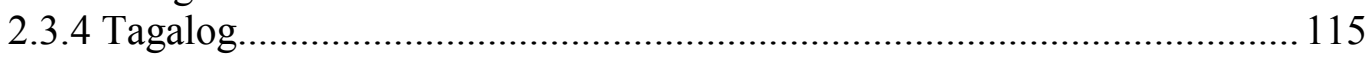

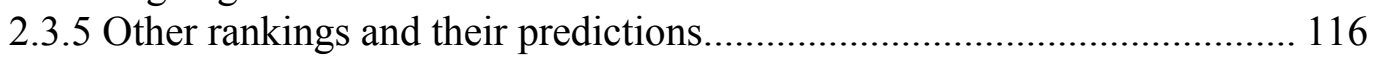

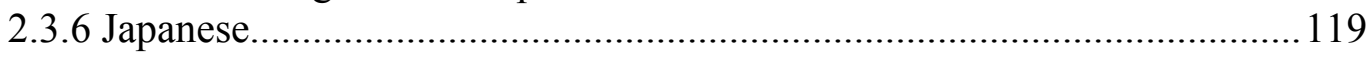




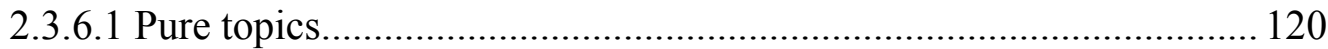

2.3.6.2 Verbal topic.................................................................................. 122

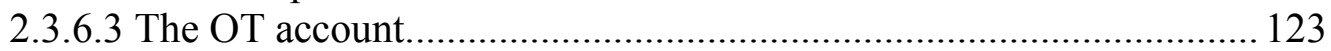

2.3.7 Hungarian and German unaccusatives..................................................... 127

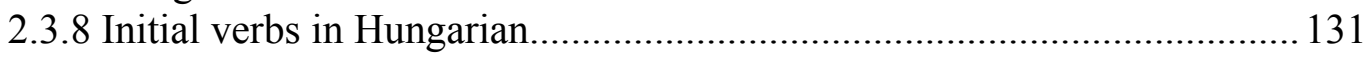

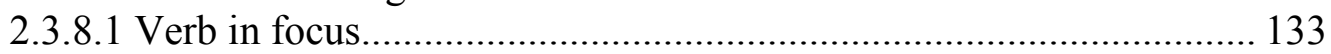

2.3.8.2 The topic of the focal verb................................................................135

2.3.8.3 The OT account............................................................................ 136

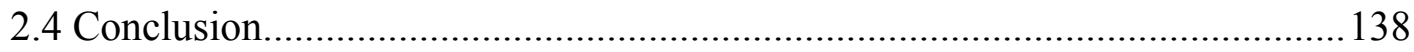

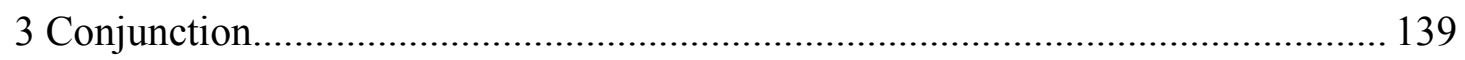

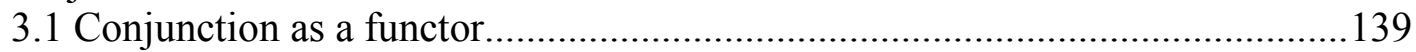

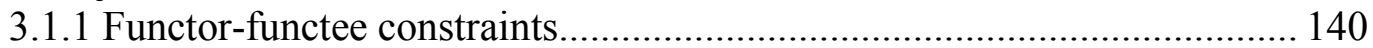

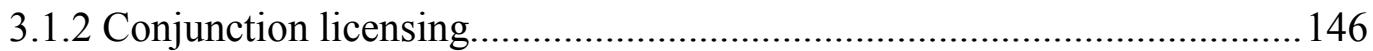

3.1.3 Cyclicity and the ranking for English ((C) ... C \& C)..............................147

3.2 Conjunction patterns and constraint reranking................................................... 150

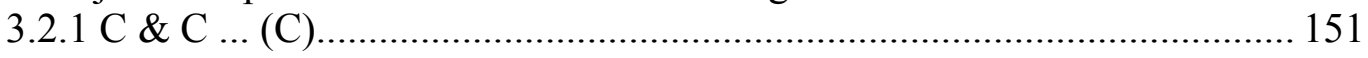

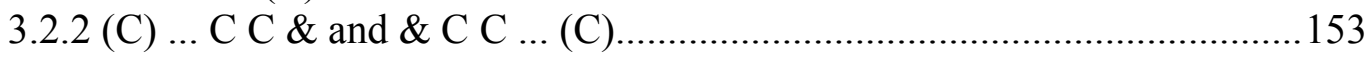

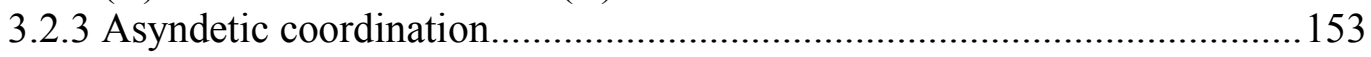

3.3 More complex conjunction patterns............................................................. 158

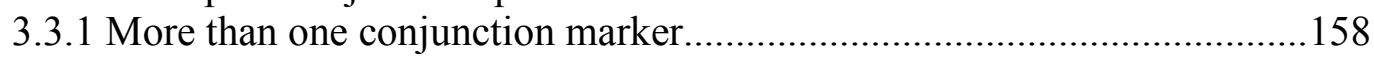

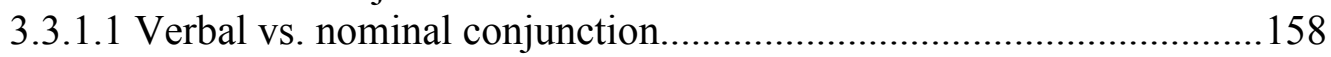

3.3.1.2 Subdividing verbal conjunction.......................................................160

3.3.2 Partially asyndetic coordination.......................................................... 165

3.3.2.1 NP coordination marked..................................................................166

3.3.2.2 Clausal coordination marked.............................................................. 168

3.3.2.3 Nominal, clausal coordination marked...............................................169

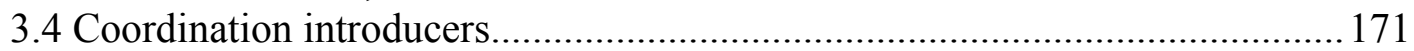

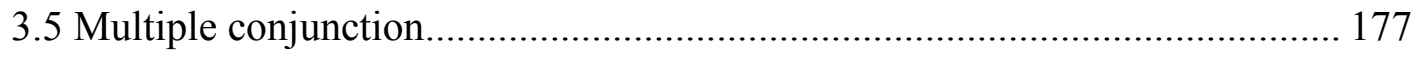

3.6 Other coordination particles...................................................................... 179

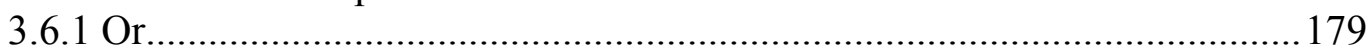

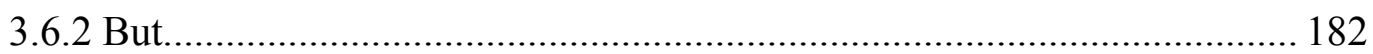

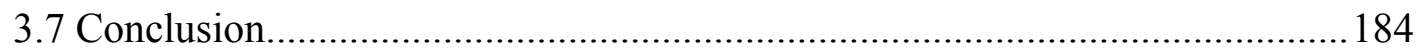

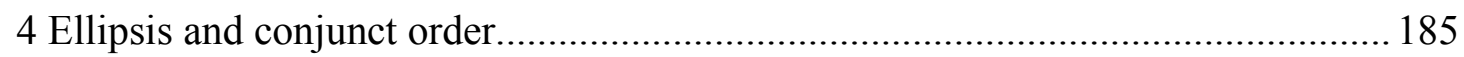

4.1 Conjunct order in full coordination............................................................... 185

4.2 Argument ellipsis in English..................................................................... 187

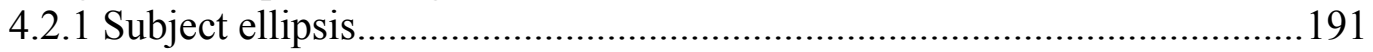

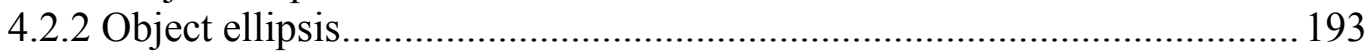

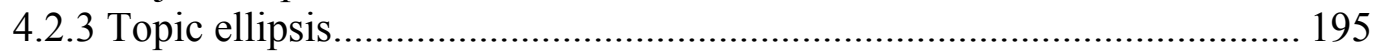

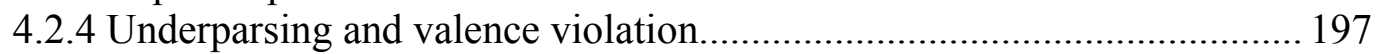

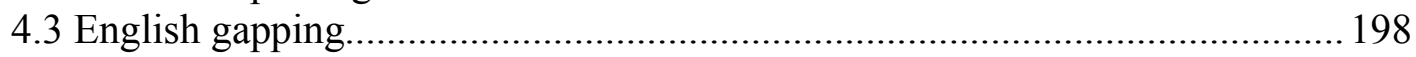

4.3.1 Verb-only gapping................................................................................ 198

4.3.2 Against Ross's generalization...................................................................202

4.3.3 Subject-verb gapping: indirect object cases.............................................. 205

4.3.4 Subject-verb gapping: adjunct cases.......................................................20

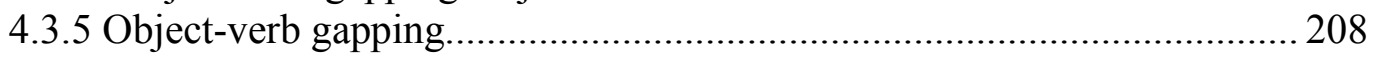

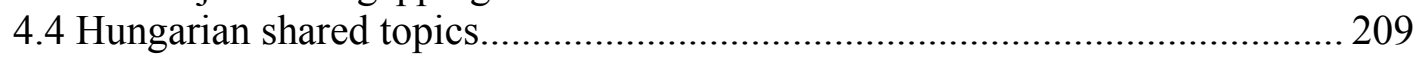

4.5 Gapping in Hungarian................................................................................. 211

4.6 Problematic Hungarian cases..................................................................... 214

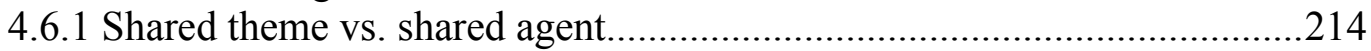

4.6.2 'Gapping' out of verb-final conjuncts.................................................... 217

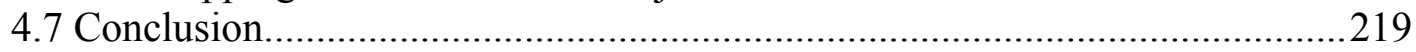




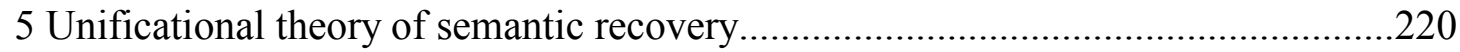

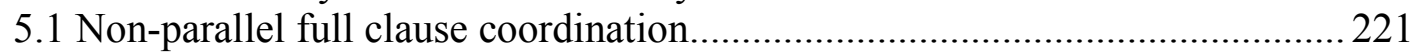

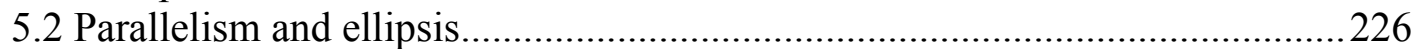

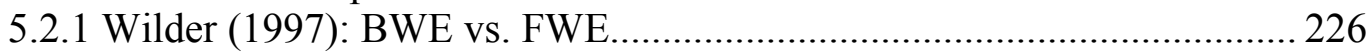

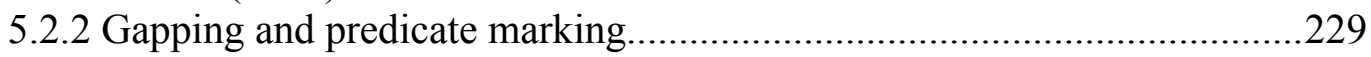

5.2.2.1 Philippine predicates: overt argument feature marking....................231

5.2.2.2 Tundra Yukaghir: focus and topic marking on predicates................ 233

5.2.2.3 Hungarian: definite and indefinite agreement................................. 233

5.2.2.4 Topic marking on predicates: first/last constraints revisited..............234

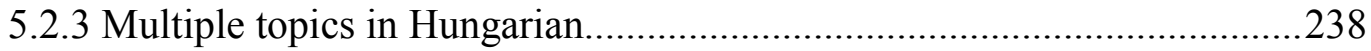

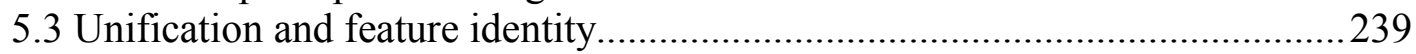

5.3.1 Asymmetrical mismatch and unary features.......................................242

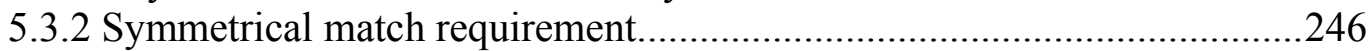

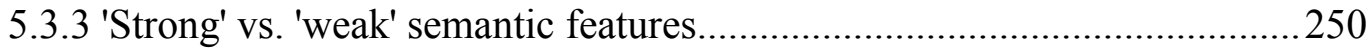

5.3.3.1 Person and number features in English............................................ 250

5.3.3.2 Person and number features in Hungarian..........................................254

5.3.3.3 Assymetric tense recovery in Québec French..................................256

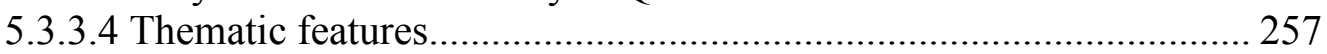

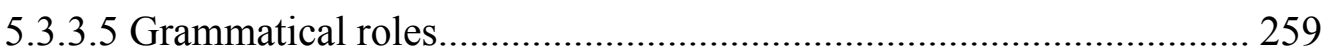

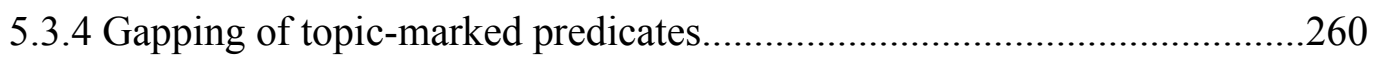

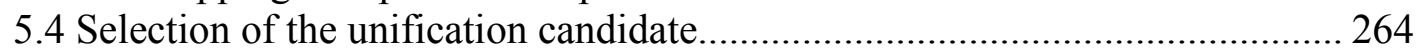

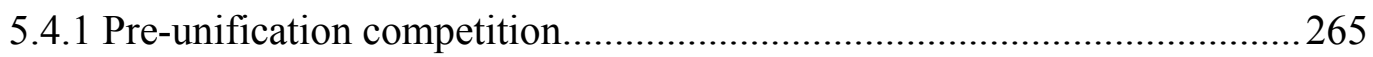

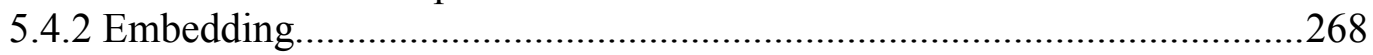

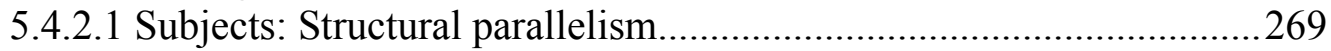

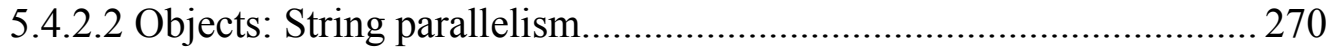

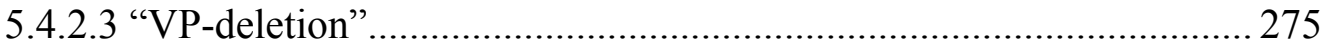

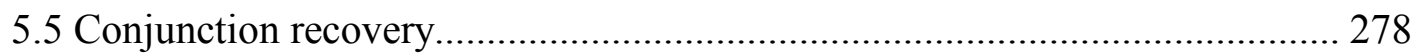

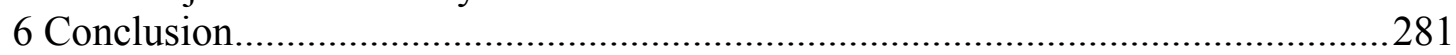

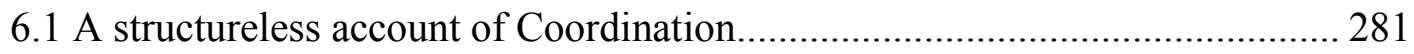

6.2 Additions to OT Alignment Syntax.............................................................228

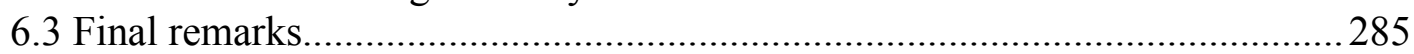

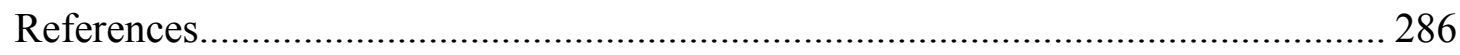





\section{Introduction}

For a three-letter word, and has received far more than its fair share of attention from generative syntacticians over the last half a century. Coordination has indeed been problematic for several grammatical theories: just defining what can be coordinated with what has proved challenging. Early versions of X-bar Theory have viewed grammatical relations in terms of subordination - so symmetrical combination of two clauses was seen as different from other grammatical phenomena. During the extension of X-bar principles to functional categories within the Principles and Parameters (PP) framework in the late 1980s and early 1990s, trying to accommodate coordination into X-bar Theory has created many problems. Theories working without the assumption of syntactic constituent structure have not had an easy ride either: similarly to X-bar accounts, they have had to introduce special rules into their grammar just to account for coordination. These rules often go against the general spirit of the theory, weakening the theoretical claims made by these grammars.

For these reasons an account of coordination within a grammatical theory that is in its infancy is both a challenge and an opportunity: many aspects of the grammar that would be available in a more mainstream framework need to be developed in order to be able to tackle coordination. At the same time, if the need to account for coordination is itself a driving force behind the development of the general aspects of a theory, the process will ensure that a theory of coordination will not require the introduction of special rules that contradict fundamental assumptions. It is this challenge-cum-opportunity that I will attempt to tackle in this thesis: to provide a theory of coordination within a restrictive version of Optimality Theory (OT), an alignment-based grammar that excludes all but a strictly defined permissible set of constraints.

In Chapter 1 I introduce issues of coordination and ellipsis by reviewing some of the influential accounts that have been proposed. I will focus on issues that have been problematic for various grammatical frameworks from a theoretical point of view in terms of fitting coordination into their models. I will also motivate a different view of ellipsis than has been traditionally assumed. 
Chapter 2 will introduce the framework I am adopting: Optimality Theory. After a review of standard optimality theoretical assumptions, I will introduce a more restrictive version of this framework, Alignment OT. This theory is very much in its infancy, which explains why Chapter 2 is the longest chapter of this thesis: many background assumptions that in the case of a similar work within a more developed framework would simply be called upon and reviewed will have to be invented and justified before any analysis of coordination can be attempted.

In Chapter $3 \mathrm{I}$ will provide an account for the placement of the coordinative conjunction within Alignment OT. Much of this chapter will be typologically based, where data from a wide variety of languages will be introduced in order to demonstrate and account for the cross-linguistic behavior of the conjunction particle. I will argue that in many ways the coordinative conjunction is similar to a predicate, and so the kinds of alignment constraints used to account for basic predicate-argument order suffice for the placement of the conjunction with respect to its conjuncts.

Chapter 4 will focus on ellipsis. I will demonstrate that, given the assumptions of Chapter 2, OT constraints responsible for basic word order facts will be able to account for argument ellipsis - and as such the direction of ellipsis will be a consequence of word order facts and will not need to be independently stipulated. Constraints introduced in Chapter 2 to account for a variety of data will be used to provide an account for verbal ellipsis, or gapping.

Finally, in Chapter 5 a rudimentary account of the semantics of ellipsis will be provided, motivated by observations in earlier chapters that many restrictions on ellipsis constructions appear to have semantic, not syntactic roots. I will develop a unificational account of semantic recovery, and the inability of the semantics to reconstruct the ellipsis gap based on information available from the other conjunct will account for the unacceptability of certain ellipsis constructions that have traditionally been treated as ungrammatical.

I will conclude by summarizing the main findings of the thesis, both in terms of an account of coordination and in the general development of Alignment OT as a syntactic theory (Chapter 6). 


\section{Coordination and ellipsis in generative grammar}

In this thesis a theory of coordination will be developed within the framework of Alignment OT. This will be the topic of Chapters 2-5. In this first chapter I would like to set the scene by surveying some of the recent developments in the theory of coordination in generative grammar. I will begin by providing a brief and crude review of standard approaches to coordination, the small conjunct hypothesis and coordination reduction/ellipsis (1.1). I will then review word order observations made in influential ellipsis accounts (1.2). I will also present empirical arguments against the ellipsis observations, as these will be an important motivation for my own account. These two sections will focus on analyses in mainstream frameworks, Government and Binding Theory and Minimalism. A crucial assumption in the framework I am going to adopt in subsequent chapters, an alignment version of Optimality Theory, is that constituent structure is not fundamental in grammar and phrases are epiphenomenal. In the second half of this chapter I will present an overview of different accounts of coordination within theories that similarly deny the existence of constituent structure and show how in many cases coordination has actually been the single most problematic area for these grammars to tackle (1.3). This will prepare the reader for the uphill battle my own account is bound to face.

\subsection{Standard approaches to coordination}

In this brief review I cannot do justice to the accounts I will introduce, and many of the arguments for and against these views will be left unsaid or only mentioned in passing rather than outright argued. My aim is not to give an exhaustive account of the approaches but to provide an overview that will set the scene for the rest of the thesis in general, and the rest of this introductory chapter in particular.

\subsubsection{Classical generative grammar}

Standard theory (Chomsky 1965) and its revised versions operated with phrase structure rules, but at the same time recognized similarities between the constituent structure trees for the different grammatical categories. X-bar Theory was proposed by Chomsky (1970) as a way to capture cross-categorial generalizations, which were missed by category specific phrase structure rules. However, phrase structure rules were not abandoned as they were needed to capture category specific phenomena that 
appeared to defy the generalizations of X-Bar Theory: X-Bar principles coexisted with phrase structure rules acting as a constraint on them (Jackendoff 1977). Coordination stood out as a structure that did not fit into even this lax X-bar model of phrase structure. I will demonstrate the difficulties encountered by reviewing two frameworks, those of Jackendoff (1977) and Radford (1981).

\subsubsection{Jackendoff (1977)}

What by now has become the classical view of constituency in generative grammar was first presented by Chomsky (1970) and more extensively developed by Jackendoff (1977). Syntactic headship was defined and phrases viewed in terms of heads, complements and specifiers.

Jackendoff introduced a four-level structure, illustrated below. The three levels of head projection were used to accommodate elements that are defined in terms of their relationship to the head. He advocated the usage of three projection levels in order to accommodate what are now called adjuncts without resorting to recursion: the mother category of a projection $\mathrm{X}^{\mathrm{i}}$ needs to be $\mathrm{X}^{\mathrm{i}+1}$.

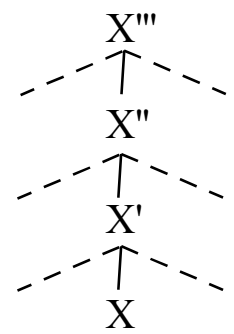

He called coordination an "obvious exception to the theory" (Jackendoff 1977: 50), and noted two kinds of problems: no constituent can be established as the unique head of the conjunction and the arrangement of the categories is not hierarchical, since the top node needs to be of the same category level as its daughters. Both of these problems are illustrated by the example structures in (2). 
(2)

a.

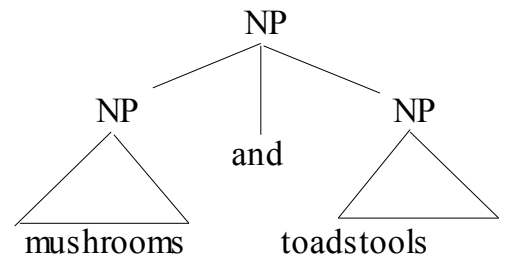

b.

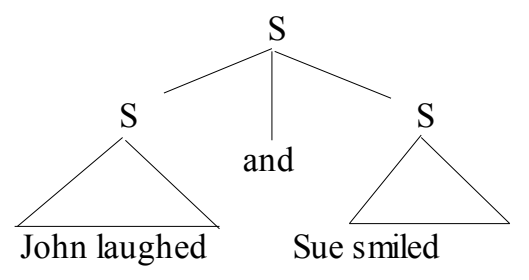

(Jackendoff 1977: 51)

Thus, Jackendoff (1977) concluded, a separate phrase structure rule was necessary to account for the exceptional nature of coordination. This multi-headed, symmetric structure for coordination was also adopted in Chomsky (1981).

\subsubsection{Radford (1981)}

While Jackendoff's work was influential in the development of a more constrained and explanatory syntactic theory, two of its central ideas were later abandoned by syntacticians: the third level of projection and symmetric structure. The X-bar schema adopted by Radford (1981) allowed recursion, so the second of Jackendoff's problems has become void: a mother and a daughter node may be of the same category.

At the same time, the problem of multi-headedness has now become a more striking exception to the asymmetric structures occurring elsewhere - so Jackendoff's problem is now replaced by an even more fundamental one. Compare the structures in (3).

a. $\mathrm{S}$

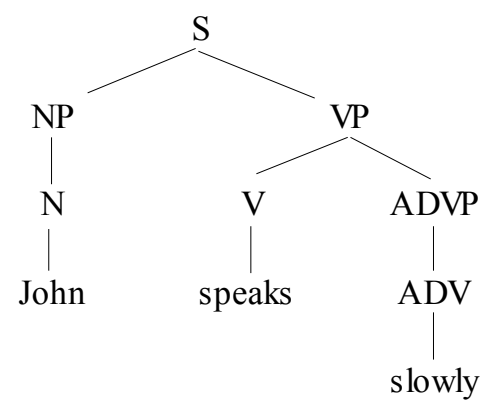

b. NP

(Radford 1981: 88)

(Radford 1981: 95) 


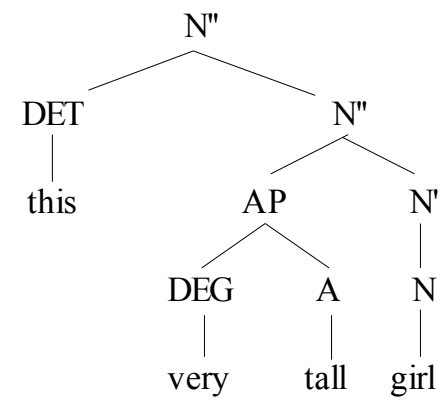

c. Coordination

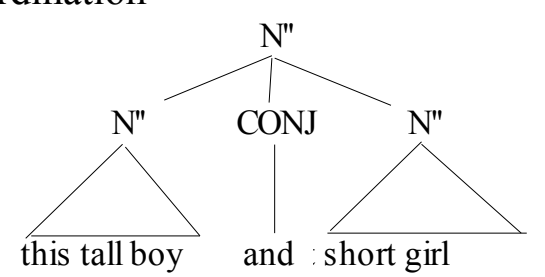

(Radford 1981: 105)

An analysis of coordination seems to wreck havoc even on the very few constraints that early generative theories operated with. Since these theories were more descriptive than explanatory and already assumed slightly different structures for the analysis of different grammatical categories, this was more of a nuance than a fundamental problem. All that was to change within the more constrained Government and Binding Theory, where more and more structures were incorporated under a single, general analysis.

\subsubsection{Small Conjunct Hypothesis}

Traditionally, coordination has been analyzed as the conjunction of constituents that can be of any category, as long as they are sufficiently alike.
a. John [vpcame in] and [vpsat down]
b. John $\left[{ }^{\circ} \mathrm{can}\right]$ and $\left[{ }^{\circ} \mathrm{W}\right.$ ill $]$ run for president
c. John [I'has left] and [r'will return]
d. *John [vpread the book] and [ppon Sunday]

Likeness, however, is a thematic/semantic, and not a grammatical constraint on what may be conjuncts in a coordination, as the following examples illustrate:

(5) a. John is [NPa Republican] and [Approud of it]

b. *John ate [ppWith his mother] and [ppWith good appetite] 
The two conjuncts under this view form a constituent, which then interacts with rest of the sentence.

This approach faces a number of problems, typically to do with the need to define the nature of the conjuncts: what can be coordinated with what. In certain languages examples such as (4d) are possible, as the German sentence below illustrates:

(6) er las das Buch und zwar am Sonntag he read the book and PRT on Sunday

'He read the book, and, to be more specific, (he read the book) on Sunday.'

(Wilder 1994: 294)

A long-standing puzzle for the small conjunct hypothesis of coordination concerned the so called non-constituent coordination phenomena, where it is not immediately obvious what the coordinated conjuncts may be.

(7) John drinks [? beer at lunchtime] and [?wine in the evening]

Larson (1988) proposes a "VP-shell" theory, which assumes that the conjuncts above are inner VPs, from which the verb has been raised to the higher V-node, heading the outer VP-shell:

(8) John [vpdrinks [vp $t_{\mathrm{V}}$ beer at lunchtime] and [ $\mathrm{vp}_{\mathrm{V}}$ wine in the evening]]

This solution can be extended to account for examples like (5a).

(9) John is $\left[\left[\mathrm{vp}_{\mathrm{V}}[\mathrm{NP} a\right.\right.$ Republican $\left.]\right]$ and $\left[\mathrm{vp}_{\mathrm{V}}[\mathrm{AP}\right.$ proud of it $\left.\left.]\right]\right]$

However, it is unclear what shell constituent can be assumed when coordinating small clause remnants (10a) or where conjoined modifiers of an NP have different categories (10b).

(10) a. I consider this [[?[APuninteresting $]]$ and [?[NPa waste of time $]]]$ 


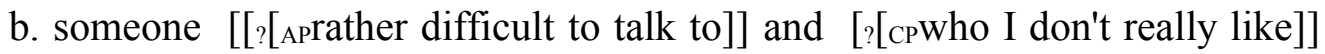
just walked in

(Wilder 1994: 297)

Small conjunct accounts operate with across the board (ATB) movement (Williams 1978) to capture the generalization that in most cases an element needs to be moved out of both conjuncts for the sentence to be grammatical, as was indicated by the traces left behind by the verbs in (8) and (9). This mechanism is a theoretical device motivated only by the need to handle shared constituents in a way compatible with the small conjunct hypothesis.

Klein (1993) pointed out that small conjunct analyses, which typically focus on peripheral deletion, need to assume the existence of ellipsis in order to account for cases of simple gapping (11a-b) as well as in case of displacement of coordinate constituents - or more complex case of gapping (11c-d).
a. [IPJohn drinks beer] and [?Mary wine]
b. [ ${ }_{\mathrm{IP}} \mathrm{J}$ ohn drinks beer] and [ ${ }_{\mathrm{IP}}$ Mary wine]
c. [CPWhat did you give to the kids] and [?what to their parents]
d. [ $\mathrm{CP}$ what did you give to the kids] and [ ${ }_{\mathrm{CP}}$ what to their parents]

Since ellipsis is motivated irrespective of coordination, we have a more constrained linguistic theory if we can dispense with the ATB mechanism altogether. Once ellipsis is motivated independently in the grammar, we can reanalyze the "small conjunct" coordination cases as ellipsis of full conjuncts as well. Besides yielding a simpler theory, the problem of having to define what the conjuncts are disappears, and examples such as (10) and (11a, c) are no longer problematic.

\subsubsection{X-bar theory and coordination}

Another theory-internal argument against the small conjunct / ATB approaches to coordination has emerged with the generalization of X-bar Theory to functional categories in the late 1980s. The small conjunct approach contradicts the X-bar theoretical axiom that only heads projects (Stowell 1981), i.e. that complements and specifiers are required to be maximal projections. 
Munn (1987) was the first to adopt an X-bar structure for coordination, with the conjunction as the head ${ }^{1}$. It takes as its complement the second conjunct to form \&'. The sister of $\&$ ', the specifier of the conjunction phrase, is the first conjunct (12).

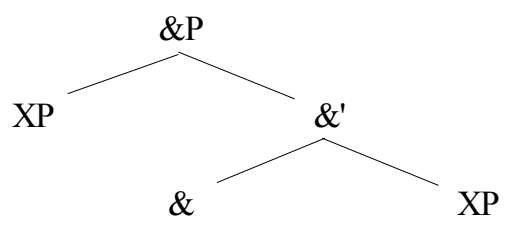

Support for the asymmetrical relationship between the conjuncts comes from binding observations, among others:
a. John ${ }_{i}$ 's dog and he $\mathrm{i}_{\mathrm{i}} / \mathrm{him}_{\mathrm{i}}$ went for a walk
b. *he ${ }_{i}$ and John''s dog went for a walk

$H e$ is a pronominal and as such must be free in its governing category, i.e. the entire coordinate expression in this case. John is an r-expression and hence must be free. (13a) is grammatical because neither the pronoun nor the r-expression are bound, since neither c-commands the other, given the structure in (12). (13b), on the other hand, is ungrammatical because the r-expression John is bound by the pronoun, since here the first branching node above he is the \&P. This leads to a binding theory violation if the pronoun and the noun are coindexed.

First conjunct agreement (Johannessen 1993, 1998, Munn 2000) also supports an analysis of asymmetry. Many languages permit agreement with a single conjunct in certain syntactic configurations. When this is the case in head initial languages the first conjunct, while in head final languages the last conjunct tends to trigger agreement. In the Czech example (14a) the verb carries first person agreement, while in the Qafar example (14b) the verb is singular, showing agreement only with the second, nominative conjunct. The idea is that the conjunction head agrees with the specifier and hence it is this element that determines the agreement on the verb.

\footnotetext{
${ }^{1}$ In subsequent work (Munn 1992, 1993, 2000) Munn has actually deviated from an X-bar structure for coordination, but he still retains the asymmetric relationship. I will briefly discuss his more recent analysis at the end of this section.
} 
(14)

a. Czech: půjdu tam [já a ty]

go-FUT-1SG there I and you

'You and I will go there.'

(Trávníček 1949: 433, cited in Johannessen 1998: 28)

b. Qafar: [lubàk-kee yanguli] yumbulle

lion-ABS-and hyena-NOM were.seen-SG

'A lion and a hyena were seen.'

(Hayward and Corbett 1988: 271, cited in Johannessen 1998: 20)

Johannessen $(1993,1996)$ offers an X-bar theoretical view of coordination within the framework of the Small Conjunct Hypothesis, with the conjunction heading its own phrase (CoP). In many ways her analysis conforms to X-bar Theory, but "CoPs diverge from $\mathrm{X}$-bar theory in one respect: while specifier and complement are generally considered to be maximal projections, in a CoP they can be categories of

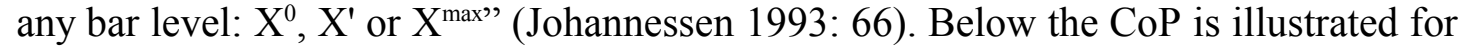
head-initial as well as for head-final languages - with the central Minimalist notion of specifier head agreement indicated by the specifier marked on the top node.

a. CoP for head-initial languages

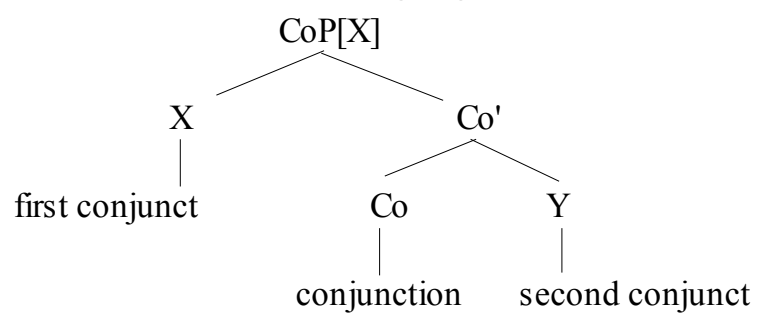

b. CoP for head-final languages

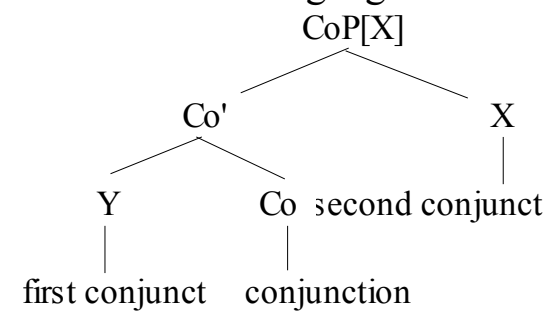

(Johannessen 1996: 669)

A second problem with this arrangement was noted by Munn (2000), who pointed out that in strictly head-final languages specifiers are usually to the left. In (15b), 
however, the specifier of the conjunction phrase must be stipulated to be on the right, contrary to all other specifiers. Munn $(1992,1993,2000)$ argued for an adjunction analysis of coordination, in which the conjunction phrase is an adjunct to a conjunct. This is compatible with other types of structures in strictly head-final languages as well, where such adjuncts are typically left-adjoined. However, a structure such as (16) does not neatly fit into the X-bar pattern in as much as the Co' level is neither motivated nor ever used. (I am using Johannessen's, rather than Munn's labeling, to make comparison easier.)

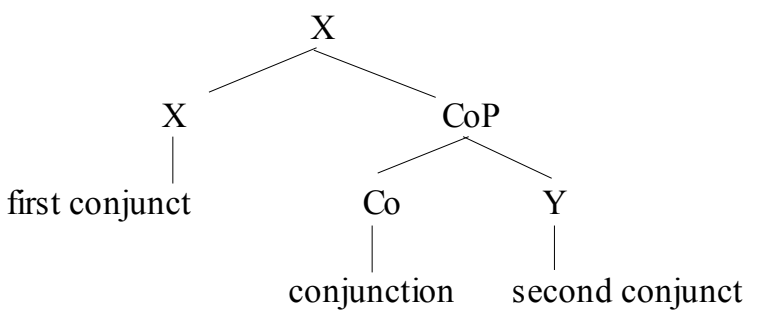

(Munn 1992, 1993, 2000)

Small Conjunct Analyses are not compatible with X-bar Theory because they allow conjuncts to be non-maximal projections. Besides the other reasons cited above, this is an important theory-internal argument for the alternative, ellipsis accounts. The problem of head-final languages pointed out by Munn (2000), on the other hand, will not be solved under any strict X-bar account: this is an area in which coordination appears to behave differently from other phrases, so is an inherent problem for any Xbar analysis of coordination regardless of the framework chosen.

\subsubsection{Ellipsis}

Coordination reduction approaches assume the (post-syntactic) ellipsis of elements. Under this view conjuncts are full CPs or DPs, and when certain identity conditions are met between the two conjuncts, deletion or non-realization of items from one conjunct or the other may take place, while the syntactic structure remains unaffected. Three types of such deletions are distinguished, left-peripheral (17a), right-peripheral (17b) and medial (17c). The gaps in the examples are left behind by elements deleted under identity with the italicized words in the other conjunct. (17d) shows an example of multiple coordination, where left peripheral and right peripheral ellipsis interact. 

a. John came in and sat down
b. John bought and Mary read today's paper
c. John drinks beer and Mary wine
d. it can must and will succeed

\subsubsection{Van Oirsouw (1987)}

Van Oirsouw was the first to define deletion in terms of a purely linear graphic representation (van Oirsouw 1987: 123), differentiating between subtypes based on directionality. The central idea is the observation that leftmost sites delete forward (i.e. that subsequent occurrence of identical material disappears), while rightmost sites delete backward. This is captured by the peripherality constraint: a deletion target site is only accessible to deletion if it is immediately adjacent to an S boundary:
a. Leftmost sites: $\mathrm{s}[\ldots(\mathrm{XX}) \mathrm{X}] \mathrm{CONJ}_{\mathrm{S}}[\ldots(\mathrm{XX}) \mathrm{X}]$
b. Rightmost sites: $\mathrm{s}[\mathrm{X}(\mathrm{XX}) \ldots] \mathrm{CONJ}_{\mathrm{s}}[\mathrm{X}(\mathrm{XX}) \ldots]$

In the representations above, ... stands for identical material between the conjuncts, while $\mathrm{X}$ indicates any constituent that is different between the conjuncts. CONJ is the conjunction, [] are S-boundaries, while () represents optionality. A special rule specifies that verb sites (gapping) delete forward.

A central problem facing this account is the assumption that conjuncts need to be grammatical structures. This assumption is necessary in the theory, as a pre-deletion conjunction structure is first created before the peripherality of deletion sites can be established. In the German examples below it is the second conjunct that determines the case of the object complement. Since van Oirsouw's account assumes all coordination to be sentential, (19c) would need to be grammatical, contrary to fact.

a. Maria begrüsste und half dem / / den Mann

Maria greeted and helped the-DAT / the-ACC man

'Mary greeted and helped the man.'

(Johannessen 1998: 38)

b. Maria begrüsste den Mann

c. Maria begrüsste *dem Mann 


\subsubsection{Wilder $(1994,1997)$}

Two major lines of analysis in the literature until the mid 1990s shared the view that ellipsis was an interface phenomenon, which left the underlying syntactic structure unaffected, but disagreed on where it occurred: at PF, as a deletion procedure (since Sag 1976) or at LF, as a reconstruction operation (since Williams 1977). Two influential papers by Chris Wilder $(1994,1997)$ argued that both approaches are partially correct: right-peripheral ellipsis is best seen as a PF phenomenon, while leftperipheral deletion and gapping require licensing at LF (see Section 1.2 for a detailed discussion - and criticism - of this idea).

Wilder (1994) follows van Oirsouw (1987) in treating deletion in terms of a purely linear graphic representation based on the position of deletion sites with respect to the material that serves as the basis for their interpretations. He termed right-peripheral ellipsis Backward Deletion and left-peripheral and medial ellipsis Forward Deletion, terms I will replace with the more theoretically neutral terms of Backward Ellipsis (BWE) and Forward Ellipsis (FWE), respectively, to continue using the terminology in my own account, which does not assume deletion. (20) illustrates these operations.
a. FWE-antecedent >
Mary came in
FWE
b.
$>\quad$ Mary sat down
c. FWE-antecedent > FWE
d. FWE-antecedent FWE
FWE

$$
\text { John drinks beer }
$$$$
\text { John bought day's paper }<\text { BWE }
$$$$
\text { Mary read today's paper } \quad<\text { BWE-antecedent }
$$$$
>\quad \text { Mary drinks wine }
$$

$>\quad$ it can steeed
$<$ BWE
$>\quad$ it must
$<$ BWE
$>\quad$ it will succeed
$<$ BWE-antecedent

Wilder $(1994,1997)$ adopts an X-bar structure as in (12) for coordination. Since the conjunction is the head of the conjunction phrase, conjuncts as non-heads must be phrasal. Once we exclude certain ATB-movement constructions on these grounds and need to assume ellipsis, Wilder attempts to simplify the theory by allowing as conjuncts only extended projections, in the sense of Grimshaw (1991). This means CP 
and DP: all predicate coordination is CP-coordination and all nominal coordination is DP-coordination. (Wilder (1997: 63) offers other arguments to exclude as conjuncts non-extended projections, but these details are not relevant for the present discussion.)

DPs are necessary even in a "hard core" version of the ellipsis approach, which otherwise treats all coordination as clausal conjunction, in order to account for data such as the following:
a. [John and Mary] left together
b. * John left together and Mary left together
c. [every dog and its owner] were checked
d. * every dog was checked and its owner was checked

In (21a) only one departure took place, as the presence of together indicates. This cannot be accounted for under the assumption that two CPs are coordinated, as indicated by the ungrammaticality of (21b). The DPs in (21c) would not stand in the ccommand relationship required for correct binding interpretation if the DPs were assumed to be embedded in clausal conjuncts, as the ungrammaticality of (21d) shows. (I will not deal with DP-coordination in this thesis, and concentrate on providing an account of what Wilder $(1994,1997)$ calls elliptical CP-coordination.)

A rare dissenting view to the analysis of ellipsis as a non-syntactic, interface phenomenon was offered by Donati (1999), who argued that the basic mechanism defining ellipsis is neither phonological nor semantic, but purely syntactic. As all syntactic phenomena, it is due to the architecture of the grammar that it gets interpreted at both interfaces, but is not itself an interface process. Donati (1999) comes to this conclusion by exploring the logical possibility available based on Minimalist axioms that not only feature checking can be done without a merge copy operation, but that also merge copy can apply without any feature checking. A copy of the item duplicated this way gets deleted, similarly to movement, which is feature checking followed by merge copy. The result of merge copy without feature checking is ellipsis, which under this view is a syntactic process, limited by constraints placed by the merge copy operation. Though her Minimalist account is very different from my own, and what are typically seen as phonological and semantic constraints on 
ellipsis, such as form identity and parallelism, respectively, are not discussed in her work, the main assumption about the syntactic nature of ellipsis is the same.

\subsubsection{Goodall (1987)}

Though Goodall's (1987) three-dimensional account is neither mainstream nor particularly recent, I would like to briefly review it for it addresses an issue that has been problematic for Wilder $(1994,1997)$ and will also lead to complications in the theory to be developed in the present work: parallelism. There appears to be a restriction that the full conjunct and the elided conjunct be sufficiently parallel:

\section{(22) a. John loves Mary and hates Jill \\ b. John, Mary loves and Bill Jill}

Only John, and not Mary can be reconstructed as the semantic agent for hates in (22a). In (22b) Bill can only be interpreted as the topicalized object, and not the subject, of the gapped verb, while Jill must be the subject and not the object. Such parallelism observations fall out from the theory developed by Goodall (1987), which makes use of three-dimensional trees to represent coordinate structures.

The gist of the argument is that for one of two strings to be elided not only do they have to be identical, but each element in one of the identical strings needs to be in the same relationship with the non-identical element(s) of its conjunct as the corresponding element in the other string is with the non-identical element(s) in its conjunct. What guarantees this is that a three dimensional tree, in which, for instance, two NPs are both the subject sisters of a VP, can only be generated if the NPs are themselves both subjects. If the arrangement is not parallel, the merged tree can not be generated and coordination will not involve ellipsis. Because I do not want to introduce Goodall's rather unique formalism, the conjuncts are represented here as clauses in (23a-b) and the three-dimensional tree is provided in (23c). A specific Linearization Principle is proposed to turn the three-dimensional tree into a string at PF. This is illustrated in (23d).
a. Jane saw Bill
b. Alice saw Bill 
c.

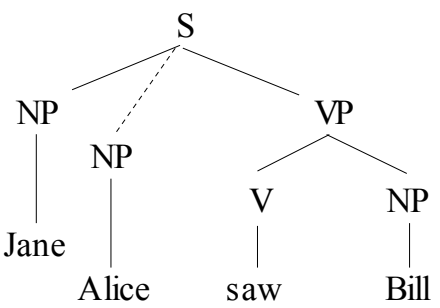

d. Jane

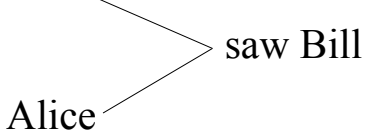

e. Jane and Alice saw Bill ${ }^{2}$

Strictly speaking, this account operates with merger, rather than ellipsis, since the two full clauses are not coordinated at any point of the derivation. However, in requiring two full clauses to exist before the operation can take place, it is rather like an ellipsis approach (facing the problem of unbalanced coordination already noted for van Oirsouw's account). The beauty of Goodall's theory is that parallelism is encoded by the very mechanisms that yield ellipsis or merger.

Non-constituency presents no problems for this account, and gapping is accommodated with the help of an extra mechanism. Under what has been presented so far, linearization of the tree generated from (24a-b) would provide (24c), which would result in (24d), and maybe (24e), but certainly not (24f).
a. John loves Mary
b. Bill loves Jill
c. John
Bill
Jill
d. John loves Mary and Bill loves Jill
e. John and Bill love Mary and Jill
f. John loves Mary and Bill Jill

\footnotetext{
${ }^{2}$ The placement of the conjunction is achieved via a fairly labor intensive operation, which I will not discuss here. This process can likely be simplified within the theory itself. However, as I will point out below, the account faces a major conceptual problem, so streamlining the details is beside the point.
} 
A special, rather descriptive operation allows for horizontal linking of the lower and higher constituents in a union of phrase markers such as (24c) (Goodall 1987: 81).

The natural account for parallelism, however, comes at a high price. As pointed out by Moltmann (1992), the very mechanism introduced for linearization means that the collective and individual readings of sentences are indistinguishable. Goodall's theory cannot account for the fact that the objects in (25a) and (25b) below may be different apples. In other words, only (25d) is generated, never (25e).
a. John saw an apple
b. John ate an apple
c.

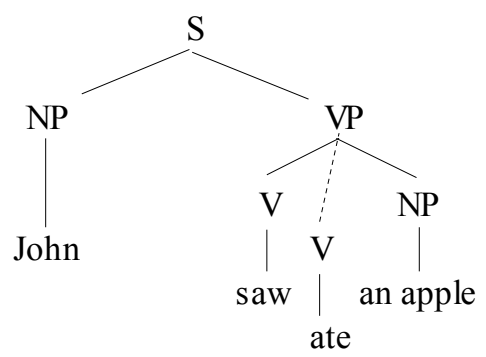

d. John saw and ate an apple

e. John saw and apple and ate an apple

This seems too high of a price to pay for an easy solution to the apparent parallelism requirement.

\subsection{Ellipsis and word order}

The central claim of Newson and Gáspár (2001) was that the direction of ellipsis can be derived from the internal word order of the individual conjuncts, and as such, it does not have to be independently stipulated as in Wilder $(1994,1997)$ among others. In this section I would like to review the arguments presented there.

In a language where the object must follow the verb, a clause with an elided object must precede the conjunct with the overt object, so that the object is on the right side of both verbs (BWE):
a. $Y_{-} \& \mathrm{XObj}$
b. ${ }^{*} \overline{\mathrm{X}}$ Obj \& $\mathrm{Y}_{-}$ 
Similarly if subjects precede verbs in the basic word order of the language, if a subject is elided, then the clause with the missing subject must follow the other so that the overt subject can be on the left of both verbs (FWE) ${ }^{3}$ :
a. Sub X \& Y
b. ${ }^{*}$ Y $\&$ Sub $\mathrm{X}$

Support for this hypothesis came from several observations. Phenomena involving the fronting of an element can force an FWE pattern. This is so, even if the elided element is in a position normally associated with BWE, as with the following cases of object topicalisation and 'wh-movement':
a. John, Bill hates but Mary loves
b. * Mary loves but John, Bill hates

(29) a. who does Bill hate but Mary love

b. * Mary loves but who does Bill hate

There is further evidence for this basic directionality from cross-linguistic observations. É. Kiss (1994) has shown that Hungarian basic word order is verb initial with the order of the post verbal arguments undetermined. Thus we predict that an elided argument will force backward deletion in constructions which observe the basic word order. This prediction is born out ${ }^{4}$ :
a. ?hámozza Mari és vágja János a krumplit peels Mari and cuts János the potato-ACC 'Mary is peeling and John is cutting the potatoes.'
b. ?hámozza Mari és vágja a krumplit János
c. *hámozza Mari a krumplit és vágja János

\footnotetext{
${ }^{3}$ Ross (1970) made a similar observation for gapping, arguing that directionality of gapping in a language reveals whether a language is underlyingly SVO or SOV. However, as I will illustrate in Section 4.3.2, gapping data from several languages undermine Ross's generalization.

${ }^{4}$ The reason for the slight degradation of (30a) and (30b) is that the sentences are contrastive and therefore normally call for the presence of the contrastive marker pedig. However this would interfere with the word order in that the contrasted element is moved to the left of the verb. In order to maintain the basic verb initial order the contrastive marker is excluded, which causes degradation of grammaticality in (30a) and (30b). The important observation is, however, that (30c) and (30d) are much worse than (30a) and (30b).
} 
d. *hámozza a krumplit Mari és vágja János

In Hungarian arguments may appear pre-verbally if they have topic or focus interpretation. Like in English, the fronting of such an element in coordination contexts has the effect of forcing a forward direction on ellipsis:

(31) Hungarian 'shared' topic

a. a sört János szereti, Mari pedig utálja

the beer-ACC János likes Mari CONTR hates

'Beer, John likes but Mary hates.'

b. * Mari utálja , a sört János pedig szereti

(32) Hungarian 'shared' focus

a. a szomszédot csapta be János és segítette ki Mari the neighbor-ACC tricked in János and helped out Mari 'It was the neighbor that John tricked and Mary helped.'

b. *__ segítette ki Mari és a szomszédot csapta be János

French also demonstrates similar phenomena. Shared objects normally force a BWE pattern, but when the object is fronted, an FWE pattern is required. Yes/no questions present an interesting case: such questions can either be formed with in situ word order with the interrogative marking "est-ce que" in front, or the shared object can be fronted. As our theory would predict, in situ word order forces BWE, while fronted word order forces FWE.

(33) French 'shared' object
a. Jean aime et Marie haïe le fromage
John likes and Mary hates the cheese
b. * Marie haïe le fromage et Jean aime

(34) French 'shared' focus

a. c'est le fromage que Jean aime et Marie haïe

it's the cheese that John likes and Mary hates

b. *__ Marie haïe et c'est le fromage que Jean aime 
(35) French interrogative 'shared' object - in situ word order

a. est-ce que Jean aime et Marie haïe le fromage?

is it that John likes and Mary hates the cheese

b. * est-ce que Marie haïe le fromage et Jean aime

?

(36) French interrogative 'shared' object - fronted word order

a. est-ce le fromage que Jean aime et que Marie haïe?

is it the cheese that John likes and that Mary hates

b. * est-ce que Marie haïe et le fromage que Jean aime?

An SOV language such as Japanese shows the opposite conjunct ordering. A shared object will force a FWE pattern:

(37) Japanese 'shared' object

a. John wa bìru ga kirai de, Mary wa __ sukida John TOP beer NOM hates and Mary TOP loves

'John hates and Mary loves beer.'

b. * Mary wa kirai de, John wa bìru ga sukida

(Yuko Kitada, p.c.)

These examples indicate that the directional nature of FWE and BWE is not simply coincidental: it is related to the position of the ellipsis site. As such, the two kinds of ellipsis patterns can be considered instances of the same phenomenon, with their apparent differences caused by independent considerations, such as word order conditions. In order to build a grammar in which the two patterns compete, and word order considerations decide grammaticality, first the arguments in favor of treating BWE and FWE as fundamentally different processes need to be addressed.

Wilder (1997) suggested that BWE has properties which indicate that it is created at the phonological level through the deletion of material which is phonologically identical to the corresponding elements in the following clause. FWE, on the other hand, demonstrates more syntactic and semantic properties, indicating that this kind of 
'deletion' is somehow controlled in the syntax, though the ellipsis itself is caused by not entering phonological material at PF.

As Bartos (2001: 8-9) pointed out, the distinction between phonological deletion and non-insertion is not obvious, as no theory-external or empirical differences can be made between the two. What is theoretically motivated is the difference between an anaphoric and a non-anaphoric relationship in FWE on the one hand and BWE on the other: since only FWE is preceded by its antecedent, satisfying the Williams' (1997) General Pattern of Anaphoric Dependencies, only in the case of FWE can the anaphoric reconstruction at LF even be considered. However, according to Bartos (2001), not all cases of FWE need to resort to an anaphoric LF reconstruction explanation. Certain cases of FWE can be explained as phonetic deficiency (PD). Since the PD mechanism, non-insertion of sound forms, is necessary anyway to account for (non-anaphoric) BWE, the grammar does not become any more complicated by extending this mechanism to certain cases of FWE. The remaining FWE cases depend on anaphoric reconstruction at LF. Bartos (2001) terms these full formal deficiency, where a null-element is present in the syntactic structure. The advantage of this account is that the "fuzzier" LF-reconstruction account is narrowed down in its scope to "an inevitable minimum" (Bartos 2001: 23). Since interpretative and pragmatic ellipsis resolution needed to be retained for some cases anyway, the theoretical advantages of Bartos' observation are limited. What his account does show, though, is that the distinction between FWE and BWE is not as sharp as Wilder (1997) suggested.

In Newson and Gáspár (2001) it was argued that the empirical observations leading to the distinction between FWE and BWE are not so clear cut either - and as such the two can be conceivably seen as the same phenomenon. I will now move on to review the arguments considering the empirical observations between FWE and BWE.

\subsubsection{Parallelism in BWE and FWE}

Wilder (1997) argued that FWE requires structural parallelism: both the elided material and its overt counterpart must be in structurally identical positions within their own conjuncts: 

a. Mary said John hit Bill and ran away
b. Mary said John hit Bill and ran away
c. * Mary said John hit Bill and ran away

The elided subject can only be recovered from a structurally parallel subject in the preceding clause. This can happen either from the main clause subject (Mary), in which case the clause of the elided subject is interpreted as non-embedded, or from the embedded clause subject (John), in which case the second clause is interpreted as embedded. What is not possible is for the elided subject to be recovered from the embedded subject AND for its clause to be interpreted as non-embedded.

String parallelism, relevant for BWE, imposes looser restrictions. The elided material must be in the same position as its overt counterpart, i.e. at the right edge of their respective conjuncts, but crucially the two do not have to be structurally parallel in that they may, for example, be related to elements at different levels of embedding within their conjuncts.
a. Mary likes but Bill thinks she hates garlic
b. Bill thinks Mary likes but in fact she actually hates garlic

Wilder's argument is that these differences between FWE and BWE indicate that the two are due to different mechanisms: recovery in FWE is syntactically restricted to structurally parallel positions, while recovery in BWE is phonologically restricted to parallel positions in the phonological string. The recovery of elided material, however, is purely a semantic process and therefore these restrictions seem better placed in the semantics rather than into the syntax.

Also, not every case of FWE has to be structurally parallel, only those involving elided subjects - suggesting that it is the recovery of the subject that forces structural parallelism, not the FWE pattern itself:

(40) a. Marmite, John hates but Mary said Peter loves

b. Marmite, John hates but ___ Mary said Peter loves

c. Marmite, John hates but Mary said ___ Peter loves 
In (40a), it may be argued that the elided element is sitting in (a structurally parallel) topicalised position in the second conjunct. This is illustrated in (40b), and confirms the structural parallelism account advocated for FWE by Wilder. However, (40a) is also compatible with a different position of the elided argument. The missing argument in (40c) is also parallel to the overt topic of the first conjunct, but this is a looser kind of parallelism: the elided topic is not at the front of the entire conjunct, as it is embedded. Since both of these interpretations are available for (40a) the observation questions the sharp BWE-FWE distinction in terms of parallelism. The following examples do not only cast doubt on Wilder's distinction, but outright contradict it:

(41) a. I think John will do the washing up but Mary certainly won't

b. John will do the washing up but I think Mary won't

Wilder (1997) discounts data such as that given in (41), as VP deletion is not restricted to a forward direction. However, given that his account stipulates the relationship between the direction of ellipsis and the different types of parallelism rather than causally linking them, ignoring such data is tantamount to sweeping potential problems under the carpet ${ }^{5}$.

\footnotetext{
${ }^{5}$ Wilder (1997) also excludes NP-deletion and sluicing, illustrated in (i) and (ii) respectively. The optionality in both cases further questions the sharp distinction between FWE and BWE.

i. $\quad$ a. John bought three pictures of Mary and Bill bought four

ii. b. Bill bought four and John bought three pictur an Bill met someone but I don't know who

b. I don't know who_ but I know Bill met someone
} 


\subsubsection{Identity in BWE and FWE}

The second major piece of evidence that leads Wilder (1997) to the conclusion that FWE and BWE result from different processes concerns restrictions on the identity between the form and content of the elided material and the 'antecedent'. Clearly in terms of the content of the two there must be identity: the content of Mary could not be recovered from the word John, for example. However, it is not the case that one can always replace the elided material with its overt counterpart and end up with a grammatical expression as some formal differences are allowed in some cases. The formal differences, he claims, are restricted to FWE, and only non-meaningful morpho-phonemic differences are allowed.
a. John drinks wine and his kids coke
b. * John arrives tomorrow but his wife yesterday

In the case of BWE, Wilder claims that complete formal identity is required:
a. * John said that I but Mary said that she is the best swimmer
b. John said that I but Mary said that she was the best swimmer

However, the English verb be requires form identity in both backward and forward directions, at least for some speakers ${ }^{6}$ :
a. * John said that I but Mary said that she is the best swimmer
b. * he is a postman and they policeman

When we consider a case of BWE not involving the verb to be we find that there is no form identity requirement, at least for some speakers:

sometimes I but more often John does the washing up

Furthermore, it is equally possible both in backward and in forward directions to retrieve the infinitival form of the verb from its tensed counterpart:

\footnotetext{
${ }^{6}$ As John te Velde (p.c.) pointed it out to me, there are cases when forward deletion examples involving non-identical forms of be are acceptable:

i. I I am writing an article and you __ a book

This adds a further level of complexity to the phenomena.
} 
(46) a. John went shopping but Mary didn’t want to go shopping

b. we told him not to go shopping but he still went shopping

Bartos (2001) cites a number of Hungarian cases in which there is no exact form identity between the elided element and the 'antecedent'.

a. én tegnap vásároltam, Péter pedig tegnapelött vásárolt

I yesterday shopped Péter CONTR yesterday.before shopped-3SG

I went shopping yesterday and Peter went the day before.'

b. ? Péter tegnap vásárolt, én pedig tegnapelőtt vásároltam

Péter yesterday shopped I CONTR yesterday.before shopped-1SG

'Peter went shopping yesterday and I went the day before.'

Although Bartos marks the BWE version as "marginal," he admits that there are some speakers who find it perfectly grammatical. He concludes that for BWE it is (marginally) possible to recover an elided form which is a phonological substring of the antecedent but not vice versa (i.e. vásárolt from vásároltam, but not vásároltam from vásárolt), hence supporting the phonological nature of BWE.

However, it seems that the distinction is not phonological: third-person forms can be recovered from first person forms, but not the other way round and this is the case even when the third person form is not a substring of the first person form, as with the so-called ' $i k$ ' verbs, which have a non-null third person inflection:

a. * én tegnap vásároltam, Péter pedig tegnapelőtt

I yesterday Péter CONTR yesterday.before shopped-3SG

'I went shopping yesterday and Peter the day before.'

b. János bort iszik, én pedig sört iszom

János wine-acc I CONTR beer-ACC drink-1SG

'John is drinking wine and I am drinking beer.'

c. * én bort iszom, János pedig sört iszik 
As iszik is clearly not a substring of iszom it seems that whatever causes the effect has more to do with grammatical features than with their morpho-phonemic forms.

The data are far from straightforward and there are clearly many differences between speakers. This may be the result of dialectal differences, but the fact that we find similar confusions and uncertainties across both Hungarian and English might argue that something extra-linguistic is influencing some of the grammaticality judgments. What does seem clear, however, is that we cannot conclude that BWE is restricted by form identity as there are too many grammatical cases in which form identity is not required. Once again, then, as it is not even certain that there are real linguistic differences between FWE and BWE patterns in terms of identity, it cannot be concluded that they are produced by different mechanisms.

\subsubsection{The complementary nature of ellipsis}

The claim that FWE and BWE are different phenomena cannot just be based on observations that they differ: if the differences are complementary they mean identity. In terms of direction and position of elided elements, FWE and BWE patterns are indeed complementary, cutting up the set of possibilities into complementary sets:
a. medial or left peripheral $\rightarrow$ forward
b. right peripheral argument $\rightarrow$ backward
c. right peripheral non-argument $\rightarrow$ no direction specified

Having argued that these are the only essential grammatical differences between ellipsis patterns it was concluded in Newson and Gáspár (2001) that from a grammatical point of view ellipsis is a unitary phenomenon and as such is best handled through a single grammatical mechanism.

The optimality theoretic framework adopted in Newson and Gáspár (2001) allowed this situation to be handled under the assumption that candidate expressions which differ with respect to the order of conjuncts compete with each other and the winning candidate is determined by the very constraints that determine basic word order. While I am going to offer an account that differs from Newson and Gáspár (2001) in 
terms of the constraints and the way ellipsis phenomena and word order are predicted, I will rely on the basic observation made there that BWE and FWE candidates compete on an equal footing and language-dependent ordering of the constraints determines which of them will be optimal, and hence grammatical.

In full coordination conjuncts may come in any order (50a). In cases of ellipsis, the order of the conjuncts matters: although both orderings are available in the candidate set, there is only one winner. This is illustrated in (50b):

$$
\begin{aligned}
& \text { a. full coordination } \\
& \text { candidates: A \& B } \\
& \text { b. elliptical coordination } \\
& \text { candidates: * A \& B } \\
& \text { B \& A }
\end{aligned}
$$

As demonstrated earlier what is relevant for determining the order of the conjuncts in argument ellipsis cases are the same principles that are relevant for determining the basic word order of the language. As objects in English, for instance, must follow the verb, a clause with an elided object must precede the conjunct with the overt object so that this object is on the right side of both verbs. This can be captured if the precedence requirement that places the object to the right of its verb is allowed to apply for the verb with the elided object as well. This requirement will be satisfied by (51a) but not (51b), as illustrated by the $x$ symbol, informally representing the violation with respect to the verb of the ellipsis conjunct.

\section{a. John loves and Mary hates wine}

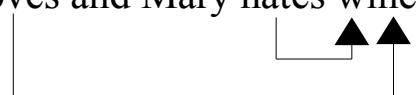

b. Mary hates wine and John loves

The suggestion is that the position of the arguments of one predicate can be relevant for satisfying the alignment requirements of another. However, the mechanisms introduced need to ensure that the verb with the missing object does not get inserted 
into the full clause in order for its object adjacency requirement to be satisfied. The word orders in (52) would better satisfy the object adjacency requirement of both predicates than the grammatical sentence in (51a).

\section{a. *John and Mary loves hates wine}

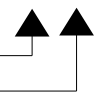

b. *John and Mary hates loves wine

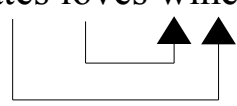

The device employed by Newson and Gáspár (2001) is the notion of cyclicity: the ordering within the individual conjuncts needs to be fixed before the satisfaction of the adjacency requirements of a predicate with a missing argument is attempted. Clearly, (52a-b) satisfy the adjacency requirement of the predicate of the full conjunct less than the grammatical sentence in (51a). In (52a) hates is no longer adjacent to its subject because of the intervening loves, while in $(52 \mathrm{~b})$ it is one position removed from its object. If, however, the adjacency requirements of the full predicate are addressed before those of the other predicate, the correct prediction is made.

I will present a formal description of the satisfaction of adjacency requirements in later chapters in what is a grammatical framework operating without the notion of phrases. I will now review the accounts of coordination offered by other such theories.

\subsection{Coordination in other "structureless" grammatical theories}

Other grammars attempting to do away with the notion of syntactic structure have also tackled the problem of coordination. As the review below will show, coordination has in fact posed some difficulty for most of these grammars. Coordination is a problematic area for structureless theories, precisely because conjuncts do appear to be constituents - i.e. strings of words that "stick together" before being coordinated.

I will begin reviewing the treatment of coordination in three kinds of Dependency Grammars (1.3.1), then will move on to Unificational Categorial Grammar (1.3.2), and finally to Generalized Argument Structure Grammar (1.3.3), the most successful of the theories to be reviewed in terms of an account of coordination phenomena. 


\subsubsection{Dependency Grammar}

Coordination has been a challenging phenomenon not only for the Government and Binding/Minimalist tradition, but also for researchers working in structureless theories, such as Dependency Grammar (Tesnière 1959).

The gist of Dependency Grammars, which are otherwise as diverse as Phrase Structure Grammars, is that in a sentence all but one word depend on other words. A word depends on another word, its ruler, if it is either a complement or a modifier of the first word. The one independent word, the one that would be termed the head of the highest clause in a phrase structure grammar, is the root of the sentence. To varying degrees all Dependency Grammars separate the notion of configurationality (or dependency) from word order (Debussmann 2000). In grammars that completely separate the two notions, word order rules are applied after the dependency relationships have been established - which means that languages with relatively free word order are easier to account for.

The challenge in treating coordination as a dependency relationship, according to Kruijff (2002: 19), is to determine which item is the root:

- it cannot be one of the individual conjuncts, because neither has a higher priority than the other;

- it cannot be both the individual conjuncts, because that would be incompatible with the notion of dependency;

- it cannot be the conjunction, because the conjunction cannot fulfill the functional requirements of the conjuncts (e.g. 'and' cannot be the subject in a NP \& NP V NP type construction), according to standard assumptions.

In the following sections I will review three dependency accounts of coordination as well as some problems they face. Word Grammar (1.3.1.1), Dependency Categorial Grammar (1.3.1.2) and Meaning Text Theory (1.3.1.3) make very different assumptions about the grammar and so offer very different analyses of coordination. 


\subsubsection{Word Grammar}

One version of Dependency Grammar that has explicitly addressed the challenge of coordination has been Word Grammar (WG) (Hudson: 1984, 1990, 2003).

In WG words are the only units of syntax. Phrases are implicit in dependencies, but play no part in the grammar: phrase structure is "redundant". Each word in the sentence is in the center of a small network of links to other words, and these networks combine into a network for the whole sentence. Words are linked by dependencies, illustrated as arrows drawn from a root to its dependent with the nature of the dependency relationship marked on the dependency arrow.

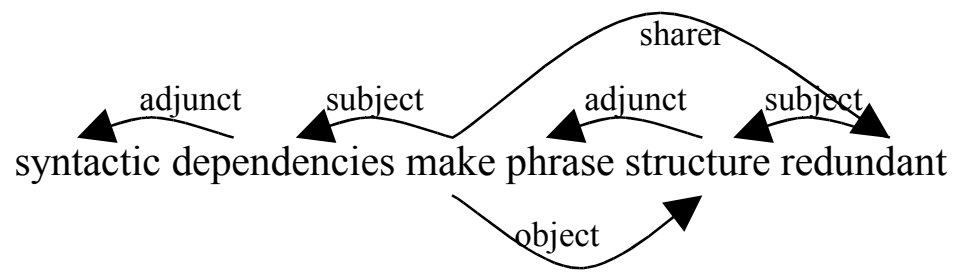

(Hudson 2002: 4)

The WG network is not simply a notational variant of a phrase structure tree. In the example above, for instance, there is a double dependency link of structure: it is the object of make and the subject of redundant at the same time. The network is generated by inheritance from the grammar, which sanctions each of the individual dependencies. The dependencies around make, for instance, are sanctioned by the lexical entry for MAKE, which allows it to have a subject, and object and a sharer the equivalent of a shared complement in standard terminology.

Though grammatical dependency is the standard concept, word order in languages like English is closely related as are other phenomena: because dependencies in (53) is the subject of make, we can predict that make agrees with it, that it precedes make, and that in semantic structure dependencies provides the 'maker' of the verb's meaning. In languages that are consistently head-final or head-initial, the directionality relationships generalize across all dependents (Hudson 2002: 5).

The (descriptive) rule that accounts for coordination in WG is the Dependency-inCoordination Principle (Hudson 1990: 220), which requires that any dependency 
between a word inside one conjunct and a word outside the coordination must also be shared by one word in every other conjunct of the same coordination. This rule correctly excludes examples such as (54), where some dependency is not shared:

* Pat enjoyed and departed that day

In (54) (that) day is object of enjoyed but adjunct of departed, so though it can combine separately with each of the verbs, it cannot be combined with both at the same time.

In WG coordination is the only phenomenon that requires relationships other than dependency. The conjuncts have equal status, they do not depend on one another. The presence of the conjunction presents further challenges for the analysis.

In WG there is no structure or abstract level of syntactic representation. This means that there are no empty elements either ${ }^{7}$. In the case of gapping, Hudson (1990: 416421) had to invoke a non-dependency relation he called 'replacer,' which allows the verb in the first conjunct to fulfill the grammatical requirements of the subject and the object in the second conjunct. Such licensing of the remnants also allows the semantic structure to be built on top of the syntax. (While WG does away with syntactic structure, it retains semantic structure.) The semantic structure of the first clause is copied, and the object and the subject are replaced by the remnant object and subject of the verbless clause. A non-dependency relationship had to be introduced to avoid an abstract syntactic structure that would have included the gapped verb.

The second problem caused by coordination is that the conjunction ('coordinator' in WG terms) is outside the dependency system: it does not have dependency links to other words. In (55) the roots of the conjuncts, tea and coffee, both have the same dependency relation to drink - known as sharers in WG terminology.

(55) I drink white coffee and tea with milk

\footnotetext{
${ }^{7}$ In fact, Hudson has allowed zero elements as a last resort in WG since 1997, but their use is so constrained that they would not be allowed in this case.
} 
Both tea and coffee are objects, and so both need a transitive verb to depend on. The only transitive verb in the construction is drink, so they have to share it. There is no syntactic construction other than coordination which allows objects to share a verb (or verbs to share a subject etc.) (Hudson: 2003). Though not stated explicitly in Hudson (2003), the coordinator may be regarded as the element that licenses this sharing relationship, allowing a verb to have two parallel objects. This, however, would still leave it outside the dependency relationships.

In fact, the usage of the very term 'conjunct' is problematic for a structureless theory, as Hudson (2003) admits. To be true to the spirit of a word-based dependency approach, it is the root words of the conjunct strings that should be seen as being coordinated. Hudson $(1990,2003)$ defies his own theory and rejects this word-based view, because placing the conjunction into the string under such an analysis would be impossible: since in the case of the conjunction word order is governed by rules other than dependency, the system could not ensure that the conjunction does not end up, say, in the middle of a conjunct as in (56). The word order of the rest of the constituents follows from dependency rules between them, but nothing prohibits placing the coordinator anywhere inside this string.

*green apples red and plums

If, on the other hand, conjuncts are pre-glued sub-strings of the sentence, the coordinator is bound to fall in the right place. The empirical facts are accounted for at the cost of weakening the fundamentals of the theory.

Another area where Hudson $(1990,2003)$ has to succumb to the notion of preassembled conjuncts (i.e. phrases) is what in phrase structure-based theories is typically termed non-constituent coordination:

(57) I drink coffee in the morning and tea in the afternoon

In (57) the conjuncts have no single root: the object and the preposition do not depend on each other. In WG there is no mechanism to decide which of the two would be coordinated - so Hudson is forced to adopt structure in the case of such constructions. 
If the conjuncts are treated as strings, the problem does not arise, as a choice no longer needs to be made between what elements may be coordinated: the pre-assembled strings are. In some ways this is doubly worse as not only is Hudson forced to assume constituents in this case, but he has to assume something to be a constituent that is not usually considered so in approaches which generally accept constituent structure.

The Dependency-in-Coordination Principle is also problematic for coordination constructions in which there is no formal agreement between the overt and the elided shared element. In the Hungarian example (58) the first verb, which would carry thirdperson agreement, is elided under identity with the second, first-person verb.

János bort (és) én pedig sört iszom

János wine-ACC (and) I CONTR beer-ACC drink-1SG

'John is drinking wine and I am drinking beer.'

The relevant dependency relationship here is subjecthood. But nowhere else in the grammar would this dependency relationship allow a mismatch in agreement. Even if a mismatch were allowed in this case, it is not obvious that the non-matching agreement would qualify as the same type of dependency relationship as the one that stands between the verb and its real subject in the second conjunct.

To conclude, it appears that not only is the account of coordination in WG based on a theoretically unmotivated, descriptive principle, but also phenomena such as gapping, non-constituent coordination and ellipsis without complete formal identity cannot be accounted for without resorting to phrases. Introducing phrases into the theory in order to account for coordination significantly weakens WG's central claim that phrases are epiphenomenal.

\subsubsection{Dependency Categorial Grammar}

Dependency Categorial Grammar (Barry and Pickering 1990) is, as its name suggests, a combination of dependency grammar and categorical grammar. Dependency is the principal relationship between words, but words are combined into larger categories, as in Categorial Grammar. DCG then is not a "purist" structureless approach, and the 
coordination account of Pickering and Barry (1993), indeed, makes use of phrases. As I will show below, that is the root of several problems with their analysis.

Phrases in DCG are flexible, not rigid, which means that there can be overlap between them: any element in an unambiguous sentence can in principle belong to more than one phrase without one of the phrases being contained in the other. Constituency can be established between words that are linked by dependencies. Since, at least in this version of DG, a word can have multiple rulers, it can also belong to more than one constituent without those constituents being subordinate to one another.

Unlike in classical categorical grammar, DCG does not operate with a finite set of predefined rules, but with a schema, which defines what type of rules are legal. The schema allows for rules generating strings that are not phrase structure constituents. The set of constituents derivable in DCG is closely related to the set of dependency relationships. In this sense this is a structureless approach at heart: it is dependency that matters, and constituency is an epiphenomenon.

Parallelism has an important role to play in the DCG coordination account: many grammatical examples that cannot be generated with traditional categorical grammar accounts (which do not operate with ellipsis), share the property that the conjuncts have parallel internal structures.

(59) a. I ate [two small] and [three large] oranges

b. I went [to Chicago on Monday] and [to New York on Tuesday]

c. [I believe that John] and [Henry thinks that Mary] climbed the mountain

For a coordination to be grammatical, conjuncts need the same pattern of external dependencies. The analysis is quite technical, but it is possible to recapture the main parallelism ideas without the formalism. If a conjunct coincides with a phrase structure constituent, its root will be the root of the phrase. A string that is not a phrase structure constituent will have more than one string root. A word is a string root if it has no ruler in the string. A longer string can be uniquely subdivided into substrings, whose roots are the string roots of the original string. These substrings are called maximal dependency constituents (MDCs) and each such constituent consists of a 
string root plus every word to which it is possible to trace a path from the string root without leaving the string. In the first conjunct of (59c), for instance, the string roots are believe and John and the maximal dependency constituents they rule are [I believe that] and [John], respectively (Pickering and Barry 1993: 891-982).

$(60)^{8} \quad[\{$ I believe that $\}\{$ John $\}]$ loves Mary

For two strings to be conjoinable the categories of the string roots must match, as should the categories of the words sought by each - with the words missing from the same position. Crucially, the dependencies within conjuncts can differ, but the external dependencies must match, as is the case is in (61a). Both conjuncts have a single string root, loves and thinks, so they are both a single maximal dependency constituent, linked to the root of the shared string, sonatas, via an object dependency.

(61) a. [ $\{$ John loves $\}]$ and [ $\{$ Mary thinks Fred hates $\}]$ sonatas by Mozart

b. John loves [\{Mary $\}\{$ madly $\}]$ and $[\{$ Sue $\}$ passionately $\}]$

c. ${ }^{*}$ John loves $[\{$ Mary $\}\{$ madly $\}]$ and $[\{$ Sue $\}]$

In (61b) the words in both conjuncts depend on the shared verb, not on each other. Mary, madly, Sue and passionately are all string roots, so each conjunct is divisible into two maximal dependency constituents. The two MDCs in both conjuncts depend on the shared verb the same way, so the structure is parallel. Not so in (61c), where the second conjunct has only one dependency link to the verb, yielding ungrammaticality.

The problem with the parallelism of Pickering and Barry (1993) is that it is strictly syntactic in nature. Thus the theory would offer an explanation similar to the one just given for (62), but the ungrammaticality of (62b) and the grammaticality of (62c) would be problematic for their account.

(62) a. John went [(to Boston $)_{\mathrm{PP}}$ (on Monday $\left.)_{\mathrm{PP}}\right]$ and [(to New York) $)_{\mathrm{PP}}$ (on Tuesday) $\left.)_{\mathrm{PP}}\right]$

b. *John went [(to Boston) $)_{\mathrm{PP}}$ (on Monday) $\left.)_{\mathrm{PP}}\right]$ and [(on Tuesday) $)_{\mathrm{PP}}$ (to New York) PP $]$

c. John went [(to Boston $)_{\mathrm{PP}}$ (on Monday $\left.)_{\mathrm{PP}}\right]$ and [(to New York $\left.)_{\mathrm{PP}}(\text { yesterday })_{\mathrm{NP}}\right]$

\footnotetext{
${ }^{8}$ This bracketing is my notation to shortcut the introduction of theory-specific formalisms. For a formal description, see Pickering and Barry (1993).
} 
In (62b) because both MDCs are PPs, the sentence escapes the coordination filter on parallelism. The unacceptability could be explained on cognitive grounds (similarly to the approach I will take in my own analysis in Chapter 5), but that would not solve the problem of (62c), which DCG would wrongly predict to be ungrammatical as long as constituent categories remain part of the definition of parallelism.

In fact, Pickering and Barry do mention unlike category coordination in a passing paragraph, but are content with concluding that "it is clear that no specific problem is posed for the present approach" (Pickering and Barry 1993: 896). The solution they sketch is to give both conjuncts the same category type.
a. John is $\left[(\text { lucky })_{\text {PredP }}\right]$ and $\left[(\text { a rogue })_{\text {PredP }}\right]$
b. John is $\left.\left[(\text { lucky })_{\text {PredP }} \text { (in the gambling hall }\right)_{\mathrm{PP}}\right]$ and $\left.\left[(\text { a rogue })_{\text {PredP }} \text { (in the tavern }\right)_{\mathrm{PP}}\right]$

However, it is unclear under what circumstances such a shared category type could or should be assigned to two conjuncts and what the shared category type would be in cases such as (62c). Simply using 'complement' and 'adjunct' as category labels, which they could do similarly to 'predicate,' would open the door too wide, generating ungrammatical cases as well. What is needed is a semantic constraint on what could count as possible conjuncts - something their theory does not provide.

Though their theory is based on dependency relationships and phrases have a limited role, it is exactly the role they are allowed to play, that of restricting coordination to like types, which causes problems.

\subsubsection{Meaning Text Theory}

Meaning Text Theory (Mel'čuk 1988) privileges one of the conjuncts as the head of coordination, and claims that coordination symmetry exists only at the semantic level.

Meaning Text Theory assumes seven strata of language representation, and maps unordered dependency trees of surface-syntactic representations onto lexeme sequences of morphological representations. Semantic relationships drive syntax, so semantics is the starting point of grammar: the semantic component feeds the deep syntactic component, which in turn feeds the surface syntactic component. The deep 
morphological component is built on syntax and feeds the surface morphological component, which in turn feeds the deep phonological component. The final stratum is the surface phonological component (Mel'čuk 1988: 72).

Syntactic relations between words on the surface may be expressed via morphological marking, intonation, word order, or some combination of these. Since word order is just one of the various means to express syntactic relations between words, it cannot be present in syntactic structure. Constituency and constituent categories are only epiphenomenal in the grammar. Syntax in Meaning Text Theory is based on relations between ultimate syntactic units, and is concerned with semantic links between them.

Mel'čuk acknowledges that pretheoretically coordination is a problem for a grammar like his, as there is no dependency relationship between constituents in a symmetric structure. However, he argues that symmetry in coordination is only semantic. In syntactic terms there is no mutual dependency.

Semantically speaking the conjunction is a two-place predicate, but its first semantic argument becomes its syntactic governor - a similar state of affairs as in the case of the preposition (Mel'čuk 1988: 90).

Syntactically the conjunction cannot be the head of the coordinate expression: the distribution of the coordinated expression is determined by the conjunct(s) and not the conjunction (Mel'čuk 1988: 41). The distribution of the conjunction depends on the first conjunct as the ungrammaticality of (64c) shows, which illustrates what Mel'čuk (1988) terms coordinative dependency relationship between them.

(64) a. several interesting and beautiful magazines

b. several interesting magazines

c. * several and beautiful magazines

(Mel'čuk 1988: 27)

Finding the head of the conjunction-second conjunct dependency relationship is less clear cut, but Mel'čuk (1988: 41) argues that the conjunction is the head in this case as "it determines the distribution of the expression to a greater degree" than does the 
second conjunct. He terms this relationship coordinative-conjunctive dependency. The relationships are illustrated in the schema below:

Dependencies in the expression ' $\mathrm{X}$ and $\mathrm{Y}$ ':

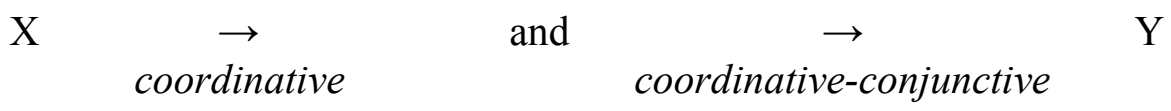

The coordinative-conjunctive dependency, however, appears dubious, if distributional dependency is decided with the help of the kind of test Mel'čuk uses to establish the first conjunct as the head of the entire conjoined expression (64). The distribution of the conjunction and the second conjunct mutually depend on each other:

(66) a. his rather harmless but many mistakes

b. * his rather harmless but mistakes

c. * his rather harmless many mistakes (vs. his many rather harmless mistakes)

Even putting this problem aside, coordination does not neatly fit into the rest of Mel'čuk's (1988) grammar. In most other cases syntactic dependency is related to semantic relationships: the gist of the theory is that it is semantic dependency that feeds the deep syntactic component in the grammar. Though the semantic-syntactic relationship is not assumed to be a one-to-one mapping, it is not explained how or why only in the case of coordination and prepositions is one of the semantic dependency relationships upheld while the second one is reversed in syntax.

It seems that coordination is proving to be a uniquely challenging phenomenon to every version of dependency grammar that dares to discuss it. DG grammars are either forced to adopt the notion of phrase to account for it, or - if they acknowledge the existence of phrases as epiphenomenal - are forced to modify the way dependency relationships create constituents. In the next section I will turn to another type of grammar operating without phrases, unificational categorial grammar.

\subsubsection{Unificational Categorial Grammar}

In Unificational Categorial Grammar (Zeevat 1988, 1991), like in other Categorial Grammars, language-specific syntactic information on how words combine to form 
constituents and then sentences is stored in the Lexicon. The role of syntax is thus reduced to concatenation: permitting words with compatible lexical components to combine with one another. In UCG this concatenation takes place via unification. Unificational approaches to grammar provide a formal mechanism in which consistent information is put together: two pieces of data are unified if their feature sets contain non-conflicting values. If they contain conflicting information, unification fails.

The novel aspect of UCG is that it is a monostratal kind of grammar, where every linguistic expression is represented by a single sign. Each sign is assigned a number of representations, phonological, categorial and semantic, along with a specification of the order in which the item needs to appear with respect to the other lexical items it combines with. The use of a single sign, rather than a number of associated representations, for a lexical item and other linguistic expressions means that the same variables may be used on several levels of the sign (Zeevat 1988: 203-204). During the unification procedure all four representations of the two signs to be unified need to be able to combine into a new representation for unification to succeed.

Coordination is one of the areas that are problematic for this approach. "The parts where our approach does less well are conjunction, where our efforts have so far not led to a very satisfactory approach as well as problems with non-configurationality" (Zeevat 1991: 23).

The problem for coordination is that the features of both conjuncts could in many cases independently unify with the rest of the sentence, but cannot unify with each other as would be required in order for them to form a conjoined entity, which then would be able to unify with the rest. The example in (67) serves to informally illustrate the problem, without using the formalisms of UCG. The starting point of the unification process, the numeration of lexical items, is provided in (67a).

(67) a. \{left, John, Mary\}

b. John left

c. Mary left

d. John and Mary left 
(67b) and (67c) are two possible unifications that will succeed, given the numeration: the verb is looking for a nominal, and each noun is looking for a verb. This information is stored in the categorial attribute of the elements, with the order of the item and the element it is looking for specified as the order attribute of the sign. The conjoined expression (67d) will fail to unify: the verb is looking for only one subject, but the nouns are neither looking for each other nor for a conjunction particle, which would allow them to unify first - and then jointly serve as the single subject of the verb. Zeevat (1991) offers accounts for several phenomena, but does not say anything about coordination - other than acknowledging that it is problematic.

I will now turn my attention to a more radically lexicalist variant of UCG, which is more successful in accounting for coordination.

\subsubsection{GASG}

Generative/Generalized Argument Structure Grammar (Alberti 1999) overcomes UCG's problems in accounting for non-configurationality and coordination. It is more successful than the theories reviewed so far in accounting for coordination and in several instances it arrives at the same conclusions as the theory to be developed in forthcoming chapters. For these reasons I have chosen to review not only the basic ideas, but also some of the formalisms, to allow the reader to appreciate the contribution of GASG to the understanding of coordination - and also to see the kind of problems that a structureless account faces in accounting for ellipsis phenomena.

GASG is "more consistently and radically 'lexicalist' than any earlier grammar" (Alberti 2001: 135-136): it replaces the entire syntactic apparatus with unification as the engine for combining lexical signs. The lexical sign contains several levels of linguistic description and expresses relations between them by sharing variables between the information related to the various levels of description. The lexical sign includes information about the sign itself (own word) as well as about the potential environment of the sign by including morphological and ordering information about elements the linguistic sign is looking for (environmental words). Two linguistic signs can pair up during the process of unification if an environmental word of one of them is a one to one match to the own word of the other and vice versa. While the selected words are being unified on the basis of their formal features, the semantic features of 
the lexical signs also undergo unification. Thus the lexicon and the semantics interface directly without any syntactic mediation - an assumption that is also key in the present theory, and which will be discussed in detail in Section 2.1.1.

The way words are seeking each other is often morphological: an accusatively-marked noun is looking for a transitive verb, while a transitive verb is looking for its object. However, linear ordering relations of precedence and adjacency are also relevant more markedly in languages with poor morphology. For example, both the article and the adjective long to immediately precede the noun, but clearly one of them will need to give up its spot and settle for the second best position. The immediate adjacency requirement of the determiner is satisfied even if it is not immediately adjacent to the noun as long as the intervening word is a legitimate element: one whose adjacency requirement to the noun is stronger. Adjectives are such elements. The intuition that certain elements long for their desired position more strongly than others is captured formally via the syntactic rank parameter $(\alpha)$ of the lexical sign. The syntactic rank parameter with respect to the noun is going to be a smaller number (=higher rank) in case of the adjective than in case of the determiner. The ordering gets sorted out during unification, when it is irrelevant whether an adjacency requirement is satisfied immediately by the element itself or indirectly, with legitimate (higher ranking), element(s) intervening.

Before proceeding to Alberti's (1999) account of coordination, let me illustrate the application of the syntactic rank parameter with an example, the derivation of a German nominative expression.

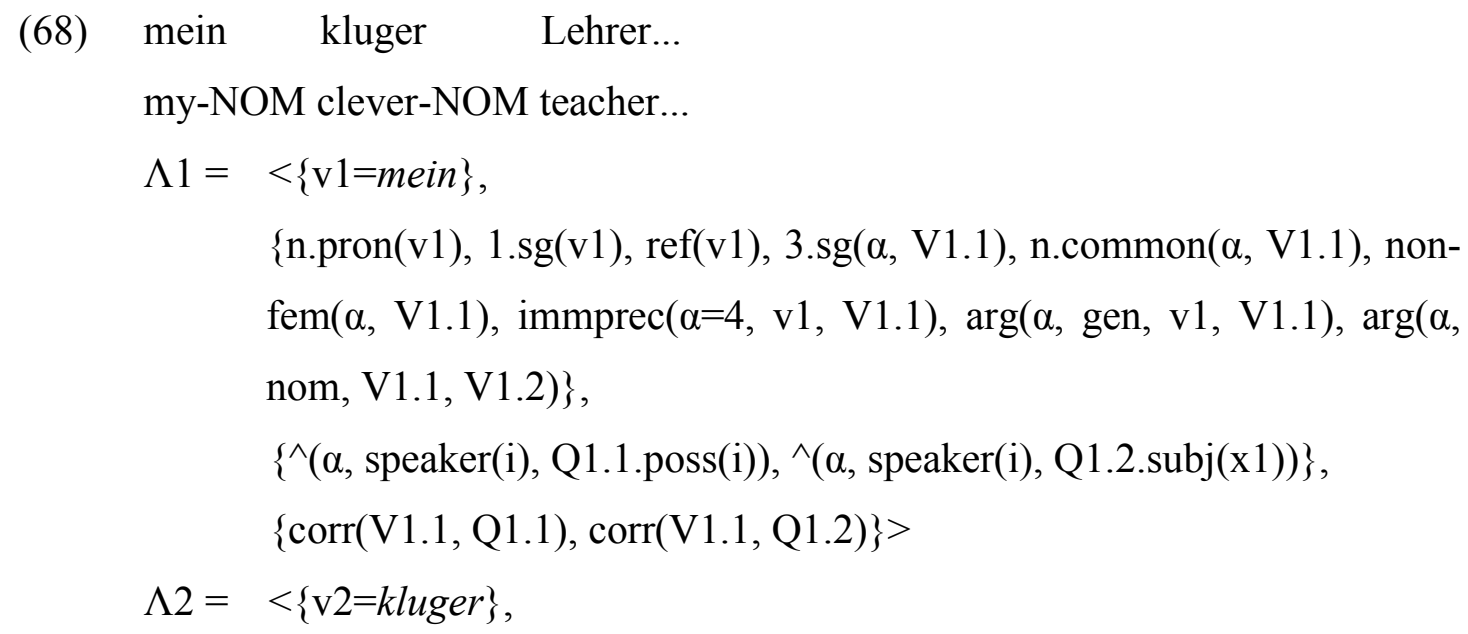




$$
\begin{aligned}
& \{\operatorname{adj}(v 2), \quad \operatorname{masc}(\alpha, \quad \mathrm{V} 2.1), \quad 3 . \operatorname{sg}(\alpha, \quad \mathrm{V} 2.1), \quad \mathrm{n} \cdot \operatorname{common}(\alpha, \quad \mathrm{V} 2.1), \\
& \text { immprec( } \alpha=2, \mathrm{v} 2, \mathrm{~V} 2.1), \arg (\alpha, \text { nom, V2.1, V2.2)\}, } \\
& \left\{\wedge(\alpha, \operatorname{clever}(\mathrm{X} 2), \mathrm{Q} 2.1(\mathrm{X} 2)),{ }^{\wedge}(\alpha, \operatorname{clever}(\mathrm{X} 2), \mathrm{Q} 2.2 \cdot \operatorname{subj}(\mathrm{X} 2))\right\} \text {, } \\
& \{\operatorname{corr}(\mathrm{v} 2, \text { clever }), \operatorname{corr}(\mathrm{V} 2.1, \mathrm{Q} 2.1), \operatorname{corr}(\mathrm{V} 2.2, \mathrm{Q} 2.2)\}> \\
& \Lambda 3=<\{\mathrm{v} 3=\text { Lehrer }\} \text {, } \\
& \text { \{n.common(v3), masc(v3), 3.sg(v3), } \arg (\alpha, \text { CASE3, v3, v3)\}, } \\
& \{\wedge(\alpha, \text { teacher(X3), Q3.GRF3(X3)) }\} \text {, } \\
& \{\operatorname{corr}(\mathrm{v} 3, \text { teacher), } \operatorname{corr}(\mathrm{V} 3, \mathrm{Q} 3), \operatorname{corr}(\mathrm{CASE} 3, \mathrm{GRF} 3)\}>
\end{aligned}
$$

(Alberti 2001: 191) ${ }^{9}$

In the lexical items above, $\mathrm{v}$ is the own word of the lexical sign $\Lambda$. The variables, denoted by capital letters, are the environmental words referred to in the lexical entry of the item. Let us begin with the second item, the adjective. The first component of the description is the phonetic form that is the realization of the lexical item in potentially accommodating sentences. The second component of kluger supplies the formal characterization of the word: it is an adjective, which requires a masculine, third person singular common noun (V2.1), which it should immediately precede (immprec). Furthermore, this V2.1 is the nominative argument of another word, V2.2. The third component of the sign is the semantic description. "clever(X2)" is the contribution of the lexical item to the semantics of the sentence, which appears in a proposition with Q2.1 - a predicate type variable of the same common noun item that was required to immediately follow the element. And "clever(X2)" will also have a subjective meaning with respect to the predicate Q2.2. The fourth component of the description establishes correspondences between the various levels: as v2 is the phonetic realization of predicate clever, the own word denoted by V2.1 belongs to Q2.1 in another lexical description. Similarly, the own word here denoted by V2.2 belongs to Q2.2 in a lexical description to be matched up with $\Lambda 2$ 's.

$\Lambda 3$, a masculine, third-person singular common noun, stands in argument relation with an environmental word V3. This argument relationship is denoted morphologically via a Case, CASE3. On the semantic side, this word carries the grammatical function variable GRF3 in relation to the environmental predicate Q3.

\footnotetext{
${ }^{9}$ In fact, the examples here are slightly simplified versions of Alberti's (2001) examples, providing just enough detail for the mechanism to be clear. In particular, what is missing is the "det-ein" attributes from the formal descriptions of all three items, referring to a peculiar property of the German agreement system, not relevant to the present discussion.
} 
This relationship will be subjecthood, and the correspondence between nominative case and subjecthood is established in the fourth part of the description.

The possessive article, $\Lambda 1$, is a first person singular referential word (i.e. pronoun), which requires a non-feminine, third-person singular common noun to immediately follow it. The common noun is the genitive argument of the article, while at the same time serves as the nominative argument of another environmental word. (In German it is the article that carries the agreement feature of the noun, hence the relationship between two environmental words needs to be encoded here.) The ' $i$ ' in the semantic description of the word refers to the speaker - i.e. that the common noun following the word is possessed by the speaker. Furthermore, it is the subject of the other environmental word specified in the entry. The fourth part of the description establishes the connection between the formal and semantic attributes belonging to what will end up being - the subject noun and the verbal predicate.

During unification, these three items fit together: the article and the noun call for each other in their lexical descriptions, while the adjective calls for a noun with the proper attributes. The terms unify and the immprec $\alpha$ values determine their order. The syntactic rank parameter values are meaningless in themselves, it is only their relative values that matter. The adjective $(\alpha=2)$ is higher ranked than the article $(\alpha=4)$, so the immprec feature of the adjective will be satisfied immediately, while that of the article will be satisfied indirectly - yielding the correct word order.

Alberti's (1999) account of coordination also operates with the same tool set. It is the abstract syntactic rank parameters that in GASG perform the function that is normally performed by constituent structure, gluing substrings of the sentence together. The first formula in the lexical sign for and (69) captures what in phrase structure theories is called the like-and-like constraint: that constituents of the same type and level can be coordinated.

and

$\operatorname{idcat}(\beta, W 1, W 2), \operatorname{prec}(\gamma 1, W 1$, and $), \operatorname{prec}(\gamma 2$, and, $W 2)$, adjc $(\gamma 3, W 1$, and $)$, $\operatorname{adjc}(\gamma, \mathrm{W} 2$, and $)$ 
The second and third formulas establish that and follows one and precedes the other conjunct $^{10}$. The next formula demands the adjacency of the conjunction and the first conjunct - and in English nominal conjunction the $\gamma 3$ value will rarely be in competition, since modifiers typically come in front of the noun, so the conjunction will be in competition only with the pre-'head' modifiers of the second noun. Whether anything is inserted between the conjunction and the second conjunct 'head' depends on the relative values of $\gamma$ and the $\alpha$-s of the adjective(s) and determiner(s) belonging to the second noun. If $\alpha_{\text {determiner }}<\gamma$, we get 'DP' coordination (70a). If, on the other hand, we have $\alpha_{\text {adjective }}>\gamma$, we get ' $N$ '-coordination (70b). If the $\gamma$ parameter is in

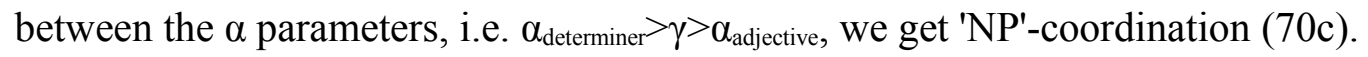
a. the big apple and the small pear
b. the big apple and pear
c. the big apple and small pear

Alberti's account predicts both conjunct orders in the case of two full conjuncts from the same numeration of lexical items: if $\mathrm{W} 1$ and $\mathrm{W} 2$ have identical structures, i.e. there is no ellipsis, both orders will unify. (70a) will thus be indistinguishable from the small pear and the big apple. (The theory to be developed in this thesis also predicts optionality in conjunct order in case of full conjuncts.) However, the analysis just summarized needs to assume the existence of a wide range of lexical signs with the same own word and, which differ only in their $\alpha$ values. In languages that make use of both pre-nominal and post-nominal adjectives, such as French, $\gamma 3$ will also potentially be in competition, further increasing the number of conjunctions in the lexicon. This is counter-intuitive and opens up the possibility that a language may use different own words for the different degrees of nominal conjunction. As far as I know there is no such language ${ }^{11}$, which is a problem for the analysis.

It is also unclear what would determine conjunct order in case of ellipsis in sentential coordination. No mechanism is provided for the formation of the conjunct with the ellipsis gap: the elided word is presumably an environmental word for at least one of

\footnotetext{
${ }^{10}$ Alberti (1999) leaves multiple coordination for future research.

${ }^{11}$ In the case of verbal coordination several languages, including Nguna and Sissala actually distinguish between 'VP' and 'clausal' coordination, as I will review in Section 3.3.1. However, the distinctions can be attributed to factors other than the grammatical category of the verbal conjuncts, so they do not necessarily lend support to the assumption that VP and clausal coordination involve different lexical items.
} 
the lexical signs present in this conjunct, and it is unclear how a conjunct in which no one to one correspondence exists between the own words and the environmental words is formed. Introduction of a second, identical lexical item but without a missing environmental word to be used in ellipsis would not be very explanatory.

One way in which the analysis provided for nominal coordination could be extended to predicate coordination is to suggest that the corresponding argument in the full conjunct satisfies the adjacency requirement of the predicate with an elided argument, as in (71) below. Since semantically the shared subject is the agent of both verbs, and semantic information is part of the lexical sign, this is a reasonable assumption.

the boy came in and sat down

However, it is unclear how the syntactic rank parameter in the lexical sign of the verb, which demands a preceding and adjacent subject, would be satisfied for the second verb under these conditions. The conjunction does not get inserted between subjects and verbs in full conjuncts, so the syntactic rank parameters holding between predicates and their arguments must be of higher rank than the ones holding between the conjunction and the conjoined propositions, presumably represented by their predicates. This ranking would yield the word order: the boy came in sat down and.

The same problem is apparent in case of a missing object:

(72) the boy loves and the girl hates wine

The syntactic rank parameter $\gamma 3$ for and needs to presumably outrank the syntactic rank parameter that holds between a verb and its object - as only a higher ranked intervening item can legalize the placement of the object further away from its desired adjacency position. But if that is the case, what would stop the conjunction intervening between a verb and its object in case of full clause coordination? One answer could be to suppose the existence of different conjunctions for elliptical and non-elliptical cases: one and for subject ellipsis with a highly ranked $\gamma$, one for object ellipsis with a highly ranked $\gamma 3$ and a third for cases when there is both object and subject ellipsis, as in (73). However, this solution would not be very explanatory. 
(73) the boy loves and drinks wine

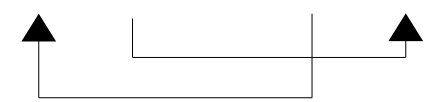

I also do not see how GASG's approach could extend to account for gapping. Since the object and the subject of a transitive verb are both related to their shared predicate, but not to each other, the unification procedure for the input numeration cannot succeed with the predicate missing. The environmental verb for both arguments is missing, and there is nothing to hold the subject and the object together. If the overt predicate can "stand in" as the environmental verb for these argument, the precedence relationships specified will mean that the arguments of the gapped verb are placed on different sides of the overt predicate: (74a) will come out as (74b-e).

(74) a. the boy loves wine and the girl beer

b. * the girl the boy loves wine beer

c. * the boy the girl loves wine beer

d. * the girl the boy loves beer wine

e. * the boy the girl loves beer wine

Similar problems would arise in case of the non-constituent coordination cases:

(75) a. John drinks beer at lunchtime and wine in the evening

b. I consider this uninteresting and a waste of time

c. someone rather difficult to talk to and who I don't really like just walked in

GASG is the most successful of the structureless theories that have tackled coordination, but several problems remain because the theory cannot resort to phrases. Coordination is a phenomenon where phrases appear to be empirically: and is inserted into what are "pre-glued" conjuncts. The problem faced by any theory operating without phrases is to account for this without compromising the framework.

Before I can proceed to my analysis of coordination, many ideas of which have been shaped by the difficulties faced by other grammatical theories operating without syntactic structure in accounting for coordinate phenomena, I introduce the theoretical framework to be applied: OT alignment syntax. This is the subject of the next chapter. 


\section{Optimality Theory}

The essence of most generative syntactic frameworks is a set of inviolable principles, typically called Universal Grammar. Language particular phenomena is accounted for with the help of language particular parameters or language-specific rules.

Optimality Theory is fundamentally different: its principles are violable. By its nature of allowing conflicting and violable constraints, OT is well-positioned to tackle issues of coordination that have caused problems for researchers working in more mainstream theories. As discussed in Chapter 1, developments in X-bar Theory during the late 80 s and early 90 s have pushed researchers working within the Principles and Parameters framework to analyze coordination as instantiation of the type of structure occurring elsewhere. These accounts have all tried to tackle the same basic problem: how to fit non-phrasal coordination into the X-bar pattern.

The problem is due to a conflict between empirical facts regarding $\mathrm{X}^{\mathrm{o}}$-coordination and hard-wired axioms of the framework. In OT, there are no hard-wired rules. This is what pretheoretically would make OT a promising framework in an account of coordination phenomena. My goal is to provide an OT account of coordination.

I will, however, have to modify assumptions generally made in current syntactic research in OT, and try to push the limits and possibilities of the theory: in standard OT X-bar Theory is typically assumed to be a core and inviolable set of metaprinciples of grammar. It is by eliminating from the grammar historically inherited axioms about X-bar Theory or even the central notion of phrases that we can unlock the real power of OT: the violable constraints that make up the evaluation system are solely responsible for the grammar and grammatical differences between languages.

After introducing the modules and features of standard OT (Section 2.1), I will argue that an OT grammar without phrases is a viable alternative and actually leads to a simpler theory (Section 2.2). I will illustrate the ability of this grammar to account for basic phenomena by providing an account of topicalization in various languages (Section 2.3), the conclusions of which will also be relevant for some of the coordination phenomena to be discussed in Chapter 4 . 


\subsection{Standard OT}

A grammar in Optimality Theory (Prince and Smolensky 1993) maps inputs into output expressions by first generating a large number of candidate expressions for each input and then selecting the optimal candidate from among them.

A generator GEN produces candidate structural analyses of input realizations, which as a first approximation can be seen as a set of words. Members of this candidate set are evaluated according to a function called EVAL, which refers to a Constraint Set: a hierarchy of universal and violable constraints that are well-formdness requirements on the candidates. Because these requirements conflict, every candidate is going to violate a subset of the constraints. The optimal (=most harmonic, least marked) candidate is the one that best satisfies the highest ranked constraint on which it differs from its competitors. This mechanism is represented in the following schema:

$$
\text { Input } \rightarrow \text { GEN } \rightarrow \text { Candidate Set } \rightarrow \text { EVAL } \rightarrow \text { Optimal Candidate }
$$

Languages differ from one another because the rankings of the well-formdness requirements differ from one grammar to the other. A candidate that is the most harmonic/least marked from among the candidates under a particular ranking may be suboptimal under a different ranking.

In OT the input and the candidate set are assumed to be the same for all languages. Systematic differences between languages arise from different constraint rankings, which affect how the candidates are evaluated (Prince and Smolensky 1993) and not from language-dependent specifications of differences in the lexical inventory. In other words, systematic lexical properties, such as whether a language morphologically marks person and number distinctions, are derived by constraint ranking (Bresnan 2002). Unsystematic properties, like language-particular formmeaning correspondences, are idiosyncratic and are learned outside the OT grammar.

In what follows I will review the building blocks of the theory in (76). 2.1.1 discusses standard assumptions about the content and interpretation of the input. 2.1.2 is devoted to the structure producing device, GEN, and to the candidates it generates. 
2.1.3 presents a standard theory of constraints and how the evaluation component selects the optimal candidate with the help of these constraints.

\subsubsection{The Input}

The input is standardly assumed to be a group of lexical items that are the building blocks of the sentence. The lexical items can themselves be complex - i.e. they are subject to derivational morphology before they are inserted into the input for a given expression. These lexical items form the basis of the candidates that are going to compete in the optimality system.

According to Grimshaw (1997), the input is a list of lexical elements, defined in terms of lexical heads and their argument structures. She also included semantic information in the input, which means that the competing candidates generated from this input have the same interpretation. Once it is selected by the grammar, the optimal candidate enters the semantic component of the grammar to receive interpretation, as is standardly assumed within the Principles and Parameters framework.

There is a redundancy in this system, as noted by Speas (1997): semantic information is present both in the input and then once more as the optimal candidate enters the semantic component. She proposes to overcome this redundancy by eliminating semantic information from the input. The input then is an unordered list of words as in (77). A structured ordering of these elements by GEN generates the candidates, among them those in (78) (since Speas allows movement, the list of candidates is infinite).

(77) John, Mary, loves

(78) a. [John [Mary loves]]

b. [[John ${ }_{\mathrm{i}}\left[\right.$ Mary [loves $\left.\left.\left.t_{\mathrm{i}}\right]\right]\right]$

c. [John [loves Mary]]

d. [[John loves] Mary]

e. [Mary [John loves]]

f. [[Mary $y_{i}\left[\right.$ John [loves $\left.\left.\left.t_{i}\right]\right]\right]$

g. [Mary [loves John]] 
h. [[Mary loves] John]

i. [loves [Mary $\left.\left[t_{\mathrm{i}} \mathrm{John}\right]\right]$

j. [[loves Mary] John]

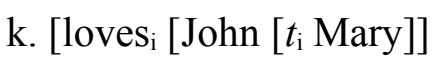

1. [[loves John] Mary]

The candidates associated with the input in (77) have different interpretations: in (78c) and $(78 \mathrm{~h})$, for instance, John is the experiencer, while Mary is the theme, while in (78d) and (78g) the opposite is true. (78b) is presumably the topicalized version of $(78 \mathrm{~g})$, and its word order coincides with (78a).

As they are generated from the same input, candidates in which a particular item bears one role compete with candidates in which the same item bears another thematic role. Since only the optimal candidate receives an interpretation, and so the constraints do not have access to semantic information, they cannot determine whether optimally John is an experiencer (thus subject) or theme (and so object) - and as a result there is more than one optimal candidate for an input. Similarly, under this view an unmarked version of a sentence competes with its topicalized version. However, it is unclear how the topicalized version would ever surface as optimal if the input does not encode semantic information: how could a structure involving movement ever be equally optimal with a structure that does not. Once movement is allowed, there needs to be a constraint against it, otherwise infinite movement would be a possibility and there would be an infinite number of optimal structures for any given input. But once we have such a constraint, the constraint violation profiles of a topicalized and a nontopicalized candidate can no longer be the same. As a result topicalization would always be suboptimal - unless the input includes, and so the constraints have access to, semantic information. If the input includes semantic information, such as a topic feature on a verbal argument, a topicalization constraint can outrank the constraint against movement. The topicalization constraint will be activated only in the presence of a topic-marked argument, and will counter the effect of the normally dominant constraint that prohibits movement. Therefore it seems that some semantic information will need to be included in the input. This would undermine Speas's (1997) account of introducing semantic information into the system only post syntax. 
Once some semantic information is present in the input, it is reasonable to assume that other semantic information is also included.

There is another logical possibility to eliminate the redundancy in Grimshaw's system but without encountering the problems that face Speas's account: keep the semantic information in the input, but get rid off the assumption of post-syntactic semantic interpretation of the optimal candidate. This is the route taken by Newson (1998a, 2000a), who concluded that the input alone should be regarded as the interface with the semantic component of the grammar. This eliminates the redundancy in Grimshaw's (1997) analysis, while at the same times maintains the view that only candidates with the same meaning compete.

The diagram below summarizes this framework - adding the interface to the interpretative component of the grammar to the schema in (76).

(79) $\quad \underset{\substack{\downarrow \\ \text { input }}}{\rightarrow}$ generation and evaluation of candidate set $\rightarrow$ optimal expression
semantic interpretation

What in effect is a similar view in an LFG version of OT is taken by Bresnan (2001), who assumes that the input consists of f-structures with their meanings ("content or points in the multidimensional spaces of possible lexical and grammatical contrasts"), and that GEN enumerates "the set of all possible types of formal realizations of that input that are available across languages" (Bresnan 2001: 21). In "traditional" LFG (Kaplan and Bresnan 1982), too, it is f(unctional)-structure rather than c(onstituent)structure that interfaces with the semantic component of the grammar. F-structure models the grammatical relations among syntactic functions - in which a predicate is marked for attributes such as tense and aspect, as well as for its complements.

To sum up, a standard OT view of the input, which will form the basis of my own view on the input to be discussed in Section 2.2.1, is that the input is a list of lexical items, which includes their argument structures as well as any other information that is relevant for interpretation. The input both gets interpreted and is fed into GEN. Standard assumptions about GEN and the candidates are the focus of the next section. 


\subsubsection{GEN and the Candidate Set}

In its most general definition, GEN is a structure producing device, which generates possible analyses of the input. These are the candidates, and are collectively called the Candidate Set. (78) above was the (partial) candidate set that resulted from a GEN operation of the input elements listed in (77).

However, if constraint ranking is the only source of language variation, it follows that the candidates must be the same in all languages. Languages then differ not in terms of the candidates themselves, but only in which member of the universal candidate set is chosen as optimal. This means that GEN is the most general, and so the least important module of the OT grammar.

GEN is, however, constrained to some degree. It is standardly assumed that only linguistically possible processes are allowed and that all output structures contain the input (Prince and Smolensky 1993). This does not necessitate that every input element must be overtly present in every candidate - it simply means that even if some input element was got rid off (underparsed), the fact that it was once part of the input is visible to EVAL. Thus the constraints "know" where candidates come from - even if we do not allow a direct comparison of inputs and outputs.

The candidates are assumed not to be simply strings of words, but also to be organized in terms of constituent structure. Grimshaw (1997) assumed that all candidates generated by GEN conform to X-bar Theory axioms of constituent structure. Thus a head has a complement sister, and this head-complement constituent in turn has a specifier. (This assumption was reflected in (78), where all the candidates were wellformed in terms of X-bar Theory.) The candidates may differ in many other ways including the presence of extra constituent structure slots, as long as they conform to X-bar Theory. The version of X-bar Theory that Grimshaw adopts is based on the assumption that functional projections are extended projections of the thematic complements of the functional head. Thus, IP and CP are extended projections of VP. Since functional elements such as complementizers do not have semantic content, Grimshaw assumes that they can be freely introduced without violating the restriction discussed above that only candidates with the same semantic interpretation compete. 
$\mathrm{X}$-bar Theory is then a set of inviolable meta-principles of the grammar. This view is shared by Speas (1997), and in fact by the overwhelming majority of OT syntactic research with origins in the Principles and Parameters framework.

A rare dissenting view is offered by Hordós (2003), who demonstrates that previously sacrosanct principles such as X-Bar Theory and the Binary Branching Condition may be translated into violable constraints "thereby opening up a space for structures not necessarily conforming to them" (Hordós 2003: 107) ${ }^{12}$. In her view the argument structure present in the input is used by GEN to build constituents, establish nodes and add empty structural slots.

I would like to take this line of research further, and propose a simpler GEN, which does not provide any kind of structure. This will be discussed in Section 2.2. First, however, I would like to summarize standard assumptions about EVAL, the evaluation component of the grammar.

\subsubsection{The Constraints}

The constraints make up the evaluation component (EVAL) of the OT grammar. Though constraints in OT are universal, their relative re-ranking is the source of grammatical variation among languages. Systemic differences between languages arise from different constraint rankings, which affect the evaluation of the candidates.

Candidates are first evaluated against the highest ranked constraint, and any candidate that satisfies it less than at least one of the other candidates is eliminated. The surviving candidates then pass on to the second most dominant constraint and the process is repeated until there is only one surviving candidate or the set of constraints is exhausted, in which case all surviving candidates are grammatical. Each constraint has absolute dominance over all the lower ranked constraints: no matter how many lower ranking constraints a candidate satisfies it is out of the grammaticality race once it conflicts with a higher ranking constraint that was satisfied by at least one of the other candidates surviving at that point of the evaluation.

\footnotetext{
${ }^{12}$ Hordós (2003) actually retains a few X-Bar Theory axioms as part of GEN: e.g. there are no multiple mothers or crossing branches. A coordination account in which restrictions on multiple mothers and crossing branches are also handled via violable constraints is provided in Gáspár (1999).
} 
Every constraint is present when evaluating the candidates for an input, but most constraints play no meaningful role in a particular analysis. For instance, constraints dealing with syllable structure have no role to play in syntax. Moreover, constraints dealing with the positioning of the focused constituent, for instance, have no role to play in constructions that do not involve a focused input element. To make the optimality tables comprehensible, only the relevant constraints are typically shown.

An example of how evaluation is represented is provided in (80). In the ranking the symbol » indicates absolute dominance of the constraint to its left over the constraint to its right (and all constraints to the right of that). ${ }^{*}$ in the cell $\mathrm{C} 1 /$ Candidate 1 indicates a violation of constraint $\mathrm{C} 1$ by Candidate 1 . The '!' in the cell indicates that this violation is 'fatal': Candidate 1 at this point is out of the grammaticality race. Even though Candidate 1 does better on constraint $\mathrm{C} 2$ than its competitors, it makes no difference to its fate. Since the surviving two candidates do equally badly on C2, nothing is decided, and both proceed to constraint $\mathrm{C} 3$. Candidate 2 violates $\mathrm{C} 3$, while Candidate 3 does not. This means Candidate 2 is out of the race (marked by !), and Canidate 3 is the optimal candidate, which is indicated with the symbol in front.

a. Constraint ranking: $\mathrm{C} 1 » \mathrm{C} 2 » \mathrm{C} 3$

b.

\begin{tabular}{|r|c|c|c|}
\cline { 2 - 4 } \multicolumn{1}{c|}{} & $\mathrm{C} 1$ & $\mathrm{C} 2$ & $\mathrm{C} 3$ \\
\hline Candidate 1 & $* !$ & & \\
\hline Candidate 2 & & $*$ & $* !$ \\
\hline Candidate 3 & & $*$ & \\
\hline
\end{tabular}

A common, and probably legitimate, criticism of OT analyses has been that they do not provide a theory of language, as no restriction on what can count as a possible constraint is usually assumed. In terms of syntactic research in OT, this issue was begun to be addressed by Grimshaw (1998), who proposed that constraints should be restricted to being members of constraint families - groups of related constraints. The grammar will consist of several such families. Grimshaw (1998) lists six types of constraint families - based on their common usage in previous OT research. As such the families she lists are empirically, rather than theoretically motivated.

Faithfulness constraints compare candidate expressions to the input, favouring candidates that faithfully represent input material. Unfaithfulness can come in two 
types: either input material is missing (called PARSE violation) or non-input material is inserted (called FiLL violation).

Markedness constraints are of the form *X, defining elements of type $\mathrm{X}$ as marked. $\mathrm{X}$ can appear in the output either if it is present in the input or if it is added by GEN. Such marked elements will only appear in the optimal candidate if the relevant markedness constraint is ranked lower than whatever constraint sanctions their appearance, e.g. PARSE if $\mathrm{X}$ is present in the input. If $* \mathrm{X}$ is ranked higher than PARSE, the element will be omitted, as such underparsing will satisfy a more highly ranked markedness constraint at the expense of the violation of a faithfulness constraint.

Economy constraints sanction against linguistic processes that may take place on input material. An example is Grimshaw's (1997) STAY, which prohibits movement.

Structure constraints prescribe certain arrangements for well-formed structures. Grimshaw's (1997) OB-HD, a constraint requiring all phrases to have non-empty heads or Grimshaw and Samek-Lodovici's (1998) SubJeCt, a constraint requiring the subject position to be filled, are examples of structure constraints.

Mapping constraints demand that elements of a certain semantic type be placed in specific positions - e.g. wh-elements into specifier positions in Grimshaw (1997).

Alignment constraints place an element to the edge of some domain. Grimshaw and Samek-Lodovici (1998) introduce an Align-Focus constraint to account for the positioning of contrastively focused subjects (and other elements) on the right edge of the clause in Italian. This contrasts with the canonical clause initial subject position.

What is unclear in Grimshaw's (1998) analysis, though, is what constitutes a family of constraints. She lists the six families as examples, not as exhaustive categories of constraints. Thus the restriction this system places on constraints is not very strong.

In Chapter 2.2.2 I introduce a stricter theory of constraints, one that makes use of only two of Grimshaw's (1998) constraint families: faithfulness and alignment constraints. This will be an extension of Newson's (2000b) approach of an alignment-based OT. 


\subsection{A more radical view of $\mathrm{OT}$}

In what has been presented so far, OT was more of a clever grammar building ploy than a theory of language in its own right. A GEN that completely or partially incorporates X-bar Theory and a constraint such as STAY making reference to notions of movement in a representational theory that does not assume movement both suggest that in its standard form OT is employed to get around some of the stumbling blocks faced in traditional accounts. While there is nothing wrong with such an approach, one in which the traditional axioms are questioned along with the notion of inviolable constraints offers more potential: pretheoretically it is not very likely that in a theory that allows constraint violation all the constraints of a theory operating with inviolable constraints will be necessary or even valid.

The novel framework presented in this section is built on Newson's (1998b, 2000a, 2000b) alignment syntax. This account has three defining characteristics:

- The sole semantic interface with the grammar's semantic component is the input, and all semantic information must be present in the OT input. I have presented this aspect of the theory in Section 2.1.1, because this view is shared by researchers in other OT frameworks (Bresnan 2002) and because this is an assumption to which I have nothing to add.

- There is no constituent structure, be it X-bar Theory based or any other notion of constituency. Phrases are epiphenomenal. The only form of structure left is in the input, where elements are organized according to what becomes a blueprint for semantic structure. I will justify this view and further define the input assumptions it makes in Section 2.2.1.

- The grammar consists of only of alignment and faithfulness constraints. Newson (2000b) contends that the effects of structure, mapping and economy constraints could be achieved through the use of alignment conditions, while markedness effects can be captured through the interaction of alignment and faithfulness constraints. In Section 2.2.2 I will justify this view and take alignment syntax beyond the predicate-argument relationship of Newson's account by defining several types of alignment constraints as well as by presenting a new, cyclical mechanism of constraint interaction and candidate evaluation. 
Even within OT, this framework represents a radical position, but one that unlocks the potential of the theory: once we adopt violable constraints, it is possible to forgo many of the assumptions present in phrase structure-based grammars. OT in its most interesting form is not a structural theory with violable constraint equivalents to traditional constraints and rules, but a full theory of grammar in its own right.

\subsubsection{Redefining the Input}

In this section I would like to put forward three separate ideas concerning the input. In 2.2.1.1 I will suggest that the input consists of feature bundles and the lexicon is consulted after the optimal candidate has been selected. In 2.2.1.2 I will propose that the input is best viewed as a data structure template, whose slots are filled with the actual input elements and in 2.2.1.3 will also show how such an input structure could extend to coordinate expressions. In 2.2.1.4 I will show how inputs for ellipsis structures can fit into a data structure template.

\subsubsection{Late Insertion}

To motivate my assumptions about the Input, I would like to refer back to the discussion of standard assumptions on GEN and the Candidate Set (2.1.1). Standardly, GEN is assumed to be able to add items to those in the input or subtract items and input features. A potential criticism against OT might be that such a powerful GEN creates computational problems: the ability of GEN to add material to the input means that the set of competing candidates is infinite. It has still to be demonstrated that it is always possible to find the optimal candidate in such an infinite search space and much depends on what else GEN is allowed to do.

However, if we limit the power of GEN to producing the possible orderings of input elements and to underparsing various features/items included in the input, we rob GEN off its most powerful device: to generate an infinite number of candidates. With GEN thus curtailed potential computational problems disappear.

If the input is directly related to meaning, non-meaningful elements are presumably not part of the input. They do, however, sometimes surface in the optimal candidate. The gist of Grimshaw's (1997) account of $d o$-support in English negation and question constructions is exactly this idea: when the grammar (the ranking of the constraints) 
forces the presence of a verbal element in a position in which the input verb is banned from surfacing, the candidate produced by GEN with the addition of the expletive do is selected as optimal. Grimshaw and Samek-Lodovici (1998) apply the same idea to account for the use of expletive it in English and most Germanic languages.

However, if GEN cannot add material, another explanation is necessary to account for the presence of expletives.

A related problem arises during underparsing. The make up of an input element may change during the optimality process due to the underparsing of a feature. Under the view in which the input is seen as a listing of lexical items, the grammar would have no access to the lexical item corresponding to the element with the underparsed feature - a key requirement in cases of neutralization, when the form of a verb is replaced by another form in certain environments.

This suggests that the lexicon can also be consulted after the optimal candidate has been selected. The language-particular lexical item that matches the feature set without a corresponding word in the optimal candidate could then be "looked up" in the lexicon and inserted into the string before the winning candidate enters the phonological apparatus. This assumption, however, would introduce redundancy into the system if we continued to take the lexicon as the starting point of input formation.

I would like to deviate from this lexicalist position and apply Distributed Morphology (Halle and Marantz 1993) to OT. In DM, just like under standard assumptions, the grammar does not manipulate lexical items, but combinations of abstract feature bundles. What differentiates DM from the traditional view is that what is normally called the lexicon is consulted only after the syntactic derivation has been completed, at which point the abstract grammatical entities are mapped to corresponding phonological forms. The pre-syntactic lexicon consists solely of semantic/grammatical feature bundles ${ }^{13}$.

\footnotetext{
${ }^{13}$ Bresnan (2001) arrives at what at first sight seems to be a similar result, working within an LFG version of OT and analyzing morphosyntactic phenomena. In her framework the universal input for morphosyntax consists of f-structures (feature matrices of classical LFG), and the universal candidates are c-structure/f-structure pairs. The optimal candidates are mapped onto a language-particular phonological string. However, under her approach, a highly ranked constraint LEX requires that candidates "normally have pronunciations" (Bresnan 2001: 37). This is less explanatory than a principled late insertion approach using DM: An inviolable LEX has the same effect as a lexicalist
} 
The motivation for DM was a redundancy in Chomsky's (1992) theory of feature checking. Halle and Marantz (1993) point out that inflectional features of the affixes attached to the verb must not only be included in the part of the structure that goes to the phonological interpretation after Spell-Out, but have to hang on to the structure in a second copy as well, so that the same elements are available to be checked off. If, on the other hand, only abstract features are inserted into the tree, there is no such duplication - since the affixes themselves are required only for the phonological interpretation after the structure forks at Spell-Out.

If we adopt the view that the vocabulary is consulted only after the optimal candidate has been identified during the syntactic process, feature changes due to underparsing do not require extra mechanisms during the phonological mapping process. The grammar determines what elements surface and where they surface, and the lexicon follows the grammar by providing lexical entries for these elements.

One example of where such a view may be useful in OT syntax is the account of case phenomena in Newson (2003), who argues that a particular ranking of constraints in English accounts for the absence of dative case. Newson suggests that the indirect object in a sentence such as he helps me is universally marked with inherent dative case when the subject is assigned nominative case. Under such circumstances the dative is reduced to accusative in English. There would be no way for this case to surface if the lexicon could not be consulted after the syntactic process, during which the accusative form of the originally inherently case marked item can be looked up.

In DM there is no lexicon - its functions are distributed among various components. The term morpheme refers to a syntactic node and its content, not to the phonological expression of the element, which is provided as a Vocabulary Item. A Vocabulary Item is a relationship between a phonological string and information about where that string may be inserted.

approach, in which input elements contain a specification for language-particular pronunciation as they are selected. (LEX's violation leads to accidental lexical gaps, which again is the same as a null lexical input item in a lexicalist approach.) 
The content of a morpheme consists of syntactico-semantic features drawn from the set provided by Universal Grammar (e.g. [plural], [CAUSE], [Det]). In case of functional categories (called f-morphemes (Harley and Noyer 1998)), it is solely bundles of these features that are manipulated during the syntactic process. Lexical words (called 1-morphemes) also carry extralinguistic meaning, which is stored in the Encyclopedia, which relates Vocabulary Items to meanings.

Encyclopedia entry

dog: canine pet, four legs, can bite, ...

Under the adoption of the DM approach an actual word in the input representations or the optimality tables that list the competing candidates is nothing more than a convenient shorthand for a particular bundle of features, which is then matched in the lexical inventory of the language.

Under the lexicalist approach only feature bundles that actually exist in the language can become input elements, since the input elements are actual words of the language. Under the current view, however, a bundle of features that have no corresponding vocabulary item may also be assembled to form an input element. The features thus assembled may be semantically incompatible with each other (e.g. if the feature [plural] and [singular] are bundled into a single item or if the feature [past] is bundled with the Encyclopedia entry 'canine pet, four legs, can bite, ...'). In this case the input will not receive a semantic interpretation, and as such the syntactic system will not need to worry about it. In OT an input always has a syntactically optimal output, since one of the candidates will always do better than the others on the constraints. However, if it cannot receive an interpretation, this input will never be a valid one: a meaningless optimal candidate will not play a "meaningful" role in language.

It is also possible, however, that what gets bundled together into an input element are compatible features that simply do not correspond to a Vocabulary Item in the 
language. Another way to arrive at a bundle of features that does not have a corresponding Vocabulary Item is via the grammatical process itself: due to underparsing a feature can be removed, and the resulting bundle of features may not match any Vocabulary Items.

Underspecification of Vocabulary Items in DM means that phonological expressions do not need to be fully specified for the syntactic positions into which they can be inserted. The Subset Principle (Halle 1997) states that the phonological exponent of a Vocabulary Item can be inserted into a morpheme if the item matches all or a subset of the morpheme's features. Crucially in DM, the Vocabulary Item cannot be inserted into a morpheme if it contains features that are not prescribed by the syntactic output.

This 'best fit' approach could then explain the insertion of pleonastic elements, such as do or it. In the case of Grimshaw's (1997) do insertion, do is inserted when higher ranking constraints keep the input verb from being able to satisfy the OB-HD (obligatory head) constraint. In Grimshaw's account, the word do that is inserted in this case is the thematic one, only its semantic content is not parsed. Her claim is that this is the least semantically contentful word and hence requires the least amount of underparsing. According to the Subset Principle, however, if the optimal output calls for a verbal element, but without any other features specified, no real verb will be able to fill in the slot: they will all have features over and above the one specified for the morpheme to be filled. We can solve this problem if we assume the exact opposite of Grimshaw's proposal: $d o$ is a semantically and functionally empty verb which perfectly fits the empty verbal slot and is the best fitting subset for the features of a verb with minimal thematic content. The vocabulary item for the (dummy) do simply states that it is a verb in present tense, and nothing more.

$$
/ \mathrm{du}: / \leftrightarrow[\text { verb] }[\text { present }]
$$

This explanation is simpler than the one offered by Grimshaw (1997: 386). She had to account for the fact that the $\theta$-requirements of the inserted do are not met: after all, when acting as a main verb, $d o$ is a $\theta$-marking and argument-taking predicate. Under the DM view, however, there is no interference from main verb do this way: the vocabulary item is the dummy $d o$. When, on the other hand, the main verb $d o$ is 
required, no perfect fit will be found in the lexicon (since the single lexical entry is the dummy do). All other verbs will carry some semantic information incompatible with what is required for the main verb $d o$, so they cannot be selected. The dummy $d o$, will not be a perfect match either (since it has no meaning), but its features will be the subset for what is required, so it can be inserted ${ }^{14}$.

Support for this view comes from Japanese, which also has a meaningless verb. Suru, known as a light verb in grammar books, has no argument or thematic roles (Saito and Hoshi 2000), and is used when a noun needs to be turned into a verb. However, Japanese contains two verbs different from suru that correspond to the main English verb do. hataraku means to act, to labour, while tegakeru is closer in meaning to do in the sense of make and produce $e^{15}$. In Japanese, when the main verb do needs to be selected at Vocabulary Insertion, dummy suru will be a worse fit than hataraku or tegakeru, whose features will match perfectly the features required. When, on the other hand, a meaningless, verbal grammaticizer is required, hataraku and tegakeru will be just as overspecified as any other verb. The only Vocabulary Item that is verbal but carries no meaning will be selected: suru. The difference between English and Japanese is captured by assuming exactly what is overtly apparent: two (or actually three) vocabulary items in Japanese but only one, the dummy do, in English.

Similarly to do in the case of verbal holes, only it can be used as a nominal expletive, because its vocabulary item contains no features other than that of a nominal ${ }^{16}$.

$$
\text { /it/ } \leftrightarrow[\text { noun }]
$$

To sum up, the theoretical importance of Late Insertion is that DM can provide OT with a back-door way of inserting elements into an expression without empowering GEN to add items to the input, and thereby exploding the number of candidates.

\footnotetext{
${ }^{14}$ be could be another potential candidate. However, we may suppose that action is the default status for verbs, so the vocabulary item of be will have to include an extra feature: i. $\quad / \mathrm{bi}: / \leftrightarrow[$ verb] [existence]

Clearly, there would need to be some other reason for why be is used pleonastically in progressive or passive constructions.

${ }^{15}$ I am thankful to Yuko Kitada (p.c.) for pointing out this contrast.

${ }^{16} \mathrm{I}$ am assuming that it is not marked for gender, number or person. When a noun is neither marked for masculine nor for feminine, it is neutral by default. When it is not marked for number it is singular by default and when it is not marked for person it is third person by default.
} 
The importance of Late Insertion will become clear in Section 3.3.1, discussing the realization of the conjunction marker in languages that use different particles for coordinating different types of items. Late Insertion allows a simple treatment of this phenomenon: the actual form of the conjunction will be dependent on conjunct types.

\subsubsection{Input as data structure}

I have concluded Section 2.1.1 by taking as the basis of my own analysis Newson's (2000a) view of the input: input items contain their argument structures as well as any other information that is relevant for semantic interpretation. In this and the following sections I would like to further develop these ideas, which were created to explain predication. Coordination is not a predication relationship, so further assumptions about the input are required before an analysis of coordination can be attempted.

I will view the input as a data structure, in which slots for elements are created via the argument structure of elements placed in it. Let us take a predicate as an example. When an element, a morpheme-encyclopedia entry feature combination, is placed into an input, that element will bring along a template in line with its needs as a predicate. The new slots correspond to the thematic needs of the predicate.

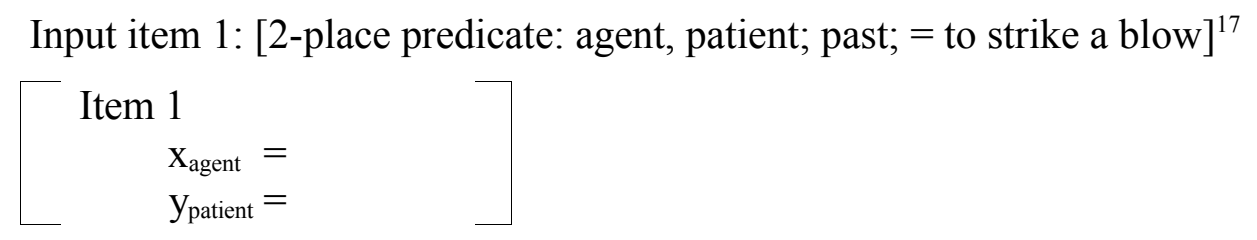

For the input to be interpretatable, the data slots created in the template need to be filled in by other elements - elements that do not semantically conflict with the first input item. For (85) these could be the two elements in (86a), resulting in the fully formed input as in (86b).

a. Input item 2: [noun, singular; = individual who is my neighbor] Input item 3: [noun, singular; = individual who is my neighbor's best friend]

$\mathrm{b}$

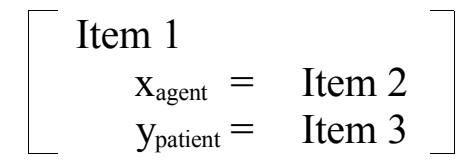

c. John hit Bill ${ }_{17}$ This a simplification of what a DM morpheme-encyclopedia entry combination would look like.
However, it should suffice for our purposes. 
Once the optimality system has established the order of these items, they are fed into the phonological component, where the relevant Vocabulary Items will be inserted, and the sentence John hit Bill is created.

Viewed as a data structure template, the thematic argument roles are automatically part of the input: they are responsible for the creation of the data slots. As discussed in Section 2.1.1 information roles are also part of the input. However, these are not input items, and as such do not have their own data slots. They are attributes to input items, and appear as features. The topicalized version of (86c) is provided below:

a. Bill, John hit

$$
\left[\begin{array}{ccc}
\text { Item 1 } & \\
\mathrm{x}_{\text {agent }}= & \text { Item 2 } \\
\mathrm{y}_{\text {patient, top }}= & \text { Item 3 }
\end{array}\right]
$$

The subject, as the licensor of the verbal predicate, has a special status among the verbal arguments, which led Newson (1998b) to automatically assign the subject feature to the most prominent argument of the verb. Prominence is decided according to Grimshaw's (1990) argument prominence hierarchy. Agents are on top of the hierarchy, while themes at the bottom ${ }^{18}$. In the input above Item 2 (=John) will become the subject - so any constraint that makes reference to the behavior of the subject will be relevant for Item 2, but not for the other two input elements (88). The importance of the subject feature will become clear in Section 2.2.2.1, where I provide an analysis for the basic predicate-argument structure of English, in which subjects are compulsory, and of Hungarian, in which they are non-existent.

a. Bill, John hit

b. $\left[\begin{array}{cc}\text { Item } 1 & \\ \mathrm{x}_{\text {agent, sub }}= & \text { Item } 2 \\ \mathrm{y}_{\text {patient, top }}= & \text { Item } 3\end{array}\right]$

\footnotetext{
${ }^{18}$ This is a simplification, as it ignores the influence of the aspectual hierarchy in Grimshaw's (1990) theory and her definition of 'external argument' as that which is prominent in both hierarchies. In The book pleased John, there is a conflict between the two hierarchies and so according to Grimshaw the external argument is undefined. Why book is selected as subject is not explained by Grimshaw, but its "causer" aspect seems to allow it to override the otherwise higher ranked agent of the sentence to become the subject. Though I will continue to talk about agent as the most prominent argument, that is meant for aspectually neutral cases only.
} 
The discussion on input so far has simply recast the view adopted from Newson (1998b) in terms of a data structure template model. In the following section, I will extend it to items other than predicates and their arguments.

\subsubsection{Functor theory of inputs}

The organizing elements of the data structures in the previous section were predicates: predicates create the template for their thematic arguments. Predication is, however, not the only type of semantic relationship that needs to be captured in the input. Coordination, for one, is not a predication relationship.

I will introduce a more general term, borrowed from mathematics via categorial grammar, that will generalize the predicate-argument relationship to other elements. A functor is the semantic organizer of an expression, around which its functees ${ }^{19}$ orbit. According to the definition in categorial grammar the functor is "a grammatical relationship with blanks (gaps, places, slots), which yields a grammatical expression of a particular category when its blanks are filled with grammatical expressions of the appropriate categories" (Hardegree in preparation: Appendix 3, p.3). The gaps created by a two-place predicate need to be filled with elements that can function as arguments - typically nouns. In this case the predicate acts as a two-place functor.

Sentential operators, which take propositions as their arguments also function as functors. In contrast with logical operators that do not have single lexical counterparts and are realized by a given structural configuration (such as implication or equivalence), operators such as conjunction, disjunction and negation seem to have lexical counterparts in natural languages. As such they can be realized as heads of propositions, and as such can be considered functors. Negation is a one-place functor, while disjunction and conjunction are two-place functors ${ }^{20}$ :

a. it is not true that

\footnotetext{
${ }^{19}$ The counterparts of functors are normally called arguments. However, to avoid confusion with the counterparts of predicates, also called arguments, I have coined the term functee.

${ }^{20}$ The conjunction can also be an anadic functor, when it has more than two operands, as in $\mathrm{i}$ :

i. $\_1, \ldots 2, \ldots$, and $\_$m

ii. An anadic functor is a syntactic expression with an open ended blank that when filled with any number $(\mathrm{n} \geq 0)$ of expressions results in an expression of a particular category.
}

(Hardegree in preparation: Appendix 3, p.3) 
b. or

c. and

The table below summarizes the functor subtypes:

\begin{tabular}{|l|l|}
\hline Functor & Functee \\
\hline Predicate & Argument \\
\hline Operator & Operand \\
\hline
\end{tabular}

An OT input is organized around the central functor of the semantic expression. Its functees could well be functors in their own right, so the semantic hierarchy is transparent in the input. Let me illustrate this with the input of a coordinate expression. I will use the $\&$ symbol to mark the coordinative conjunction operator in input representations - to emphasize that it is the operator, and not the corresponding Vocabulary Item that forms part of the input. However, for simplicity's sake, I will represent the other input elements with their Vocabulary Items and not with their morpheme-encyclopedia entry feature combinations (cf. 2.2.1.1.)

$$
\left[\begin{array}{ccc}
\& & & \\
\mathrm{x}= & \text { worked } \\
\mathrm{y}= & \mathrm{x}_{\mathrm{ag}, \text { sub }}= & \text { John } \\
& \mathrm{x}_{\text {exp } \text { sub }}= & \text { Mary }
\end{array}\right]
$$

The top functor is the conjunction operator. Its inclusion in the input creates two data slots in the template - these are filled with its operands: the predicates. The inclusion of each predicate (as an operand/functee) creates new data slots, corresponding to the number of theta roles in the morpheme feature bundle of the predicate. Since both worked and slept are one-place predicates, only one argument slot is created for each. The agent data slot for worked is filled with the single argument of the predicate, which automatically gets marked as subject. The experiencer data slot for slept gets occupied by the single argument of the verb, which also gets marked for subject status. This input contains all the information required for interpretation, and will also serve as the basis of the optimality syntactic mechanism. GEN will generate candidates from the input, and these candidates will be evaluated by the constraints. The elements in the optimal candidate will be matched by Vocabulary Items and the resulting string will form the basis for the phonological apparatus. 
While the data slots created by predicates in the input differ from one another and their occupants bear different theta roles, this is not the case with data slots created by all operators. For the conjunction, the functees play identical roles. This is the source of the symmetry of coordination as opposed to the asymmetry of subordination. Note that the order of the conjuncts is not determined in the input - so worked preceding slept in (91) is inconsequential for the grammar. The conjunct order is up to the grammar to decide. In fact, for an input like (91) the grammar will not determine an ordering as both are equally optimal ways of expressing the input's content.
a. John worked and Mary slept
b. Mary slept and John worked

There is another type of element that can "orbit" around a functor: a modifier. Unlike functees, whose existence is determined by the existence of the functor, modifiers are not compulsory. When a modifier is included in an expression, it is clear which element it modifies - which means that in the input representation it has to be "tied" to a particular element. This is achieved if data slots are created in the template for modifiers as well. I will assume that such modifier data slots are indeed created for every input element, but they differ from functee slots in that they are not mandatory to be filled in for the input to receive a semantic interpretation. I will indicate modifier slots in input representations only when they are filled with content, and will enclose the reference for the abstract data slot in brackets, to emphasize that this is not a functee position. (93b) below is thus the representation of the input for (93a).

(93) a. John worked angrily and Mary slept happily

$$
\text { b. } \begin{aligned}
\& & \\
\mathrm{x}= & \text { worked } \\
\mathrm{x}_{\mathrm{ag}, \mathrm{sub}} & =\text { John } \\
(\mathrm{y}) & =\text { angrily } \\
\mathrm{slept} & \\
\mathrm{x}_{\mathrm{exp}, \text { sub }} & =\text { Mary } \\
(\mathrm{y}) & =\text { happily }
\end{aligned}
$$


The possibility of an unfilled data slot has become apparent in the case of modifiers. However, data slots for functees can also be left empty. This, and the relevance of such missing input items to the analysis of ellipsis are the focus of the next section.

\subsubsection{Impoverished inputs}

Any collection of morpheme/encyclopedia entry combinations and any assignment of function, argument and information roles may in theory form an input. However, a large number of these will be semantically uninterpretable and so uninteresting in terms of syntax. The same applies for inputs in which functee data slots created by the placement of a functor remain unfilled: an input for a two-place predicate with just one argument will be uninterpretable. (Inputs in which modifier - i.e. only bracketed slots are unfilled are interpretable.)

In the right circumstances, though, the semantic component may be capable of interpreting certain defective inputs.

Suppose that in an input containing a coordination operator an argument of one of the conjuncts is unassigned. Under normal circumstances such a defective input would be uninterpretable as there would be too few arguments to express the relevant proposition. However, with coordination, the other conjunct, as long as it is not defective exactly the same way, can provide a blueprint for the missing element. Newson and Gáspár (2001) called interpretable defective inputs impoverished inputs.

It was claimed that ellipsis in coordination contexts is due to exactly this possibility: the elided element is simply a faithful representation of a 'gap' in the input which is interpretable due to certain semantic recovery strategies.

The input in (94) would be realized as (95a) and interpreted as (95b).

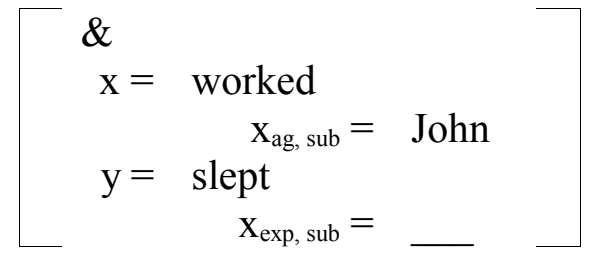


In Chapter 5 I will address the mechanisms for reconstructing the semantics of an empty element from an appropriate blueprint in the other conjunct.

In the previous section I showed how legitimate inputs are created, with functors creating data slots for the appropriate number of functees. However, another way of arriving at the same result would be to claim that inputs are randomly generated - and the ones reviewed in the previous section just happen to conform to semantic wellformedness requirements. If any collection of elements may form an input, which then may or may not be semantically interpretable, inputs with empty functor positions can also arise, as in (96) below.

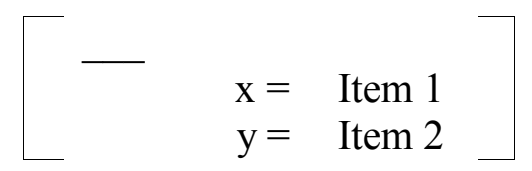

Since the relationship between the input elements is not established, such an input will be uninterpretable to the semantic component. However, if the appropriate blueprint exists, the semantic component may be capable of interpreting an input which lacks a functor. This is the case in verbal ellipsis, or gapping constructions - the predicate is reconstructed based on the predicate of the other conjunct. Since this input is interpretable, the candidate the OT mechanism churns out will be both grammatically and semantically well formed and hence a valid sentence of the language.

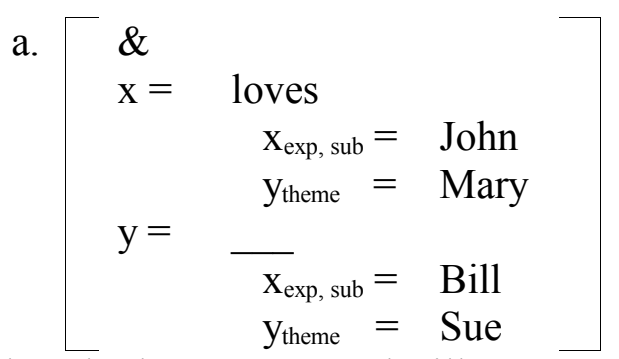

b. John loves Mary and Bill Sue

Note that though I have discussed uninterpretability in terms of inputs with contradictory or unfilled data slots, fully specified inputs can also be uninterpretable. (98) is one such case: though both input items (and possibly their functees) are filled, both of the unconnected elements would count as root nodes of separate semantic 
structures. Since these are unconnected, the semantics will not know how to relate them and hence the input will be uninterpretable.

$\left[\begin{array}{ll}\mathrm{x}= & \text { Item 1 } \\ \mathrm{y}= & \text { Item 2 }\end{array}\right]$

This section concludes my assumptions about the input. The apparatus developed here will be of importance in the actual analysis sections. However, before I can demonstrate the analyses of coordinate constructions, I need to present my views on the EVAL component of the OT grammar, as these views deviate substantially from the standard assumptions I summarized in Section 2.1.3.

\subsubsection{EVAL Revisited: Alignment Syntax}

Grimshaw (1998) argued for a constrained theory of constraints - one in which the requirement that constraints are organized in constraint families mitigates against the introduction of ad hoc constraints and an unrestrictive, and hence unconvincing theory of grammar (see 2.1.3). Newson (2000b) has argued that constraints fall into just two of the six families: faithfulness and alignment constraints. I will summarize his predicate alignment constraint-based approach in 2.2.2.1. In 2.2.2.2 I will introduce a second, independently motivated family of alignment constraints, the first/last constraints, and show that their introduction allows us to account for cross-linguistic variation in basic word order within an alignment approach. 2.2.2.3 will raise and attempt to answer a problem raised by the introduction of first/last constraints, namely by introducing a mechanism to ensure that they are not overly powerful. 2.2.2.4 will deal with the mechanics of evaluation, proposing that evaluation works cyclically, and a different functor is the focus of each evaluation cycle. The last section (2.2.2.5) will discuss the consequences of the cyclicity assumption.

\subsubsection{Predicate alignment constraints}

The most radical aspect of Newson's (2000b) framework is that the concept of syntactic structure is done away with, be it X-bar Theory or any other notion of syntactic constituency. The only form of structure left is in the input, where elements are organized according to what becomes a blueprint for semantic structure (2.2.1). This section summarizes the basic ideas of this alignment-based theory of OT syntax, 
which focused on the syntax of the basic clause: predicate-argument alignment. With a single exception to be noted below, this section is a summary of Newson (2000b).

Alignment constraints are normally understood to place elements to the right or left edge of some domain. The notion of domains presupposes structure, so a structurefree definition of alignment is that constraints align elements to each other, either to the left or to the right. While in principle constraints may refer to any valid input element, in dealing with grammatical phenomena in terms of argument alignment, Newson (2000b) makes use of alignment constraints that align some element to a predicate. This seems to indicate a general notion of headedness within the system.

Since languages are either head-initial or head-final, the alignment constraints indicating headedness also need to have left and right versions: predicate-argument and argument-predicate. Because by standard OT assumptions constraints are universal, both members of this pair of constraints need to be present in every language, regardless of whether the language is head-initial or head-final. This yields a further restriction in the alignment system: for every constraint that aligns an element to the right of another, there is an opposite constraint aligning the same element to the left. The assumption that all constraints come in right/left pairs yields a more constrained system than one which allows some constraints to be left, some to be right and some to be in left/right pairs. The relative ranking of the right/left constraints determines the basic order of the relevant elements within the language. However, as is standard in OT, outranked constraints are still potentially active and although a language may be basically right oriented with respect to certain elements, left orientation can still be possible when the more dominant right alignment constraint is violated by an eventually optimal candidate in order to satisfy some even higher ranking constraint (such cases are provided at the end of Section 2.2.2.4 as well as in Chapter 3 on the placement of the conjunction particle). Therefore a system of right/left alignment pairs does not necessarily contain a mass of redundant constraints.

The alignment constraints in Newson (2000b) are gradient constraints, which means they can be violated to different degrees. When two elements are in competition with each other for a single position, one will win, but the losing element will still prefer the second best position to any other slot in the sequence. This view is motivated by 
various syntactic phenomena, such as the order of direct and indirect objects in English: when there is no indirect object, the direct object immediately follows the verb. In the presence of a verb adjacent indirect object the direct object will occupy the second best position, immediately following the indirect object.
a. John sent a letter yesterday
b. *John sent yesterday a letter
c. John sent Bill a letter yesterday
d. *John sent a letter Bill yesterday
e. *John sent Bill yesterday a letter

Calculating the degree of violation of an alignment constraint is simply a matter of counting the number of items between an element and the position required by that constraint. As (99) showed, elements will prefer to violate an alignment constraint by keeping on the right side but being further away from the target edge (which Newson terms edge violation), even if they could be nearer to the target position by swapping sides (side violation). In the optimality tables I adopt his formalism of representing side violations with a 'big star' $\star$ and edge violations with a 'little star' $* 21$.

Let us briefly see how this works in practice. Newson (2000b) is concerned with basic predicate-argument constructions, so the three type of elements of interest are the predicate, its arguments, and its subject - a special argument, which in English appears on the other side of the predicate than the rest of the arguments.

Unlike the other arguments, the subject in English is compulsory - a notion that has been descriptively captured by the Extended Projection Principle in Government and Binding theory, and was simply adopted by Grimshaw (1997). Rather than evoking the EPP, which refers to constituent structure, we can achieve its effects by making the subject feature compulsory in every input, thereby capturing that the element that bears it will be the subject. Newson (1998b) assigns the subject feature automatically to the most prominent argument of the verb. Prominence is decided according to

\footnotetext{
${ }^{21}$ Because side violations are either unavoidable or fatal, we need only to note the fact of the violation rather than its degree in terms of how far on the wrong side an element is. Thus for every side violation there will only be one $\star$. Multiple side violations are possible, but only if more than one element is on the wrong side. With edge violations, on the other hand, distance matters. If an element cannot be aligned to the target edge, then it will be aligned as near as possible to it.
} 
Grimshaw's (1990) argument prominence hierarchy. What this means is that by assigning the subject feature, we are not adding any more information to the input, but are simply picking out one of the verbal arguments according to a pre-existing algorithm, and giving it a special name - a shorthand description, which will allow our grammar to more easily refer to this particular argument of the verbal predicate.

We can capture the alignment facts through the proposal of two basic constraints, one which aligns arguments to their predicate and another which aligns the argument marked in the input as subject to its predicate. For English the constraint which aligns the arguments to the right of the predicate $(\mathrm{pA})$ must outrank its counterpart which aligns arguments to the left (Ap). The constraint which aligns the subject to the left of the predicate $(\mathrm{Sp})$ outranks the constraint that aligns the subject to the right $(\mathrm{pS})$. Since the subject is also an argument, and as such is governed by the pA/Ap constraints, Sp must outrank pA to ensure that the subject is to the left of the verb.

(100) Predicate alignment constraints: ${ }^{22}$

$\mathrm{pA}$ : if input element $p$ is a predicate it must be left-adjacent to its argument $A$

Ap: if input element $p$ is a predicate it must be right-adjacent to its argument $A$ $\mathrm{pS}$ : if input element $p$ is a predicate it must be left-adjacent to its subject $A_{\text {sub }}$ Sp: if input element $p$ is a predicate it must be right-adjacent to its subject $A_{\text {sub }}$

The ranking for English is the following:

$$
\text { English: } \mathrm{Sp} » \mathrm{pA} » \mathrm{pS}, \mathrm{Ap}^{23}
$$

The input for the sentence in (102a) is (102b), and the optimality table is in (103).

$$
\begin{aligned}
& \text { a. John loves Mary } \\
& \text { b. }\left[\begin{array}{cl}
\text { loves } \\
\mathrm{x}_{\text {exp sub }}= & \text { John } \\
\mathrm{y}_{\text {theme }}= & \text { Mary }
\end{array}\right]
\end{aligned}
$$

\footnotetext{
${ }^{22}$ The exact definition of the constraints is the one respect in which I differ from Newson (2000b) in this section: Newson viewed alignment from the point of view of the arguments (i.e. an argument needs to be right adjacent to its predicate, etc.). This difference is inconsequential as far as the data described in Newson $(2000 b)$ - or in this section - is concerned. However, in case of ellipsis in Chapter 4, the distinction will matter, and only the revised definitions presented here will make the correct predictions. ${ }^{23}$ Comma between two constraints indicates that their relative ranking cannot be established based on the data here.
} 


\begin{tabular}{|c|c|c|c|c|}
\cline { 2 - 5 } \multicolumn{1}{c|}{ English } & $\mathrm{Sp}$ & $\mathrm{pA}$ & $\mathrm{pS}$ & $\mathrm{Ap}$ \\
\hline John $_{\text {sub }}$ loves Mary & & $\star$ & $\star$ & $\star$ \\
\hline John $_{\text {sub }}$ Mary loves & $* !$ & $\star \star$ & $\star$ & $*$ \\
\hline loves John $_{\text {sub Mary }}$ & $\star !$ & $*$ & & $\star \star$ \\
\hline loves Mary John $_{\text {sub }}$ & $\star !$ & $*$ & $*$ & $\star \star$ \\
\hline Mary John $_{\text {sub }}$ loves & & $\star \star !$ & $\star$ & $*$ \\
\hline Mary loves John $_{\text {sub }}$ & $\star !$ & $\star$ & & $\star$ \\
\hline
\end{tabular}

The highest ranking constraint $\mathrm{Sp}$ is satisfied when the argument marked as subject immediately precedes the predicate. This is the case in the first and fifth candidates, thus no violation is entered for these. The others all violate the Sp constraint: the second candidate registers an edge violation, while the remaining three a side violation each. Though an edge violation is less "serious" than a side violation because two of the candidates do not violate the constraint to any degree, any violation here will be fatal, marked with a !.

The next highest constraint is pA. Since the verb has two arguments, but only one can be right adjacent to it, every candidate is going to violate this constraint. The first and last candidates will violate it once: one argument is on the wrong side of the predicate, as far as this constraint is concerned. The second and fifth candidates are verb final, so both arguments are on the wrong side of the predicate, and two side violations are registered. The third and the fourth candidate fare much better: they are verb initial, so one argument will be in the perfect constellation with respect to the predicate, while the other will be in the second best position: one slot too far to the right, yielding an edge violation. However, both of these candidates are out of the grammaticality race by this point, having failed the previous constraint, so it is inconsequential that they score better on the second constraint. Of the two constraints that survived the dominant $\mathrm{Sp}$, the first one does better on $\mathrm{pA}$ - and so the second side violation registered by the fifth candidate will be fatal. At this point the first candidate emerges as victorious and hence optimal. Though violations are registered in the table for the two lowest ranking constraints as well, optimality is decided before the candidates reach these constraints, so they will play no part in deciding grammaticality. There is no vertical line between these two constraints in the rows of the candidates, indicating that their ranking with respect to one another is not determined, and total violations for the two constraints need to be compared when evaluating the candidates' 
performance. Since these constraints are inactive, this notational distinction is inconsequential here, but will be of importance in optimality tables to come.

The account for English hinged upon the compulsory assignment of the subject feature to an input element - the adoption of the EPP into this version of OT syntax. This raises the question of how to handle languages that do not have subject positions, such as Hungarian, which, according to É. Kiss (1994), has a flat, not a hierarchical VP. The order of the post-verbal arguments is free, and arguments appear pre-verbally only to mark a specific information role (focus, topic, quantification or Wh). This also means that under É. Kiss' analysis the notion of subject is irrelevant. To maintain that the only source of systemic language variation is the ranking of the constraints, the compulsory input assignment of the subject feature must be upheld for Hungarian as well. The assignment of the feature is universally obligatory, but whether this feature gets the chance to influence alignment in a language is another matter.

The assumption that the most prominent argument of the verb gets assigned the subject feature is also universal, so in Hungarian inputs, too, the agent, or if it is not present the most prominent argument, will be assigned the subject feature. We are thus left with a feature and a corresponding pair of constraints that do not have correlates in the language.

Recall from section 2.1.2 that GEN has the power to underparse input elements or features on these elements. The only way to satisfy both members of a contradictory pair of constraints such as $\mathrm{pS}$ and $\mathrm{Sp}$ is by getting rid off the subject feature and thus vacuously satisfying them both ${ }^{24}$. This occurs at the expense of a faithfulness violation. Newson (2000b) proposed to rank pS and Sp above the faithfulness constraints, as this ranking would legitimize such a faithfulness violation. If in the winning candidate the subject feature is underparsed by GEN, its role as the subject will not have any consequences in its positioning. It will simply be one of the verbal arguments. Since arguments appear post-verbally in Hungarian, pA needs to dominate Ap. The table in (105) illustrates such an optimality competition for (104):

\footnotetext{
${ }^{24}$ In Chapter 4 I will modify this view by introducing a third kind of violation. However, this alteration to the theory will not change the outcome of the optimality contest in the underparsing cases.
} 
a. megverte Pétert János

perf.beat-PST, 3SG Péter-ACC János

'John beat up Peter.'

b. megverte

$\mathrm{X}_{\mathrm{ag}, \mathrm{sub}}=$ János

$\mathrm{y}_{\mathrm{th}}=$ Pétert

\begin{tabular}{|c|c|c|c|c|c|c|}
\hline \multirow[t]{3}{*}{$(105)^{25}$} & Hungarian & $\mathrm{Sp}$ & $\mathrm{pS}$ & PARSE & $\mathrm{pA}$ & Ap \\
\hline & János sub $_{\text {megverte Pétert }}$ & \multicolumn{2}{|r|}{$\star !$} & & $\star \star$ & 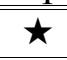 \\
\hline & megverte János $_{\text {sub }}$ Pétert & $\star !$ & & & $\star$ & $\star$ \\
\hline & JánoS $_{<\text {sub }>}$ megverte Pétert & & & $*$ & $\star$ & $\star$ \\
\hline & JánoS $<$ sub $>$ Pétert megverte & & & * & $\star ! \star$ & $*$ \\
\hline 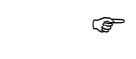 & megverte János $<_{\text {sub }>}$ Pétert & & & $*$ & $*$ & $\star \star$ \\
\hline 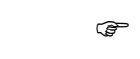 & megverte Pétert János ${ }_{<\mathrm{sub}>}$ & & & * & $*$ & $\star \star$ \\
\hline & Pétert János $<_{\text {sub }>}$ megverte & & & $*$ & $\star ! \star$ & $*$ \\
\hline & Pétert megverte János $<_{<\mathrm{sub}}>$ & & & * & $\star !$ & $\star$ \\
\hline
\end{tabular}

The two candidates that emerge as winners from the optimality competition, are the two that are predicted by É. Kiss's (1994) theory as unmarked free variants.

The word orders in the first (=third) and the last candidates, however, are also grammatical. The input subject is moved to a pre-verbal position not because of its status as the subject, but because it also carries a topic information role. Since it is related to the interpretation of the sentence, the topic nature of an element must be marked in the input. Unlike the subject feature, which has no semantic correlate and is assigned automatically to the most prominent argument, adding no extra information to what was already included in the input, the topic feature gets assigned to the input element that is interpreted as topic. The subject feature can and must be assigned to the most prominent element in an input. The topic feature can be assigned to any argument (or modifier) of the predicate.

The first (=third) candidate, for example, is related to a different input than $(104 b)^{26}$ :
a. János
megverte
Pétert

János-TOP perf.beat-PST, 3SG Péter-ACC

'As for John, he beat up Peter.'

\footnotetext{
${ }^{25}$ Underparsing of a feature is standardly denoted by placing it in $<>$ brackets: $<$ sub $>$.

${ }^{26}$ The inclusion of the perfective marker meg ensures that the preverbal argument is in topic position. For simplicity's sake, I will treat meg as an integral part of the verb, even though it is in focus position, according to É. Kiss (1994), and as such blocks the verb-adjacency of the topic.
} 
b.

megverte

$\mathrm{X}_{\mathrm{ag}, \text { sub, top }}=$ János

$\mathrm{y}_{\mathrm{th}} \quad=$ Pétert

Since topicalized arguments move preverbally, Tp needs to dominate not only $\mathrm{pT}$, but also pA (and thus Ap), according to the account developed in Newson (2000b). The ranking of the relevant constraints is provided in (107) and the competition for the input in (106b) in (108):

Hungarian: $\mathrm{Sp}, \mathrm{pS} » \mathrm{P}_{\mathrm{ARSE}} » \mathrm{Tp} » \mathrm{pA} » \mathrm{Ap}, \mathrm{pT}$

\begin{tabular}{|c|c|c|c|c|c|c|c|}
\hline Hungarian & $\mathrm{Sp}$ & $\mathrm{pS}$ & PARSE & $\mathrm{Tp}$ & $\mathrm{pA}$ & Ap & pT \\
\hline Pétert János sub, top megverte & & $\star !$ & & & $\star \star$ & & $\star$ \\
\hline Pétert megverte János ${ }_{\text {sub, top }}$ & $\star !$ & & & $\star$ & $\star$ & $\star$ & \\
\hline János $_{<\text {sub }>\text { top }}$ megverte Pétert & & & $*$ & & $\star$ & $\star$ & $\star$ \\
\hline János $<$ sub $>$ top Pétert megverte & & & $*$ & $* !$ & $\star \star !$ & $*$ & $\star$ \\
\hline megverte János $_{<\text {sub }>\text { top }}$ Pétert & & & $*$ & $\star !$ & * & $\star \star$ & \\
\hline megverte Pétert JánoS $<_{s u b>\text { top }}$ & & & $*$ & $\star !$ & $*$ & $\star \star$ & $*$ \\
\hline Pétert János ${ }_{<\text {sub }>\text { top }}$ megverte & & & $*$ & & $\star ! \star$ & $*$ & $\star$ \\
\hline Pétert megverte JánoS $<_{<\text {sub }>\text { top }}$ & & & $*$ & $\star !$ & $\star$ & $\star$ & \\
\hline
\end{tabular}

When the word order is SVO, the cause is not the special status of the subject, but its topic status in the input. This is in line with É. Kiss's analysis of the basic clause.

This system smells of the typical English bias in generative syntax: in the analysis just provided subject-predicate languages are seen as more "normal," and an extra mechanism had to be inserted to circumvent the effect of the subject to give an account of topic-predicate languages. I will return to topic prominent languages in Section 2.3 and propose that the topic feature is also a universally compulsory input element. A different ranking of the constraints will be provided for Hungarian there.

In this section I have demonstrated that predicate alignment constraints can account for the placement of the predicate and its arguments in English and Hungarian. However, pairwise constraints cannot account for the placement of every element.

\subsubsection{Motivation for first/last constraints}

The view developed in Newson (2000b) faces a number of empirical problems. Object topicalization in Japanese, for instance, cannot be easily explained using predicate alignment constraints. Japanese is a head-final language, exhibiting OV word order. 
When an object is topicalized, it gets moved from its verb adjacent position to the front of the clause, and is marked with the wa topic particle.

a. Chomusukiii $\mathrm{i}_{\mathrm{i}}$ wa Jiroo-ga Hanako-ni jibun ${ }_{\mathrm{i}}$-no musuko-san-o

Ch.-

TOP J.-NOM Hanako-DAT self-GEN son-Mr./Mrs.-OBJ

shookai-shi-ta

introduce-do-PAST

'Chomsky, Jiro introduced his s $_{i}$ son to Hanako.'

b. Hannin-wa Jiroo-ga ayashii

perpetrator-TOP J.-NOM suspicious

'The perpetrator, Jiro is suspicious. (=The perpetrartor, I suspect Jiro is.)'

(Tateishi 1994: 102)

Since Japanese exhibits OV order, Ap must be the dominant argument alignment constraint. As (non-subject) topics precede non-topicalized objects, Ap must dominate $\mathrm{Tp}$, too. However, when the object is topicalized, it appears at the beginning of the clause. Since it retains its status as an object, and Ap » Tp is the established ranking, a candidate in which the topicalized object retains its verb-adjacent position will always be more optimal than a candidate in which it is fronted. As an example, let us consider a double object sentence with a topicalized (and thus fronted) direct object in front of the indirect object. The correct word order is represented schematically in (110a), and the optimality competition in (110b): the candidate in which the topicalized object is verb-adjacent will be incorrectly predicted as optimal.

a. O-wa O-ni V

b.

\begin{tabular}{|r|c|c|c|c|}
\cline { 2 - 5 } \multicolumn{1}{c|}{ Japanese } & Ap & Tp & pT & pA \\
\hline O-wa O-ni V & $*$ & $* !$ & $\star$ & $\star \star$ \\
\hline O-wa V O-ni & $\star !$ & & $\star$ & $\star$ \\
\hline O-ni O-wa V & $*$ & & $\star$ & $\star \star$ \\
\hline O-ni V O-wa & $\star !$ & $\star$ & & $\star$ \\
\hline V O-wa O-ni & $\star ! \star$ & $\star$ & & $*$ \\
\hline V O-ni O-wa & $\star ! \star$ & $\star$ & $*$ & $*$ \\
\hline
\end{tabular}

If we assume the existence of a constraint that demands the placement of a constituent with respect to all other items, and not just the predicate, (110a) becomes easily predictable. I will provide a more detailed explanation of Japanese topics in section 2.3.6, but the simplified table in (112) suffices as an illustration for our present purposes. I will also provide a more formal definition of the first constraint and its 
violations in the next section. For now, suffice it to say that a candidate registers a violation of the TOPIC FIRST (T1) constraint for each word that intervenes between the topicalized element and its desired position at the front of the string.

(111) Topic FIRST (to be revised): if input element $i$ is assigned the topic feature $\left(i_{\text {top }}\right)$, it must appear to the left of all other items in the string

\begin{tabular}{|r|c|c|c|c|c|}
\cline { 2 - 6 } \multicolumn{1}{c|}{ Japanese } & $\mathrm{T} 1$ & $\mathrm{Ap}$ & $\mathrm{Tp}$ & $\mathrm{pT}$ & $\mathrm{pA}$ \\
\hline O-wa O-ni V & & $*$ & $*$ & $\star$ & $\star \star$ \\
\hline O-wa V O-ni & & $\star !$ & & $\star$ & $\star$ \\
\hline O-ni O-wa V & $* !$ & $*$ & & $\star$ & $\star \star$ \\
\hline O-ni V O-wa & $* ! *$ & $\star$ & $\star$ & & $\star$ \\
\hline V O-wa O-ni & $* !$ & $\star \star$ & $\star$ & & $*$ \\
\hline V O-ni O-wa & $* ! *$ & $\star \star$ & $\star$ & $*$ & $*$ \\
\hline
\end{tabular}

I have carefully avoided the mention of the subject in the Japanese examples above. This is because another problem of a system operating exclusively with the predicate alignment constraints introduced by Newson (2000b) is that it cannot predict SOV or VOS word order. Japanese is an SOV language.

To illustrate this, let us take as a starting point the SVO (English) ranking from (101), repeated below as (113).

$$
\text { SVO: } \mathrm{Sp} » \mathrm{pA} » \mathrm{pS}, \mathrm{Ap}
$$

No matter how we re-rank the constraints, SOV word order will never be predicted. Since the word order is verb final, $\mathrm{Sp}$ and Ap need to dominate their verb-initial counterparts: $\mathrm{Sp} » \mathrm{pS}$ and Ap » $\mathrm{pA}$. All three relative rankings of $\mathrm{Sp}$ and Ap will predict the same OS pattern, and thus an overall OSV word order. This is because the subject is also an argument, so Sp and Ap do not presernt contradictory requirements: they can both be maximally satisfied if the subject is verb-adjacent, and the object precedes the subject. The OSV ranking is shown in (114a), while the competition in (114c) illustrates how the OSV pattern would emerge from the input of (114b).

(114) a. OSV: Ap, Sp »pS, pA

b. $\left[\begin{array}{rl}\text { eats } & \\ \mathrm{x}_{\mathrm{ag}, \mathrm{sub}} & =\text { John } \\ \mathrm{y}_{\mathrm{th}} & =\text { fish }\end{array}\right.$ 
c.

\begin{tabular}{|c|cc|c|c|}
\cline { 2 - 5 } \multicolumn{1}{c|}{} & $\mathrm{Ap}$ & $\mathrm{Sp}$ & $\mathrm{pS}$ & $\mathrm{pA}$ \\
\hline John eats fish & $\star !$ & & $\star$ & $\star$ \\
\hline John fish eats & $*$ & $* !$ & $\star$ & $\star \star$ \\
\hline eats John fish & $\star ! \star$ & $\star$ & & $*$ \\
\hline eats fish John & $\star ! \star$ & $\star$ & $*$ & $*$ \\
\hline fish John eats & $*$ & & $\star$ & $\star \star$ \\
\hline fish eats John & $\star !$ & $\star$ & & $\star$ \\
\hline
\end{tabular}

Similarly, the system of predicate alignment constraints cannot predict a VOS pattern either. To achieve a verb-initial word order, $\mathrm{pS}$ and $\mathrm{pA}$ would need to dominate their verb-final counterparts: $\mathrm{pS} » \mathrm{Sp}$ and $\mathrm{pA} » \mathrm{Ap}$. Similarly to the previous case, all three relative rankings of $\mathrm{pS}$ and $\mathrm{pA}$ will lead to the same word order prediction: VSO. This is again because the subject is also an argument, so $\mathrm{pS}$ and $\mathrm{pA}$ do not place contradictory requirements on word order: they can both be maximally satisfied if the subject is verb-adjacent, and the object follows the subject. The VSO ranking is shown in (115a), while the competition in (115c) illustrates how the VSO pattern would emerge from the input of (115b).

a. VSO: $p S, p A » S p, A p$

b. eats

$$
\begin{aligned}
& \mathrm{X}_{\mathrm{ag}, \text { sub }}=\text { John } \\
& \mathrm{y}_{\mathrm{th}}=\text { fish }
\end{aligned}
$$

c.

\begin{tabular}{|c|c|c|c|c|}
\cline { 2 - 5 } \multicolumn{1}{c|}{} & $\mathrm{pS}$ & $\mathrm{pA}$ & $\mathrm{Ap}$ & $\mathrm{Sp}$ \\
\hline John eats fish & $\star !$ & $\star$ & $\star$ & \\
\hline John fish eats & $\star !$ & $\star \star$ & $*$ & $*$ \\
\hline eats John fish & & $*$ & $\star \star$ & $\star$ \\
\hline eats fish John & $* !$ & $*$ & $\star \star$ & $\star$ \\
\hline fish John eats & $\star !$ & $\star \star$ & $*$ & \\
\hline fish eats John & & $\star !$ & $\star$ & $\star$ \\
\hline
\end{tabular}

To round off the word order possibilities, (116) shows how the OVS pattern is also predictable by the predicate-alignment system developed by Newson (2000b). This is the anti-English pattern, so the constraint ranking will be the opposite of the one established for SVO word order.

(116) a. OVS: $\mathrm{pS} » \mathrm{Ap} » \mathrm{Sp}, \mathrm{pA}$

b. eats

$\mathrm{X}_{\mathrm{ag}, \mathrm{sub}}=\mathrm{John}$

$\mathrm{y}_{\mathrm{th}}=$ fish 
c.

\begin{tabular}{|c|c|c|c|c|}
\cline { 2 - 5 } \multicolumn{1}{c|}{ OVS } & $\mathrm{pS}$ & $\mathrm{Ap}$ & $\mathrm{pA}$ & $\mathrm{Sp}$ \\
\hline John eats fish & $\star !$ & $\star$ & $\star$ & \\
\hline John fish eats & $\star !$ & $*$ & $\star \star$ & $*$ \\
\hline eats John fish & & $\star \star !$ & $*$ & $\star$ \\
\hline eats fish John & $* !$ & $\star \star$ & $*$ & $\star$ \\
\hline fish John eats & $\star !$ & $*$ & $\star \star$ & \\
\hline fish eats John & & $\star$ & $\star$ & $\star$ \\
\hline
\end{tabular}

To sum up then, the grammar operating only with predicate-alignment constraints could predict four of the six basic word order patterns. And while the word-order patterns differ drastically in terms of the number of languages in which they are attested, one of the word orders that would never become optimal under the system is actually one of the more widespread cases. The table below summarizes the results of the above discussion. Example and frequency data are based on Comrie (1981).

\begin{tabular}{|lccc|}
\hline & example & frequency & predicted? \\
SVO & English & most common type & Yes \\
SOV & Japanese & $2^{\text {nd }}$ most common & No \\
VSO & Welsh & only a few examples & Yes \\
OVS & Hixkaryana & very few & Yes \\
OSV & Malagasy & very few & Yes \\
VOS & $? ?$ & unclear if any & No \\
\hline
\end{tabular}

If Subject first (S1) and Subject last (S $\Omega$ ) constraints are introduced, the SOV and VOS word orders can also be predicted, as shown in (119) and (120), respectively.

(118) a. Subject first (to be revised): if input element $i$ is assigned the subject feature $\left(i_{\text {sub }}\right)$, it must appear to the left of all other items in the string

b. Subject Last (to be revised): if input element $i$ is assigned the subject feature $\left(i_{\text {sub }}\right)$, it must appear to the right of all other items in the string

Each input element that separates the subject from its desired position in terms of the $\mathrm{S} 1 / \mathrm{S} \Omega$ constraint causes a violation for the candidate.

a. SOV: $\mathrm{S} 1 » \mathrm{Ap}, \mathrm{Sp} » \mathrm{pS}, \mathrm{pA}, \mathrm{S} \Omega$ 
b.

\begin{tabular}{|c|c|c|c|c|c|c|}
\cline { 2 - 7 } \multicolumn{1}{c|}{$S O V$} & $\mathrm{~S} 1$ & $\mathrm{Ap}$ & $\mathrm{Sp}$ & $\mathrm{pS}$ & $\mathrm{pA}$ & $\mathrm{S} \Omega$ \\
\hline John eats fish & & $\star !$ & & $\star$ & $\star$ & $* *$ \\
\hline John fish eats & & $*$ & $*$ & $\star$ & $\star \star$ & $* *$ \\
\hline eats John fish & $* !$ & $\star \star$ & $\star$ & & $*$ & $*$ \\
\hline eats fish John & $* ! *$ & $\star \star$ & $\star$ & $*$ & $*$ & \\
\hline fish John eats & $* !$ & $*$ & & $\star$ & $\star \star$ & $*$ \\
\hline fish eats John & $* ! *$ & $\star$ & $\star$ & \multicolumn{4}{c|}{} \\
\hline
\end{tabular}

(120) a. VOS: $\mathrm{S} \Omega$ » $\mathrm{pA}, \mathrm{pS} » \mathrm{Ap}, \mathrm{Sp}, \mathrm{S} 1$

b.

\begin{tabular}{|c|c|c|c|c|c|c|}
\cline { 2 - 7 } \multicolumn{1}{c|}{ VOS } & $\mathrm{S} \Omega$ & $\mathrm{pA}$ & $\mathrm{pS}$ & $\mathrm{Ap}$ & $\mathrm{Sp}$ & $\mathrm{S} 1$ \\
\hline John eats fish & $* ! *$ & $\star$ & $\star$ & $\star$ & & \\
\hline John fish eats & $* ! *$ & $\star \star$ & $\star$ & $*$ & $*$ & \\
\hline eats John fish & $* !$ & $*$ & & $\star \star$ & $\star$ & $*$ \\
\hline eats fish John & & $*$ & $*$ & $\star \star$ & $\star$ & $* *$ \\
\hline fish John eats & $* !$ & $\star \star$ & $\star$ & $*$ & & $*$ \\
\hline fish eats John & & $\star !$ & & $\star$ & $\star$ & $* *$ \\
\hline
\end{tabular}

Having provided an account for basic Japanese word order, I can now demonstrate a third problem the original alignment account faces. The sentence initial topic position introduced at the beginning of this section cannot be scrambled over by another constituent, such as a focused object or a Wh-word:

a. *jibun ${ }_{\mathrm{i}}$-no musuko-san-o Chomusukii ${ }_{\mathrm{i}}$-wa Jiroo-ga Hanako-ni self-GEN son-Mr./Mrs.-OBJ Ch.- TOP J.-NOM Hanako-DAT shookai-shi-ta ${ }^{27}$ introduce-do-PAST

'Chomsky, Jiro introduced his ${ }_{i}$ son to Hanako.'

b. ${ }^{*}$ Taroo $_{\mathrm{i}-\mathrm{O}}$ hannin-wa Jiroo-ga $t_{\mathrm{i}}$ ayashin-deiru

Taroo-OBJ perpetrator-TOP J.-NOM suspect-PROG

'The perpetrator, Jiro suspects is Taro.'

(Tateishi 1994: 110)

c. Jiroo-wa naze Taroo-ga Hanako-ni shookai-shi-ta-ka-ne?

Jiroo-TOP why Taroo-NOM Hanako-DAT introduce-do-PAST-Q-PRT

'As for Jiro, why did Taroo introduce him to Hanako?'

(Tateishi 1994: 150)

d. * naze Jiroo-wa Taroo-ga Hanako-ni shookai-shi-ta-ka-ne?

why Jiroo-TOP Taroo-NOM Hanako-DAT introduce-do-PAST-Q-PRT

\footnotetext{
${ }^{27}$ Ungrammaticality is not due to a binding violation. As Tateishi (1994) explains the reconstruction of the binding relation between jibun and the subject is possible as long as jibun is not a direct object. (Tateishi 1994: 110, footnote 12.)
} 
'As for Jiro, why did Taroo introduce him to Hanako?'

e. Jiroo-wa Taroo-ga naze Hanako-ni shookai-shi-ta-ka-ne?

Jiroo-TOP Taroo-NOM why Hanako-DAT introduce-do-PAST-Q-PRT

'As for Jiro, why did Taroo introduce him to Hanako?'

(Yuko Kitada, p.c.)

I will provide an analysis of this phenomenon in Section 2.3.6. Of immediate interest to us is that the topic does not just need to be pre-verbal, it also has to be in front of all other pre-verbal constituents such as the verb's arguments, including the otherwise initial focused argument or Wh-word, which can otherwise be freely placed within the string. This topic first phenomenon could in theory be captured by a weak $\mathrm{Tp}$ constraint, which would be dominated by Ap, Sp and Fp (Focus-PredicAte) to ensure that the topic is the preverbal constituent least close to the verb. However, such a constraint does not contradict, and thus could not override, the S1 constraint. Once S1 is introduced, no matter how weak Tp is, a pre-topic subject would not cause an extra violation of either constraint, so a subject initial pattern will be predicted as optimal. To position a pre-subject Focus and a pre-focal topic, the F1 (Focus FIRST) and T1 constraints will be necessary. I will provide the exact ranking and illustrate this in Section 2.3.6, where a further complication will also be pointed out.

Another piece of empirical motivation for the use of first constraints comes from Biblical Hebrew, where, according to Holmstedt (2000), contrast is expressed via fronting - regardless of whether the contrasted material is old information (topicalization) or new (focus). Formally, the fronting can either take the shape of proper topicalization, when the sentence includes a gap at the canonical position of the fronted element, or as left-dislocation, when a resumptive pronoun sits at the canonical position of the fronted constituent. Pragmatic topicalization and focus can both manifest either as formal topicalization or as left-dislocation.

a. 'matkem lənegdəkem zārîm 'ōḳəlîm' ōtâh land.your to.before.you strangers eating ACC-it 'Your land before you strangers are consuming it.' (Isa 1.7b) 
b. wว̉et 'ammî yināşûn mihyôt 'ộ gôy lipnêhem and-ACC people.my hate-3PL from.being still nation to.face.their

'And my people they despise so that it is no longer a nation before them.' (Jer 33.24)

(Holmstedt 2000: 1)

Holmstedt (2000) argues that fronting in all these cases is related to the pragmatic notion of contrast, and as such is the syntactic manifestation of the same phenomenon. Under an alignment account the two phenomena could receive the same treatment: fronting. Since contrast is part of the meaning of the sentences, it needs to be present in the input. The position of the element marked for contrast could then be governed by the highly ranked Con1 constraint.

Empirical motivation exists for the introduction of last constraints as well. While the focused element appears preverbally in Japanese (Kuno 1973, Tateishi 1994) or Hungarian (É. Kiss 1981, 1994) (123), contrastive focus in Italian appears as the last element in the postverbal cluster (124). Belletti and Shlonsky (1995) place the focused subject in the rightward specifier of a focused position, while Grimshaw and SamekLodovici (1998) align the left-edge of the focused element to the right-edge of the VP.
(123) JÁNOST ütötte
el a busz
János-ACC hit-3SG, PAST away the bus
'John was hit by the bus.'
(124) chì ha gridato?
who has screamed
'Who screamed?'
a. Gianni
b. ha gridato Gianni
c. *Gianni ha gridato
d. ??GIANNI ha gridato
e. *ha gridato, ${ }^{28}$ Gianni

(Grimshaw and Samek-Lodovici 1998: 209)

\footnotetext{
${ }^{28}$ The double commas indicate the intonational breakdown and potential pause preceding the rightdislocated phrase, which is grammatical in non-focused cases.
} 
(125) ha soltano ${ }_{i}$ cantato Gianni $i_{i}$

has only sung Gianni

'The only one who sang was John.'

(Grimshaw and Samek-Lodovici 1998: 210)

As can be seen, there is both empirical and theoretical motivation for the introduction of first/last constraints. What was common in these cases is that - contrary to the cases focused on by Newson (2000b) to motivate predicate alignment constraints - in the examples above the position of the element was not related to what can be called a licensing relationship: the placement of an element with respect to its functor. The position of the Japanese (non-subject) topic with respect to the focal or the whconstituent is not related to a licensing relationship between these elements. The position of the Italian focus, too, is relevant with respect to all members of the verbal cluster, not just with respect to the verb, by which it gets licensed ${ }^{29}$.

The lack of licensing was true even in the case of the basic word order examples: only in the verb-medial patterns SVO and OVS is the relationship of the subject (or the object) with respect to the other arguments a consequence of its alignment with the verb. In the SOV pattern its position is fixed not just in terms of the predicate, but also in terms of the other constituents. So is the position of the object in the OSV case, but because of the asymmetrical relationship between arguments in general and the subject in particular, the OSV (and VSO) pattern could be predicted without making reference to a first/last pair of constraints.

First/last constraints can also be used to account for the internal ordering of different kind of objects in English. In a simple indirect object construction the order of the post-verbal elements is fixed.

John showed Mary Bill

This sentence is not ambiguous. The only available meaning is that Bill was being shown (theme) and Mary is the person who is being shown to (beneficiary). This

\footnotetext{
${ }^{29}$ What is admittedly unclear is the existence of the $\mathrm{Sp} / \mathrm{pS}$ constraints: though descriptively the verb is said to be licensed by its subject, the subject is not the functor of the verb but one of its functees. This licensing relationship is already captured by the $\mathrm{pA} / \mathrm{Ap}$ constraints, i.e. the subject is licensed by virtue of being an argument. In this sense the theoretical motivation for the $\mathrm{pS} / \mathrm{Sp}$ pair needs to be the subject of future research - or its effects need to be captured by the intearction of the $\mathrm{pA} / \mathrm{Ap}$ and first/last constraints.
} 
suggests that the constraint we have used so far for post-verbal ordering of arguments is not sufficient to generate English data: pA made no distinction between postverbal elements, and the ranking we have established so far would predict that the postverbal order of the elements is free. If arguments with different thematic roles are distinguished in the input, separate first/last constraints may exist for them. (I will suggest below that first/last constraints be assumed for every type of input element.)

The input for (126) will be as follows:

$$
\left[\begin{array}{rll}
\text { showed } & \\
\mathrm{x}_{\mathrm{ag}, \text { sub }} & = & \text { John } \\
\mathrm{y}_{\exp }= & \text { Mary } \\
\mathrm{Z}_{\mathrm{th}}= & \text { Bill }
\end{array}\right]
$$

A1 then heads a family of (sub)constraints, in which $\mathrm{A} 1_{\exp }$ dominates $\mathrm{A} 1_{\text {theme }}$ (or A1 in general). Since the argument slots created in the data structure by a verbal functor are created according to the subcategorization needs of the predicate, thematic information is already present in the input. The subconstraints of the A1 family would be universally ordered, presumably based on an argument prominence hierarchy along the lines of Grimshaw (1990). As long as all of the A1 constraints are ranked below pA (in English), all (non-subject) arguments will be behind the verb, and their internal ordering will be decided by the universal hierarchy of the A1 family: these will impose the canonical ordering on the arguments as they fight to get closest to the front, within the limits imposed upon them by higher ranking constraints.

Conceptually first and last constraints differ from pairwise constraints in as much as they describe a different kind of ordering relationship - one without licensing.

There is an alternative to the introduction of this new type of constraints. Rather than introducing a conceptually new type of constraint, we could instead extend the notion of pairwise constraints beyond the predicate-argument relationship. A system in which every type of input element (or feature) has a pairwise alignment constraint relating it to every other type of input element (feature) would yield a general system in which we do not need to explain why alignments of this type actually exist: they are simply defined for every element. We could have pairs of constraints that determine the relative ranking of elements such as the Top/Wh, Wh/Foc, Top/Foc etc. pairs. While 
this alternative approach is simpler in the sense of sticking to the already existing family of pairwise constraints, there would be little motivation for pairwise constraints in cases when no pairwise relationship exists between the elements. By introducing constraints regulating the order of elements that are not in a licensing relationship with each other, we introduce a new kind of relationship in any case. Looking at it in this light, it actually looks more explanatory to transparently separate the two kinds of relationships (licensing vs. non-licensing) with the use of different types of constraints (pairwise vs. first/last). It is natural that elements between which a licensing relationship holds should be aligned with respect to each other, whereas it is also natural to position an element with a certain status in a prominent, privileged position - first or last. I will assume that a first/last pair of constraints exists in the system for every type of input element (feature). This yields maximum generality, and removes the need to define which elements are sanctioned by this type of constraint: all are.

Furthermore, as we develop the grammar further and the number of types of input elements we consider increases, the system would need a significantly higher number of pairwise constraints than first/last constraints. To place an input element of a certain type first out of $n$ types of (independent) input elements requires $n-1$ active pairwise constraints. The opposite ordering for each constraint would also need to be included, so the addition of a new type of input element would add $2 *(n-1)$ active constraints to the system. Looking at the grammar as a whole, a system with $\mathrm{n}$ types of elements operating with pairwise constraints solely would need to include pairwise ordering constraints for all types of elements, requiring $(n-1)^{2}$ constraints.

At the same time, there are only two additional first/last constraints for an additional type of input element (one first, one last), or $2 \mathrm{n}$ first/last constraints in total. With four or more types of input elements, the system with first/last constraints yields a grammar with fewer constraints, which - other things being equal - is more desirable.

This account of first (and last) constraints is more principled than what seem ad hoc X1 constraints introduced by Choi (1996, 1999, 2001). Scrambling facts from various languages, including German, led Choi (1996) to introduce the CANON1 constraint, which requires subjects to precede other arguments. This constraint demands that the constituents be aligned according to their syntactic information and thus be in the 
"canonical" order where the subject precedes the object and other arguments. Choi $(1999,2001)$ renamed this constraint SuBJ, which simply states that subjects precede non-subjects. Under the present theory, this notion can be captured with the S1 constraint. There are two minor differences between the two constraints: one is that CAnOn1 and Subu establish ordering between non-verbal constituents only. The other is that in my system the S1 constraint is part of a family of first/last constraints, while Choi's constraints privilege the subject. My approach is more general - and replacing SuBJ with S1 in Choi (2001) would be inconsequential to the account of scrambling and binding phenomena discussed there. That is because Choi (2001) is concerned with subordinate clauses, where verbs need to come last. That, however, can be handled by the combination of first and Xp constraints. Thus it does not matter that $\mathrm{S} 1$ puts the subject first among all input elements, while SuBj requires it to be first only among non-verbal elements.

To sum up, then, the OT alignment grammar introduced in this and the preceding sections operates with the following types of constraints:

- pairs of predicate-argument constraints for every licensing relationship determined by the input template structures,

- pairs of first/last constraints for every type of input element or feature,

- the PARSE constraint, banning the complete or partial underparsing of input items.

In the following sections I will discuss the working mechanisms of a grammar operating with these constraints.

\subsubsection{The domain of first/last constraints}

I have so far avoided the question of the domain of first/last constraints: With respect to what elements does $\mathrm{X}$ need to be ordered first to satisfy the $\mathrm{X} 1$ constraint? This is the subject of this section.

The topicalized examples in (128) are not exactly the same, as indicated by the difference in the paraphrases.

(128) a. I believe Bill John hit

'It is my belief that as far as Bill is concerned, John hit him.' 


\section{b. Bill I believe John hit}

'As far as Bill is concerned, it is my belief that John hit him.'

(128a) and (128b) differ in terms of the scope of the topicalized element: in (128a) it has scope over its own predicate and its predicate's dependents, while in (128b) its scope domain includes the matrix verb and its dependents. To the extent that the two sentences differ from one another, this difference needs to be marked in the input.

For the time being let me introduce a formalism that will indicate the domain of a scope bearing element in the input. In Chapter 5 I will introduce a semantic theory in which features traditionally seen as argument features are going to be treated as features of the predicate - at which point the formalism introduced here will become less ad hoc and more explanatory. For now, however, let us simply indicate the scope taking element with a bracketed Greek letter superscript on the scopally relevant feature of the element's data slot attribute. The scope domain is identified with a subscript of the same Greek letter on the highest element in the scope domain.

The input for (128a) and (128b) are provided in (129a) and (129b), respectively. The scope domain of the topic is the theme's immediate predicate in (129a) and the matrix predicate in (129b). When an element has scope over a predicate, it automatically has scope over the predicate's input dependents, so marking the scope on the non-highest elements within its scope domain is unnecessary. (In fact, I take the default scope domain to be the scope taking element's immediate predicate and its dependents, so I will continue not to mark the default scope domain going forward.) Note that though the scope domain is marked on two elements, it is not a licensing relationship. This will be most clearly seen in case of quantifiers at the end of this section: though they have scope over each other, they are not in a licensing relationship.

$$
\text { a. }\left[\begin{array}{ll}
\text { believe } & \\
\mathrm{X}_{\mathrm{exp}, \text { sub }}= & \mathrm{I} \\
\mathrm{y}_{(\alpha) \text { th }}= & \text { hit } \\
& \mathrm{X}_{\mathrm{ag}, \mathrm{sub}}=\mathrm{John} \\
& \mathrm{y}_{\mathrm{th}, \mathrm{top}}(\alpha)=\text { Bill }
\end{array}\right.
$$




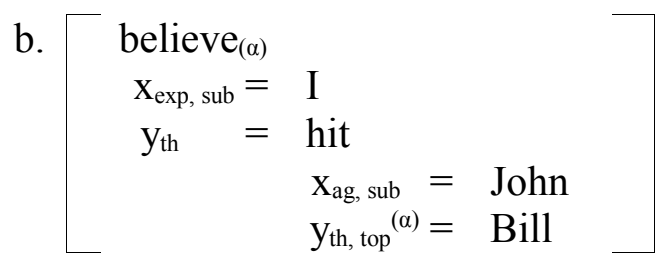

With its scope domain marked, the violation of the relevant topic constraint(s) will be tabulated with respect to this scope domain: Bill is vying for the initial position of the entire string in case of (129b), but per T1 it needs to precede only hit and John in case of (129a). I will continue to refer to the relevant constraint as a topic constraint, but under the interpretation just given this is really a scope constraint $\left(\mathrm{Sc}_{\mathrm{C}}\right)=$ place element in front of the items it has scope over), which in this case is relevant for topic scope. The definition for the T1 constraint, revised from (111), is as follows:

(130) TOPIC FIRST: if input element $i$ is assigned the topic feature $\left(i_{\text {top }}\right)$, it must appear to the left of all other items within its input scope domain

Note that the definition does not talk about immediate precedence or alignment: as long as the topicalized element precedes all the relevant elements, it is satisfied. No licensing relationship exists between these elements, so there is no reason for them to be aligned. The first/last constraints only determine a precedence relationship. The competition for (129a) is provided in (131a) and for (129b) in (131b). However, a few remarks are in order before proceeding to the optimality table:

- Though English data is possible to capture with the $\mathrm{Sp}$ » $\mathrm{Tp}$ » Ap ranking, for theory-internal reasons I will use the T1 constraint instead: the licensing relationship between the verb and the topic exists because the element is an argument, and not because it is topic. Thus the topic-predicate one is a nonlicensing relationship, so the use of pairwise constraints is not legitimized. However, this assumption has no bearing on the prediction made ${ }^{30}$.

- Since the topic is the argument of the lower predicate, it is the $\mathrm{pA} / \mathrm{Ap}$ constraint with respect to the lower verb that will be relevant for the topic in both cases.

- In the following tables I will ignore the position of the verbal argument of the matrix predicate, and will count $\mathrm{pA} / \mathrm{Ap}$ violations for the three nominal arguments only. I will return to the treatment of embedding in Section 2.2.2.4.

\footnotetext{
${ }^{30}$ For a more detailed account of topics in English, see Section 2.3.2.
} 


\begin{tabular}{|c|c|c|c|c|c|c|}
\hline & \multirow{2}{*}{\multicolumn{2}{|c|}{\begin{tabular}{c|c} 
Sp & T1 \\
& $* ! *$ \\
\end{tabular}}} & \multirow{2}{*}{$\frac{\mathrm{pA}}{\star \star}$} & \multirow{2}{*}{$\frac{\mathrm{pS}}{\star \star}$} & Ap & $\mathrm{T} \Omega$ \\
\hline & & & & & \multicolumn{2}{|l|}{ 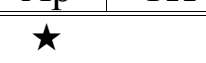 } \\
\hline & & & $\star \star \star$ & $\star \star$ & $*$ & $* *$ \\
\hline & $\star \star \star$ & $\star \star$ & $* * ! *$ & $* * * *$ \\
\hline \multirow{2}{*}{\begin{tabular}{|l|}
$\mathrm{I}_{\text {sub }}$ believe John \\
$\mathrm{I}_{\text {sub }}$ believe Bil Bil Bill $_{\text {top }} \mathrm{John}_{\text {sub }}$ hit \\
Bill $_{\text {top }} \mathrm{I}_{\text {sub }}$ believe John \\
$\mathrm{I}_{\text {sub }}$ Bill \\
Bill ${ }_{\text {top }}$ believe John \\
sub hit \\
sub believe hit John \\
sub \\
\end{tabular}} & $* !$ & & $\star \star \star \star$ & $\star \star$ & $* * *$ & $* * *$ \\
\hline & $\star !$ & & $\star \star$ & $\star$ & $\star * *$ & $* * * *$ \\
\hline
\end{tabular}

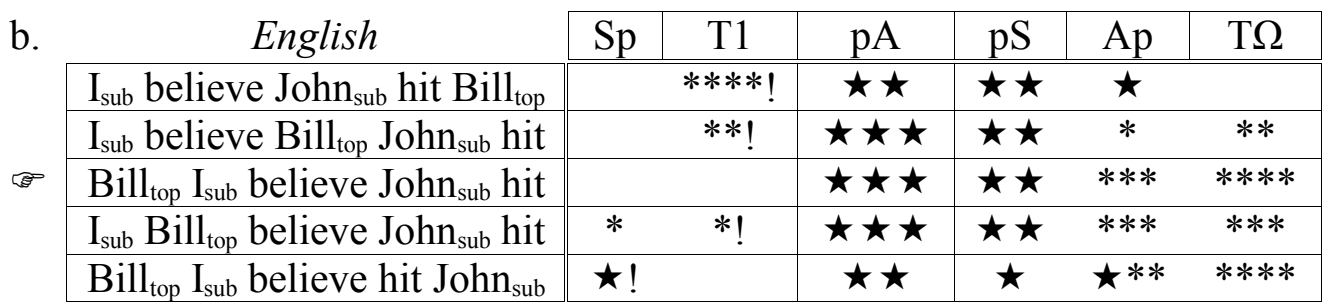

The placement of wh-elements can be accounted for the same way. Wh-elements get fronted, as the contrast between (132a) and (132b) shows. However, in case of predicates that can take interrogative arguments, the wh-element appears in front of the higher predicate (and its subject).

a. who (did) Bill hit

b. * Bill hit who

c. who (do) you think hit Bill

d. * you think who hit Bill

The wh-element in is an object in all the examples, and as such is licensed by its verb. This relationship is regulated by pA. However, at the same time the wh-element also marks the interrogative domain - which in case of interrogative predicates extends beyond the object's own clause. This can be captured with scope marking.

The input for (133a) is in (133b).

a. who (did) Bill hit

b. $\begin{aligned} \text { hit }_{(\alpha)} & \\ \mathrm{x}_{\mathrm{ag}, \mathrm{sub}} & =\text { Bill } \\ \mathrm{y}_{\mathrm{th}, ?},{ }^{(\alpha)} & =\text { who }\end{aligned}$

The violation of the pA constraint with respect to the wh-object is legitimized by a higher ranking $\mathrm{W}_{\mathrm{H}} 1\left(=\mathrm{Sc} 1\left(\mathrm{~W}_{\mathrm{H}}\right)\right)$ constraint. 
(134)

\begin{tabular}{|c|c|c|c|c|c|c|}
\hline English & $\mathrm{Sp}$ & WH1 & $\mathrm{pA}$ & $\mathrm{pS}$ & Ap & $\mathrm{WH}_{\mathrm{H}} \Omega$ \\
\hline hit Bill sub $_{\text {who }}$ & $\star !$ & ** & $*$ & \multicolumn{3}{|c|}{$\star \star \star$} \\
\hline hit who Bill ${ }_{\text {sub }}$ & $\star !$ & * & * & $*$ & $\star \star$ & $*$ \\
\hline Bill $_{\text {sub }}$ hit who & & $* ! *$ & $\star$ & $\star$ & $\star$ & \\
\hline Bill $_{\text {sub }}$ who hit & $* !$ & $*$ & $\star \star$ & $\star$ & $*$ & $*$ \\
\hline who hit Bill $_{\text {sub }}$ & $\star !$ & & $\star$ & & $\star$ & $* *$ \\
\hline who Bill sub hit & & & $\star \star$ & $\star$ & * & $* *$ \\
\hline
\end{tabular}

The input for (135a) is given in (135b).

(135) a. who (do) you think Bill hit

b. $\left[\operatorname{think}_{(\alpha)}\right.$

$$
\begin{array}{cl}
\mathrm{x}_{\mathrm{ag}, \text { sub }}= & \text { you } \\
\mathrm{y}_{\mathrm{th}}= & \text { hit } \\
\mathrm{x}_{\mathrm{ag}, \text { sub }}= & \text { Bill } \\
\mathrm{y}_{\mathrm{th}, ?}(\alpha)= & \text { who }
\end{array}
$$

The violation of $\mathrm{pA}$ with respect to the wh-object is again legitimized by a higher

\begin{tabular}{|c|c|c|c|c|c|c|}
\hline English & $\mathrm{Sp}$ & Wн1 & $\mathrm{pA}$ & $\mathrm{pS}$ & Ap & Wн $\Omega$ \\
\hline you $_{\text {sub }}$ think Bill sub hit who & & $* ! * * *$ & $\star * \star$ & $\star \star \star$ & $\star \star$ & \\
\hline you $_{\text {sub }}$ think who Bill ${ }_{\text {sub }}$ hit & & $* ! *$ & $\star * * \star \star$ & $\star \star$ & $\star *$ & ** \\
\hline you $_{\text {sub }}$ who think Bill sub hit & $* !$ & * & $\star * \star \star$ & $\star \star$ & $* \star * *$ & $* * *$ \\
\hline who you $_{\text {sub }}$ think Bill sub hit & & & $\star * \star \star$ & $\star \star$ & $\star * * *$ & $* * * *$ \\
\hline Bill $_{\text {sub }}$ hit who you sub think & & $* ! *$ & $\star \star \star$ & $\star \star$ & $* * \star$ & $* *$ \\
\hline who Bill sub hit you sub $_{\text {sun }}$ think & & & $\star \star \star \star !$ & $\star \star$ & $\star *$ & $* * * *$ \\
\hline
\end{tabular}
ranking $\mathrm{WH}_{\mathrm{H}}\left(=\mathrm{Sc} 1\left(\mathrm{WH}_{\mathrm{H}}\right)\right)$ constraint - however, this time that constraint demands the wh-element to move in front of the matrix predicate and all its input dependents.

Another possibility in the input would be for an embedded wh-element to mark the lower predicate as its scope domain.

a. *you think who Bill hit

b. [ think

$$
\begin{aligned}
\mathrm{X}_{\mathrm{ag}, \text { sub }}= & \text { you } \\
\mathrm{y}_{\mathrm{th}(\alpha)}= & \text { hit } \\
\mathrm{X}_{\mathrm{ag}, \text { sub }}= & \text { Bill } \\
\mathrm{y}_{\mathrm{th}, ?}(\alpha)= & \text { who }
\end{aligned}
$$

With a verb like think, however, this is impossible in English, as the unacceptability of (137a) illustrated. Since the option of marking a lower scope domain for such words exists in other languages, such as Hungarian, as well as for other predicates in English, the unacceptability in the case of think could be reasonably argued to have 
semantic roots. It is standardly assumed that verbs like think cannot take interrogative arguments. Translating this to the terminology employed in the present theory, we can state that the argument of think cannot be within an interrogative scope domain unless think itself is within the same scope domain.

I would also like to demonstrate the working mechanism of these constraints in case of quantifier scope interaction. Though this is unrelated to coordination, it is important to show that the theory introduced is capable of handling more complex scope phenomena, in which no licensing can be argued to exist. Because there is no licensing relationship between the quantifiers (both of which are licensed by the predicate), scopal interaction needs to be accounted for with first/last constraints.

In Hungarian, quantifier scope is marked transparently: preverbal operators have scope over the elements that follow them. This is especially visible in the case of two quanitifiers, when in a sentence with no focus and neutral intonation their order alone indicates their scope relations, as pointed out by É. Kiss et al. (1998).

a. többször is mindenkit megbuktatott János more too everyone-ACC failed-3SG János

'There were several occasions when John failed everyone.'

b. mindenkit többször is megbuktatott János everyone-ACC more too failed-3SG János

'Everyone was failed more than once by John.'

(É. Kiss et al. 1998: 58)

Neither of these sentences are ambiguous: többször is has obligatory wide scope in the first, and mindenkit in the second example. In order to have wide scope, a Hungarian quantifier must appear in front of the elements is has scope over. This is possible to capture with the help of the $\mathrm{S}_{\mathrm{C}} 1$ constraint mentioned above.

Since scope relations are relevant for interpretation, they must be included in the input, and their interactions marked (Legendre et al. 1998). The feature relevant for the items with scope is quantification, identified by a $q$ subscript. It is the $q$ feature, which has scopal properties, so the Greek letter naming the respective scope domains 
of the quantifiers appear as bracketed superscripts of the quantifier feature. Both elements have scope over the predicate, so the data slot of the predicate will contain their scope letter as subscript. The input for (138b) is:

$$
\left[\begin{array}{rl}
\text { buktatott }_{(\alpha)} & \\
\mathrm{x}_{\mathrm{ag}, \mathrm{sub}} & =\text { János } \\
\mathrm{y}_{\mathrm{th}, \mathrm{q}}{ }^{(\alpha 1)} & =\text { mindenkit } \\
(\mathrm{z}) & =\text { meg } \\
\left(\mathrm{w}_{\mathrm{q}}^{\left({ }^{(\alpha 2)}\right)}=\right. & \text { többször is }
\end{array}\right.
$$

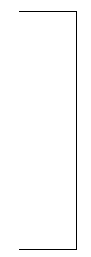

The difference between this and the previous, topicalized input in (129) is that there are two elements bearing the same type of scope, which are in an asymmetrical relationship. This does not follow from what I have said so far, which would indicate a symmetrical relationship, since I have defined the scope domain of an element as the scope-marked predicate and its dependents in the input. When there is more than one element taking the same kind of scope in an input, I will assume that their relative scope is indicated by the numbers attached to their scope-marking Greek letters: element with scope $\alpha 1$ has scope over the element with scope $\alpha 2$, which in turn has scope over the element with scope $\alpha 3$, etc. Thus the scope domain of input item $\mathrm{w}_{\mathrm{q}}{ }^{(\alpha 2)}$ will be the predicate, and its dependents with the exception of item $\mathrm{y}_{\mathrm{q}}{ }^{\left({ }^{(a 1)}\right.}$, whose scope marking has the same Greek letter, but a lower number. The definition for the domain of first/last constraints and the related notion of scope-marking is provided in (140):

(140) a. $\mathrm{X} 1 / \mathrm{X} \Omega$ : align input element $\mathrm{X}$ in front of/behind the elements it has scope over in the input.

b. Scope: input element $i$ has scope over input element $j$ iff:

i. $i$ is scope marked,

ii. $i$ is not scope dominated by $j$, and

iii. $j$ is domain-marked by $i$ 's scope marker.

c. Scope domination: input element $i$ is scope dominated by input element $j$ with respect to scope marker $\delta$ iff:

i. $\quad \delta$ is the scope marker marking both $i$ and $j$ as $i^{(\delta k)}$ and $j^{(\delta l)}$ and

ii. $k>l$.

d. Domain marking: input element $j$ is domain-marked by input element $i$ iff:

i. $j$ bears $i$ 's scope marker in a subscript (=direct scope domain marking) or 
ii. $j$ is a direct or indirect functee of an element directly scope marked by $i$ 's scope marker (=indirect scope domain marking).

Let us now see how this works in terms of the rankings and the optimality competition. Sc1 needs to be ranked higher than the dominant argument alignment constraint pA, so that quantifier arguments appear preverbally. János is placed by pA, in line with the observation that informationally neutral elements in Hungarian appear postverbally (Section 2.2.2.1). Sc1 will place both quantifiers in front of the predicate and will also decide their order with respect to each other: $\mathrm{Q}^{(\alpha 1)}$ scope dominates $\mathrm{Q}^{(\alpha 2)}$ so the domain of $\mathrm{Q}^{(\alpha 1)}$ includes $\mathrm{Q}^{(\alpha 2)}$ but not vice versa. Thus candidates in which $\mathrm{Q}^{(\alpha 2)}$ precedes $\mathrm{Q}^{(\alpha 1)}$ will incur a violation of $\mathrm{S}_{\mathrm{c}} 1$ with respect to $\mathrm{Q}^{(\alpha 1)}$, while the $\mathrm{Q}^{(\alpha 1)}-\mathrm{Q}^{(\alpha 2)}$ ordering will not violate Sc1. Though there is only one Sc1 constraint, for expository purposes I will indicate its violations separately with respect to the two quantifiers ${ }^{31}$.

\begin{tabular}{|c|c|c|c|c|c|}
\hline$(141)^{32}$ & Hungarian & $\mathrm{Sc}_{\mathrm{C}}\left(\mathrm{Q}^{(\alpha 1)}\right)$ & $\mathrm{S}_{\mathrm{C}} 1\left(\mathrm{Q}^{(\alpha 2)}\right)$ & $\mathrm{pA}$ & Ap \\
\hline & megbuktatott János többször is mindenkit & $* ! * *$ & $* *$ & $* *$ & 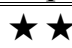 \\
\hline & megbuktatott János mindenkit többször is & $* ! *$ & $* * *$ & $*$ & $\star \star$ \\
\hline & megbuktatott többször is János mindenkit & $* ! * *$ & $*$ & $* * *$ & $\star \star$ \\
\hline & megbuktatott többször is mindenkit János & $* ! *$ & $*$ & $* * *$ & $\star \star \star$ \\
\hline & megbuktatott mindenkit többször is János & $* !$ & $* *$ & $* *$ & $\star \star \star$ \\
\hline & megbuktatott mindenkit János többször is & $* !$ & $* * *$ & $*$ & $\star \star \star$ \\
\hline & János megbuktatott többször is mindenkit & $* ! * *$ & $* *$ & $\star *$ & $*$ \\
\hline & János megbuktatott mindenkit többször is & $* ! *$ & $* * *$ & $\star$ & $\star$ \\
\hline & János többször is megbuktatott mindenkit & $* ! * *$ & $*$ & $\star$ & $\star *$ \\
\hline & János többször is mindenkit megbuktatott & $* ! *$ & $*$ & $\star \star$ & $* *$ \\
\hline & János mindenkit megbuktatott többször is & $* !$ & $* * *$ & $\star \star$ & $*$ \\
\hline & János mindenkit többször is megbuktatott & $* !$ & $* *$ & $\star \star$ & $* * *$ \\
\hline & többször is megbuktatott János mindenkit & $* ! * *$ & & $*$ & $\star \star$ \\
\hline & többször is megbuktatott mindenkit János & $* ! *$ & & $*$ & $\star \star$ \\
\hline & többször is János megbuktatott mindenkit & $* ! * *$ & & $\star$ & $\star$ \\
\hline & többször is János mindenkit megbuktatott & $* ! *$ & & $\star \star$ & $*$ \\
\hline & többször is mindenkit megbuktatott János & $* !$ & & $\star$ & $\star$ \\
\hline & többször is mindenkit János megbuktatott & $* !$ & & $\star \star$ & $*$ \\
\hline & mindenkit megbuktatott János többször is & & $* ! *$ & $\star$ & $\star$ \\
\hline & mindenkit megbuktatott többször is János & & $* !$ & $\star *$ & $\star$ \\
\hline & mindenkit János megbuktatott többször is & & $* ! *$ & $\star \star$ & $*$ \\
\hline & mindenkit János többször is megbuktatott & & $* !$ & $\star \star$ & $* * *$ \\
\hline 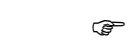 & mindenkit többször is megbuktatott János & & & $\star$ & $\star *$ \\
\hline & mindenkit többször is János megbuktatott & & & $\star \star !$ & $* *$ \\
\hline
\end{tabular}

\footnotetext{
${ }^{31}$ Inclusion of the verbal modifier meg is necessary to ensure that the focus position is filled and so the other elements are clearly not in focus. I will not discuss the placement of focus, but refer to the view of É. Kiss (1994) that the focus position immediately precedes the verb, and can be filled by verbal modifiers, among other elements.

${ }^{32}$ Some of the other candidates are also grammatical sentences, but not for the informationally neutral input in (139).
} 
When the agent of (138b) is topicalized, it appears in front of not only the verb but also the quantifiers, as the example in (142a) shows. The input is provided in (142b).

(142) a. János mindenkit többször is megbuktatott

b.

$\left[\begin{array}{rl}\text { buktatott }_{(\alpha),(\beta)} & \\ \mathrm{x}_{\mathrm{ag}, \mathrm{sub}_{\text {, top }}(\beta)}= & \text { János } \\ \mathrm{y}_{\mathrm{th}, \mathrm{q}}(\alpha 1) & =\text { mindenkit } \\ (\mathrm{z})= & \text { meg } \\ \left(\mathrm{w}_{\mathrm{q}}^{(\alpha 2)}\right)= & \text { többször is }\end{array}\right]$

Note that according to the definition in (140), the topic and the wide scope quantifier are in a symmetrical scope relationship: their scope domain is the predicate and all its dependents. While the ordering of two elements with the same type of scope are decided in the input, the ordering of different types of scope taking elements are decided by the constraints. This is consistent with the view that the input is responsible for issues related to meaning, while systematic properties of the language are accounted for in terms of constraint ranking.

The topic position is regulated by the T1 constraint, a shorthand for $\operatorname{Sc} 1(\beta)$. For theory-internal reasons I have argued for the use of T1 rather than the Tp/pT constraints, but note that the sentence in (142a) also provides empirical justification for this view: Tp would place the topic preverbally, but not in front of the scopebearing quantifiers. This would be the case regardless of the ranking of the two constraints, since Tp and Sc1 do not conflict. If, on the other hand, we have T1 » $\mathrm{Sc}_{\mathrm{C}}$ the correct word order is obtained. The observation that topics precede quantifiers is captured in terms of scope interaction: the topic has wide scope over the quantifiers, which in turn have wide scope over the focus, which dominates the verb. The ranking for Hungarian (revised from (107)) under these considerations is the following:

Hungarian: $\mathrm{Sp}, \mathrm{pS}$ » $\mathrm{P}_{\mathrm{ARSE}}$ » $\mathrm{Sc} 1(\mathrm{~T})$ » $\mathrm{Sc}(\mathrm{Q})$ » $\mathrm{Sc}(\mathrm{F})$ » $\mathrm{pA}$ » $\mathrm{Ap}, \mathrm{Sc} \Omega(\mathrm{T}), \mathrm{Sc} \Omega(\mathrm{Q}), \mathrm{Sc} \Omega(\mathrm{F})$

The optimality table for the input in (142a) is below, with only the relevant constraints from (143) shown. The violation for each scope taking constraint is determined according to the definition in (140) above: Sc1(T) is violated by any element in front of the topic; $\mathrm{Sc1}(\mathrm{Q})$ with respect to the wide scope quantifier is violated by any 
element that is in front of the quantifier; and the same $\mathrm{Sc}_{\mathrm{C}}(\mathrm{Q})$ with respect to the narrow scope quantifier is violated by every element but the wide scope quantifier in front of the narrow scope quantifier. These are contradictory conditions, since Sc1(T) and $S_{C} 1(Q)$ with respect to the wide scope quantifier cannot be satisfied at the same time. Since $\mathrm{Sc}_{\mathrm{C}}(\mathrm{T})$ dominates $\mathrm{Sc} 1(\mathrm{Q})$, it is $\mathrm{Sc}_{\mathrm{C}}(\mathrm{Q})$ with respect to the wide scope quantifier that will be violated in the winning candidate.

\begin{tabular}{|l||c|c|c|c|c|}
\cline { 2 - 5 } \multicolumn{1}{c}{ Hungarian } & $\mathrm{Scl}(\mathrm{T})$ & $\mathrm{Sc}\left(\mathrm{Q}^{(\alpha 1)}\right)$ & $\mathrm{Sc}\left(\mathrm{Q}^{(\alpha 2)}\right)$ & $\mathrm{pA}$ & $\mathrm{Ap}$ \\
\hline megbuktatott János többször is mindenkit & $* !$ & $* * *$ & $* *$ & $* *$ & $\star \star$ \\
\hline megbuktatott János mindenkit többször is & $* !$ & $* *$ & $* * *$ & $*$ & $\star \star$ \\
\hline megbuktatott többször is János mindenkit & $* ! *$ & $* * *$ & $*$ & $* * *$ & $\star \star$ \\
\hline megbuktatott többször is mindenkit János & $* ! * *$ & $* *$ & $*$ & $* * *$ & $\star \star$ \\
\hline megbuktatott mindenkit többször is János & $* ! * *$ & $*$ & $* *$ & $* *$ & $\star \star$ \\
\hline megbuktatott mindenkit János többször is & $* ! *$ & $*$ & $* * *$ & $*$ & $\star \star$ \\
\hline János megbuktatott többször is mindenkit & & $* * ! *$ & $* *$ & $\star *$ & $*$ \\
\hline János megbuktatott mindenkit többször is & & $* * !$ & $* * *$ & $\star$ & $\star$ \\
\hline János többször is megbuktatott mindenkit & & $* * ! *$ & $*$ & $\star$ & $\star *$ \\
\hline János többször is mindenkit megbuktatott & & $* * !$ & $*$ & $\star \star$ & $* *$ \\
\hline János mindenkit megbuktatott többször is & & $*$ & $* * * !$ & $\star \star$ & $*$ \\
\hline János mindenkit többször is megbuktatott & & $*$ & $* *$ & $\star \star$ & $* * *$ \\
\hline többször is megbuktatott János mindenkit & $* ! *$ & $* * *$ & & $*$ & $\star \star$ \\
\hline többször is megbuktatott mindenkit János & $* ! * *$ & $* *$ & & $*$ & $\star \star$ \\
\hline többször is János megbuktatott mindenkit & $* !$ & $* * *$ & & $\star$ & $\star$ \\
\hline többször is János mindenkit megbuktatott & $* !$ & $* *$ & & $\star \star$ & $*$ \\
\hline többször is mindenkit megbuktatott János & $* ! * *$ & $*$ & & $\star$ & $\star$ \\
\hline többször is mindenkit János megbuktatott & $* ! *$ & $*$ & & $\star \star$ & $*$ \\
\hline mindenkit megbuktatott János többször is & $* ! *$ & & $* *$ & $\star$ & $\star$ \\
\hline mindenkit megbuktatott többször is János & $* ! * *$ & & $*$ & $\star *$ & $\star$ \\
\hline mindenkit János megbuktatott többször is & $* !$ & & $* *$ & $\star \star$ & $*$ \\
\hline mindenkit János többször is megbuktatott & $* !$ & & $*$ & $\star \star$ & $* * *$ \\
\hline mindenkit többször is megbuktatott János & $* ! * *$ & & & $\star$ & $\star *$ \\
\hline mindenkit többször is János megbuktatott & $* ! *$ & & & $\star \star$ & $* *$ \\
\hline
\end{tabular}

English differs from Hungarian in terms of operator scope: the relative scope of two quantifiers is not transparent. The sentence in (145a) is ambiguous: either the first quantifier has wide scope, as the paraphrase in (145b) indicates, or the second one does, as shown in (145d). The inputs are provided in (145c) and (145e). 
(145) a. someone believes everyone to have the flu

b. 'There is a single person who believes that everybody has the flu.'

c. $\operatorname{believes}_{(\alpha)}$

$\mathrm{X}_{\mathrm{ag}, \mathrm{sub}, \mathrm{q}}{ }^{(\alpha 1)}=$ someone

$\mathrm{y}_{\text {th }}=$ to have

$\begin{array}{ll}\mathrm{X}_{\text {ben, sub, }}{ }^{(\alpha 2)}= & \text { everyone } \\ \mathrm{y}_{\text {th }} & =\text { the flu }\end{array}$

d. 'For everyone there is one person who believes they have the flu.'

e. $\quad\left[\begin{array}{rl}\operatorname{believes}_{(\alpha)} & \\ \mathrm{x}_{\mathrm{ag}, \operatorname{sub}_{\mathrm{q}}{ }^{(\alpha 2)}} & =\text { someone } \\ \mathrm{y}_{\mathrm{th}} & =\text { to have }\end{array}\right.$

$$
\begin{aligned}
\mathrm{X}_{\text {ben, sub, }}{ }^{(\alpha 1)} & =\text { everyone } \\
\mathrm{y}_{\text {th }} & =\text { the flu }
\end{aligned}
$$

Meaning-related relative quantifier scopes are marked in the input. If $\mathrm{Sp}$ is ranked above $\mathrm{Sc}_{\mathrm{C}}(\mathrm{Q})$, it will tie the subjects to their respective verbs, so scope relations will not become transparent, and the same word order is predicted for both inputs, yielding the attested ambiguity. pA also has to dominate $\mathrm{Sc} 1(\mathrm{Q})$, as otherwise the embedded clause could appear in front to satisfy $\mathrm{Sc}_{\mathrm{C}}(\mathrm{Q})$ with respect to a wide scope everyone in (145e). Since the lower predicate is an argument of the matrix verb, pA could sanction against this constellation. $\mathrm{Sc}(\mathrm{Q})$ is a single constraint, but for expository purposes I tabulate its violations separately for the quantifiers. Also, just like before, the predicate alignment constraints are satisfied if the arguments are aligned to their respective predicates. I only show the relevant constraints and focus on candidates in which the quantifiers are arranged in various ways.

\begin{tabular}{|c|c|c|c|c|c|}
\hline \multirow[t]{2}{*}{ a. } & English & $\mathrm{Sp}$ & $\mathrm{pA}$ & Sc1 $\left(Q^{(\alpha 1)}\right)$ & $\mathrm{Sc} 1\left(\mathrm{Q}^{(\alpha 2)}\right)$ \\
\hline & sy.sub ey.sub believes to have the flu & $* ! *$ & $\star \star$ & & \\
\hline \multirow{7}{*}{$\sigma^{\circ}$} & ey.sub sy.sub believes to have the flu & $* ! *$ & $\star \star$ & * & \\
\hline & believes sy.sub ey.sub to have the flu & $\star !$ & $* * \star$ & * & ** \\
\hline & believes ey.sub sy.sub to have the flu & $\star ! *$ & $* * * \star$ & $* *$ & $*$ \\
\hline & ey.sub believes sy.sub to have the flu & $\star !^{*}$ & $* \star$ & $* *$ & \\
\hline & \multirow{2}{*}{$\begin{array}{l}\text { sy.sub believes ey.sub to have the flu } \\
\text { ey.sub to have the flu sy.sub believes }\end{array}$} & & $\star * \star$ & & * \\
\hline & & & $\star \star \star !$ & $* * *$ & \\
\hline & sy.sub to have the flu ey.sub believes & $* ! * * \star$ & $\star \star *$ & & ** \\
\hline
\end{tabular}




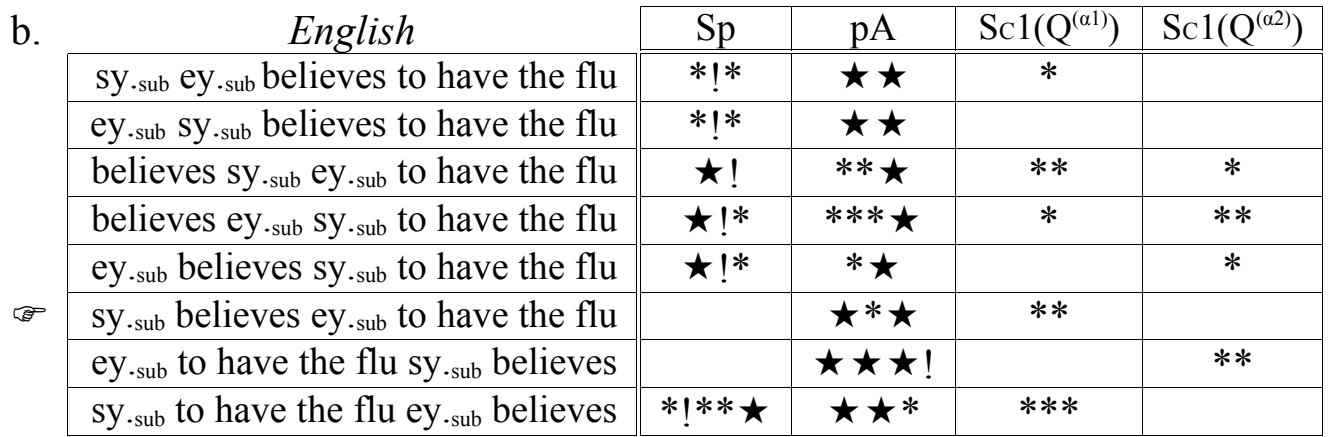

This concludes my discussion on the domain of first/last constraints in simple cases. In the next sections I will consider more complex sentences involving embedding.

\subsubsection{Cyclicity}

Typically in OT it is assumed that the candidate set is evaluated as a whole by the ranked constraints in a single competition until the optimal candidate is decided on. This works even in case of many multiple predicate inputs, as the example below illustrates.

(147) a. John saw Mary cry

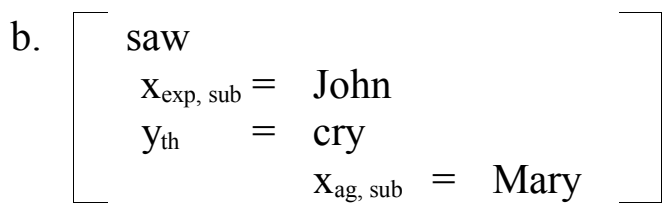

The highest ranking Sp constraint will "glue" each subject to its predicate, so only two candidates will survive this constraint. Since the lower verb is the argument of the matrix verb, the next constraint, pA will place the two Sp strings in the correct order: in John saw Mary cry the lower predicate is one slot removed from its desired position (*), but that is better than in Mary cry John saw, where the lower predicate is on the wrong side of the matrix verb $(\star)$. 
(148)

\begin{tabular}{|c|c|c|c|c|}
\hline English & $\mathrm{Sp}$ & $\mathrm{pA}$ & $\mathrm{pS}$ & Ap \\
\hline saw John sub $_{\text {cry Mary }}$ sub & $\star ! \star$ & $*$ & & 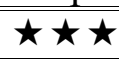 \\
\hline saw John sub $_{\text {sary }}$ cry & $\star !$ & $* * \star$ & $\star$ & $\star \star$ \\
\hline saw cry John ${ }_{\text {sub }}$ Mary & $\star ! \star$ & $* *$ & $* *$ & $\star \star \star$ \\
\hline saw cry Mary sub $_{\text {sohn }}$ sub & $\star ! \star$ & $* *$ & $* *$ & $\star \star \star$ \\
\hline saw Mary sub John $_{\text {sub }}$ cry & $\star !^{*}$ & $* * * \star$ & $* \star$ & $\star \star *$ \\
\hline saw Mary sub $_{\text {cry } J_{\text {ohn }} \text { sub }}$ & $\star !$ & $* * * \star$ & $* * \star$ & $\star \star$ \\
\hline John $_{\text {sub }}$ saw cry Mary sub & $\star !$ & $\star$ & $\star$ & $\star \star$ \\
\hline John $_{\text {sub }}$ saw Mary sub cry & & $\star * \star$ & $\star \star$ & $\star$ \\
\hline John $_{\text {sub }}$ cry saw Mary sub & $* ! \star$ & $\star \star *$ & $\star *$ & $* \star$ \\
\hline $\mathrm{John}_{\text {sub }}$ cry Mary sub $_{\text {saw }}$ & $* ! * \star$ & $\star \star$ & $\star$ & $* * \star$ \\
\hline John $_{\text {sub }}$ Mary $_{\text {sub }}$ saw cry & $* ! *$ & $\star \star$ & $\star \star$ & $* \star *$ \\
\hline John $_{\text {sub }}$ Mary $_{\text {sub }}$ cry saw & $* ! *$ & $\star \star \star$ & $\star \star$ & $* *$ \\
\hline cry saw John sub $_{\text {Mary sub }}$ & $\star ! \star$ & $\star * *$ & $* *$ & $\star \star$ \\
\hline cry saw Mary $_{\text {sub }}$ John $_{\text {sub }}$ & $\star ! \star$ & $* \star *$ & $* *$ & $\star \star$ \\
\hline cry John $_{\text {sub }}$ saw Mary sub & $\star !$ & $\star \star * *$ & $\star * *$ & $* \star$ \\
\hline cry John $_{\text {sub }}$ Mary sub $_{\text {saw }}$ & $* \star$ & $\star \star *$ & $\star *$ & $* * * \star$ \\
\hline cry Mary sub $_{\text {saw } \text { John }_{\text {sub }}}$ & $\star ! \star$ & $\star$ & & $\star * * \star$ \\
\hline cry Mary sub $\mathrm{John}_{\text {sub }}$ saw & $\star !$ & $\star \star$ & $\star$ & $* * * \star$ \\
\hline Mary $_{\text {sub }}$ saw John sub $_{\text {cry }}$ cro & $\star ! * *$ & $* \star$ & $\star$ & $\star \star *$ \\
\hline Mary $_{\text {sub }}$ saw cry John sub & $* ! *$ & $* \star$ & $* \star$ & $\star \star *$ \\
\hline Mary sub $_{\text {John }}$ sub saw cry & $* ! *$ & $\star \star$ & $\star \star$ & $* * \star$ \\
\hline Mary sub $J h_{\text {sub }}$ cry saw & $* ! *$ & $\star \star \star$ & $\star \star$ & $* *$ \\
\hline Mary $_{\text {sub }}$ cry John sub $_{\text {saw }}$ & & $\star \star \star !$ & $\star \star$ & $*$ \\
\hline Mary $_{\text {sub }}$ cry saw John ${ }_{\text {sub }}$ & $\star !$ & $\star \star$ & $\star$ & $\star$ \\
\hline
\end{tabular}

In some other cases, however, it is necessary to consider the satisfaction of the constraints with respect to the predicates separately. The example below will illustrate the problem of a single competition, which makes the wrong prediction. Example (128a) is repeated here as (149a), with its input repeated from (129a) as (149b). In the competition table in (131a) I have disregarded the $\mathrm{pA} / \mathrm{Ap}$ constraints with respect to the verbal argument of the matrix predicate. To focus attention on the problem, I am marking these $\mathrm{pA} / \mathrm{Ap}$ violations in square brackets in $(149 \mathrm{c})$ below.

(149) a. I believe Bill John hit

b. $\quad$ believe

$$
\begin{array}{ll}
\mathrm{x}= & \mathrm{I} \\
\mathrm{y}_{(\alpha)}= & \text { hit } \\
& \mathrm{x}_{\mathrm{ag}, \text { sub }}=\text { John } \\
& \mathrm{y}_{\text {th, top }}(\alpha)=\text { Bill }
\end{array}
$$




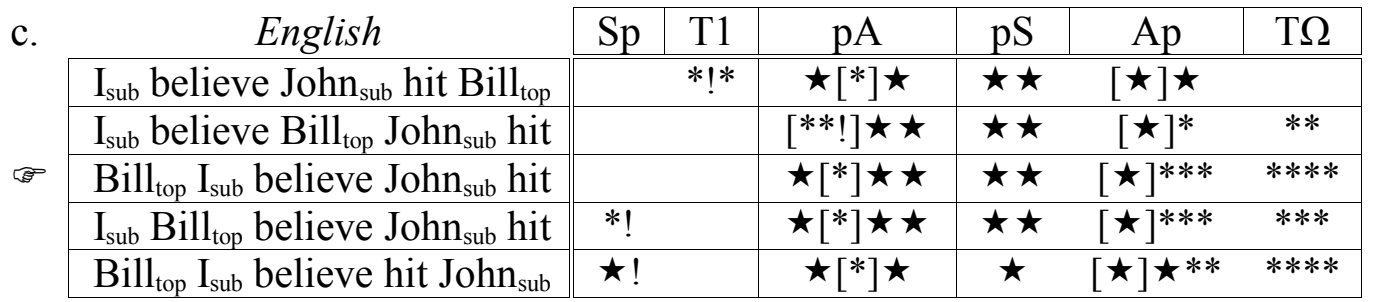

The problem is that the third candidate fares better on pA than the grammatical second candidate, because only one element intervenes between the the matrix predicate and its verbal argument. In a sense fronting of the topicalized element too far is rewarded at this stage. This is clearly the wrong prediction. (Recall that $\mathrm{T} 1$ is satisfied as long as the topicalized element appears before the elements in its scope domain. Immediate precedence is not required in case of the first/last constraints.)

Newson (2000b) introduced an aspect of cyclicity into the evaluation. The candidate set is evaluated against the ranked constraints in a number of cycles, each of which limits the scope of the satisfaction of the constraints to a particular predicate. In each cycle facts about non-relevant predicates are simply ignored. In effect what this does is to eliminate from the candidate set those candidates which do not best satisfy the constraints with respect to a certain predicate, but keeps in the running all candidates which differ in terms of how they satisfy the constraints with respect to the other predicates, providing that these do not interfere with the requirements of the particular predicate at the focus of the cycle. Contrary to the standard view, the cyclicity introduced by Newson works top down: superordinate predicates are considered first. All the candidates remaining in the running after the superordinate predicate cycle are then re-cycled through the constraints, but with the focus on the next predicate, and this process continues until the optimal candidate is selected or all the predicates have been cycled through. By this method then the optimal candidate is gradually homed in on through a number of cycles. I would like to borrow the idea of cyclicity, even though the original rationale for its introduction becomes obsolete in the grammar developed here, as the first/last constraints would on their own be capable of predicting grammaticality for the cases that without cyclicity would have been problematic for Newson's account. 
The view of cyclicity developed in Newson (2000b) causes problems for simple embedding examples such as (147a), repeated here as (150), which could be explained with a straight forward, acyclical evaluation mechanism.

\section{(150) John saw Mary cry}

The argument of the matrix verb is the lower verb, and per cyclicity the needs of the matrix verbs would need to be satisfied first. The candidates surviving this cycle thus need to include the string John saw cry - with Mary tagged on on either end. This is clearly the wrong prediction.

\begin{tabular}{|c|c|c|c|c|c|}
\hline & 'saw'cycle & $\mathrm{Sp}$ & $\mathrm{pA}$ & $\mathrm{pS}$ & Ap \\
\hline & John $_{\text {sub }}$ saw Marysub cry & & $\star * !$ & $\star$ & 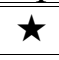 \\
\hline & John $_{\text {sub }}$ saw cry Mary sub & & $\star$ & $\star$ & $\star$ \\
\hline & Mary sub $_{\text {John }}$ sub saw cry & & $\star$ & $\star$ & $\star$ \\
\hline & saw John sub $_{\text {cry }}$ Mary sub & $\star !$ & * & & * \\
\hline
\end{tabular}

The 'cry' cycle then would select the third candidate, as there the subject of the lower verb is on the right side of its predicate.

\begin{tabular}{|l|c|c|c|c|}
\cline { 2 - 5 } \multicolumn{1}{|c|}{ 'cry' cycle $^{\text {Sp }}$} & pA & pS & Ap \\
\hline John $_{\text {sub }}$ Saw cry Mary & $\star !$ & & & $\star$ \\
\hline Mary $_{\text {sub }}$ John $_{\text {sub }}$ Saw cry & $* *$ & $\star$ & $\star$ & $* *$ \\
\hline
\end{tabular}

An alternative view of the way cyclicity works does not encounter this problem: if the superordinate predicate cycle is in effect 'blind' to the internal make up of the items it places. It is as if these input items were not packed out at this stage. The purpose of this cycle is to determine the order of $s a w, J o h n$ and $\operatorname{cry}_{[\mathrm{x}(\mathrm{ag}, \mathrm{sub})=\mathrm{Mary}]}$. However, to maintain the assumption that there is a single set of candidates throughout the evaluation process of successive cycles, I view the candidates that are being compared at the saw cycle as shorthand versions, each standing in for a subset of the candidates.

Thus we have the following shorthand candidates of relevance in the cycle.
a. John saw cry ${ }_{\text {[Mary }]}$
b. John cry [Mary] Saw
c. saw John cry [Mary]
d. saw cry ${ }_{[\text {Mary }]}$ John 

e. cry ${ }_{\text {[Mary }]}$ saw John
f. cry[Mary] John saw

The set that (153a) represents is listed below, where the elements in the focus of attention for this cycle are in bold type and non-bold material is simply ignored in calculating constraint violations.

\section{(153) ai. Mary John saw cry \\ aii. John Mary saw cry \\ aiii. John saw Mary cry \\ aiv. John saw cry Mary}

The set that (153b) represents includes:
(153) bi. Mary John cry saw
bii. John Mary cry saw
biii. John cry Mary saw
biv. John cry saw Mary

etc.

The table below illustrates the evaluation of the shorthand candidates in (153).

\begin{tabular}{l} 
(154) \\
\cline { 2 - 5 }
\end{tabular}

The four candidates that for convenience' sake were represented by the shorthand form that was the winning candidate above compete in the cycle of the subordinate predicate. This cycle cannot be blind to the items of the superordinate cycle, since these items are already placed at this stage: they matter for "slot counting". What this means in practice is that the order of the items placed by the superordinate cycle is fixed relative to one another, but the items placed by the subordinate cycle may be inserted in between them. Since the superordinate cycle is already completed, the 
valences of the superordinate predicate having been satisfied both in terms of a subject and the two arguments in its argument structure, there is no interference at this stage with the needs of the lower predicate.

\begin{tabular}{|c|c|c|c|c|c|}
\hline & 'cry' cycle & $\mathrm{Sp}$ & $\mathrm{pA}$ & $\mathrm{pS}$ & Ap \\
\hline & Mary $_{\text {sub }} J_{o h n}$ sub saw cry & $* ! *$ & $\star$ & $\star$ & $* *$ \\
\hline & John $_{\text {sub }}$ Mary $_{\text {sub }}$ saw cry & $* !$ & $\star$ & $\star$ & $*$ \\
\hline & John $_{\text {sub }}$ saw Mary sub cry & & $\star$ & $\star$ & \\
\hline & John $_{\text {sub }}$ saw cry Marysub & $\star !$ & & & $\star$ \\
\hline
\end{tabular}

Let us now return to the example that was used to motivate the introduction of cyclicity in the first place, (149). The shorthand candidates of relevance in the superordinate cycle are as follows:

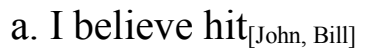
b. I hit [John, Bill] believe
c. believe I hit [John, Bill]

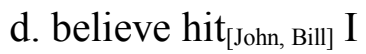

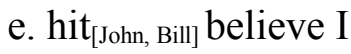

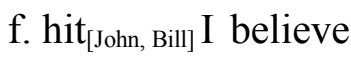

The table below illustrates the evaluation of the shorthand candidates in (156). Note that since the matrix verb is outside the topicalization domain, the topic constraint will not be relevant at this stage.

\begin{tabular}{|c|c|c|c|c|}
\hline 'believe' cycle & $\mathrm{Sp}$ & $\mathrm{pA}$ & $\mathrm{pS}$ & Ap \\
\hline $\mathrm{I}_{\text {sub }}$ believe hit ${ }_{\text {John, Bill] }}$ & & $\star$ & $\star$ & 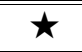 \\
\hline $\mathrm{I}_{\text {sub }}$ hit $_{\text {[John, Bill] }}$ believe & *! & $\star \star$ & $\star$ & * \\
\hline believe $I_{\text {sub }}$ hit $_{\text {[John, Bill] }}$ & $\star !$ & $*$ & & $\star \star$ \\
\hline believe hit ${ }_{\text {[John, Bill] }} I_{\text {sub }}$ & $\star !$ & * & * & $\star \star$ \\
\hline hit $_{[J o h n, \text { Bill] }}$ believe I sub & $\star !$ & $\star$ & & $\star$ \\
\hline hit $_{\text {[John, Bill] }} I_{\text {sub }}$ believe & & $\star \star !$ & $\star$ & * \\
\hline
\end{tabular}

The candidates whose shorthand candidate survived the cycle enter into the cycle of the lower verb, now competing among themselves. Violations are marked only with respect to the lower predicate, but all items matter for slot counting. The topic constraint is also relevant at this stage. (To simplify the table I am ignoring irrelevant details - e.g. that all but one of the candidates in which John does not satisfy Sp). 


\begin{tabular}{|c|c|c|c|c|c|c|}
\hline 'hit' cycle & $\mathrm{Sp}$ & $\mathrm{T} 1$ & $\mathrm{pA}$ & $\mathrm{pS}$ & Ap & $\mathrm{T} \Omega$ \\
\hline $\mathrm{I}_{\text {sub }}$ believe John sub $_{\text {hit Bill }}$ top & & $* ! *$ & $\star \star$ & $\star$ & 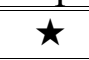 & \\
\hline $\mathrm{I}_{\text {sub }}$ believe Bill top $_{\text {sohn }}$ sub $_{\text {hit }}$ & & & $\star \star$ & $\star$ & * & $* *$ \\
\hline Bill $_{\text {top }} \mathrm{I}_{\text {sub }}$ believe $\mathrm{J} \mathrm{hn}_{\text {sub }}$ hit & & & $\star \star$ & $\star$ & $* * ! *$ & $* * * *$ \\
\hline $\mathrm{I}_{\text {sub }}$ Bill $_{\text {top }}$ believe John sub hit & & & $\star \star$ & $\star$ & $* * !$ & $* * *$ \\
\hline Bill $_{\text {top }} I_{\text {sub }}$ believe hit John $n_{\text {sub }}$ & $\star !$ & & $\star$ & & $\star * *$ & $* * * *$ \\
\hline
\end{tabular}

Note that the grammatical order is picked by the Ap and $T \Omega$ constraints from among the second, third and fourth candidates in the table. Although the 'fatal violation' mark is placed under the Ap constraint, the last three constraints are not ranked with respect to each other and hence they act together to determine the optimality of a candidate. These constraints are dominated by their counterparts pA and T1, and so typically do not get the chance to play. However, it is these constraints that can sanction against the "movement" of the topic further to the front than absolutely necessary in order to satisfy the T1 constraint. Since the scope domain of the topic is the lower verb and its dependants, there is nothing to be gained by "moving" the topic further to the left, as in the third and fourth candidates. This unnecessary "movement" is penalized by the lower ranked constraints. This demonstrates how an alignment based Optimality theory account can capture economy observations without making reference to either movement or any economy principle.

This ranking also addresses a common criticism against OT: that the lower ranked mirror images of important constraints are meaningless and so OT is no different than defining language specific parameters. In the ranking suggested here the effect of recessive constraints is clear: when (even partial) satisfaction of its dominant pair is blocked for some reason, the recessive constraint becomes active, and so word order considerations for the elements in the focus of the constraint will still be relevant.

\subsubsection{Unequal strings}

A perennial problem for a theory based on gradient alignment constraints has been the issue of competing strings of unequal length. If when calculating the distance between the desired and the actual position of an element, we are counting each word, more wordy arguments will do worse than shorter ones. 
Let me illustrate the issue with a Hungarian example. The order of post-verbal arguments in Hungarian is free. According to É. Kiss (1994) all the sentences below carry the same meaning and stylistic information ${ }^{33}$ - thus the sentences in (159) need to be related to the same input (160).

a. adott Mari kopasz Jánosnak nagy piros almákat gave-3SG Mari bald John-DAT big red apples-ACC

'Mary gave bald John big red apples.'

b. adott Mari nagy piros almákat kopasz Jánosnak

c. adott kopasz Jánosnak Mari nagy piros almákat

d. adott kopasz Jánosnak nagy piros almákat Mari

e. adott nagy piros almákat Mari kopasz Jánosnak

f. adott nagy piros almákat kopasz Jánosnak Mari

(160)

$\left[\begin{array}{rll}\text { adott } & & \\ \mathrm{x}_{\mathrm{ag}, \text { sub }}= & \text { Mari } & \\ \mathrm{y}_{\mathrm{th}}= & \text { almákat } & \\ & (\mathrm{x})= & \text { nagy } \\ & (\mathrm{y})= & \text { piros } \\ \mathrm{z}_{\mathrm{ben}}= & \text { Jánosnak } & \\ & (\mathrm{x})= & \text { kopasz }\end{array}\right]$

The only relevant pair of constraints is $\mathrm{pA} » \mathrm{Ap}$ - and this would make the wrong prediction that (159a) is the only grammatical candidate.

\begin{tabular}{|c|c|c|}
\cline { 2 - 3 } \multicolumn{1}{c|}{ 'adott' cycle } & pA & Ap \\
\hline adott Mari kopasz Jánosnak nagy piros almákat & $2^{* 34}, 6^{*}$ & $\star \star \star$ \\
\hline adott Mari nagy piros almákat kopasz Jánosnak & $4^{*}, 6^{*} !$ & $\star \star \star$ \\
\hline adott kopasz Jánosnak Mari nagy piros almákat & $*, 2^{*}, 6^{*} !$ & $\star \star \star$ \\
\hline adott kopasz Jánosnak nagy piros almákat Mari & $*, 5^{*}, 6^{*} !$ & $\star \star \star$ \\
\hline adott nagy piros almákat Mari kopasz Jánosnak & $3^{*}, 4^{*}, 6^{*} !$ & $\star \star \star$ \\
\hline adott nagy piros almákat kopasz Jánosnak Mari & $3^{*}, 5^{*}, 6^{*} !$ & $\star \star \star$ \\
\hline
\end{tabular}

The problem for alignment syntax has been that the number of total pA violations differs in the various alternative expressions. This is because the string nagy piros

\footnotetext{
${ }^{33}$ I will actually contest this view in Section 2.3.8, arguing that in the case of verb-initial expressions, the verb is in focus and the verb-adjacent argument is topicalized. However, as the phenomenon here serves only to illustrate the problem of unequal strings, the modification I will propose is inconsequential in this respect.

${ }^{34} 2^{*}$ is shorthand for $* *$ and $6 *$ for $* * * * * *$. This makes the tables easier to read. I have incidated separately the violations with respect to the three arguments to make the tables more transparent. However, only the total number of violations in each box counts in the competition, and the breakdown of the violations is included for explanatory purposes only.
} 
almákat, if immediately following the verb, pushes the second and third arguments further away from the verb than if the shortest argument, Mari, is verb adjacent. This has been true even under the original cyclical approach of Newson (2000b), in which the arguments themselves stick together - as the table above demonstrates.

Under the current view of cyclicity longer arguments do not get discriminated against. Though in the previous section a different predicate was the focus of each cycle, I treat predicates just as one of several types of functors. Other types of functors can also be thought of as commanding their own functor cycles. Thus slot counting in the verbal functor cycle focuses only on the immediate arguments of the verb. Because the placement of the items belonging to the arguments is not yet decided at this stage, the internal length of the arguments does not matter. In the table below the shorthand candidates stand for their respective sets, as shown in 2.2.2.4.

\begin{tabular}{|c|c|c|c|}
\hline 2) & 'adott' cycle & $\mathrm{pA}$ & Ap \\
\hline 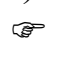 & adott Mari Jánosnak $_{[\text {kopasz] }}$ almákat $_{[\text {nagy piros] }}$ & $* *$ & 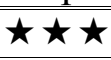 \\
\hline (F) & adott Mari almákat [nagy piros] $] \operatorname{lasnak}_{[\mathrm{kopasz}]}$ & ** & $\star \star \star \star$ \\
\hline (⿻) & $\operatorname{adott~Jánosnak~}_{[\text {kopasz] }}$ Mari almákat [nagy piros] & ** & $\star \star \star \star$ \\
\hline & $\operatorname{adott~Jánosnak~}_{[\text {kopasz] }}$ almákat $_{\text {[nagy piros] }}$ Mari & $* *$ & $\star \star \star$ \\
\hline Co & ${\text { adott almákat }{ }_{\text {[nagy piros] }} \text { Mari Jánosnak }}_{[\text {kopasz] }}$ & ** & $\star \star \star$ \\
\hline (a) & adott almákat $_{\text {[nagy piros] }}$ Jánosnak $_{[\mathrm{kopasz}]}$ Mari & ** & $\star \star \star$ \\
\hline
\end{tabular}

The winners of this predicate cycle will proceed to the nominal functor cycle, which will sort out the placement of the items within the arguments - just as the cycle of a lower verb followed the cycle of the matrix verb in earlier examples.

This view of cyclicity and the assumptions about the inclusion of the items' (semantic) argument structure in the input have allowed me to avoid introducing the level of the phrase, while I could still ensure that the internal arrangements of items glued together in one cycle have no consequences for the arrangements of elements in other cycles.

This way we could maintain that the needs of superior functors take precedence over lower functors, but still retain the integrity of the lower functors and their functees as determined in the input. If the conjunction is also a functor, as I claimed in 2.2.1.2, then its needs will also be the focus of a functor cycle. I will propose a mechanism for cyclicity in coordination and ellipsis in Chapters 3 and 4 respectively. 


\subsection{The universality of topics ${ }^{35}$}

Having introduced the first and last constraints, I am now in the position to return to a problem mentioned at the end of Section 2.2.2.1 - that the account of basic clauses appeared to have been designed to account for subject-predicate languages, and entailed that topic-comment languages are somehow more complex. I assumed, based on Newson (1998b), that subjecthood is a universal feature of inputs: i.e. that some element, the one that is most prominent according to Grimshaw's (1990) argument prominence hierarchy, will be automatically assigned the subject feature in the input. In contrast, I have so far treated topichood as a feature that is optionally assigned in the input, and is simply more prevailing in Hungarian inputs than in English ones. This is not an appealing distinction: there is no extra-theoretical reason to distinguish in such a way between languages that are organized according to the topic/comment and the subject/predicate distinction. I would like to claim that the topic feature, too, is a compulsory part of the input, just like the subject feature. In the following sections I will show that analyses developed based on this assumption are available for languages with very different topic/comment behavior. I demonstrate this specifically for German, English, Hungarian, Tagalog and Japanese. I will conclude this section with the placement of topics in a type of Hungarian verb-initial construction that has been neglected in traditional accounts, but an analysis of which will prove to be crucial for the understanding of certain Hungarian gapping facts in Section 4.5.

I also hope to use this exercise to show that the theory developed so far is capable of accounting for a range of linguistic facts, and its ability to account for coordination phenomena in the forthcoming chapters is not its sole raison d'être.

\subsubsection{German}

Jacobs (2001) has argued that German, like Hungarian, makes use of topics rather than subjects in its grammar. Sentences have a topic-comment rather than a subjectpredicate structure.

\footnotetext{
35 The basic ideas of this section were originally developed in Gáspár (2004). The section on Tagalog and morphological marking as well as the Local Conjunction approach adapted for Japanese are improvements on that analysis. The section on the special status of Hungarian verbs is an extension of my original account.
} 
In a German main clause a topicalized expression precedes the verb, which is always in second (V2) position. Jacobs $(1999,2001)$ assigns little importance to the notion of subjecthood in his grammar and divides German constructions into what he calls topic and - the only exceptionally allowed - anti-topic clauses. The division is a semantic one, but it manifests itself in a different stress pattern for the two types of sentences.

A German topic-comment sentence has a characteristic stress pattern that is related to the division of the expression into a topic, which is introduced in the first step and a comment, added in the second (Hockett 1958). The topic and the predicate are informationally separated, i.e. the semantic processing of the sentence involves two steps, one for the topic and another for the comment. The stress correlate of this semantic separation is illustrated in (163) - where "/" marks rising and "”" falling intonation: the speaker announces the topic and then says something about it.

a. (subject) topic

/Peter $\backslash$ schläft

Peter sleeps

'Peter is sleeping.'

b. (non-subject) topic

in der /Küche hat Peter gelschirr gespült

in the-DAT kitchen has Peter dishes washed

'In the kitchen, Peter did the dishes.'

A strong indication that the topic and the predicate in these sentences are informationally separated, i.e. that semantic processing involves two steps, is that both the topic and the comment are stressed. In contrast, the semantic processing of antitopic sentences takes place in one step only. The event is described in one fell swoop, without separating reference to an entity from a comment made about that entity. This informational integration is reflected in the stress patterns of the sentence, as there is only one stressed syllable. An example for such an anti-topic construction is provided in (164) below. These are introduced by subjects - which suggests that, unlike in Hungarian, the notion of subjects is actually relevant in German, even if it appears only in a limited amount of cases. 
a. (subject) anti-topic

die Poli $\backslash z e i$ kommt

the police comes

'The police are coming.'

b. (non-subject) anti-topic

$\varnothing$

Jacobs (1999) showed that informational separation and integration not only play a central role in the analysis of sentence stress, but also influence syntactic behavior. Focus projection, for instance, is allowed only for informationally integrated elements, suggesting that on top of influencing stress pattern, information relations are also fixed in the semantic form of sentences. He provides the following list of diagnostic criteria for the presence of informational integration on semantic form:

(165) $\mathrm{X}$ is integrated into $\mathrm{Y}$ only if

i. $\quad \mathrm{X}$ is a syntactic argument of $\mathrm{Y}$

ii. If $\mathrm{Y}$ assigns a $\theta$-role to $\mathrm{X}$, it is one that involves proto-patient properties or appearance on the scene

iii. $\quad \mathrm{Y}$ does not assign a spatio-temporally unlimited property to $\mathrm{X}$ (i.e. the relationship is non-generic) and

iv. $\quad \mathrm{Y}$ does not contain more than one constituent with lexical (as opposed to functional) meaning.

(Jacobs 1999: 71-72)

If one of these conditions is not met for the semantic representation of a sentence, $\mathrm{X}$ and $\mathrm{Y}$ are informationally separated and the syntactic manifestation of the clause will be topic-comment. Integration is only possible in highly restricted grammatical circumstances, whereas its opposite, separation, is the unmarked option. If the conditions above are all met, we have an anti-topic sentence with a subject. This was the case in (164), where the predicate is unaccusative (or ergative or passive) ${ }^{36}$ and/or implies appearance on the scene (condition ii), and where it is syntactically noncomplex (condition iv).

\footnotetext{
${ }^{36}$ These are the types of arguments that in the theory of Dowty (1991) are grouped together as predicates that assign proto-patient theta-roles to their single argument - the terms used in the definition of integration in (164).
} 
The anti-topic sentences thus form a limited subclass of V2 constructions: syntactically non-complex arguments of unaccusative predicates.

Most of the expressions, on the other hand, are organized according to a topiccomment, not a subject-predicate, dimension. (Jacobs (2001) in fact argues that there is no unitary functional notion underlying all topic-comment constructions in languages. Rather, the constructions that are normally called topic are related by semantic and pragmatic similarities to prototypical cases, and they should be recognized as different sentence types. However, the V2 constructions of concern to us here are a unified subtype under his analysis as well.)

This approach simplifies the account for V2 word order in German main clauses under an alignment analysis. If the notion of subject placement were central in the grammar, we would need extra mechanisms to explain why a topicalized constituent may replace the subject in the single preverbal slot of the main clause. If, on the other hand, we define the initial constituent as the topic, we may leave the notion of subject as relevant in terms of word order only in the case of anti-topic sentences.

Jacobs's (2001) analysis of German easily lends itself to an alignment account under an assumption that the topic feature is not only universal but is present in every input: $\mathrm{T} 1$ dominates the predicate alignment constraints. The exact ranking will be provided in Section 2.3.7. Subject-verb word order under this assumption would need to be viewed as topic-verb order, with the subject also marked as topic. ${ }^{37}$

I will return to the anti-topic constructions in Section 2.3.7, after providing an analysis for Japanese topic data in Section 2.3.6.

\footnotetext{
${ }^{37}$ For an alternative alignment account of German V2, see Anderson (2000). In his account, Non-INITIAL $\left(\mathrm{V}_{\text {fin }}, \mathrm{S}\right)\left(=\right.$ finite verb must not be sentence initial) dominates EdGEMost $\left(\mathrm{V}_{\text {fin }}, \mathrm{L}, \mathrm{S}\right)$ (=finite verb needs to be the leftmost constituent of the clause) and both outrank constraints relevant to clause internal word order Anderson 2000: 323-324). The Non-Initial (element, domain) and Edgemost (element, side, domain) families are motivated by cross-linguistic evidence in clitic positioning. Though Anderson (2000) accounts for the second position of the verb, the topic status of the first constituent is not explained. My account is also simpler, because Anderson (2000) needs to assume an (X-bar theoretic) phrase structure of the sentence for definition of domains for his constraints both in the case of clitic and verb placement.
} 


\subsubsection{English}

English shows exactly the opposite behavior compared to German as far as the topic/subject dichotomy is concerned: it always has subjects, but it appears sometimes, but not always, to mark its topics syntactically.

Topics are marked clause-initially when they are not subjects. The input for Mary, John loves would look like (166).

$$
\left[\begin{array}{ll}
\text { loves } & \\
\mathrm{x}_{\text {exp sub }}= & \text { John } \\
\mathrm{y}_{\mathrm{th} \text {, top }}= & \text { Mary }
\end{array}\right]
$$

A ranking such as the one below ensures that topics are placed in front of the subject.

$$
\text { English: PARSE » } \mathrm{Sp}, \mathrm{T} 1 » \mathrm{pA} » \mathrm{pS}, \mathrm{T} \Omega, \mathrm{Ap}
$$

But what about the SVO word order - when there appears to be no topic in English? We could view English as a mirror image of German and suppose that it is the subject that is marked for topic status in the inputs of these sentences, and a preverbal topicsubject satisfies both Sp and T1 fully at the same time by being left-adjacent to the verb. In other words, the English topic is always syntactically represented, like in German, but when it coincides with the subject the topic is given no special positioning over and above its position as a subject. It is only when a non-subject is marked as topic that we see any overt sign of the topic ${ }^{38}$.

The effect of this assumption is similar in spirit to the account given for focused English subjects in Grimshaw and Samek-Lodovici (1998). In their account the constraint AlignFocus requires the focused constituent to be right adjoined to the VP (the Italian constellation), while SuBject requires clauses to have subjects. In Italian AlignFocus dominates Subject, and subject-focused sentences have a null-subject in the canonical, preverbal subject position. In English, the constraints are ranked the other way round. As a result, even when a subject is marked for focus in the input, it will retain its preverbal subject position, and the optimal candidate will be the same as

\footnotetext{
${ }^{38}$ This is a simplification, as I am disregarding the behavior of adverbials here. If there is a pre-subject adverbial and the subject is topic, the subject/topic will not be first, thus violating T1 but satisfying Sp. In German, on the other hand, the topic is always first. This difference can be accounted for with the difference in the relative ranking of the $\mathrm{T} 1$ and $\mathrm{Sp}$ constraints with respect to the constraint that places such adverbials.
} 
the optimal candidate for an input with no focus marking on the subject (Grimshaw and Samek-Lodovici 1998: 213). Similarly to my topic constraint, AligNFocus still plays a role in English grammar. Grimshaw and Samek-Lodovici (1995) argue, following Rochemont and Cullicover (1990: 24), that English direct objects focus structurally in VP-adjoined position.

What is common in the two analyses is that an input with topic/focus marking on the subject resolves to the same optimal candidate as an input without apparent topic/focus marking in English. The difference is that whereas in my analysis the topic constraint is satisfied when a subject is marked for topic status, in the account of Grimshaw and Samek-Lodovici (1998) the focus constraint is violated when the subject is marked for focus status in the input.

\subsubsection{Hungarian}

The analysis of stereotypical topic-comment Hungarian sentences was provided in Section 2.2.2.1, and compulsory topic marking in the input will not cause any problems for this account: Hungarian sentences have topics anyway.

\section{(168) Marit szereti János \\ Mari-TOP loves János \\ 'Mary, John loves.'}

When the word order is SVO, the cause is not the special status of subjects, but the topic status of the subject argument in the input ${ }^{39}$. This is in line with É. Kiss's (1994) analysis of basic clause structure, and led to the constraint ranking established in (107), and then modified with the introduction of first/last constraints in (143):

(169) Hungarian: $\mathrm{Sp}, \mathrm{pS} » \mathrm{P}_{\mathrm{ARSE}} » \mathrm{~T} 1 » \mathrm{pA} » \mathrm{Ap}, \mathrm{T} \Omega$

Just like in German, in Hungarian, too, there are sentences that have no initial topic. In fact, É. Kiss (1994) has used the existence of these to argue for a verb initial underlying, or basic, word order. Curiously, all her examples are single-argument

\footnotetext{
${ }^{39}$ Indeed, in a language like Hungarian the notion 'subject' has no role to play in the syntax and hence the descriptions SVO, SOV, etc. are misleading. However, the subject feature is assigned in the input, even in Hungarian, and hence we can refer to the 'subject argument' as the one which was assigned the subject feature and has had it underparsed.
} 
expressions of unaccusative verbs - the very same group of verbs that yield anti-topic constructions in German.

a. alakult egy énekkar

formed a choir

'A choir was formed.'

b. megjött a vonat

PERF-came the train

'The train has arrived.'

c. esik a hó

falling the snow

'It is snowing.'

I will return to these examples in Section 2.3.7, and in Section 2.3.8 will discuss other types of verb-initial sentences, not discussed by É. Kiss (1994), which will lead me to modify the analysis and ranking for Hungarian presented here. What is crucial for now is that for the mainstream Hungarian examples it has been inconsequential whether or not the topic feature is seen as an obligatory or as an optional input element.

\subsubsection{Tagalog}

In OT the only source of grammatical variation between languages is the difference in the ranking of constraints in different languages. Topics in all three languages I have looked at so far are syntactically marked. In a sense they were the easy cases for a theory that claims the universality of an underlying topic feature.

Tagalog, an Austronesian language, which is the official language of the Philippines, attests a completely different behavior: it marks its topics morphologically with the use of a topic prefix ang, but the topic has no special syntactic position (Rakowski (2001) and references cited there).

There is an intricate system to determine which argument becomes the topic. Whatever mechanism is responsible for picking out the constituent that is going to get ang-marked, the position of the topic remains free - or, more specifically, the argument that becomes topic retains its non-topic position even after it has been 
topicalized. The examples in (171) illustrate morphological topicalization of the agent, theme and beneficiary argument, respectively ${ }^{40}$.

a. mag-lu-luto ang lalaking adobo para sa asawa

NOM-ASP-cook TOP man CASE adobo P DAT spouse

'The man will cook adobo for his wife.'

b. lu-lutu-in ng lalaki ang adobo para sa asawa

ASP-cook-ACC CASE man TOP adobo P DAT spouse

'The adobo, the man will cook for his wife.'

c. i-pag-lu-luto ng lalaking adobo ang asawa

OBL-PAG-ASP-cook CASE man CASE adobo TOP spouse

'For his wife, the man will cook adobo.'

(Rakowski 2001)

Since interpretation is read off the input, the topic feature needs to be present in the input of what come out as sentences with ang, regardless of the theory-internal assumption about the obligatory nature of the topic feature. Since ang shows up overtly as a particle on the topicalized element, the feature has to be present in the optimal candidate as well, so that it can receive a phonological form. At Late Insertion a noun that is marked with the topic feature is going to be realized with the ang particle attached to it. This is similar to agreement: in languages that have a rich inflectional morphology, the Vocabulary Item most closely matching a verb will be one with the correct person and number features explicitly marked. In Tagalog a different Vocabulary Item is available for the topicalized version of a given noun than for the informationally neutral one.

We can achieve this under the current system if we assume that both topic constraints $\mathrm{T} 1$ and $\mathrm{T} \Omega$ are ranked very low - and may be ranked equally. Though all other considerations being equal a constraint with a very low ranking can still influence word order, if we assume that every single $\mathrm{Xp} / \mathrm{pX}$ and all the relevant $\mathrm{X} 1 / \mathrm{X} \Omega$ constraints dominate $\mathrm{T} 1$ and $\mathrm{T} \Omega$, that influence remains only a theoretical possibility.

\footnotetext{
${ }^{40}$ Clearly a lot more differentiates these sentences than topic marking. Morphology on the verb, for instance, is related to the topic. In this sense the ang-marked argument can also be seen as the 'subject'. Semantically and in relation to the discourse, however, it clearly has topic qualities according to Rakowski (2001) and her references.
} 
In Tagalog sentences that apparently do not involve topicalization, no element is going to be morphologically topic-marked. Still, some element will still need to be marked with the topic feature in the input according to our assumptions - an issue I will return to at the end of Section 2.3.7.

\subsubsection{Other rankings and their predictions}

An alternative to the ranking in (172) could be to completely circumvent the effects of the constraints by ranking them both above the faithfulness constraint. This is how the lack of subject position in Hungarian has been accounted for despite the presence of a universal subject feature in the input. The candidate in which the universal topic feature is underparsed will vacuously satisfy both of the highly ranked alignment constraints at the expense of a faithfulness violation.

\begin{tabular}{|c|c|c|c|}
\hline Anti-topic language & $\mathrm{T} 1$ & $\mathrm{~T} \Omega$ & Parse \\
\hline V $\operatorname{Arg}_{(\mathrm{T})}$ & & $* !$ & \\
\hline $\operatorname{Arg}_{(\mathrm{T})} \mathrm{V}$ & $* !$ & & \\
\hline $\mathrm{V} \operatorname{Arg}_{(\varnothing)}$ & & & $*$ \\
\hline $\operatorname{Arg}_{(\varnothing)} \mathrm{V}$ & & & $*$ \\
\hline
\end{tabular}

The result is the total absence of syntactic topic marking in this language. However this cannot be the case with Tagalog, because if the feature were not present in the winning candidate, there would be no basis for an ang-marked Vocabulary Item to be inserted at the Late Insertion stage. Note also that the topic is morphologically marked not only on itself but also in terms of an agreement morpheme on the verb. This demonstrates that topichood still plays a syntactic role in the system. It is thus better to view the constraints ranked low, rather than above PARSE in Tagalog.

The theoretical possibility, however, exists for the topic constraints to be ranked high - even if this is not the case in Tagalog. A language which has such a ranking would not mark its topics syntactically, but neither could it mark the topics morphologically - since there would be no topic feature left in the winning candidate for the particle or clitic to match up with at the Late Insertion stage. I have not come across such a language in the typological works consulted, but this is not surprising: topics play an important part in the discourse, and it seems reasonable to assume that this will put 
pressure on realizing them in some overt way. Note that this conclusion does not contradict the one reached for the subject feature, which in a language like Hungarian does not exist overtly at all. Unlike the topic feature, the subject feature does not have a semantic correlate - it is simply a grammatical entity, the licensor of the predicate. Thus the same pressure to overtly realize the subject does not exist.

The possibilities discussed so far are summarized in first five rows of the table below.

\begin{tabular}{lccc} 
& subject & syntactic & morphological \\
& & topic marking & topic marking \\
German & yes, recessive & yes, dominant & no \\
English & yes, dominant & yes, recessive & no \\
Hungarian & no & yes & no \\
Tagalog & yes & no & yes \\
L1 (anti-topic) & $N A$ & no & no \\
L2 (super-topic) & $N A$ & yes & yes \\
\hline
\end{tabular}

What has not been discussed yet is the sixth possibility, a language that marks its topic both syntactically and morphologically. As I will show in the next section Japanese comes close to such a language: in case of non-subject topics it marks topics both syntactically and morphologically. However, even in Japanese, which itself is a rare example, there is only a partial overlap between syntactic and morphological topic marking. This indicates that there is a complementary relationship between syntax and morphology - and when a particular phenomenon is expressed by one of them it tends to be less expressed by the other. This is most often discussed in terms of the relationship between agreement morphology and word order: the richer a language's agreement morphology, the freer its word order can be.

The relationship between morphology and syntax within an optimality theoretic framework has been the subject of two recent papers by Joan Bresnan (1998, 2001). She capitalizes on the observation that as much of the grammar as the morphological system of the language allows gets done before syntax to suggest different c-structures for the same expression in languages with rich morphology such as Russian than in languages with poor morphology such as English. 


\author{
a. staruyu ladku my prodali \\ old-ACC boat-ACC we-NOM sold-1PL \\ 'The old boat, we sold.'
}

b. the old boat t $_{\mathrm{i}}$ we sold $e_{\mathrm{i}}$

(Bresnan 1998: 73-74)

When an object is topicalized, a coreferential empty element is typically assumed to stay in the structural object position, as in (175b) for English. Under the hypothesis that morphology and syntax are not independent, in Russian, where object status is indicated by accusative case, we do not need to hypothesize an empty category for the post-verbal (base) position of the object, because the relationship between the verb and its object is represented by case marking, no matter where the object is.

This analysis is very different from the current one, in as much as in the present approach there are no (c-)structures or empty elements. We can, however, adapt the general idea that morphology and syntax cooperate, and the syntax needs to mop up whatever the morphology could not express. Though this process is typically referred to as morphosyntactic competition, complementarity may be a better term.

Reality is more complex than the language patterns, real or hypothesized, summarized in (174). In the following section I will look at topic marking in Japanese, which comes closest to an L2 language in the sense of (174) I have found. The analysis offered for Japanese will also help closing the open issue of topicless sentences in German, Hungarian and Tagalog.

\title{
2.3.6 Japanese
}

Japanese also marks its topic morphologically, but sometimes syntactically as well. There are also cases when there is no topic marking.

Under the traditional generative view of Japanese (Kuno 1973), topics marked by the particle -wa occupy a special position, left-adjoined to IP (S in 1973) at the top of the clause. Topic marking, however, is not compulsory: not every sentence includes a -wa marked constituent. Nominative marking does not override topic marking, as I have argued it does in English, since an element may appear either with -wa or nominative 
marker -ga, depending on its topic status. This then is a problem for the present analysis: if both topic and subject are compulsory input elements, no ranking of the constraints would predict that they are both attested in some but not all sentences. Before addressing this issue, let me present another view of Japanese - one that will lead me to conclude that the theory presented here can be adopted to accommodate the Japanese topic-marking data.

\subsubsection{Pure topics}

The traditional analysis of the topic-subject relationship is untenable according to Tateishi (1994), who argued that there is no special clause initial position for the -wa marked constituent and there is no syntactic reason to distinguish between - $g a$ and -wa marked NPs. In other words, a subject NP marked with -wa is simply a special kind of subject.

As discussed briefly in Section 2.2.2.2, there is, however, a second -wa slot available at the front of the sentence, reserved for non-subject topics, which have to be strictly -wa marked.

(176) a. Chomusukii $i_{-}$wa/*ga Jiroo-ga Hanako-ni jibun ${ }_{\mathrm{i}}$-no musuko-san-o Ch.- $\quad$ TOP/*NOM J.-NOM Hanako-DAT self-GEN son-Mr./Mrs.-OBJ shookai-shi-ta introduce-do-PAST 'Chomsky, Jiro introduced his $s_{i}$ son to Hanako.'

b. Hannin-wa/*ga Jiroo-ga ayashii perpetrator-TOP/*NOM J.-NOM suspicious 'The perpetrator, Jiro is suspicious. (=The perpetrartor, I suspect Jiro is.)'

(Tateishi 1994: 102)

Tateishi calls sentences such as (176) examples of the Pure Topic Construction. A - ga marked element can not appear in this position. In his GB account, the ordinary -wa (or $-g a$ ) is base generated in the Spec, IP position. The Pure Topic position, on the other hand, is the specifier of the outermost extended verbal projection, MP, otherwise reserved for the modal auxiliary daroo ('I guess/must') (Tateishi 1994: 116). 
Tateishi brings several arguments to differentiate the special, pure topic position from other nominal positions. For an alignment account the crucial one is that the pure topic position cannot be scrambled over by another constituent, such as a whexpression or a focused object. Whatever happens the pure topic position must be sentence initial.

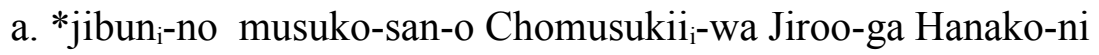
self-GEN son-Mr./Mrs.-OBJ Ch.- TOP J.-NOM Hanako-DAT introduce-do-PAST shookai-shi-ta ${ }^{41}$

'Chomsky, Jiro introduced his ${ }_{i}$ son to Hanako.'

b. ${ }^{*}$ Taroo $^{-}-\mathrm{o}$ hannin-wa Jiroo-ga $t_{i}$ ayashin-deiru

Taroo-OBJ perpetrator-TOP J.-NOM suspect-PROG

'The perpetrator, Jiro suspects is Taro.'

(Tateishi 1994: 110)

Topicalized subjects, on the other hand, can be scrambled over the same way as nontopicalized subjects.

a. Tookyoo-ga/wa koogai-ga hitobito-o kurushimeru Tokyo-NOM/TOP pollution-NOM people-OBJ torture

'It is in Tokyo where the pollution tortures people.'

b. hitobito-o Tokyoo-ga/wa koogai-ga kurushimeru people-OBJ Tokyo-NOM/TOP pollution-NOM torture

'(Of the possibilities), as for in Tokyo, (it is) pollution that tortures people. ${ }^{42}$

(Tateishi 1994: 149)

The existence of pure topics suggests that we cannot silence the topic constraint by ranking it above faithfulness and so allowing for feature underparsing. Scrambling facts suggest that the position of the pure topic is not determined in terms of its alignment to the verb: it does not just have to be pre-verbal, it has to be in front of all other pre-verbal constituents. This requires a T1 constraint that is highly ranked, though below PARSE, so that the topic feature does not get underparsed.

\footnotetext{
${ }^{41}$ Ungrammaticality is not due to a binding violation. As Tateishi (1994) explains the reconstruction of the binding relation between jibun and the subject is possible as long as jibun is not a direct object. (Tateishi 1994: 110, footnote 12.)

${ }^{42}$ This is my gloss. None is provided in the original.
} 
If underparsing the topic feature is not an option and every input needs to have an element marked for topic status, how can we account for the -ga/-wa alteration in the $\theta$-marked subject slot?

\subsubsection{Verbal topic}

- $g a$ and -wa marked subject NPs carry different meanings. This needs to be captured in the input. When a subject comes out -wa-marked, it needs to be topic-marked in the input as well - since that is the basis of interpretation. This would satisfy the requirement that every input needs to include an element with a topic feature.

When the subject is - $g a$-marked, not wa-marked, the compulsory topic marking needs to fall on some other input element. But if there is no -wa-marked element in the sentence, the other arguments or adjuncts cannot be taken to be topic marked. Furthermore, the interpretation of -wa-less sentences is certainly not that they carry a topicalized non-subject argument or adjunct. Since interpretation is read off the input, this lack of topicalization of non-subject arguments and adjuncts needs to be apparent in the input as well. The only input element left to fulfill the requirement that each input needs to contain a topic feature is the verb.

Verbs, or predicates, are normally seen as the counterparts of topics: the predicate makes a statement about the topic. So a topic marked predicate may seem an odd thing to assume. However, there is nothing conceptually wrong with the notion of a prominent verb carrying old information, suggesting that a verb could bear the topic feature: we may be aware that an event, such as drinking for example, took place, but may not know who drank what. However, it is also conceivable that no element in an input is interpreted as carrying old information - at the outset of a conversation, for instance, which would seem to go against the present assumption that the assignment of the topic feature is universal and compulsory. At the same time, even in this case when something is being said, we know that an event has taken place, which is going to be talked about - and in that sense the predicate of that even can be seen as topic.

Recall from Section 2.2.1 that I have assumed the input to be a data structure, in which slots are created for each functor according to that functor's subcategorization 
requirements, and further modifier data slots are optionally created. Then the functee data slots created get filled in by elements that, in the case of verbal functors, are arguments of the predicate. To assume that the assignment of the topic feature is compulsory means that whenever a predicate enters the input, along with its argument data slots a topic feature is also created, and typically one of the arguments or modifiers would be assigned the feature. However, when none of the arguments or modifiers fits the bill for topic feature assignment, the feature is left with nowhere to be assigned to, so it stays "stuck" on the predicate. This would be the case even when the verb does not carry old information in the conventional sense. However, it can be regarded as old information in as much as before someone says something we may take it as given that something, which is about to be spoken about, has happened. The ability to assign the topic feature to the verb (or for it to remain on the verb) contrasts with the subject feature, which gets automatically assigned to the most prominent argument. Since every verb has at least one argument, the subject feature will never remain a feature of the verb. The topic feature is not restricted this way - it may be assigned to arguments, modifiers or the verb itself.

The important point for our purposes is that when none of the arguments is prominent, old information, none can be topic. This is precisely what we want to account for - waless Japanese examples.

Every input needs to have a subject, and the thematic subjecthood of an element is represented in syntax by it being the - $g a /$-wa marked constituent least far from the verb. (Objects, for instance, would come between the subject and the verb in nonscrambled sentences, but objects are easy to distinguish in the string as they can never be - $g a$-marked.) If the input subject is not marked for topic, it will surface with - $g a$. If it is, it will surface with -wa. (Which of them is going to mark the subject will be decided during Late Insertion: depending on the status of the subject, the -wa or - ga marked Vocabulary Item will be the best fit, as explained above for Tagalog.)

\subsubsection{The OT account}

The pure topic position is governed by a T1 constraint - as scrambling facts illustrate. This needs to be the dominant constraint, since the pure topic position cannot be scrambled over. Then would come F1, which would account for the scrambling of the 
focused constituent, such as an object, to the sentence-initial but post pure topic position. Ap also needs to be highly ranked to account for the fact that direct and indirect objects are closer to the verb than subjects. Recall from the discussion on SOV word order in Section 2.2.2.2 that $\mathrm{S} 1$ is the constraint responsible for subject placement, and so must dominate Sp.

$$
\text { Japanese: } \mathrm{PARSE} » \mathrm{~T} 1 » \mathrm{~F} 1 » \mathrm{Ap}, \mathrm{S} 1 » \mathrm{Sp}, \mathrm{pS}, \mathrm{pA}, \mathrm{T} \Omega, \mathrm{F} \Omega
$$

This ranking, however, would catapult the topic-marked subject to the front of the clause, in front of the scrambled focal constituent. What is missing from the analysis developed so far is that topics come first only if the topic is not also the subject. T1 dominates F1 only if the topic is an element other than the subject. This complication can be handled with the Local Conjunction device of constraints (Smolensky 1993, Moreton and Smolensky 2002). The insight behind Local Conjunction is that when two constraints are violated by the same candidate, the combined violation is worse if the violations both relate to the same domain in the candidate.

(180) If $\mathrm{C}_{1}$ and $\mathrm{C}_{2}$ are constraints, and $\mathrm{D}$ is a representational domain type, then $\left(\mathrm{C}_{1}\right.$ and $\left.\mathrm{C}_{2}\right)_{\mathrm{D}}$, the local conjunction of $\mathrm{C}_{1}$ and $\mathrm{C}_{2}$ in $\mathrm{D}$, is a constraint which is violated whenever there is a domain of type $\mathrm{D}$ in which both $\mathrm{C}_{1}$ and $\mathrm{C}_{2}$ are violated.

(Moreton and Smolensky 2002)

It is universally true about Local Conjunction that $\mathrm{C}_{1} \& \mathrm{C}_{2} » \mathrm{C}_{1}, \mathrm{C}_{2}$, capturing the generalization that the concurrence of constraint violations is stronger locally than non-locally.

A candidate may violate $\mathrm{T} 1$ by the topic marked constituent appearing anywhere but at the left-edge of the string; the same candidate may violate O1 (ОвJест FIRST), Mod1 (MODIFIER FIRST), etc. as well by not stacking its non-subject elements at the front. But it will violate the (higher ranking) Local Conjunction of the two constraints (T1 \& O1) or (T1 \& MoD1) only if an object or modifier topic does not appear left-most. The candidate violating the Local Conjunction of the two constraints will be worse than candidates that also violate both constraints, but do so at different places in the string - i.e. a candidate in which the subject topic or the predicate topic does not come first. 
By keeping T1 ranked low, there is in fact no requirement for the element bearing the topic feature to come first when it is not also an object or modifier.

Note that even though the $\mathrm{O} 1$ constraint requires the placement of objects, this is not a category of elements that is explicitly introduced in the grammar. Objects in the sense intended here are predicate arguments not marked by the subject feature.

The ranking we have established for Japanese is the following:

(181) Japanese: PARSE » $(\mathrm{T} 1 \& \mathrm{O} 1),(\mathrm{T} 1 \& \mathrm{Mod} 1) » \mathrm{~F} 1 » \mathrm{Ap}, \mathrm{S} 1 » \mathrm{Sp}, \mathrm{pS}, \mathrm{pA}, \mathrm{T} 1$, $\mathrm{T} \Omega, \mathrm{F} \Omega, \mathrm{O} 1, \mathrm{O} \Omega, \mathrm{Mod} 1, \mathrm{Mod} \Omega$

A more detailed study of Japanese within the framework adopted here would be required to test the full ramifications of this analysis. Japanese subject asymmetry facts are complex ${ }^{43}$ and a full examination of the phenomena would go beyond a thesis on coordination.

The account presented here is superior to the one I proposed in Gáspár (2004). There I had to make the extra assumption that alignment constraints may relativise to particular elements, so that we have $\mathrm{T} 1_{\text {subj }}$ and $\mathrm{T} 1_{\text {non-subj }}$ and $\mathrm{T} 1_{\text {pred. }}$. These could then be ranked differently, with only $\mathrm{T} 1_{\text {non-subj }}$ high. This was not a very elegant solution as $\mathrm{T} 1_{\text {non-subj }}$ was a constraint invented for this single problem - so was descriptive rather than explanatory at best.

\footnotetext{
${ }^{43}$ The data summarized here was in fact a very simplistic recapitulation of Tateishi's (1994) account of the distribution of $-g a /-w a$. The most radical aspect of Tateishi's book was the separation of the Pure Topic Construction from the Major Subject Construction, and arguing that Japanese is configurational with three distinct preverbal nominal slots: Spec MP, Spec CP and Spec IP. The Major Subject is a double nominative construction where there is no genitive-head relationship between two adjacent nominative arguments, but where only the second of these arguments is theta-marked by the verb. The - $g a$ or -wa-marked Major Subject allows to be scrambled over, as illustrated in (178). Though it is called a subject position because of the - ga/-wa marking, a distinction between the ordinary subject and this subject would need to be made in the input, and probably also among the constraints. The order of the subjects is crutial, with the theta-marked one closer to the verb.
}

i. nihon-no tabemono-ga/*no sakana-ga umai

Japan-GEN food-NOM/*GEN fish-NOM good

'It is Japanese food among which fish is good.'

ii. nihon-no tabemono-wa/*ga sakana-ga fugu-ga umai

Tateishi (1994: 101)

Japan-GEN food-TOP/*NOM fish-NOM bowlfish-NOM good

'Speaking of Japanese food, among fish, bowlfish are good.' 
In the following tables I will show how that the ranking in (181) yields the attested word order patterns.

(182) a. Topic-object-wa, Subject-ga, Indirect object-ni, Verb

b. Verb $\mathrm{x}_{\mathrm{sub}}=$ Subject $\mathrm{y}_{\mathrm{top}}=$ Object $\mathrm{z}=$ Ind. Obj.

c.

\begin{tabular}{|l|c|c|c|c|c|c|}
\cline { 2 - 7 } \multicolumn{1}{c|}{ Japanese } & T1\&O1 & $\mathrm{Ap}$ & $\mathrm{S} 1$ & $\mathrm{~T} 1$ & $\mathrm{O} 1$ & $\mathrm{Sp}$ \\
\hline Subj Obj Ind.Obj. Verb & $* !$ & $* * *$ & & $*$ & $* * *$ & $* *$ \\
\hline Obj $\mathrm{j}_{\mathrm{t}}$ Subj Ind.Obj. Verb & & $* * *$ & $*$ & & $* *$ & $*$ \\
\hline Obj $\mathrm{t}_{\mathrm{t}}$ Ind.Obj. Subj Verb & & $* * *$ & $* * !$ & & $*$ & \\
\hline Subj Ind.Obj. Obj $\mathrm{j}_{\mathrm{t}}$ Verb & $* ! *$ & $* * *$ & & $* *$ & $* * *$ & $* *$ \\
\hline Ind.Obj. Obj $\mathrm{t}_{\mathrm{t}}$ Subj Verb & $* !$ & $* * *$ & $* *$ & $*$ & $*$ & \\
\hline Ind.Obj. Subj Obj $\mathrm{t}_{\mathrm{t}}$ Verb & $* ! *$ & $* * *$ & $*$ & $* *$ & $* *$ & $*$ \\
\hline
\end{tabular}

(183) a. Topic-object-wa, Focus indirect object-ni, Subject-ga, Verb

b. Verb

$\mathrm{x}_{\text {sub }}=$ Subject

$\mathrm{y}_{\text {top }}=$ Object

$\mathrm{z}_{\text {(foc) }}=$ Ind. Obj.

c.

\begin{tabular}{|c|c|c|c|c|c|c|c|}
\hline Japanese & $\mathrm{T} 1 \& \mathrm{O} 1$ & $\mathrm{~F} 1$ & Ap & S1 & $\mathrm{T} 1$ & $\mathrm{O} 1$ & $\mathrm{Sp}$ \\
\hline Subj Obj ${ }_{t}$ Ind.Obj.f Verb & $* !$ & *** & **** & & * & **** & *** \\
\hline $\mathrm{Obj}_{\mathrm{t}}$ Subj Ind.Obj.f Verb & & $* * !$ & $* * *$ & * & & ** & * \\
\hline $\mathrm{Obj}_{\mathrm{t}}$ Ind.Obj.f Subj Verb & & * & $* * *$ & ** & & * & \\
\hline Subj Ind.Obj.f Obj ${ }_{\mathrm{t}}$ Verb & $*$ !* & $*$ & $* * *$ & & ** & *** & ** \\
\hline Ind.Obj.f Obj $_{\mathrm{t}}$ Subj Verb & $* !$ & & $* * *$ & ** & * & * & \\
\hline Ind.Obj.f Subj Obj $j_{\mathrm{t}}$ Verb & $*$ !* & & $* * *$ & * & ** & $* *$ & * \\
\hline
\end{tabular}

(184) a. Topic-object-wa, Topic-subject-wa, Indirect Object-o, Verb

b. verb

$$
\begin{array}{ll}
\mathrm{X}_{\text {sub, top }} & =\text { Subject } \\
\mathrm{y}_{\text {top }} & =\text { Object } \\
\mathrm{Z} & =\text { Ind. Obj. }
\end{array}
$$

c.

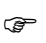

\begin{tabular}{|c||c|c|c|c|c|c|c|}
\cline { 2 - 8 } \multicolumn{1}{c|}{ Japanese } & T1\&O1 & $\mathrm{F} 1$ & $\mathrm{Ap}$ & $\mathrm{S} 1$ & $\mathrm{~T} 1$ & $\mathrm{O} 1$ & $\mathrm{Sp}$ \\
\hline Subj $_{\mathrm{t}}$ Obj $\mathrm{j}_{\mathrm{t}}$ Ind.Obj. Verb & $* !$ & & $* * *$ & & $*$ & $* * *$ & $* *$ \\
\hline Obj $_{\mathrm{t}}$ Subj $\mathrm{j}_{\mathrm{t}}$ Ind.Obj. Verb & & & $* * *$ & $*$ & $*$ & $* *$ & $*$ \\
\hline${\text { Obj } \mathrm{t}_{\mathrm{t}} \text { Ind.Obj. Subj Verb }}$ & & & $* * *$ & $* * !$ & $* *$ & $*$ & \\
\hline Subj $\mathrm{j}_{\mathrm{t}}$ Ind.Obj. Obj $\mathrm{j}_{\mathrm{t}}$ Verb & $* ! *$ & & $* * *$ & & $* *$ & $* * *$ & $* *$ \\
\hline Ind.Obj. Obj $\mathrm{j}_{\mathrm{t}}$ Subj Verb & $* !$ & & $* * *$ & $* *$ & $* * *$ & $*$ & \\
\hline Ind.Obj. Subj $\mathrm{j}_{\mathrm{t}}$ Obj Verb & $* ! *$ & & $* * *$ & $*$ & $* * *$ & $* *$ & $*$ \\
\hline
\end{tabular}


(185) a. Topic-subject-wa, Object-o/Indirect Object-ni, Verb

b. verb

$\mathrm{x}_{\text {sub, top }}=$ Subject

$\mathrm{y}=$ Object

$\mathrm{z}=$ Ind. Obj.

c.

Japanese

Subj $\mathrm{H}_{\mathrm{t}}$ Obj Ind.Obj. Verb

Obj Subj Ind.Obj. Verb

Obj Ind.Obj. Subj $j_{t}$ Verb

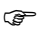

Subjt Ind.Obj. Obj Verb

Ind.Obj. Obj Subj $j_{\mathrm{t}}$ Verb

Ind.Obj. Subj Obj Verb

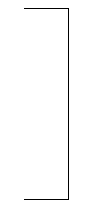

(186) a. Focus Indirect Object-ni, Topic-subject-wa, Object-o, Verb

b. verb

$\mathrm{x}_{\text {sub, top }}=$ Subject

$\mathrm{y}=$ Object

$\mathrm{Z}_{\mathrm{foc}}=$ Ind. Obj.

c.

\begin{tabular}{|c|c|c|c|c|c|c|c|}
\cline { 2 - 9 } \multicolumn{1}{c|}{ Japanese } & T1\&O1 & F1 & Ap & S1 & T1 & O1 & Sp \\
\hline Subj Obj Ind.Obj.f Verb & & $* ! *$ & $* * *$ & & & $* * *$ & $* *$ \\
\hline Obj Subj Ind.Obj.f Verb Ind & & $* ! *$ & $* * *$ & $*$ & $*$ & $* *$ & $*$ \\
\hline Obj Ind.Obj.f Subj $j_{\mathrm{t}}$ Verb & & $* !$ & $* * *$ & $* *$ & $* *$ & $*$ & \\
\hline Subj Ind.Obj.f Obj Verb & & $* !$ & $* * *$ & & & $* * *$ & $* *$ \\
\hline Ind.Obj.. Obj Subj $j_{\mathrm{t}}$ Verb & & & $* * *$ & $* * !$ & $* *$ & $*$ & \\
\hline Ind.Obj. Subj Inj $_{\mathrm{t}}$ Obj Verb & & & $* * *$ & $*$ & $*$ & $* *$ & $*$ \\
\hline
\end{tabular}

(187) a. Subject-ga, Indirect Object-ni/Object-o, Verb

b. verb

$$
\begin{array}{lll}
\mathrm{X}_{\text {sub }} & =\text { Subject } \\
\mathrm{y} & =\text { Object } \\
\mathrm{Z} & =\text { Ind. Obj. }
\end{array}
$$

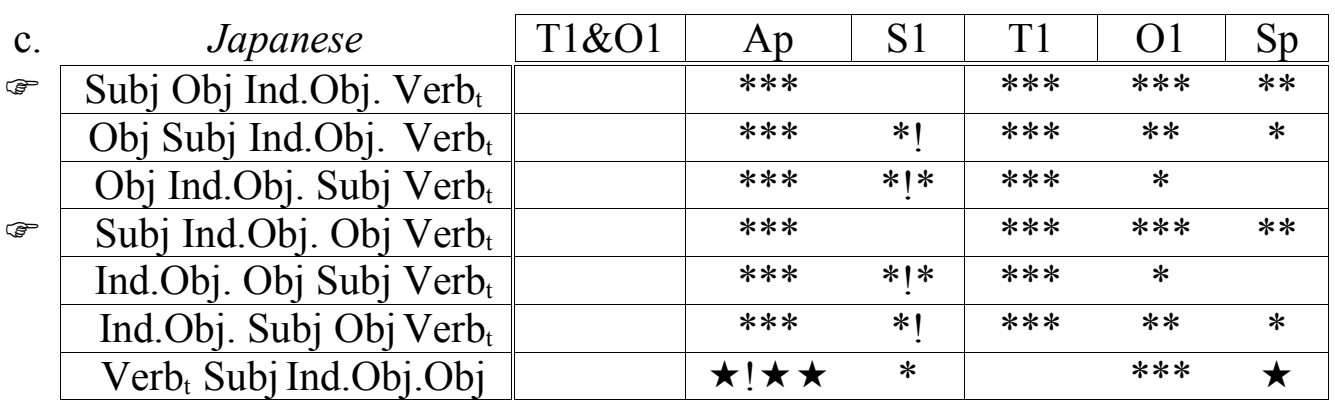

\subsubsection{Hungarian and German unaccusatives}

The option of assigning the compulsory topic-feature to the predicate we assumed in the previous section allows us to account for the unaccusative Hungarian sentences in 
(170) that have a neutral interpretation even though they have no preverbal topic: the verbs carry the compulsory topic feature in the input. The input of (170a), repeated here as (188a) will be as in (188b).

(188) a. alakult egy énekkar

formed a choir

'A choir was formed.'

b. $\left[\begin{array}{c}\text { alakult }_{\text {top }} \\ \mathrm{x}_{\mathrm{exp}} \text {, sub }\end{array}=\right.$ egy énekkar $]$

The T1 constraint will determine the correct ordering. (The subject feature is underparsed, like before.)

\begin{tabular}{|c|c|c|c|c|c|c|c|}
\hline Hungarian & $\mathrm{Sp}$ & $\mathrm{pS}$ & PARSE & T1 & $\mathrm{pA}$ & Ap & $\mathrm{T} \Omega$ \\
\hline alakult $_{\text {top }}$ egy énekkar ${ }_{\text {sub }}$ & $\star !$ & & & & & 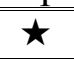 & * \\
\hline egy énekkar $_{\text {sub }}$ alakult top $_{\text {top }}$ & & $\star !$ & & * & $\star$ & & \\
\hline alakult $_{\text {top }}$ egy énekkar ${ }_{<\text {sub }}$ & & & * & & & $\star$ & * \\
\hline egy énekkar ${ }_{\text {sub> }}$ alakult $_{\text {top }}$ & & & $*$ & $* !$ & $\star$ & & \\
\hline
\end{tabular}

Sentences with (pre-verbal) focus but no topic can be explained the same way. The input for (190a) is in (190b), with the compulsory topic feature assigned to the verb.

(190) a. А BÖRTÖNBEN alakult egy énekkar

the prison-in formed a choir

'(Of all the possible places it was) in the prison that a choir was formed.'

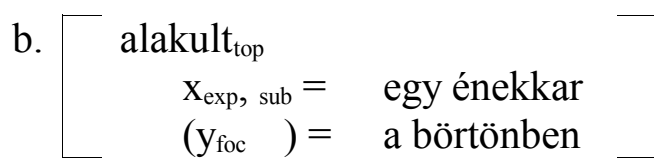

The competition will be as in (191), with prominent F1 placing the focal modifier. (To simplify the table, I am including only candidates with the sub feature underparsed.) 


\begin{tabular}{|c|c|c|c|c|c|c|c|}
\hline Hungarian & PARSE & F1 & T1 & $\mathrm{pA}^{44}$ & $\mathrm{~F} \Omega$ & Ap & $\mathrm{T} \Omega$ \\
\hline alakult $_{\text {top }}$ egy énekkar a börtönben ${ }_{\text {foc }}$ & ** & $* ! *$ & & * & & $\star \star \star$ & *** \\
\hline egy énekkar alakult top a börtönben ${ }_{\text {foc }}$ & * & *!* & * & $\star$ & & $\star *$ & * \\
\hline alakult $_{\text {top }}$ a börtönben ${ }_{\text {foc }}$ egy énekkar & * & *! & * & * & * & $\star \star$ & ** \\
\hline egy énekkar a börtönben ${ }_{\text {foc }}$ alakult $_{\text {top }}$ & * & *! & ** & $\star \star !$ & * & * & \\
\hline a börtönben ${ }_{\text {foc }}$ alakult $_{\text {top }}$ egy énekkar & * & & * & $\star *$ & ** & $\star *$ & * \\
\hline a börtönben foc $_{\text {egy énekkar alakult }}$ top & * & & $* * !$ & $\star \star$ & & & \\
\hline
\end{tabular}

The option of topic-marking the verb also allows us to treat Jacobs' (1999) German anti-topic construction under the current model: German topics are compulsory input elements, but when the topic feature remains on the predicate the subject, not the topic, becomes sentence initial and we get an intonationally different V2 sentence. ${ }^{45}$ The ranking in (192) leads to this prediction: the local conjunction constraint is satisfied if an element marked as topic is also an argument or an adjunct that immediately precedes the predicate. If the topic is neither an argument nor an adjunct (i.e. it is the predicate) the subject precedes the verb. This will account for V2, since the next highest constraints state that arguments and adjuncts follow the verb.

$$
\text { German: PARSE » (T1\&Ap), (T1\&(Ad)p) » } \mathrm{Sp} » \mathrm{pA}, \mathrm{p}(\mathrm{Ad}) » \mathrm{pS}, \mathrm{Ap},(\mathrm{Ad}) \mathrm{p}, \mathrm{T} 1, \mathrm{~T} \Omega
$$

The following examples illustrate the possibilities with the topic feature assigned to a non-subject and a subject, respectively.

a. im Bett schläft Peter

in-the bed sleeps Peter

'As for the bed, that is where Peter is sleeping.'

b.

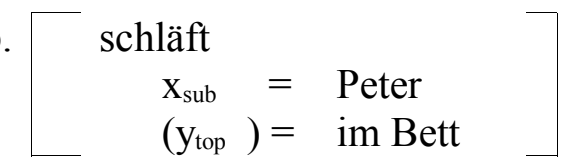

c.

\begin{tabular}{|c|c|c|c|c|c|}
\hline German & T1\&(Ad)p & $\mathrm{Sp}$ & $\mathrm{pA}(\mathrm{d})$ & $\mathrm{pS}$ & $\mathrm{T} 1$ \\
\hline schläft Peter im Bett & $* ! * \star$ & 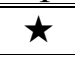 & $*$ & & $* *$ \\
\hline schläft im Bett ${ }_{t}$ Peter & $* ! \star$ & $\star$ & $*$ & $*$ & $*$ \\
\hline Peter schläft im Bett & $* ! * \star$ & & $\star$ & $\star$ & $* *$ \\
\hline Peter im Bett ${ }_{t}$ schläft & $* !$ & $*$ & $\star \star$ & $\star$ & $*$ \\
\hline im Bett ${ }_{t}$ schläft Peter & & $\star$ & $\star$ & $\star$ & \\
\hline im Bett ${ }_{t}$ Peter schläft & $* !$ & & $\star \star$ & & \\
\hline
\end{tabular}

\footnotetext{
${ }^{44}$ As briefly discussed in Section 4.3.4, adjunct placement is regulated by $\mathrm{p}(\mathrm{Ad}) /(\mathrm{Ad}) \mathrm{p}$. However, the distinction would has no bearing here, so I am ignoring the difference between argument and modifier.

${ }^{45}$ Why only in the case of unaccusative verbs do we have this option in both German and Hungarian is another question. I am assuming that this has interpretative reasons, though at this point I am not sure what these might be. I cannot argue that an expression that has a potential topic must be about that topic to be interpretable, because I would lose the -wa/-ga subject distinction that was apparent in Japanese.
} 
a. Peter schläft im Bett

Peter sleeps in-the bed

'As for Peter, he is sleeping in the bed.'

b. schläft

$$
\begin{array}{ll}
\mathrm{X}_{\text {sub top }} & =\text { Peter } \\
(\mathrm{y})= & \text { im Bett }
\end{array}
$$

c.

\begin{tabular}{|r|c|c|c|c|c|}
\cline { 2 - 6 } \multicolumn{1}{c|}{ German } & T1\&Ap & Sp & pA(d) & pS & T1 \\
\hline schläft Peter im Bett $_{\mathrm{t}}$ & $* ! \star$ & $\star$ & $*$ & & $*$ \\
\hline schläft im Bett Peter $_{\mathrm{t}}$ & $* ! * \star$ & $\star$ & $*$ & $*$ & $* *$ \\
\hline Peter $_{\mathrm{t}}$ schläft im Bett & & & $\star$ & $\star$ & \\
\hline Peter $_{\mathrm{t}}$ im Bett schläft & $* !$ & $*$ & $\star \star$ & $\star$ & \\
\hline im Bett schläft Peter & $* ! * \star$ & $\star$ & $\star$ & $\star$ & $* *$ \\
\hline im Bett Peter ${ }_{\mathrm{t}}$ schläft & $* !$ & & $\star \star$ & & $*$ \\
\hline
\end{tabular}

In case of anti-topic constructions, the topic feature is not assigned to the single argument of the unaccusative verb, so it is retained by the verb. The highest ranking constraint is vacuously satisfied by all candidates, since there is no argument that bears the topic feature, for which the constraint would be relevant.

a. die Polizei kommt gleich

the police comes soon

'The police are coming soon.'

b. $\left[\begin{array}{rl}\text { kommt }_{\text {top }} & \\ \mathrm{x}_{\text {sub }} & =\text { die Polizei } \\ (\mathrm{y}) & =\text { gleich }\end{array}\right.$

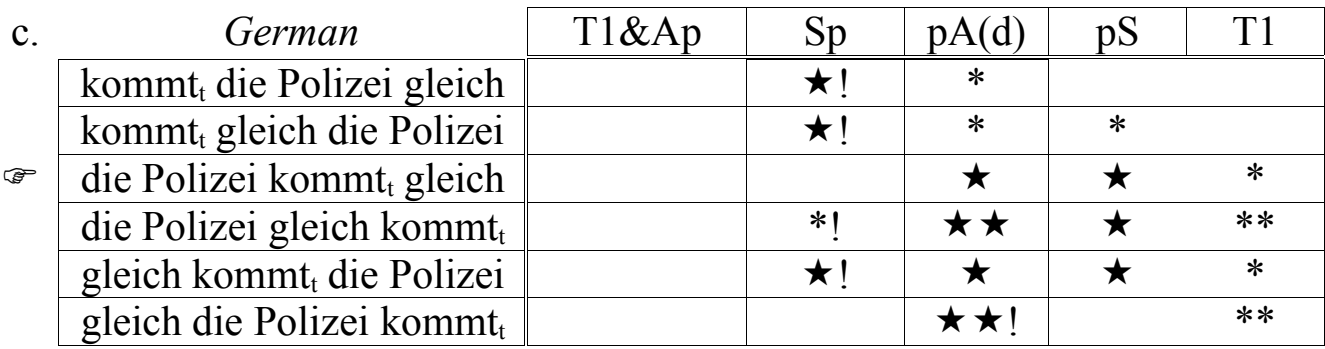

In Tagalog sentences with no ang-marking, too, we can assume that the verb gets topic marked in the input. As far as syntax is concerned, any input element could get the topic marking - since the constraints affecting topic placement are ranked so low they never get the chance to influence word order. At Late Insertion ang is not added to a topic-marked predicate if we assume that the feature set of ang includes that it is a 
nominal marker. This is a reasonable assumption given that ang never shows up on anything but nominal expressions, according to Rakowski (2001). At the Late Insertion stage Tagalog then behaves like German or Hungarian: no distinction is made for an element that is marked as topic in the winning candidate of the syntactic competition over and on top of when the same element is not marked as topic.

In this section I have shown that not only is it reasonable to assume compulsory topic marking in inputs for theory-internal reasons, but also that this assumption is compatible with the data. There is, however, another type of verb-initial structure in Hungarian, which I have not yet accounted for. To round out the theory of compulsory topic-marking, I will now turn to these verb-initial structures, in which assignment of the topic feature to the verb is impossible. The pattern to be discussed in the next section will also be important for cases of coordinate ellipsis.

\subsubsection{Initial verbs in Hungarian}

As discussed in the previous section, Hungarian sentences typically come in a topicpredicate pattern, but not every sentence has a preverbal topic. Sentences such as (170), repeated as (196) below, have led É. Kiss (1994) to conclude that the base position of arguments is post-verbal.

a. alakult egy énekkar

formed a choir

'A choir was formed.'

b. megjött a vonat

PERF-came the train

'The train has arrived.'

c. esik a hó

falling the snow

'It is snowing.'

It is under this ordering that an argument receives a non-marked interpretation, according to É. Kiss (1994). When an argument is fronted, it needs to have special (topic, focus, quantification or wh) interpretation. All of É. Kiss's (1994) verb-initial examples are of this kind: single-argument expressions of intransitive verbs. In fact, in 
his analysis of German topics and subjects reviewed in the previous chapter, Jacobs (1999) concludes that syntactically simple arguments of unaccusative predicates are the only kinds of subjects that cannot be accounted for under a topic-comment analysis of German. In the previous section I concluded that the compulsory topic feature is assigned to the verb in these cases both in German and in Hungarian.

There is, however, another kind of verb-initial expression in Hungarian, in which the verb receives heavy stress. This contrasts with the typical topic-comment construction.

a. SZERETI Mari Jánost

loves Mari János-ACC

'(Of all the possible emotions) it is love that Mary feels towards John.'

b. Mari szereti Jánost

'Mary loves John.'

For Hungarian, I will claim that in transitive cases, such as those in (197), topic-initial expressions are the neutral expressions - as the glosses illustrate.

In contrast to the examples in (196) the verb-initial example in (197a) above can never have neutral interpretation. Such examples are only neutral to the extent that neither argument sits in a syntactically marked topic or focus position. However, both the interpretation and the stress pattern of these sentences indicate that it is the verb that acquires a special status in the V1 constructions with very heavy stress falling on it. The verbal stress here is stronger than the normal, compulsory stress falling on the first syllable of the extended predicate in any Hungarian sentence.

Under the alignment OT view of this thesis, I have maintained that Hungarian is 'underlyingly' verb initial, because the alignments of the verb and its arguments put the verb first ( $\mathrm{pA} » \mathrm{Ap}$ ), but then typically this is disrupted as some argument precedes the verb as a topic. In the unaccusative verb initial expressions in (196) the verb bears the topic feature, so no argument is marked for topic status, which explains why the string is verb-initial. This explanation cannot carry over to (197a), where the verb is stressed, new information - so it cannot be the semantic topic. The compulsory topic feature must be assigned to one of the verbal arguments then. The only way to stop the 
topicalized argument from appearing preverbally is for there to be some special feature on the verb, which overrides topic first alignment. This will allow us to account for sentences like (197a), which, as far as I can see, are problematic for the traditional analysis. Let me first tackle the special feature on the verb before moving on to the discussion of the topic in these cases.

\subsubsection{Verb in focus}

Why would the stressed verb appear initially, or - to ask the same question the other way - why are not any of the other elements preverbal? We cannot simply say that constituents not marked for semantic/contextual emphasis in the input - such as the arguments of the stressed verb in (197a) - need to appear postverbally, because a preverbal topic has no emphasis either. For the same reason we cannot say that the emphatically marked input element needs to be in initial position. At first sight it also seems problematic to argue that the verb is somehow in focus, because topic in Hungarian typically precedes focus, while here the string is verb-initial.

From both semantic and intonational points of view, however, there are important similarities between argument focus and the stressed verb of sentences like (197a). Let me review the arguments that will allow me to call this verbal position verbal focus.

An argument in focus position identifies a particular subset of contextually or situationally relevant elements for which the predicate phrase could potentially hold. The interpretation is that of the set of potentially applicable elements, the predicate phrase in reality holds exclusively for the one in focus.

(198) a. a szomszédom ESÖ ELÖTT szereti locsolni a virágokat the neighbor.my rain before likes watering the flowers '(Of the relevant weather conditions) it is before rain that my neighbor likes watering his flowers.'

b. a szomszédom A VIRÁGOKAT szereti eső előtt locsolni

'(Of all his plants in his garden) it is his flowers that my neighbor likes watering before it rains.'

c. LOCSOLNI szereti a szomszédom a virágokat eső előtt 
'(Of all the relevant actions in relation to flowers) it is watering that my neighbor likes to do before it rains.'

d. a SZOMSZÉDOM szereti eső előtt locsolni a virágokat

'(Of all the relevant people) it is my neighbor who likes watering his flowers before it rains.'

This interpretation of picking out the subset from the contextually relevant set holds for verbs in initial positions as well.
a. Mari szereti Jánost
'Mary loves John.'
b. SZERETI Mari Jánost

'(Of all the possible emotions) it is love that Mary feels towards John.'

While (199a) is a matter-of-fact statement, (199b) is anything but. It emphasizes the fact that Mari loves János - maybe signaling a recent change in Mari's feelings towards János or contradicting a statement to its own negation. The emphasis is on the verb, not on the experiencer or the theme.

Intonationally, too, the similarity with focus is striking. As É. Kiss et al. (1998: 39) point out the intonation of focus is not only characterized by the stress it receives but also by the lack of any measure of sentential stress on the following verb. The constituent following the emphasized verb in verb-initial structures also carries no sentential stress. In (200) the verb has strong primary stress (indicated by ') and it is the first syllable of the sentence final argument that carries the secondary sentential stress (indicated by .) regardless of its thematic role. The medial, verb-adjacent constituent, be it the experiencer or the theme, carries no sentential stress.
(200)
a. `szereti Jánost .Mari
b. `SZERETI Mari .Jánost

The one way in which verbal emphasis, let us call it verbal focus, differs from argument focus is the topic position. Like all of its arguments, the topic follows the emphasized verb in these expressions while it precedes the focal argument in typical 
focus constructions. This difference is not surprising: if the topic preceded the emphasized verb, sentences like (199a) and (199b) would be indistinguishable in terms of word order. This would contrast with the general pattern of Hungarian, in which emphasis and stress are marked positionally as well as intonationally. By keeping the focused verb string-initial, both of these issues are solved and expressions with emphatic verbs nicely fall into the general structural and intonational patterns of other emphasis markers, such as argument focus.

\subsubsection{The topic of the focal verb}

I have assumed that the topic feature is universal, i.e. that a topic feature must be assigned for every predicate that enters the input data structure. I would now like to show that emphatic verb-initial expressions can be incorporated into this analysis.

The argument immediately (right) adjacent to the focal verb seems to act as the topic. Let me illustrate this by first setting up the subject of (200b) as a discourse topic.

(201) egy hónap után tegnap végre beszéltem Marival a month after yesterday finally spoke-1SG Mari.with 'After a month I finally spoke with Mary yesterday.'
a. SZERETI Jánost
b. SZERETI Mari Jánost
c. ?? SZERETI Jánost Mari

Though the topic can be left out as is standard, and as shown in (201a), if it is present it needs to appear adjacent to the verb. (201c), in which new information is verbadjacent and old information sentence final, is very strange. The same relative difference in grammaticality holds for object topics, too.

(202) egy hónap után tegnap végre beszéltem Jánossal

a month after yesterday finally spoke-1SG János.with

'After a month I finally spoke with John yesterday.'

a. SZERETI Mari

b. * SZERETI Mari Jánost/őt

loves Mari János_ACC/him 


\section{c. ? SZERETI Jánost/őt Mari}

The following is a more natural set-up:

(203) a falusi feleségek nagy veszélyben vannak the villager wives big danger.in are 'Village wives are in great danger.' ÜTNÉK őket a férjeik is, ha hagynák beat-COND, 3PL them the husband.theirs too if allowed-3PL

'(Of all the dangers) it is getting beaten up even by their husbands that would happen to them if they didn't watch out.'

?ÜTNÉK a férjeik is őket, ha hagynák.

Again, verb-topic-non-topic is the preferred word order.

Quantificational expressions with minden ('every') cannot be topicalized, as they are not referential (É Kiss et al 1998: 23). It is hard to force a minden expression outside its canonical preverbal position, but strange (204b) is better than (204a), indicating that if the expressions in (204) have a topic, it can only be verb adjacent Jánost.

(204) a. *SZERETI minden lány Jánost

b. ?SZERETI Jánost minden lány

It appears that if a topic is blocked from appearing preverbally, it will fight for the immediate post verbal position. The optimality theoretical mechanism that can yield this result is provided in the next section.

\subsubsection{The OT account}

The ranking for Hungarian from (169) is repeated below:

(205) Hungarian: $\mathrm{Sp}, \mathrm{pS} » \mathrm{P}_{\mathrm{ARSE}} » \mathrm{~T} 1 » \mathrm{pA} » \mathrm{Ap}, \mathrm{T} \Omega$

We also need a constraint that would push a verb marked for emphasis in the input to the front of the expression. I have argued that the emphatic verb is in focus. In 
Sections 2.2.2.2 and 2.3.6.3 I used data from Italian and Japanese to introduce the Focus First (F1) and Focus LAST (F $\Omega$ ) pair of constraints. I have also mentioned that in Hungarian focal arguments strictly left-align to the predicate (footnote 26 in secion 2.2.2.1 and footnote 31 in section 2.2.2.3). Since there is no licensing for focus (it is licensed by virtue of being an argument) it is the F1 constraint that needs to account for this position. Topics typically precede both the verb and its focal argument so, a $\mathrm{T} 1 » \mathrm{~F} 1$ ranking can account for the $\mathrm{A}_{\mathrm{T}} \mathrm{A}_{\mathrm{F}} \mathrm{V}$ word order in the preverbal cluster.

As we have seen, however, the word order is different when the verb is in focus. In this case the topic immediately follows the verb, the opposite of what would be predicted by the $\mathrm{T} 1 » \mathrm{~F} 1$ order that accounts for argument focus. Local conjunction (see Section 2.3.6.3) of (V1\&F1) will allow us to make the correct prediction: when an element is both verbal and in focus, it needs to come first. T1, ranked next, will have the effect of a verb-adjacent topic - as in these cases the topic will have to make it do with the next best position. The ranking for Hungarian is as in (206).

(206) Hungarian: $\mathrm{Sp}, \mathrm{pS} » \mathrm{P}_{\mathrm{ARSE}} »(\mathrm{~V} 1 \& \mathrm{~F} 1) » \mathrm{~T} 1 » \mathrm{~F} 1 » \mathrm{pA} » \mathrm{Ap}, \mathrm{T} \Omega, \mathrm{F} \Omega, \mathrm{V} 1$

Let me demonstrate how the optimality system works in practice with the ranking in (206). Let us take (207a) to be the input for what will end up being (207b).

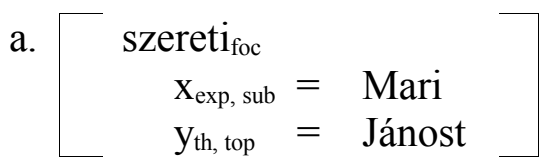

b. SZERETI Jánost Mari

(208) shows how the interaction of the constraints in (206) yields the correct result without representing candidates with parsed subjects or constraints that are irrelevant.

\begin{tabular}{|c|c|c|c|c|c|c|}
\hline \multirow[t]{2}{*}{$(208)$} & & V1\&F1 & T1 & F1 & $\mathrm{pA}$ & Ap \\
\hline & Mari szereti $i_{\text {foc }}$ Jánost $_{\text {top }}$ & $* !$ & ** & * & $\star$ & $\star \star$ \\
\hline \multirow{5}{*}{ 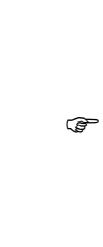 } & Mari Jánost $t_{\text {top }}$ szereti $_{\text {foc }}$ & $*$ !* & * & ** & $\star \star$ & $*$ \\
\hline & szereti $_{\text {foc }}$ Mari Jánost ${ }_{\text {top }}$ & & $* * !$ & & $*$ & $\star \star$ \\
\hline & szereti $_{\text {foc }}$ Jánost $_{\text {top }}$ Mari & & * & & $*$ & $\star \star$ \\
\hline & Jánost $_{\text {top }}$ Mari szereti foc & $*$ !* & & $* *$ & $\star \star$ & $*$ \\
\hline & Jánost $_{\text {top }}$ szereti $_{\text {foc }}$ Mari & $* !$ & & * & $\star$ & $\star$ \\
\hline
\end{tabular}


The findings of this section on emphatic verb-initial expressions will be central to the explanation of the apparent parallelism requirement in case of gapping in Hungarian.

\subsection{Conclusion}

The goal of this chapter was to develop the OT framework that will form the basis of my account of coordination phenomena and ellipsis.

I have presented mainstream OT assumptions in syntax and concluded that their use of $\mathrm{X}$-bar Theoretical axioms and lack of a disciplined definition of what may count as a constraint means that these theories are variations of mainstream theories rather than grammars in their own right. I have introduced an alternative view, developed in Newson (2000a) and (2000b) and Newson and Gáspár (2001), which attempts to overcome both of these problems: it uses only alignment and faithfulness constraints.

While this OT account, operating with predicate alignment constraints, could account for basic word order in both English and Hungarian, no reranking of its constraints would predict SOV languages. Data such as Italian focus, Japanese topic or transparent scope interaction in Hungarian could not be explained with predicate alignment constraints only. I have introduced a second (sub)family of alignment constraints, the first/last pair, to account for these cases. A new view of cyclicity in evaluation has meant that embedding cases and strings of unequal length that were problematic in the original OT alignment account could also receive an explanation.

In the third part of the chapter I hope to have shown that OT alignment grammar is capable of accounting for topic phenomena in a wide variety of languages. With the apparatus established, it is time now to tackle coordination and apply the findings of this chapter to the problems noticed and observations made in Chapter 1. 


\section{Conjunction}

In this chapter I would like to provide an alignment syntactic account of the placement of the coordinative conjunction in both dual and multiple coordination and also discuss coordination introducers and other conjunction markers. I will expand on the consequences of the assumption made in Chapter 2 that the conjunction is a propositional functor and as such has functees and requires licensing (3.1). I will show how a redefinition of the predicate constraints will yield the conjunction alignment constraints (3.1.1-3.1.2) and how the cyclicity mechanism applies for the coordination functor (3.1.3). Most of this discussion will be theoretical, preparing the ground for Sections 3.2 and 3.3, where I will show how the theory developed can account for coordination data from a wide variety of languages, attesting different coordination patterns. Then I will briefly discuss coordination introducers (3.4), multiple conjunction (3.5) and other coordination particles (3.6).

\subsection{Conjunction as a functor}

In Section 2.2.1.3 I introduced a functor theory of inputs, claiming that the input's data structure is organized around the semantic relationships of input elements: the insertion of a functor into an input automatically creates data slots for the functees of the functor, which in turn can be functors in their own right.

Besides logical predicates, I also viewed certain types of operators as functors. In contrast with operators that do not have single lexical counterparts and are realized by certain structure (such as equivalence or implication), operators such as conjunction, disjunction and negation seem to have lexical counterparts in most natural languages. If we can use the same constraints to account for the behavior of predicates and their arguments and for other types of functors and their functees, we would have a more restrictive and thus more powerful theory than one in which different types of constraints are employed for different types of items. I will first review the use of the predicate argument constraints in case of coordination (3.1.1) and then will discuss conjunction licensing, i.e. the relevance of the subject constraint for clausal (3.1.2) coordination. 


\subsubsection{Functor-functee constraints}

If the operators are viewed as functors, the functor-functee alignment constraints introduced in Chapter 2 would apply to the conjunction as well. Predicates are a subset of functors, so we can view the predicate argument alignment constraint discussed there (209a) as a subfamily of the more general functor functee alignment constraints (209b).
a. $\mathrm{pA} / \mathrm{Ap}$ :
argument alignment
b. $\mathrm{fA}^{46} / \mathrm{Af}$
functee alignment

That this constraint can be applied for the conjunction functor is exemplified by coordination data from Cayuga, a Northern Iroquoian language spoken in Ontario.

(210) ne:' tshõ: ne' onẽhẽ' sahe’tá hni' õkwayẽthwẽ hne:'

it only the corn beans and we.planted CONTR

'No, we only planted corns and beans.'

(Mithun 1988: 342)

This pattern can be accounted for by the the Af » fA ranking. This is illustrated in the table below, where the two conjuncts are represented as $a$ and $b$.

\begin{tabular}{|c|c|c|c|}
\hline (211) & Cayuga & Af & fA \\
\hline \multirow[t]{2}{*}{ 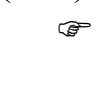 } & $\ldots \mathrm{ab} \& \ldots$ & $*$ & 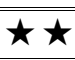 \\
\hline & $\ldots a \& b \ldots$ & $\star !$ & $\star$ \\
\hline \multirow[t]{4}{*}{ 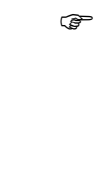 } & $\ldots b$ a $\& \ldots$ & $*$ & $\star \star$ \\
\hline & $\ldots b \& a \ldots$ & $\star !$ & $\star$ \\
\hline & $\ldots \& \mathrm{a} b \ldots$ & $\star ! \star$ & * \\
\hline & $\ldots \& b$ a $\ldots$ & $\star ! \star$ & * \\
\hline
\end{tabular}

The two conjunction final word orders emerge as optimal. (Recall the discussion in Chapter 1 that in most cases of coordination the order of the conjuncts is optional.)

Obviously, most languages are not of the Cayuga type, but place the conjunction in between the conjuncts. Even in these cases, however, all but one of the conjuncts in multiple coordination cases appear on one side of the conjunction, suggesting the operation of the Af/fA pair of constraints.

\footnotetext{
${ }^{46}$ I will represent the functee as $A$ (for argument), since $f$ is already reserved for functor and $F$ for focus.
} 
a. English: C ... (C) \& C

John, Bill, Peter and Fred went to the park

b. Japanese: C \& (C) ... C

taroo to akiko ya ${ }^{47}$ miwa ya kaori wa kohen ni ikimashita

Taroo and Akiko PRT Miwa PRT Kaori TOP park to went

'Taro and Akiko as well as Miwa, Kaori went to the park.'

(Yuko Kitada, p.c.)

The position of all but one of the conjuncts in English can be accounted for by the ranking established for Cayuga, Af » fA. The similarity with the predicate-argument relationship is striking: all but one of the arguments in English are one one side of the predicate, and only one is on the other side. I will discuss the extension of the subject constraint to other functors, such as the coordination in the next section. First I would like to discuss an equally striking difference between predication and conjunction in terms of the functor-functee ordering: in English, while in predication all but one of the conjuncts follow the functor, in coordination all but one of them precede it.

This seems to contradict the X-bar Theoretic observation of the head-left/head-right parameter for languages. However, while languages such as English and Japanese do appear to be uniform in this respect, not all languages display such consistency regardless of coordination facts. If this is so, it would suggest that relativization in headedness is troubling for the X-bar generalization, and as such is not a problem for the account of coordination presented here.

Santorini and Kroch (2000) show that German exemplifies mixed-headedness: it is head-final for VP and AP but is head initial for CP, PP, NP and DP.

\footnotetext{
${ }^{47}$ In Japanese a particle must follow every nominal element, and the particle contributes its meaning to the clause, so the meaning of (212b) differs sligtly from (212a) as a result of the particular particle chosen. This, however, is an independent feature of the language, unrelated to coordination. The relevant observation from our purposes is that the conjunction particle is after the first conjunct. I will return to this case in more detail in Section 3.2.
} 
(213) German mixed headedness

a. V: dass sie [V' [DP ihr Ziel ] verfolgten ] that they their objective pursued 'that they pursued their objective'

b. ob sie [ $\mathrm{V}^{\prime}$ [DP ihre Bewerbung ] einreichte ] if she her application submitted 'if she submitted her application'

c. A [A' [DP seinen Prinzipien ] treu ] his principles-Dat loyal 'loyal to his principles'

d. $\quad$ [A' [PP auf seine Kinder ] stolz ] on his children proud 'proud of his children'

e. $\mathrm{C} \quad\left[\mathrm{C}^{\prime}\right.$ dass [IP sie ihr Ziel verfolgten ] ] that they their objective pursued 'that they pursued their objective'

f. [C' ob [IP sie ihre Bewerbung einreichte ] ] if she her application submitted 'if she submitted her application'

g. $\mathrm{N}$ die [N' Verfolgung [DP ihres Ziels ] ] the pursuit their-Gen objective-Gen 'the pursuit of their objective'

h. diese [N' Treue [PP zu seinen Prinzipien ] ] this loyalty to his principles 'this loyalty to his principles'

i. D [D' die [NP Verfolgung ihres Ziels ] ] the pursuit their-Gen objective-Gen 'the pursuit of their objective'

j. [D' diese [NP Treue zu seinen Prinzipien ] ] this loyalty to his principles 'this loyalty to his principles'

k. P [P' über [DP die nächsten fünf Jahre ] ] over the next five years 'over the next five years' 
1. [P' mit [DP großem Trara ] ]

with great fanfare

'with great fanfare'

(Santorini and Kroch 2000: examples 94-99)

Dutch is similar to German in being head initial for CP, DP and NP but head final for VP and IP, according to Koster (1987). Yiddish is a language with "adjustable directionality values," concludes Haider (in press: 15), claiming that the value of the headedness parameter is underspecified. According to Kroch (2003), the majority of languages in fact show mixed directionality in headedness - a major problem for the X-bar parametrization view. Besides the languages mentioned so far, Kroch also lists Chinese and Farsi as examples of languages with mixed headedness. Even English, which has prenominal adjectives, is not straightforwardly head initial, so he concludes that "the lack of consistency in directionality in most languages raises questions of how strong the pressure for harmony could possibly be."

Chinese, according to Huang (1982, 1984) and Huang et al. (in preparation), is overwhelmingly head final with a few exceptions: pragmatically neutral object arguments of verbs and prepositions must follow their heads as do frequency/duration expressions. (The restriction applies to modifiers, too, as the contrast between (214d) and (214e) shows for manner, temporal and locative adverbials.)

(214) a. fanyi yi-bu xiaoshuo

translate one-Cl novel

'translate a novel'

b. (dui) yi-bu xiaoshuo de fanyi

to one-Cl novel DE translation

'(the) translation of a novel'

(Huang et al. in prep.: 104)

c. ta shang-guo Zhangsan (liang-ci) jinyinzhubao

he award-EXP Zhangsan two.time money.jewellery

'He awarded Zhangsan money and jewellery (twice).'

(Huang et al. in prep.: 189) 
d. ta dasheng de/jintian zaoshang/zai dixiashi li change-le yi-shou minger he loudly $\mathrm{DE} /$ today morning/P basement L sing-ASP one-Cl folk.song 'He sang a folk song loudly/this morning/in the basement.'

e. *ta change-le yi-shou mingerdasheng de/jintian zaoshang/zai dixiashi li

(Huang et al. in preparation: 98)

Data such as the above suggest that head alignments are better viewed as category specific: alignment constraints may relativize to particular types of elements. Within the family of functor-alignment argument constraints we may distinguish between $A f_{V} / f_{V} A$ relevant for predicates and $\mathrm{Af}_{\&} / f_{\&} A$ relevant for the conjunction functor.

This raises a theoretical issue: should the grammar include only constraints relativizing to various kinds of functors (as the examples in the previous paragraph), or also a general functor alignment constraint pair (fA/Af), the relative ranking of which would determine the general order between functors and functees in a language. The two approaches would make different predictions: if we use only the relativized sub-constraints to build the grammar, the uniform or close to uniform head directionality in languages such as English and Japanese would be coincidental. Under this view, in these languages the only way to achieve the effect of the headinitial/head-final parameter would be to have the same relative ranking between the pairs of the relativized functor-functee constraints. Such a solution would not be very explanatory. (215) below illustrates a few pairs of rankings for English under such an approach. Predicates $\left(f_{V}\right)$ as well as nominal $\left(f_{N}\right)$ and prepositional $\left(f_{P}\right)$ heads are always initial. Another head-final functor-functee relationship besides coordination is nominal modifiers: adjectives appear in front of nouns. The brackets in $\mathrm{f}_{\mathrm{N}}(\mathrm{A})$ indicate that this is a modifier relationship.

(215) English: $f_{V} A » A f_{V}$

$$
\begin{aligned}
& \mathrm{f}_{\mathrm{N}} \mathrm{A} \gg \mathrm{Af}_{\mathrm{N}} \\
& \mathrm{f}_{\mathrm{p}} \mathrm{A} \gg \mathrm{Af}_{\mathrm{p}} \\
& \ldots \\
& (\mathrm{A}) \mathrm{f}_{\mathrm{N}} \gg \mathrm{f}_{\mathrm{N}}(\mathrm{A})^{48} \\
& \mathrm{Af}_{\&} \gg \mathrm{Af}_{\&}
\end{aligned}
$$

\footnotetext{
${ }^{48}$ In fact, this is simplification: while adjectives are head-initial, prepositional modifiers follow nouns.
} 
The inclusion of a general pair of alignment constraints in the grammar, on the other hand, would provide a more explanatory account of such languages. Under such a constraint system overwhelming or partial uniformity in headedness would be the norm rather than the exception. The relative ranking between the two general functorfunctee constraints would determine the default headedness in the language, but the effect of the dominant general constraint could be overridden by a higher ranking constraint relativized to a particular functor. In English, for instance, this would be the case for coordination. The default functor-initial constraint would need to be outranked by the functor-final coordination-specific constraint to capture that all but one of the conjuncts appear in front of the conjunction. The nominal modifier constraint would also need to be in front of the default functor-initial constraint to yield the prenominal placement of adjectives. This is captured in the ranking below:

(216) English: $(\mathrm{A}) \mathrm{f}_{\mathrm{N}}, \mathrm{Af}_{\&} \gg \mathrm{fA} » \mathrm{Af}, \mathrm{f}_{\&} \mathrm{~A}, \mathrm{f}_{\mathrm{N}}(\mathrm{A})$

For a language with mixed-headedness such as German, several specific functorfunctee constraints would outrank the default constraint. Yiddish, according to Haider (in press) and references cited there, shows no uniform directionality even in case of a particular type of predicate, in that $\mathrm{VO}$ and $\mathrm{OV}$ variants are both equally acceptable. Haider rules out the possibility that this is scrambling phenomena, and argues that Yiddish genuinely differs from languages that show headedness. One way to account for the data would be to equally rank the fA and Af constraints - and leave it for other constraints to determine word order.

In Chinese we could suppose that the default ordering is determined by the Af » fA ranking, but the constraints that specify the exceptions are ranked above these. ( $\mathrm{Sp}$, the subject constraint to be revised in the next chapter, is ranked on top to make sure that the post-verbal positioning is overruled for non-object arguments.)

$$
\text { Chinese: } \mathrm{Sp} » \mathrm{f}_{\mathrm{V}} \mathrm{A}, \mathrm{f}_{\mathrm{v}}(\mathrm{A})_{\mathrm{fr} / \mathrm{d}} \gg \mathrm{Af} \text { » } \mathrm{A}, \mathrm{Af} \mathrm{f}_{\mathrm{V}},(\mathrm{A})_{\mathrm{fr} / \mathrm{d}} \mathrm{f}_{\mathrm{v}}, \mathrm{pS}
$$

We can conclude that the motivation exists for a default functor/functee constraint, which can be outranked by particular subconstraints in each language to produce patterns that do not follow the language's default functor-functee order. 
Thus we could account for the placement of all but the last conjunct in English. The placement of the last conjunct will be the focus of the next section.

\subsubsection{Conjunction licensing}

In Chapter $2 \mathrm{I}$ introduced the requirement that every element entering the input data structure needs to get syntactically licensed - so some licensing constraint will be relevant for each element. Since the coordination functor is an input element, this requirement will apply. The licensing of the conjunction is the focus of this section.

The conjunction functor does not have a subject, as the predicative functor does, but there is an intuitive similarity between subjects and one of the conjuncts - at least in languages like English. One of the verb's arguments can and must appear on the opposite side of the verb to the rest of the arguments. This argument is the subject. Of the conjuncts, too, one and only one must appear on the opposite side of the conjunction to the other conjuncts.

(218) a. John gave Mary an apple

$\begin{array}{llll}\mathrm{A}_{1} & \mathrm{~V} & \mathrm{~A}_{2} & \mathrm{~A}_{3}\end{array}$

b. John is drinking wine, Mary is eating fish and Bill is smelling the roses

$\begin{array}{llll}\mathrm{C}_{1} & \mathrm{C}_{2} & \& & \mathrm{C}_{3}\end{array}$

Newson (1998b) argued that the subject is the syntactic licensor of the verb, licensing it from the left in English the same way as the verb licenses its arguments. The question is whether the final conjunct can be treated as the licensor of the conjunction.

To establish the similarity, the semantic and syntactic notions of the predicate need to be decoupled. Predicates are standardly assumed to be the semantic heads of propositions, being of a semantic type which takes an argument and yields a proposition. Lexical operators, too, can be seen in a similar way, taking propositional arguments and yielding propositions. Sentential coordination is semantically a coordination of propositions, so it is conceivable to think of the conjunction as the head of a proposition itself. I have tried to capture this logical/semantic similarity between the predicate and the conjunction through the introduction of the term functor. As a predicate requires arguments, a conjunction requires conjuncts. If lexical 
operators, such as the conjunctions, are treated as semantic predicates, the licensing requirement of the verbal predicates can extend to all functor heads of propositions ${ }^{49}$.

If we view the predicate-subject alignment constraint $(\mathrm{pS} / \mathrm{Sp})$ as shorthand for a predicate functor-licensor constraint $\left(\mathrm{f}_{\mathrm{V}} \mathrm{L} / \mathrm{Lf} \mathrm{f}_{\mathrm{V}}\right)$, the same sort of constraint can account for the special licensing relationship between the conjunction and one of its conjuncts $\left(f_{\&} L / L f_{\&}\right)$. Similarly to the case of functor-functee constraints, the grammar may include a more general licensing constraint that is relevant for all propositional functors (fL/Lf), determining a default ordering in the language. It then can be overridden by a more specific constraint in cases where licensing takes place from the opposite direction. In English the licensing conjunct follows the conjunction whereas subjects of predicates precede them. Thus we can have the following ranking:

$$
\text { English: } \quad f_{\&} L \gg L f » f L, \mathrm{Lf}_{\&}
$$

\subsubsection{Cyclicity and the ranking for English ((C) ... C \& C)}

With the constraints established, I would now like to propose the ranking that will deliver the coordination facts. I will deal with English in this section and then extend the analysis to other languages in the rest of this chapter.

The licensing constraint $f_{\&} L$ needs to dominate the argument alignment constraint $\mathrm{Af}_{\&}$ to ensure that the one of the conjuncts appears to the right of the conjunction.

\section{English: $\mathrm{f}_{\&} \mathrm{~L} \gg \mathrm{Af}_{\&} \gg \mathrm{Lf}_{\&}, \mathrm{f}_{\&} \mathrm{~A}$}

Clearly there is going to be a conflict between the alignment needs of the verbal predicate and the conjunction - in as much as the verbal predicates are, under the present assumptions, the functees of the conjunction. Recall that in the present framework we are claiming that evaluation takes place cyclically: candidate expressions are evaluated selectively, each cycle concentrating on a particular aspect of their internal organization. Only candidates that survive the previous cycle are admitted into the next one, where another aspect of their internal organization is the focus of the evaluation.

\footnotetext{
${ }^{49}$ It is not obvious how this argument can extend to cover nominal coordination, which is not propostitional. One possible approach would be to semantically type-raise (Dowty 1988, Hendrinks 1993) nominal conjuncts to yield propositions. This issue, however, is left for future research.
} 
I argued in Section 2.2.2.4 that though the needs of a superior predicate are satisfied before the needs of a subordinate predicate are attended to, the constraints during the superordinate cycle are in effect 'blind' to the make up of this predicate's arguments. The predicate cycle of the superordinate predicate, in this case the conjunction, determines the relative order of the items it places, but it does not bother with the information packed into these items. This is why in coordination the conjunction never intervenes between a predicate and its arguments - even though the conjunction is placed first with respect to its arguments, the verbs.

Let us take an example with three conjuncts.

$$
\begin{aligned}
\& & \\
\mathrm{x} & =\text { Verb a } \\
\mathrm{x}_{\text {sub }} & =\text { Noun } \mathrm{d} \\
\mathrm{y}=\operatorname{Verb~} \mathrm{b} & \\
\mathrm{x}_{\text {sub }} & =\text { Noun } \mathrm{e} \\
\mathrm{z}=\text { Verb c } & \\
\mathrm{x}_{\text {sub }} & =\text { Noun } \mathrm{f} \\
\mathrm{y} & =\text { Noun } \mathrm{g}
\end{aligned}
$$

The arguments of the verbal predicates are not going to be relevant in the superordinate cycle. What matters are four elements: the conjunction and its three arguments. With four elements, we have 24 possible orderings - each of which is a shorthand version of a number of real candidates, in which all the elements are placed, as discussed in Section 2.2.2.4. These are evaluated in the conjunction functor cycle illustrated in (222). 


\begin{tabular}{|c|c|c|c|c|c|}
\hline (222) & \& functor cycle & $f_{\&} L$ & $\mathrm{Af}_{\&}$ & $\mathrm{Lf}_{\&}$ & $f_{\&} A$ \\
\hline \multirow{3}{*}{ 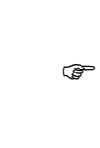 } & $a b c \&$ & $\star !$ & $* * *$ & & 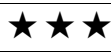 \\
\hline & $a b \& c$ & & $\star *$ & & $\star \star$ \\
\hline & a c b \& & $\star !$ & $* * *$ & & $\star \star \star \star$ \\
\hline \multirow[t]{4}{*}{ 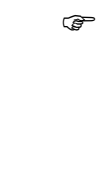 } & $a c \& b$ & & $\star *$ & & $\star \star$ \\
\hline & $\mathrm{a} \& \mathrm{bc}$ & & $\star \star !$ & & $\star *$ \\
\hline & $a \& c b$ & & $\star \star !$ & & $\star *$ \\
\hline & b a c \& & $\star !$ & $* * *$ & & $\star \star \star \star$ \\
\hline \multirow[t]{2}{*}{ 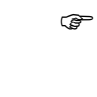 } & b a \& c & & $\star *$ & & $\star \star$ \\
\hline & b c a \& & $\star !$ & $* * *$ & & $\star \star \star \star$ \\
\hline \multirow[t]{4}{*}{ 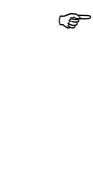 } & $\mathrm{b} c \& \mathrm{a}$ & & $\star *$ & & $\star \star$ \\
\hline & $b \& a c$ & & $\star \star !$ & & $\star *$ \\
\hline & $\mathrm{b} \& \mathrm{c} a$ & & $\star \star !$ & & $\star *$ \\
\hline & c a b \& & $\star !$ & $* * *$ & & $\star \star \star \star$ \\
\hline \multirow[t]{2}{*}{$\theta$} & $c a \& b$ & & $\star *$ & & $\star \star$ \\
\hline & $\mathrm{cb}$ a $\&$ & $\star !$ & $* * *$ & & $\star \star \star \star$ \\
\hline \multirow[t]{9}{*}{$\leftrightarrow$} & $c b \& a$ & & $\star *$ & & $\star \star$ \\
\hline & $c \& a b$ & & $\star \star !$ & & $\star *$ \\
\hline & $c \& b a$ & & $\star \star !$ & & $\star *$ \\
\hline & $\& a b c$ & & $\star \star \star ! !$ & $\star$ & $* * *$ \\
\hline & $\& \mathrm{acb}$ & & $\star \star \star ! !$ & $\star$ & $* * *$ \\
\hline & $\& b a c$ & & $\star \star \star ! !$ & $\star$ & $* * *$ \\
\hline & $\& \mathrm{bca}$ & & $\star \star \star !$ & $\star$ & $* * *$ \\
\hline & $\& \mathrm{cab}$ & & $\star \star \star ! !$ & $\star$ & $* * *$ \\
\hline & $\& \mathrm{cba}$ & & $\star \star \star !$ & $\star$ & $* * *$ \\
\hline
\end{tabular}

Unlike the verb's licensor, the subject, in case of the conjunction functor none of the arguments are privileged - as in most cases of coordination the order of the conjuncts is free. The conjunction functor can be licensed by any of its arguments. It is conceivable that this is, indeed, the "normal" case: a functor needs to be licensed by one of its functees, and any functee can perform this function. Predicates are special in that one of their arguments is privileged - prominent under Grimshaw's (1990) terminology, and it is this which restricts the possible licensors. In general all functees are licensors unless one of them has privileged status. The difference in licensing between the predicate and the conjunction boils down to the hierarchy of arguments.

Constraint satisfaction in the present theory is viewed from the point of view of the functor: it is the functor whose requirement to be licensed (and the requirement that its functees appear on one side) are sanctioned by the constraints. Once one of the licensor conjuncts is in the appropriate constellation to satisfy the licensing constraints, the others can appear anywhere, as far as the licensor constraint is concerned. Thus having one conjunct to the right of the conjunction is the least costly 
way of satisfying $f_{\&} L$ in terms of the price to be paid at the next highest $\mathrm{Af}_{\&}$. $\left(\mathrm{Af}_{\&}\right.$ is not a functor licensing constraint, so it will not be satisfied with just one functee to the left of the predicate: it demands that all functees appear on that side.)

This latter view is represented in (222), where six shorthand candidates are equally more optimal than the others, as they have the same constraint violation profiles. This is because the internal make up of the lower functors does not matter at this stage, so it is inconsequential to $\mathrm{Af}_{\&}$ that argument $\mathrm{c}$ has an object as well as a subject argument, which would push argument c further from the conjunction by one slot.

Because they have the same constraint violation profiles, all six shorthand candidates with exactly one conjunct following the conjunction will survive into the lower functor cycles, which will determine the internal word order of the conjuncts. Note that in the present cycle elliptical conjuncts and full conjuncts are treated the same way. This is again because the constraints are "concentrating" on the superordinate functor and do not see inside the conjuncts. In case of ellipsis the order of the conjuncts is not free, but this will have to be worked out later. I will return to elliptical conjuncts and to what happens after the superordinate functor cycle in Chapter 4. First I would like to illustrate how the conjunction functor cycle operates crosslinguistically. This is the topic of the following sections.

\subsection{Conjunction patterns and constraint reranking}

Treating the conjunction as a functor, which - like a predicate - has functees and needs to get licensed predicts five basic word order patterns in terms of the conjunction and its conjuncts. These are the result of different rankings of the functee $\left(f_{\&} A / A f_{\&}\right)$ and licensing $\left(f_{\&} L / L f_{\&}\right)$ constraints with respect to each other and the faithfulness constraint. The patterns are illustrated below.
(223)
a. C \& C ... (C)
b. (C) ... C \& C
c. (C) ... C C \&
d. \& C C ... (C)
e. C C ... (C) 
I provided an analysis for English, which falls under the pattern in (223b), in Section 3.1.3, and would like to illustrate how the optimality mechanism applied there can be used to account for languages that exhibit the other word order types - and that with the exception of (223d), the patterns predicted by the theory are actually attested. I will begin with the faithful cases (3.2.1 and 3.2.2) and then end the section with an account of the pattern in (223e), in which the conjunction is underparsed (3.2.3).

\subsubsection{C \& C ... (C)}

Sidaamu Afo is an Afro-Asiatic, Highland Cushitic language spoken by 1.4 million people in southern Ethiopia. The language is head-final, and in multiple coordination the conjunction appears after the first conjunct - the anti-English pattern. This is illustrated by the rather complex example below, in which the procedure for making dough is explained.

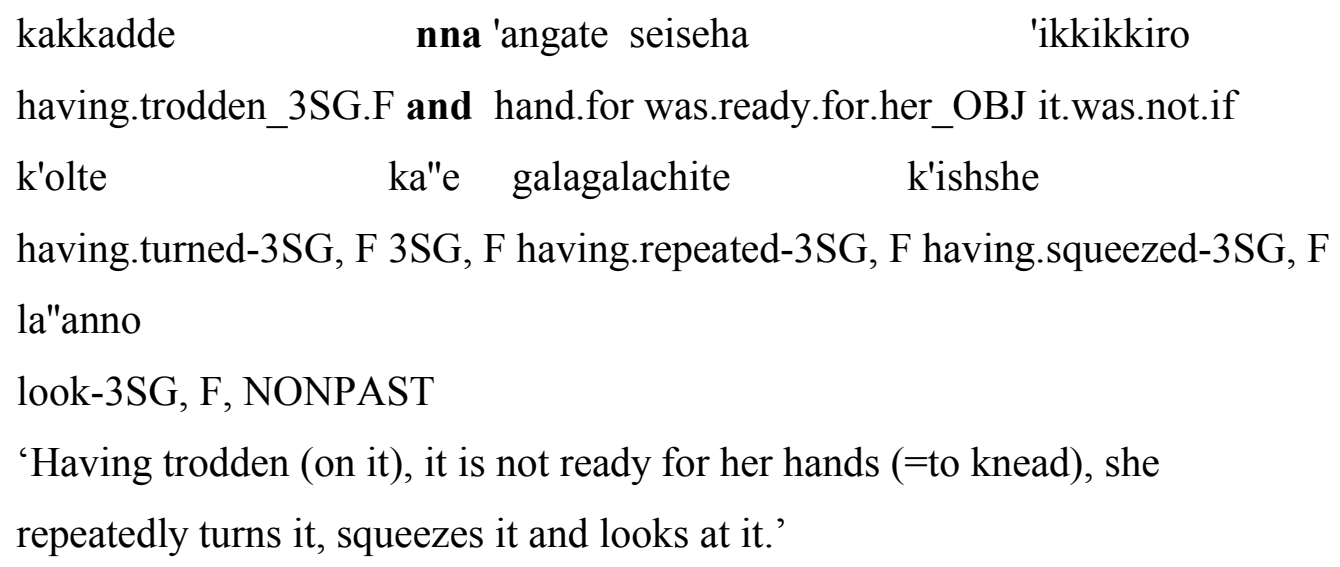

(Johannessen 1998: 37, 71)

According to Johannessen's (1998) informant the presence of the infinitival -te/-de (=3SG.F) suffix on all but the final conjuncts shows that this is an instance of a single case of multiple conjunction of the C \& C C C C schema.

Japanese is a uniformly head final language, and so my theory would predict that in cases of multiple coordination the conjunction appears only after the first conjunct, as in Sidaamu Afo. However, in Japanese such a pattern would be ungrammatical for independent reasons: nominals always need to be followed by a particle. With this restriction in mind, the options are summarized below. 
a. taroo to akiko to miwa to kaori wa kohen ni ikimashita

Taroo and Akiko and Miwa and Kaori TOP park to went

'Taro (and) Akiko (and) Miwa and Kaori went to the park.'

b. taroo to akiko ya miwa ya kaori wa kohen ni ikimashita

Taroo and Akiko PRT Miwa PRT Kaori TOP park to went

'Taro and Akiko as well as Miwa, Kaori went to the park.'

c. *? taroo ya akiko ya miwa to kaori wa kohen ni ikimashita

Taroo PRT Akiko PRT Miwa and Kaori TOP park to went

'Taroo, Akiko, Miwa and Kaori went to the park.'

(Yuko Kitada. p.c.)

The most natural way of multiple coordination in Japanese is to have to inserted between all the conjuncts, and the last one marked for topic or subject status. The meaning of (225a) is ambiguous between dual and multiple coordination. In the case of dual coordination this indicates that only one to is the real conjunction and the others are duplicates serving some morphological function. The question is which is the real one and which are the duplicates. If to is to appear only once, another particle needs to be inserted following all non-final conjuncts. (The final conjunct will be followed by the particle that marks the status of the entire conjunction, subject topic in the cases above.) Crucially, to in this case needs to appear following the initial conjunct, as the contrast between (225b) and (225c) illustrates, indicating that this is the position of the real conjunction.

However, particles do not come along for free: they contribute their meaning. ya is also a connective, indicating a more incidental connection - a meaning between and and with. My informant chose ya as the particle closest in meaning to to. However, other particles could have been chosen for the non-initial and non-final conjuncts, and they would have modified the meaning of the sentence differently.

Though the Japanese data shows interference from other grammatical principles, we can establish the following, anti-English ranking for both Sidaamu Afo and Japanese:

(226) Sidaamu Afo, Japanese: $\mathrm{Lf}_{\&} \gg \mathrm{f}_{\&} \mathrm{~A} \gg \mathrm{f}_{\&} \mathrm{~L}, \mathrm{Af}_{\&}$ 


\subsection{2 (C) ... C C \& and \& C C ... (C)}

Cayuga nominal coordination, already mentioned in Section 3.1.1, also represents a head-final pattern, but in this case the conjunction is placed at the end of the conjoined expression, as mentioned above. (210) is repeated here as (227).

(227) ne:' tshõ: ne' onẽhẽ' sahe'tá hni' õkwayẽthwẽ hne:'

it only the corn beans and we-planted CONTR

'No, we only planted corns and beans.'

(Mithun 1988: 342)

It is possible to capture this ordering by assuming that the dominant constraints do not place conflicting requirements on the placement of the conjuncts with respect to the conjunction and the conjunct immediately before the conjunction acts as its licensor.

(228) Cayuga:

$$
\begin{aligned}
& A f_{\&} \gg f_{\&} A \\
& L f_{\&} \gg f_{\&} L
\end{aligned}
$$

The opposite ranking of constraints would result in a language in which the conjunction precedes all the conjuncts. I have not found such a language. I assume that this is an accidental gap and can see no principled reason why such a possibility should be excluded. The possible rankings for such a language are the following:

(229) Anti-Cayuga:

$\mathrm{f}_{\&} \mathrm{~A} \gg \mathrm{Af}_{\mathrm{k}}$

$\mathrm{f}_{\mathcal{k}} \mathrm{L} \gg \mathrm{Lf} \mathrm{f}_{\mathcal{k}}$

\subsubsection{Asyndetic coordination}

The rankings considered so far have dealt with candidates that were all faithful to the input. There are languages, however, that are unfaithful to the input in terms of coordination: though a sentence clearly conveys the meaning of coordinative conjunction, which implies that the conjunction itself is part of the input, the language lacks any lexical conjunctions - which is known as asyndetic coordination. 
Languages that contain no grammaticized markers of coordination use juxtaposition and intonation to signal conjunction. In some of these languages a particle is used to express disjunction (or) or contrast (but), while in other cases there is no overt disjunction or contrastive marker either, and it is left to the context, verbal forms or adverbials to indicate whether the juxtaposition represents conjunction, disjunction, contrast or even subordination. Kamchadal, a Luoraveltan language spoken in Siberia, Gurung, a Sino-Tibetan language spoken in central Nepal and Kathlamet, a Chinook language in North America are examples of languages with asyndetic coordination.

\section{(230) Kamchadal}

a. nominal

nic pēc qam inxkinkīn

wife son not he-found

'He did not find his wife and son.'

b. verbal ('VP')

Walenn-Sinayéwtanke kólknen, qanay kspensknan kínknen

Walen-Sinanewt-to he-came thus threw-himself seized-her

'He came to Walen-Sinanewt, threw himself on her and seized her.'

c. verbal ('clause')

ktkil-ín lil, ktéwsiknen ína, méyen ína, kétcaknan, she-threw the-line was-taken-up he in such a way he was dried out, kriatqazúknen, knúqzuknen, kneyúqzuknen he became glad, he ate, he became satiated 'She threw down the cord, he was pulled up, dried out, and became happy; he ate, he became satiated.'

(Worth 1961, cited in Mithun 1988: 333-335)

(231) Gurung

a. nominal

jxa:lé yxywí coló pĩ-m

then cape skirt give-NP

'Then (we) give (them) a cape and a skirt.'

(Glover 1974: 210.22, cited in Mithun 1988: 332) 
b. verbal ('clause')

sxĩ-1 xrẽsyo mxi gxrí gxrí aba xrõsa xrõsa-é mró xya:-í birí

houses-EMPH each person one one now self self.of field go-CONJ

xrõsa xrõsa-é mró-r-bae mxa:rsi mlxa-e na: tí-na

self self.of field.in-ADJ marsi rice.of head pluck-DI

'One person from each household went to their respective fields and plucked off their own field a head of marsi rice.'

(Glover 1974: 207, cited in Mithun 1988: 335)

\section{(232) Kathlamet}

a. nominal, subject

quä'nEmîkc tkā'lukc itge'pa, ēexā't Lqagē'lak

five boys went.out one girl

'Five boys and one girl went out.'

b. nominal, object

quä'nEmîkc tkā'lukc tk;ōtk;ī'tkc, aēxā't aqagè'lak iktoxô'tōm

five male dogs one female she.gave.birth.to.them

'She gave birth to five male and one female dogs.'

c. verbal ('VP')

iLō'qumst Lā'qauwulqt nä2ct iō'qctē

he.drank.it their.blood not he.was.satisfied

'He drank their blood and/but he did not have enough.'

d. verbal (clause)

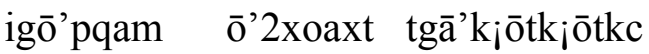

she.came.in there.were her.dogs

'She entered and there were her dogs.'

e. contrastive

môkct LkLEmrna'kc iqō'naxl näcqē iqō'cgam

two months she.was.searched not.at.all she.was.found

'They searched for her for two months, but they did not find her.'

(Boas 1901: 156-161)

For languages that demonstrate asyndetic coordination across the board Johannessen (1998: 86-88) assumes a null-conjunction, i.e. a conjunction marker that is phonologically empty. This is not a very attractive analysis: on what basis would we 
claim that these languages contain coordination particles that never materialize? Indeed, the sole motivation for the assumption was the extension of X-bar Theory to include the conjunction as the head of the conjunction phrase. As pointed out by Borsley (1994), this approach faces numerous empirical and theoretical problems.

Instead of hypothesizing the existence of an element that never materializes in the language, it seems more reasonable to assume that the lack of conjunction is not a lexical gap but a syntactic feature of these languages. This is possible to capture under the present assumptions. Recall that GEN, which prepares the competing candidates from the input data structure, has the power not only to generate all possible permutations of the input elements, but also to underparse input items. Thus from an input consisting of items $[\mathrm{x}, \mathrm{y}, \mathrm{z}]$ GEN will prepare the following candidates.

$\begin{array}{ll}\text { (233) a. } & \mathrm{x} \mathrm{y} \mathrm{z} \\ \text { b. } & \mathrm{x} \mathrm{z} \mathrm{y} \\ \text { c. } & \mathrm{y} \mathrm{x} \mathrm{z} \\ \text { d. } & \mathrm{y} \mathrm{z} \mathrm{x} \\ \text { e. } & \mathrm{z} \mathrm{x} \mathrm{y} \\ \text { f. } & \mathrm{z} \mathrm{y} \mathrm{x} \\ \text { g. } & \mathrm{x} \mathrm{y}<\mathrm{z}> \\ \text { h. } & \mathrm{y} \mathrm{x}<\mathrm{z}> \\ \text { i. } & \mathrm{x} \mathrm{z}<\mathrm{z}> \\ \text { j. } & \mathrm{z} \mathrm{x}<\mathrm{y}> \\ \text { k. } & \mathrm{y} \mathrm{z}<\mathrm{x}> \\ \text { l. } & \mathrm{z} \mathrm{y}<\mathrm{x}> \\ \text { m. } & \mathrm{x}<\mathrm{y}><\mathrm{z}> \\ \text { n. } & \mathrm{y}<\mathrm{x}><\mathrm{z}> \\ \text { o. } & \mathrm{z}<\mathrm{x}><\mathrm{y}> \\ \text { p. } & <\mathrm{x}><\mathrm{y}><\mathrm{z}>\end{array}$

Normally, candidates that include underparsing of an input item do not stand a chance in the grammaticality race, as they violate the PARSE constraint. However, if constraints that impose contradictory conditions are ranked above the faithfulness constraint, the best way to satisfy them both may be to omit an item.

If we rank both the $\mathrm{f}_{\&} \mathrm{~A}$ and $\mathrm{Af}_{\&}$ constraints above PARSE, an unfaithful candidate in which the conjunction functor is underparsed will do better than one which would satisfy either $f_{\&} A$ or $A f_{\&}$ at the expense of violating the other. This is because the 
functees cannot be on both sides of the conjunction at the same time - which is what would be required for the simultaneous faithful satisfaction of these two constraints ${ }^{50}$.

The licensing constraints will be vacuously satisfied in this case - so it is inconsequential where they are ranked with respect to the faithfulness constraint. (Ranking the licensing, rather than the functee constraints above PARSE would not have achieved the same result: placing the two conjuncts on either side of the conjunction would satisfy both licensing constraints.) Underparsing the conjuncts, rather than the conjunction, would not satisfy any of the constraints: this is because constraint violation is being considered from the point of view of the functor, not the functees. (234) shows the ranking for Kamchadal, Gurung and Kathlamet, and (235) shows how the attested pattern is the result of this ranking.

(234) Asyndetic ranking: $f_{\&} A, A_{\&} \gg$ PARSE

$$
f_{\&} L, \operatorname{Lf}_{\&}
$$

\begin{tabular}{|c|c|c|c|c|c|}
\hline $\begin{array}{l}\text { \& functor cycle } \\
{[\&(x, y)]}\end{array}$ & $\mathrm{f}_{\&} \mathrm{~A}$ & $\mathrm{Af}_{\&}$ & Parse & $f_{\&} L$ & $\mathrm{Lf}_{\&}$ \\
\hline x y \& & $\star ! \star$ & $*$ & & $\star$ & \\
\hline$x \& y$ & $\star !$ & $\star$ & & & \\
\hline y x \& & $\star ! \star$ & $*$ & & $\star$ & \\
\hline$y \& x$ & $\star !$ & $\star$ & & & \\
\hline$\& x y$ & $* !$ & $\star \star$ & & & $\star$ \\
\hline$\& \mathrm{yx}$ & $* !$ & $\star \star$ & & & $\star$ \\
\hline x y & & & $*$ & & \\
\hline $\mathrm{yx}$ & & & $*$ & & \\
\hline$\& \mathrm{x}$ & $* !$ & $\star *$ & $*$ & & $\star$ \\
\hline x \& & $\star ! *$ & $*$ & $*$ & $\star$ & \\
\hline$\& y$ & $* !$ & $* \star$ & $*$ & & $\star$ \\
\hline y \& & $* ! \star$ & $*$ & $*$ & $\star$ & \\
\hline $\mathrm{x}$ & & & $* * !$ & & \\
\hline $\mathrm{y}$ & & & $* * !$ & & \\
\hline$\&$ & $* ! *$ & $* *$ & $* *$ & $*$ & $*$ \\
\hline$\varnothing$ & & & $* * ! *$ & & \\
\hline
\end{tabular}

In this section I hope to have demonstrated that the principles developed in Section 3.1 can account for basic coordination patterns attested.

\footnotetext{
${ }^{50}$ Duplicating the arguments on either side of the conjuncts (i.e. $i j$ and $i j$ ) would be another way to satisfy the contradictory constraints at the same time, but I am assuming that GEN does not have the power to add elements to the input (see Section 2.2.1.1). As far as I am aware this seems to reflect the natural situation as natural languages do not reduplicate elements in this way.
} 


\subsection{More complex conjunction patterns}

The goal of this data-heavy section will be to show how the theory developed in the first part of this chapter can account for a wide variety of coordination facts that go beyond the basic coordination patterns discussed so far: when the language has only one morpheme to mark coordination, and when it has none.

In several languages only certain kinds of coordination are overtly marked. In others the marking of coordinating conjunctions is optional. In yet others different kinds of conjunctions are employed for various types of coordination: nominal and verbal, sometimes even distinguishing between different kinds of verbal conjunction. In what follows I will present an analysis of these various possibilities, starting with languages with more than one conjunction marker (3.3.1) and then moving on to partially ascyndetic coordination (3.3.2).

\subsubsection{More than one conjunction marker}

In several languages there is no unitary particle for and. Instead, the form of the conjunction differs depending on the type of conjuncts being coordinated. Most African languages distinguish this way between nominal and event coordination, according to Welmers (1973: 305-306). In this section I will show how the theory developed here can account for coordination phenomena in such languages as well.

\subsubsection{Verbal vs. nominal conjunction}

Besides African languages, Korean is another example of a language that distinguishes between verbal and nominal conjunction in terms of the coordination particle. Korean uses $-(k) w a$ to mark nominal and $-k o$ to mark verbal coordination.

\section{(236) Korean}

a. nominal

yenphil-kwa congi

pencil.and paper

'pencil and paper'

(Martin and Lee 1986: 51) 
b. verbal (full (='clausal'))

Chelswu-ka Seoul-ey sal-ko Yenghuy-ka Pusan-ey sak-n-ta

Chelswu-NOM Seoul.at live.and Yenghuy.NOM Pusan.at live-PRES-DEC

'Chelswu lives in Seoul and Yenghuy lives in Pusan.'

c. verbal (elliptical $\left(={ }^{\prime} V P^{\prime}\right)$ )

John-i cinan tal-ey-nun cip-ul sa-ko taum tal-ey-nun

John-NOM last month.in-CON house-ACC buy.and next month.in-CON sungcinha-n-ta

get.promoted-PRES-DEC

'John bought a house last month and is getting promoted next month.'

(Chung 2001: 1-3)

In none of the languages with different conjunctions, some of which will be reviewed below, did I find a difference in the position of the conjunctions. This suggests that we may view this alteration as an agreement-like feature of the conjunction functor, since verbs with different agreement features also occupy the same position regardless of the value of the agreement. The lexicon contains more than one Vocabulary Item for coordination, the same way as conjugated forms of verbs are stored. The type of conjuncts it selects is part of the lexical specification of the conjunction - similarly to how the lexical entry of a verb carrying an agreement feature would determine the type of argument it can take. This follows from standard Distributed Morphology assumptions, under which the context of insertion is part of the Vocabulary Item of elements. The Korean Vocabulary Items could be the following:

(237) Korean conjunctions

a. $/ \mathrm{kwa} / \leftrightarrow \quad[\quad,+ \text { nominal, }+ \text { nominal }]^{51}$

b. $/ \mathrm{ko} / \leftrightarrow \quad[\quad$, -nominal, -nominal $]$

Under the Late Insertion hypothesis of DM, the appropriate Vocabulary Item is inserted into the expression after the syntactic derivation has taken place and the optimal candidate has been identified. A Vocabulary Item is inserted into an abstract morpheme if the item matches all or a subset of the grammatical features of the morpheme. The Vocabulary of single-conjunction languages, such as English or

\footnotetext{
${ }^{51}$ The $k w a-w a$ alteration is phonologically conditioned allomorphy, so there do not need to be separate Vocabulary Items for $k w a$ and $w a$.
} 
Japanese, includes only one conjunction - with the context of insertion values unspecified. This underspecified Vocabulary Item will be the best fit for the abstract coordination particle regardless of the nature of the conjuncts.

Thus from a syntactic point of view it is inconsequential whether a language has a single conjunction marker or several - as long as the position of these conjunction markers is the same in their string, the syntax has nothing to say about them. Obviously a language where this is not the case would be a problem for this theory which inherently predicts that such a language does not exist. However, I have found no such language in the typological works consulted.

\subsubsection{Subdividing verbal conjunction}

While the contrast between nominal coordination and event coordination is the most widespread - Welmers (1973: 305) says he has not come across any African language that would express nominal and clausal coordination the same way, - there are also languages with even more contrast. In Sissala, a Niger-Congo Voltaic language spoken in Burkina Faso, a distinction is made between sentential coordination (ká), "VP" coordination ( $a$, which is optional) and non-verbal coordination (ri or ari), which includes nominals, numerals and adjectives (Blass 1989).

\section{(238) Sissala}

a. nominal

Plléké rí wowv́lénćré né mvé hé bakse cameleon and spider $\quad$ SDM went put farms

'The cameleon and the spider went and made their farms.'

b. verbal ('VP')

l sısćnyé sıé tok nị (a) mú (a) coki yıбoú ná (a) nyıke (a) you now so take fire (and) go (and) cut mound DEF (and) light (and) бacut yıla viva mound walk-IMP

'You clear the mound place there and burn (the place) and you now form the mounds while walking.' 
c. verbal ('clause')

betúú congoron pérí méćtré belle ká v́ zín má peri kíiló

elephant height reach meters two and his weight also reach kilos

thousand-five

bvi-ammvo

'The height of the elephant reaches two meters and his weight reaches five thousand kilos.'

(Blass 1989: 33-35)

In Nguna, a Melanesian language of the Central New Hebrides, poo conjoins "VPs," while go is used to conjoin nominals as well as clauses (Schütz 1969).

(239) Nguna

a. verbal ("VP")

a ga vano poo tape na-peka seara

I INT go and get yam some

'I'll go and get some yams.'

b. verbal (clause)

te pa-ki varea ke-rua go tam-na e togo na-taleo-na

he go.to branch second and father.his he hear voice.his

'He went to the second branch and his father heard his voice.'

c. nominal

e pei na-vinaga go suu-goro

it be food and clothing

'It was food and clothing.'

(Schütz 1969: 49-50)

Sissala and Nguna could be problematic for the present theory in as much as they differentiate between "VP" and "clausal" coordination, while in the present framework all non-nominal coordination is treated as clausal coordination with ellipsis, in which the verbal predicates are the functees of the conjunction.

There is, however, a way to account for the Sissala and Nguna distinction within the present framework. What distinguishes "VP" and clausal coordination is a shared 
subject. Only when the two verbal conjuncts share a subject are both "VP" and clausal coordination possible:

(240) a. John came in and John sat down

b. John came in and sat down

In fact, Blass (1989: 38) reports that Sissala "VP" coordination (with $a$ ) and "clausal" coordination (with $k a$ ) are sometimes interchangeable: when "clausal" coordination is chosen instead of "VP" coordination "the effect is generally to suggest that there is something unusual, unexpected or particularly significant about the events described in the second conjunct." She goes on to say that "ká and S coordination is used when the activity takes a different turn from the way things went before" (Blass 1989: 46). This suggests that the coordination particle can carry more meaning than simply marking coordination ${ }^{52} . k a ́$ is used when the events are unexpected, while $a$ is used when they are expected. However, when the subjects of the two conjuncts are different, "VP" coordination is impossible, so ká must be used regardless of whether the meaning of the second conjunct is an expected outcome of the first conjunct or not. This does not mean, though, that $k a$ cannot be thought of as a marker of unexpected turn of events. Languages often make use of a word that exists in their lexicon to mean something they do not have a lexical item for. Reinhart and Reuland (1993) point out that in English, which has no logophoric pronouns, the anaphoric pronouns double up as markers of (non-anaphoric, i.e. free) logophoricity.

(241) if you fail the exam, please come to see John and myself

Similarly, we can think of $k a ́$ as standing in as the default verbal coordinator even when there is no element of surprise in the sentence. Of the four input possibilities summarized below, $a$ will be the best fit for the conjunction in (242a) only, while $k a$ will be the matching Vocabulary Item in the other three cases. Since the unexpected outcome is part of the (pragmatic) meaning, it will have to be marked in the input. I have chosen to mark this as a feature of one of the predicates, but it is not important for the purposes of the present discussion how such a feature gets marked.

\footnotetext{
${ }^{52}$ This is not unusual. In Pitjantjatjara, an Australian language of the Western Desert Group, the referential properties of the subjects of coordinated clauses are marked by the coordination particle. As pointed out by Bowe (1990: 96) $k a$ is used when the second conjunct has a subject that differs from the previous one, while типи is used when the subjects are the same. This represents semantic content in the conjunctions over and above their roles as coordinators.
} 
(242) a. shared subject, expected outcome $(\rightarrow a)$

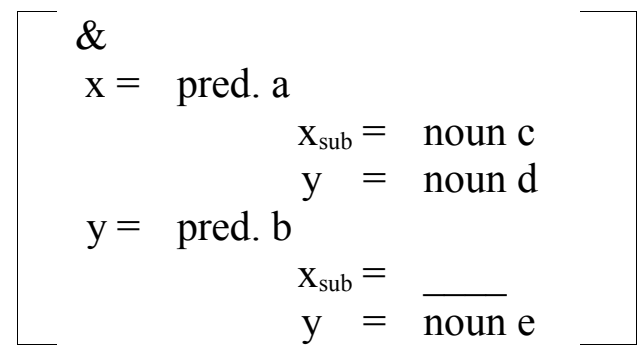

b. shared subject, unexpected outcome $(\rightarrow k a ́)$

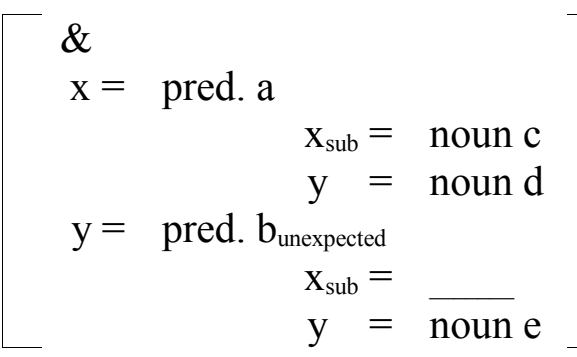

c. different subjects, expected outcome $(\rightarrow k a ́)$

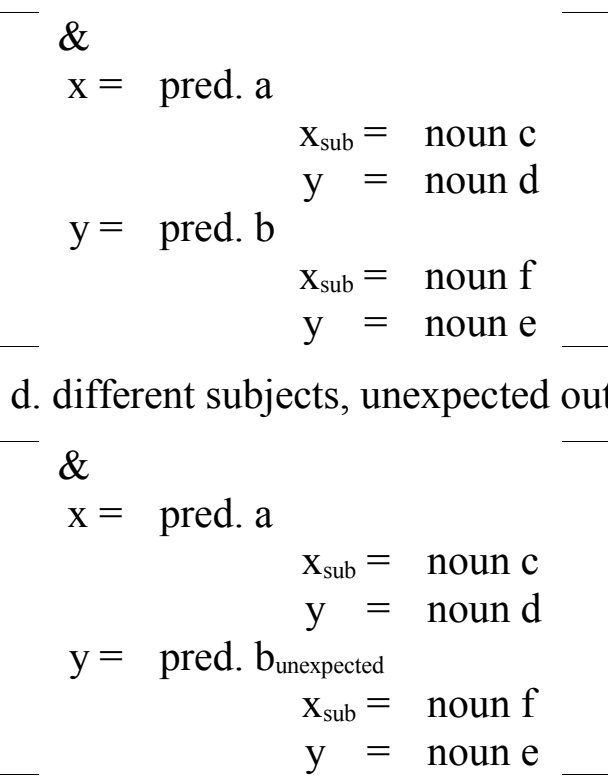

The Vocabulary Items for the conjunctions are in (243) below. (a) ri is inserted when the insertion context is specified for nominal conjuncts. $a$ is inserted when the conjuncts are non-nominal, one of them lacks a subject and one is the expected outcome of the other. $k a$, specified simply as the conjunction for non-nominal conjuncts, is inserted in all other cases, thanks to the Subset Principle of DM, which states that the 'best fit' Vocabulaty Item is chosen in each case, provided that it does not contain features or context specification that are not present in the morpheme. As the conjuncts for $a$ are specified more fully, $k a ́$ acts as default for verbal coordination. 
(243) Sissala conjunctions
a. $/(\mathrm{a}) \mathrm{ri}^{\prime} /{ }^{53} \leftrightarrow \quad\left[\quad,+\right.$ nominal, + ${ }^{+}$nominal $]$
b. $/ \mathrm{a} / \leftrightarrow$ , -nominal, -nominal/no subject; -unexpected]
c. $/ \mathrm{ká} / \leftrightarrow$ ,-nominal, -nominal]

Nguna can be handled similarly: the environment in which poo is used is fully defined, so go will be selected in all other cases per the Subset Principle.

\section{(244) Nguna conjunctions}

a. $/ \mathrm{poo} / \leftrightarrow$ [__ , - -nominal, -nominal/no subject $]$

b. $/ \mathrm{go} / \leftrightarrow$<smiles>[3H][AlH2][AlH2]</smiles>

In both of the languages discussed in this section there was a distinction between full and elided predicates - which could be taken as an argument against the ellipsis approach adopted here, in which no distinction is made between "VPs" and clauses. However, it turns out that the "VP"/"clause" distinction is just one among several possibilities when it comes to the use of verbal conjunctions - so actually turns into an argument in favor of a theory in which all non-nominal coordination is treated as clausal. In Yoruba, spoken in southwestern Nigeria and Benin, verbal conjunction is subdivided between relative clauses and other verbal conjuncts: àti is used for nominal coordination, $t i$ for the coordination of relative clauses and si for other verbal conjuncts.

\section{(245) Yoruba}

a. nominal
émi àti Kéhìndé
I and Kéhìndé
'Kehinde and I'

\footnotetext{
${ }^{53}$ There is a further pragmatic difference between $r i$ and ari, but it is not relevant for the discussion here: ari is used when the interpretation is and/with (Blass 1989: 40).

${ }^{54}$... means that the context is not specified - i.e. the Vocabulary Item can appear in any context (in which it is the best fit).
} 
b. verbal (relative clauses)

epo ni mo n-rà tí mo tún n-tà

palm.oil FOC I PROG-buy and I repeat PROG-sell

'It is palm oil that I buy and in turn sell.'

c. verbal (other)

ó mú mi l' ára dá, èmi kì yió sì gbàgbé

he cause me in body well I NEG FUT and forget

'He caused me to get better and I shall not forget.'

(Rowlands 1969: 201-203)

The relevant Yoruba Vocabulary Items are below. The definition for $t i$ states that there exists a nominal item $i$ (outside the coordination) and both the predicate conjuncts include $i$ in an argument slot. Note, that this definition excludes shared subjects of a "VP"-coordination, since under the present approach such an expression is analyzed as a full predicate (="clausal") coordination with ellipsis. As such it contains no independent nominal element outside the coordination, so ti will be context overspecified and sì will be 'best fit' Vocabulary Item.

(246) Yoruba conjunctions
a. /àti/ $\leftrightarrow$
[__ , + nominal, +nominal $]$
b. $/$ tí/ $\leftrightarrow$
$\left[+\right.$ nominal $_{i}$; , - nominal $_{(\ldots, \mathrm{i}, \ldots)},-$ nominal $\left._{(\ldots, \mathrm{i}, \ldots)}\right]$
c. $/ \mathrm{sì} / \leftrightarrow$ ,-nominal, -nominal]

In the light of the Yoruba data the distinction between "VP" and "clausal" verbal coordination in Sissala and Nguna is just one of several subdivisions to differentiate between types of verbal coordination, and the distinction simply happens to coincide with the phrase structure notions of the VP and the clause. An ellipsis account of coordination within the present framework is capable of handling this distinction without making specific references to the "VP" as a conjunct.

\subsubsection{Partially asyndetic coordination}

So far I have reviewed, and provided analyses for, languages that are at the two extreme ends of the coordination marking scale: asyndetic coordination, where conjunction is never marked, versus languages in which conjunction is always marked 
by a particle - be it a uniform particle across the language or a different one depending on the type of conjunction. In this section I will review languages that are between these two extremes.

\subsubsection{NP coordination marked}

In Cayuga, which I used as an example of the [C C \&] pattern in Section 3.2.2, only nominal coordination is marked. Verbal elements are connected via juxtaposition.

(247) Cayuga

a. nominal

ne:' tshõ: ne' onẽhẽ' sahe'tá hni' õkwayẽthwẽ hne:'

it only the corn beans and we-planted CONTR

'No, we only planted corns and beans.'

b. verbal

tho thsõ: nhe:yóht ake'tré' atká:ta'

there only so it is I-drove it-stopped

'I was just driving along and it (=the car) stopped.'

(Mithun 1988: 342)

In Vai, a northern Mende language spoken on the north-western coast of Liberia and in Sierra Leone, nominal expressions are conjoined by bé (='and'). Elliptical verbal predicates (i.e. 'VP's) are conjoined by juxtaposition. ámù may optionally be used as a clausal connective, but Welmers (1976) suggests that is an adverbial rather than a conjunction. I will return to the issue of optional clausal conjunctions, including ámù in Vai, in the next section.

Vai, nominal

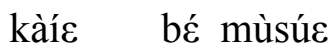

man.the and woman.the

(Welmers 1976: 72)

This pattern, according to Welmers (1973), is rather typical for West African and Bantu languages, where conjunction marking of anything but NP coordination is the exception rather than the rule. 
I see two possible treatments within the theory presented here. One option is to treat these languages similarly to Sissala and Nguna (3.3.1.2), and assume that the Vocabulary Item that is the best fit conjunction marker in the ascyndetic cases is a null lexical item. This is a common approach in DM. In the section on ascyndetic coordination I rejected the assumption that languages like Kamchadal, Gurung and Kathlamet include a null Vocabulary Item as their conjunction on theoretical grounds: there appeared to be no empirical, theory-external motivation for the existence of a conjunction particle in the language. In case of partially ascyndetic coordination the null item assumption is less problematic: we do have evidence that these languages make use of a coordinating conjunction ${ }^{55}$. Thus languages in which only nominal coordination is marked would be treated the same way as those in which different conjunction particles exist for nominal and verbal coordination:

Cayuga conjunctions
a. /hni'/ ↔ , +nominal, +nominal]
b. $\varnothing \leftrightarrow$ , -nominal, -nominal]

(250) Vai conjunctions
a. /bé/ $\leftrightarrow$
[__ , + +nominal, +nominal $]$
b. $\varnothing \leftrightarrow$ ,-nominal, -nominal]

A potential alternative is to suppose the existence of separate nominal and verbal conjunction functors and assume that the constraints relativize to these two elements. The corresponding constraints could then be differently ranked with respect to PARSE. In Cayuga and Vai, the verbal conjunction functee constraints would be ranked above PARSE, while the nominal functee constraints would be ranked below it. Thus, for Cayuga, for instance, the ranking of the constraints would be as in (251).

$$
\begin{aligned}
\text { Cayuga: } & \mathrm{Af}_{\& \mathrm{~V}}, \mathrm{f}_{\& \mathrm{~V}} \mathrm{~A} \gg \mathrm{P}_{\text {ARSE }} \gg \mathrm{Af}_{\& \mathrm{~N}} \gg \mathrm{f}_{\& N} \mathrm{~A}, \mathrm{Lf}_{\& \mathrm{~N}}, \mathrm{f}_{\& N} \mathrm{~L} \\
& \mathrm{Lf} \mathrm{f}_{\& \mathrm{~V}}, \mathrm{f}_{\& \mathrm{~V}} \mathrm{~L}
\end{aligned}
$$

\footnotetext{
${ }^{55}$ Newson (2002: 114), without using Late Insertion, reaches the same conclusion for Chinese clausal conjunction, based on data that Chinese has no conjunctive coordination particle for clauses, but it does have a disjunctive coordination particle. I will return to coordination other than conjunction in Section 3.6 below.
} 
The problem with relativizing the constraints this way (quite apart from a lack of independent motivation) is that once we suppose different conjunctions for verbal and nominal conjunction we open up the possibility for rankings in which all eight are ranked below PARSE, but in which the relative ranking of the $\&_{\mathrm{V}}$ constraints is different from that of the $\&_{\mathrm{N}}$ constraints. In such a language nominal and verbal conjunctions would behave differently, with nominal conjunctions appearing behind the conjuncts, while verbal conjunctions appearing in between them, for instance. I have come across no such language in the typological works consulted: the conjunct's type never seems to affect the syntactic behavior/alignment requirements of the conjunction particle.

Thus the approach assuming a zero Vocabulary Item in case of languages with partially ascyndetic coordination is more attractive.

\subsubsection{Clausal coordination marked}

At the beginning of the $20^{\text {th }}$ century Mohawk, spoken in northern New York state, Ontario and southern Québec, made use of what is often seen as conjunction for clausal coordination ${ }^{56}$.

(252) Mohawk

a:ke ne tsi náhe' watyakv́: ${ }^{?} v$, tanũ' katũhkárya'ks

oh the so long I was out and I am hungry

'I was out a long time and I am hungry.'

(Mithun 1988: 347)

Mithun (1988: 344) argues that markers used to conjoin clauses only should not be treated as conjunctions, but as discourse particles or adverbials like 'then' or 'so.'

These adverbials connect clauses and imply a temporal and/or causal relationship. Crucially, unlike in coordination, the order of the two clauses is fixed. The many West African and North American languages that do not mark nominal or "VP"

\footnotetext{
${ }^{56}$ Under what Mithun (1988) attributes to the influence of English and French, the use of conjunction particle has since spread to nominal and bare verbal coordination as well.

i. $\quad$ o'wà:rũ tanũ' osahè:ta wakekhũ:ni

meat and beans I food.make

'I'm cooking meat and beans.'
}

(Mithun 1988: 350) 
coordination but have been seen as including an optional conjunction for clausal coordination could under this view be treated as languages with no conjunction at all.

This is the position taken by Bogoras (1922), who provided the first written grammars for many of these languages. In describing American Indian languages he gave up on distinguishing between clausal conjunctions and adverbials: "I give a list of adverbs and conjunctions without attempting to differentiate between the two groups. The meaning of many of the adverbial or connective particles is so uncertain that a division seems hardly possible" (Bogoras 1922: 849).

Welmers (1976) points out that the optional particle used to conjoin sentences in the West African Vai language cannot be translated simply as and but it "seems to primarily convey the idea of 'and then', 'and so"' (Welmers 1976: 128). The marker ámù is in fact derived from àwá mù (= 'it is it'), referring to the previous predication, which further indicates that "its very use constitutes parataxis at least in the underlying structure" (Welmers 1976: 129).

We can conclude then, that our grammar does not need to distinguish languages in which only clausal coordination is marked from languages in which coordination is not marked at all. Because these particles are not conjunctions, there is no difference between the two types of languages as far as coordination is concerned. The particles would of course still need to be accounted for in the grammar, but that would necessitate the development of a treatment of adverbials and discourse markers. What is important for us at this point is that these markers are not conjunction functors.

This distinction also means that we can uphold our own assumption about clausal and "VP" coordination being the same - since in our theory in both cases it is the verbs that get coordinated by being the arguments of the conjunction. If the connective elements are sentence/discourse adverbials, it is the behavior of those adverbials that will explain why they may not be used in elliptical coordination cases.

\subsubsection{Nominal, clausal coordination marked}

The last case I will discuss is that of Sacree, an Athapaskan language spoken in Alberta. In this language "VP" coordination is obligatorily unmarked, with the two 
conjuncts simply juxtaposed. Nominal coordination is marked, and clausal coordination is optionally marked with the same conjunction $i h$, reports (Cook 1984).

(253) Sacree, nominal

tcágúá k’ìyìdjí ìstlá ká-àhílà kàdīlá-là

weasel coat legging shoe.and he.brought.out

'He brought out weasel coats, leggings and shoes.'

(Cook 1984: 87)

When used to conjoin clauses, $i h$ is affixed to $m i-$, a third person singular specified marker referring to the preceding clause, and yielding the combination $\mathrm{mih}$. Its use is optional, as clauses can be coordinated with simple juxtaposition only.

(254) Sacree, clausal

tcúwa mih nánìstlús-í nínádìstlò

wait it with I-sew-NOML0 I-go-get

'Wait and I'll go get what I was sewing.'

(Cook 1984: 97)

The difference between Sacree on the one hand and Cayuga and Vai on the other is that in Sacree the conjunction marking nominal coordination and the optional adverbial joining clauses are the same. Cook (1984) remarks that the conjunction originated as a comitative/instrumental preposition - but has grammaticized. Conjoined nominals trigger plural verb forms, indicated by the lá particle in (253), which means 'to handle plural objects.' The plural verb form indicates that the nominals are indeed coordinated. ih means both with and and, so it is plausible to assume that it functions as a sentence adverbial when optionally used as a clausal connective $^{57,58}$. Thus we have reduced Sacree to the Cayuga/Vai case with the following Vocabulary Items:

\footnotetext{
${ }^{57}$ I do not regard comitative/instrumental constructions used to circumvent coordination as cases of coordination. Dyirbal, for instance, has a similar construction for the expression of two NP subjects. (For examples and discussion, see Dixon 1972: 62.) Jacaltec, a Mayan language from Guatemala, also circumvents coordination with the use of with (Craig 1977: 32, cited in Mithun 1988: 338).

${ }^{58}$ Why $i h$ cannot be used as a sentential adverbial in "VP" coordination needs to be explained. One possible assumption is that $i h$ cannot be used in elliptical cases. Whether such an assumption is plausible depends on the behavior of other adverbials in Sacree, an issue that is not discussed either by Cook (1984) or descriptive grammars of the language I have found.
} 
(255) Sacree conjunctions
a. $/ \mathrm{ih} / \leftrightarrow$
,+nominal, +nominal]
b. $\varnothing \leftrightarrow$ , -nominal, -nominal]

This concludes the cross-linguistic survey of the placement of the conjunction. I hope to have demonstrated that the theory developed here can account for conjunction placement facts in a wide variety of languages.

\subsection{Coordination introducers}

Coordination introducers are adverb particles that contribute some additional meaning to coordination. In European languages they typically precede the coordinating construction, which is why they have traditionally been called coordination introducers or initial conjunctions.

The coordination introducer both has been problematic for XP analyses of coordination, in which the specifier of the conjunction phrase is occupied by the first conjunct (Johannessen 1998) or where it is the coordination introducing particle itself that is in this position, with both conjuncts sitting as daughters of Conj' on either side of the conjunction head (Rothstein 1991). As pointed out by Borsley (1994: 240) the coordination introducer does not form a constituent with the first conjunct under either approaches. Since in X-bar Theory distribution facts are explained on the basis of constituency, this is a problem for these analyses.

While this particular problem does not need to concern us here, the other criticism noted by Borsley does: that coordination introducers are in some languages identical to conjunctions - a strong indication that they, too, should be analyzed as no different from the conjunction, heads under both Johannessen's and Rothstein's analysis.

(256) a. Polish

$$
\begin{aligned}
& \text { i Jan i Jerzy widzeli Marię } \\
& \text { and Jan and Jerzy saw-M, PL Marię } \\
& \text { 'Both Jan and Jerzy saw Mary.' }
\end{aligned}
$$

(Borsley 1994: 241) 
b. Latin

et ego et Cicero meus flagitabit

and I and Cicero my will.demand-3SG

'Both I and my Cicero will demand (it).'

c. Greek

ke egho ke o petros to thelume

and I and the Petros it want-1PL

'Both Peter and I want it.'

(Johannessen 1998: 91)

\section{d. French}

et Jean et Marie sont allés au parc

and Jean and Marie were-3PL gone to the park

'Both John and Mary have gone to the park.'

The data above indicate the presence of two conjunctions. This led Newson (2002) to argue that conjunctions mark the coordinated status of the conjuncts and not the coordination itself. (Zwart (1995) arrives at the same conclusion within a phrasestructure based model.) Under this analysis, the ranking of the constraints ensures that in languages like English only the last conjunct carries this coordination marking, while in Polish and French both conjuncts would.

A problem with this analysis, as Newson (2002) himself points out, is that these constructions are not ordinary conjoined expressions; in all of these cases coordination is emphatic. In all four languages neutral coordination is expressed by a single conjunction placed between the conjuncts, just like in English.

In none of the typological works on coordination have I come across a language that marks normal coordination this way, which is a problem for Newson's account, which predicts $[\& \mathrm{a} \& \mathrm{~b}]$ and $[\mathrm{a} \& \mathrm{~b} \&]$ patterns. In contrast, the input assumptions and the constraints responsible for the placement of the conjunction particle introduced here do not predict the unattested $[\& \mathrm{a} \& \mathrm{~b}]$ and $[\mathrm{a} \& \mathrm{~b} \&]$ patterns.

Since the languages that exhibit this phenomenon have normal coordination as well, and the meaning of conjunctions with coordination introducers slightly differs from 
unmarked cases, the expressions with coordination introducers must be related to different inputs than their respective versions without the first instance of the conjunction. Having a coordination introducer in the input is simply an option for languages - and in some languages this coordination introducer is a different word such as both, while in others it is identical to the conjunction. This identity can be regarded as coincidental, especially when considering that in Hungarian the coordination 'introducer' is identical to the particle meaning as well or too, not and, and it appears after both conjuncts - with the conjunction particle also retained ${ }^{59}$.

(257) János is és Mari is fára másznak

János too and Mari too tree-on climb-3PL

'Both John and Mary are climbing trees.'

In the case of the coordination introducer 'either...or' Hungarian behaves similarly to the languages illustrated in (256): the coordination introducer in this case is another instance of the disjunction particle:

vagy János vagy Mari mászik fára

or János or Mari climbs tree.on

'Either John or May is climbing trees.'

This contrast is a problem for an analysis in which coordination introducers are treated as a conjunction particle in some languages and as a separate adverbial in others. However, the present approach, in which the identity of the coordination introducer and the conjunction in languages like French and Polish is coincidental, does not face this problem: the Vocabulary Item for the conjunctive coordination introducer is different from the conjunction, while the Vocabulary Item for the disjunctive coordination introducer happens to be identical with the disjunctive marker.

\footnotetext{
${ }^{59}$ In formal style (and in grammar books) Hungarian has a specific coordination introducer - different both from and and $o r$.

i. mind János mind Mari fára mászik

both János both Mari tree-on climb-3sg

'Both John and Mary are climbing trees.'

The existence of correlative conjunctive coordinators that are both different from the normal conjunction would further support the view that coordination introducers are best not to be treated as conjunctions. It is a further complication that the normal conjunction is missing from such correlative coordinations. In fact, in (very) formal style the conjunction can be left out even in simple coordination: ii. János, Mari fára másznak
} 
What at first sight seemed a theoretically weak point in the analysis turns out to be advantageous: if there were a systemic reason for both to be the same as and in certain languages, the fact that in Hungarian either is the same as or but both differs from and would require a special explanation ${ }^{60}$. Under the current approach, Late Insertion would account for the shape of the coordination 'introducer' in each language.

Note also that while discussion in the literature of these double conjunction constructions typically concerns nominal coordination, the $[\&$ a $\&$ b] pattern is not restricted to this environment, as the spoken French examples in (259) illustrate. This shows a further similarity with independent coordination introducers like both, which can introduce any type of coordination, as the grammaticality of the glosses indicates.

(259) a. et Jean et Marie grimpent dans les arbres and Jean and Marie climb-3PL in the-PL trees

'Both John and Mary are climbing trees.'

b. je suis et parti et revenu jeudi i am and left and returned Thursday

'I both left and returned Thursday.'

c. il est quatre heures: et Jean est parti au parc et Marie est revenue de it is four hours: and Jean is left to.the park and Marie is returned from l'école the.school

'It is four o'clock: both John has left for the park and Mary has returned from the school.'

(Marie-Eve Sévigny, p.c.)

The presence of coordination introducers to mark emphatic nominal coordination in northeastern Australian Dyrbal also lends support to my analysis. Dyrbal is asyndetic both for verbal (260) and neutral nominal (261) coordination, so it would be problematic to treat as conjunctions the optional, symmetric coordination particles -gara, which follow each conjunct in the case of what Dixon (1972) calls emphatic coordination (262).

\footnotetext{
${ }^{60}$ This advantage is not available to XP accounts. In these accounts the notion of phrase is crucial, and so it remains problematic that the coordination introducer does not form a phrase with the first conjunct. This problem becomes void in an analysis that does not operate with phrases, such as the present one.
} 
(260) verbal

a. yad,a bayi yara balgan walmbin baygun d,ilwan

I NOM man hit lift threw kick

'I hit the man, lifted him up, threw him down and kicked him.'

b. bayi yara bangul gubingu mundane (bayi) (yara) baygun d,ugumbiru balgan NOM man ERG gubi brought NOM man ERG woman hit

'The man was brought here by the gubi and (he) was hit by the woman.'

(Dixon 1972: 73, 154)

(261) nominal

balan d,ugumbil baygul yarangu gigan bagun

THERE-NOM-II wOMan-NOM THERE-ERG-I man-ERG tell-PRES/PAST THERE-DAT-II

bunigu bagun nayinbagu

fire_DAT THERE-DAT-II girl-PL-DAT

'Man told woman to concern herself with the fire and the girls.'

(Dixon 1972: 76)

(262) nominal, emphatic subject ${ }^{61}$

a. bayi yaragara balan d,ugumbilgara baninu

NOM man-one-of-a-pair NOM woman-one-of-a-pair come

'Both the man and the woman are coming.'

(Dixon 1972: 62)

Distribution of both also provides evidence against a treatment of the particle as a special conjunction or even as a coordination introducer - in the literal sense.

(263) a. both John and Mary left

b. John and Mary both left

c. both the men left

d. the men both left

e. that both John left and Mary arrived is obvious

f. that John left and Mary arrived are both obvious

\footnotetext{
${ }^{61}$ Dixon (1972) is not explicit on the position of emphatic coordination. However, the examples of
} -gara coordination in his book are all in subject position. 
The optionality between (263a) and (263b) suggest that the coordination introducer is not necessarily the left-most element in the coordinate string, i.e. it does not necessarily introduce the coordination or the first conjunct. The grammaticality of (263c) and (263d) shows that the appearance of both is not necessarily related to coordination. The contrast in verb forms between (263e) and (263f) indicates that both may modify one conjunct or the coordination of the conjuncts.

To sum up then, there is plenty of cross-linguistic data to support the claim that coordination introducers are not conjunctions, but adverbials that are included in the input to convey emphasis. Their form is independent from the form of the conjunction. (264b) below is the input for (264a).

(264) a. both John arrived and Mary left

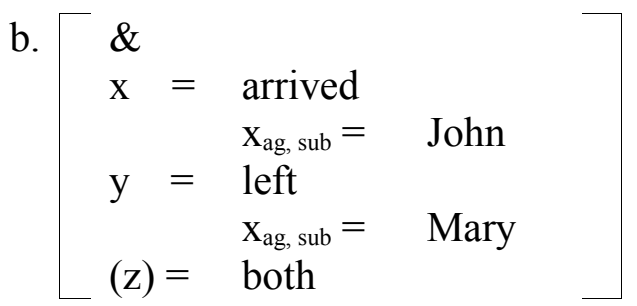

Though the treatment of adverbials is beyond the scope of this thesis, we can assume for now that the placement of both is regulated by an ADvf \& constraint. As long as this constraint is ranked lower than $\mathrm{Af}_{\&}$ both will have to make do with the second best position - in front of the first conjunct, which will be the left edge of the conjoined expression. Both is not an argument of the functor (hence it is in brackets in the input), and as such it cannot license it. However, as a dependent of the superordinate functor, it is placed during the superordinate functor cycle.

The superordinate functor cycle is shown in (265), where the candidates are shorthand candidates representing candidates that do not differ in the placement of the elements at the focus of this cycle: the functor and its immediate dependents. 


\begin{tabular}{|c|c|c|c|c|c|c|c|}
\hline \multirow[t]{14}{*}{$(265)$} & \& functor cycle & $\mathrm{f}_{\&} \mathrm{~L}$ & $\mathrm{Af}_{\&}$ & $\mathrm{ADVf}_{\&}$ & $\mathrm{Lf}_{\&}$ & $\mathrm{f}_{\&} \mathrm{~A}$ & $\mathrm{f}_{\&} \mathrm{ADV}$ \\
\hline & $\operatorname{arrived}_{[\text {Mary] }}$ left $f_{\text {John] }}$ both \& & 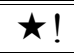 & **** & & * & $\star \star \star$ & $\star$ \\
\hline & $\operatorname{arrived}_{[\text {Mary }}$ left $_{[\mathrm{John}]} \&$ both & $\star !$ & $*$ & $\star$ & & $\star \star$ & \\
\hline & $\operatorname{arrived}_{[\text {Mary] }}$ both left [John] $\&$ & $\star !$ & ** & $*$ & & $\star \star$ & $\star$ \\
\hline & $\operatorname{arrived}_{[\text {Mary }]}$ both \& left ${ }_{[\mathrm{John}]}$ & & $\star * !$ & & * & $\star$ & $\star$ \\
\hline & $\operatorname{arrived}_{[\text {Mary }]} \&$ both left ${ }_{[\mathrm{John}]}$ & $* !$ & $\star$ & $\star$ & & $* \star$ & \\
\hline & arrived $_{[\text {Mary }]} \&$ left $_{[\text {John] }}$ both & & $\star$ & $\star !$ & & $\star$ & $*$ \\
\hline & left $_{\text {[John] }} \operatorname{arrived}_{[\text {Mary] }}$ both \& & $\star !$ & $* * *$ & & * & $\star \star$ & $\star$ \\
\hline & left $_{[\text {John] }} \operatorname{arrived}_{[\text {Mary] }} \&$ both & $\star !$ & * & $\star$ & & $\star \star$ & \\
\hline & left $_{\text {[John] }}$ both arrived ${ }_{[\text {Mary] }} \&$ & $\star !$ & $* *$ & $*$ & & $\star \star$ & $\star$ \\
\hline & left $_{\text {[John] }}$ both \& arrived $[$ Mary] & & $\star * !$ & & * & $\star$ & $\star$ \\
\hline & left $_{\text {[John] }} \&$ both arrived ${ }_{[\text {Mary] }}$ & $* !$ & $\star$ & $\star$ & & $* \star$ & \\
\hline & left $_{[\mathrm{John}]} \& \operatorname{arrived}_{[\text {Mary }]}$ both & & $\star$ & $\star !$ & & $\star$ & $*$ \\
\hline & both left $_{\text {[John] }}$ arrived ${ }_{[\text {Mary] }} \&$ & $\star !$ & $*$ & $* *$ & & $\star \star$ & $\star$ \\
\hline \multirow[t]{2}{*}{ 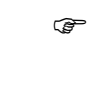 } & both left $_{[\mathrm{John}]} \&$ arrived $[$ Mary] & & $\star$ & $*$ & & $\star$ & $\star$ \\
\hline & both arrived $_{[\text {Mary] }}$ left $_{\text {[John] }} \&$ & $\star !$ & $*$ & $* *$ & & $\star \star$ & $\star$ \\
\hline \multirow[t]{9}{*}{ 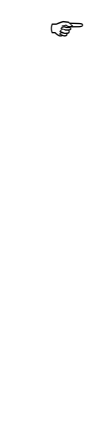 } & 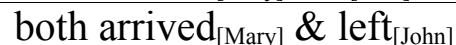 & & $\star$ & * & & $\star$ & $\star$ \\
\hline & both $\&$ arrived ${ }_{[\text {Mary] }} l_{\text {eft }}[$ John] & & $\star \star !$ & & $\star$ & $*$ & $\star$ \\
\hline & 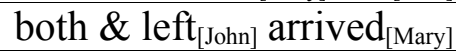 & & $\star \star !$ & & $\star$ & $*$ & $\star$ \\
\hline & $\&$ left $_{[\mathrm{John}]}$ both arrived $_{[\text {Mary] }}$ & & $\star \star !$ & $\star$ & $\star$ & $* *$ & $*$ \\
\hline & \& left ${ }_{[\mathrm{John}]} \operatorname{arrived}_{[\text {Mary] }}$ both & & $\star \star !$ & $\star$ & $\star$ & $*$ & $* *$ \\
\hline & \& both left ${ }_{[\mathrm{John}]} \operatorname{arrived}_{[\text {Mary] }}$ & $* !$ & $\star \star$ & $\star$ & $\star$ & $* * *$ & \\
\hline & \& both arrived $\left[\right.$ Mary] ${ }$ left $_{[\mathrm{John}]}$ & $* !$ & $\star \star$ & $\star$ & $\star$ & $* * *$ & \\
\hline & $\&$ arrived $_{[\text {Mary] }}$ both left $_{[\mathrm{John}]}$ & & $\star \star !$ & $\star$ & $\star$ & $* *$ & $*$ \\
\hline & $\& \operatorname{arrived}_{[\text {Mary }]} \operatorname{left}_{[\mathrm{John}]}$ both & & $\star \star !$ & $\star$ & $\star$ & * & $* *$ \\
\hline
\end{tabular}

Once the subordinate functor cycles have placed the subjects with respect to their predicates, the following candidates will emerge as optimal:

(266) a. both John arrived and Mary left

b. both Mary left and John arrived

Since there is no semantic difference between them this is the correct prediction.

\subsection{Multiple conjunction}

Another potential problem for the analysis presented here is the presence of more than one conjunction in multiple coordination (267b).

(267) a. John, Mary and Peter are climbing trees

b. John and Mary and Peter are climbing trees 
If the conjunction can optionally surface more than once my analysis would need to be revised. However, as pointed out by Borsley (1994: 233-239), and applied to an OT alignment account by Newson (2002: 106-107), (267a) and (267b) have a different structural organization: multiple coordination particles mean multiple coordinations.

(268) a. John wrote the letter, Mary posted it and Bill received it on Tuesday b. John wrote the letter and Mary posted it and Bill received it on Tuesday

(268a) is two ways ambiguous, with the time adverbial either modifying all of the conjuncts or only the last one. The interpretation that John wrote the letter, say, on Monday and that on Tuesday Mary posted it and Bill received it is not available. Such an interpretation, however, is possible with (268b). The last two conjuncts can be interpreted as a semantic unit, indicating that they form a conjoined expression. The first and coordinates this conjoined expression with the first conjunct. Embedding the other way is also possible. Under this interpretation the second instance of and coordinates the last conjunct with the conjoined expression formed from the first two. In (269) the time adverbial may modify the first or the second conjunct:

(269) John wrote the letter and Mary posted it on Tuesday and Bill received it on Wednesday

If different interpretations are available to coordinations with one and two instances of the conjunction marker, the difference needs to be reflected in the input. The inputs corresponding to (268b) and (269) contain two instances of the conjunction functor and the ambiguity arises depending on which conjunction functor is embedded under the other one. The inputs are illustrated in (270), following Newson (2002: 107).

(270) simplified inputs for (268b)

a. $\left[\begin{array}{lll}\& & & \\ \mathrm{x}= & \text { wrote } & \\ & \ldots & \\ \mathrm{y}= & \& & \\ & \mathrm{x}= & \text { posted } \\ & \ldots \\ & \mathrm{y}= & \text { received } \\ & \ldots\end{array}\right]$


b.

$\left[\begin{array}{lll}\& & & \\ \mathrm{x}= & \& & \\ & \mathrm{x}= & \text { wrote } \\ & \mathrm{y}= & \text { posted } \\ & & \ldots \\ \mathrm{y}= & \text { received } \\ & \ldots\end{array}\right]$

When multiple instances of the conjunction particle are present, they signal multiple coordinations with each particle marking one instance of a conjunction relationship.

\subsection{Other coordination particles}

I do not have much to say about the other coordination particles, but and or, which in most respects behave similarly to the conjunction particle. The differences that exist are possible to capture under the account presented here.

Johannessen (1998: 98) assumes five coordination particles in English: and, but, or, for and so. She offers no justifications or references for the inclusion of for and so but not, say, however. They all seem to be discourse connectives that can only combine full, non-eliptical clauses. I will thus restrict my attention to or and but.

\subsubsection{Or}

It seems safe to assume that all I have said about coordinative conjunction applies to disjunctive conjunction as well. Ellipsis directionality (271) and multiple disjunction (272) operate the same way. (The examples in (272) need a pragmatic set up.)

(271) a. John walked or slept

b. * walked or John slept

c. John likes or Mary hates garlic

d. * John likes garlic or Mary hates

(272) a. John wrote the letter, Mary posted it or Bill received it on Tuesday b. John wrote the letter or Mary posted it or Bill received it on Tuesday 
Coordination introducers also behave similarly in conjunction and disjunction. In some languages 'either... or' is expressed as 'or...or'. In French the examples in (259) are grammatical when introduced by 'ou....ou' as well.

(273) a. ou Jean ou Marie grimp dans les arbres

or Jean or Marie climbs in the-PL trees

'Either John or Mary are climbing trees.'

b. je suis ou parti ou revenu jeudi

i am or left or returned the same day

'I either left or returned on Thursday.'

c. il est quatre heures: ou Jean est parti au parc ou Marie est revenue de it is four hours: or Jean is left to.the park or Marie is returned from l'école the.school

'It is four o'clock: either John has left for the park or Mary has returned from the school.'

(Marie-Eve Sévigny, p.c.)

As discussed in section 3.4, Hungarian, which uses the equivalent of too for both, uses the equivalent of 'or... or' for emphatic disjunction. The lack of a one-to-one relationship between 'and... and' and 'or... or' in languages was an argument I used to support my analysis of these constructions: it is a lexical coincidence that in some languages another instance of the conjunction marker is used as the conjunction introducer. The relevant Hungarian example, repeated from (258), was the following:

(274) vagy János vagy Mari mászik fára

or János or Mari climbs tree.on

'Either John or May is climbing trees.'

The syntax of 'either... or' in fact has a vast literature (see Larson 1985, Seuren 1985, Munn 1993, Schwarz 1999 among others) because in English it differs in one important aspect from 'both... and'. Consider the examples (275) below.

(275) a. John ate either rice or beans 
b. John either ate rice or beans

c. either John ate rice or beans

d. John ate both rice and beans

e. * John both ate rice and beans

f. * both John ate rice and beans

g. John ate rice and beans both

These often cited examples suggest that either does not need to mark the left edge of the disjunction, while both normally marks the left edge of the conjunction. However, in other cases the placement of both is freer, as the contrast between (276c) and (276d) shows. Also, either is not restricted to cases of coordination, suggesting that again similarly to both - it is an adverbial that sometimes appears in coordination contexts. But while in non-coordinate contexts both behaves as a predeterminer, either cannot (cf. (276e) and (276f)).

(276) a. both John and Mary left

b. either John or Mary left

c. John and Mary both left

d. * John or Mary either left

e. both the men left

f. * either the men left

g. either of the men left

I do not have an explanation for the various differences between both and either under the account developed here: To explain (275b), (275c) and the less common, but still possible (275g), I would need an account of floating quantificational phenomena.

A treatment of adverbials within alignment OT may help solve the problem of either: adverbials modifying verbs can get inserted between a verb and a subject:

(277) a. John ran home quickly

b. John quickly ran home 
A treatment of adverbials will need to be the subject of future research. However, it seems that though either and both often appear in coordination contexts, they are justifiably handled separately from an account of coordination.

\subsubsection{But}

Under the classical view, but is simply like and plus something non-truth-conditional. While this view is maintained by many linguists (including Iten 2001), it is also challenged by many researchers, including Blakemore (1987: 125-141).

Semantically speaking, $P$ and $Q$ functions as a single unit of relevance - i.e. there is no guarantee that either $P$ or $Q$ is relevant on in its own. With but, however, the second expression is relevant in its own right. But then functions more like a discourse connective like however, nevertheless or moreover. A problem with treating but as a discourse connective is that discourse connectives cannot trigger coordinate ellipsis.

(278) a. John did not come home but went straight to the party

b. *John did not come. However, went straight to the party

A difference between but and and, which probably has semantic roots, is that and may link more than two units, while but can only ever link two units. If there are three units, the first is interpreted to be in a conjoined relationship to the second, and both of these are contrasted with the third.

(279) a. John likes coffee, Jim likes tea and Jane likes Horlicks

b. John likes coffee, Jim likes tea but Jane likes Horlicks

(Blakemore 1987: 135)

This is possible to capture under the account presented here. But is a two-place functor, contrasting the third conjunct with the coordination of the first two. The issue is why the coordinative conjunction particle does not appear in (279b) - but at the same time its meaning is clearly recovered. There could be two possible causes for this. Either the input is impoverished (280a) or the conjunction particle is present in the input (280b) but then somehow goes missing. 
(280) a. impoverished input for (279b)

$\left[\begin{array}{cll}\text { but } & & \\ \mathrm{x}= & \text { likes } & \\ \mathrm{y}= & \ldots & \\ & \overline{\mathrm{x}=} & \text { likes } \\ & \ldots \\ & \mathrm{y}= & \text { likes } \\ & & \ldots\end{array}\right]$

b. full input for $(279 b)$

$\left[\begin{array}{lll}\text { but } & & \\ \mathrm{x}= & \text { likes } & \\ & \ldots & \\ \mathrm{y}= & \& & \\ & \mathrm{x}= & \text { likes } \\ & \ldots \\ & \mathrm{y}= & \text { likes } \\ & & \ldots\end{array}\right]$

When the input is impoverished, the missing conjunction needs to be recovered. The only item that can act as the possible source for recovery is but, which means and plus contrast. We cannot have a three-way contrast, probably for semantic reasons.

(281) * John likes coffee but Jim likes tea but Jane likes Horlicks

Since the contrastive aspect of but cannot be recovered, as it would give rise to a three-way contrast, only the coordinative aspect is recovered, so the correct interpretation for (279b) from (280a) is available.

The alternative explanation, assuming that (280b) is the input for (279b), is problematic. In this case it would be unclear how or why the conjunction functor would be underparsed or be matched by a null lexical item - the only instance in which we would need to hypothesize the existence of a null lexical item for the coordinative conjunction for English. Instead, (280b) is more naturally seen as the input for a sentence, in which both particles are overt. An account of the partial semantic reconstruction proposed will be provided in Section 5.5. 


\subsection{Conclusion}

In this Chapter I have shown how the basic OT principles developed in Chapter 2 can account for the placement of the coordinative conjunction in a wide variety of languages exhibiting very different coordination patterns.

The account developed hinges on the observation that in many respects the coordinative conjunction behaves similarly to predicates. Though it is clearly not a predicate from a semantic point of view, the introduction of the umbrella term functor to include predicates, certain operators and other heads has meant the grammar can make use of the predicate constraints, renamed as functor constraints, to account for the behavior of non-predicate functors, such as the conjunction.

The combined use of the licensing and functee alignment constraints predicts the following four basic word order patterns:
(282) a. C \& C ... (C)
b. (C) ... C \& C
c. (C) ... C C \&
d. \& C C ... (C)

The first three of these are attested, while the fourth may be an accidental gap.

The account developed can account for a wide range of more "exotic" behavior, which has received much less attention in traditional accounts. Asyndetic coordination can be handled via the reranking of the constraints, without the need to assume a null conjunction element. Languages that make use of different conjunction markers depending on the type of conjuncts could be handled via the assumption of Late Insertion. Partially asyndetic languages could also be accounted for.

I have offered an account of what are historically referred to as coordination introducers, viewing them as neither conjunctions nor coordination introducers in the literal sense of the term, but as adverbials that need to be included in the input of emphatic coordination. Treatments for multiple coordination as well as disjunction and contrastive coordination are also available under the account developed. 


\section{Ellipsis and conjunct order}

In the previous chapter I presented an account for the placement of the coordinative conjunction in various languages. This account suffices in cases where both conjuncts are complete clauses in their own right. In such cases the order of the conjuncts is free (283a-b), so the placement of the coordinative conjunction particle is the only coordination-specific task the grammar needs to attend to. In cases of impoverished inputs, on the other hand, at least one of the conjuncts is elliptical, and the order of the conjuncts is no longer free, as the contrast between (283c) and (283d) illustrates.

(283) a. John jumps and Mary runs

b. Mary runs and John jumps

c. John jumps and runs

d. * runs and John jumps

In Section 1.2 I pointed out that basic word order facts of a language appear to be relevant for determining the word order of coordinate conjuncts in many ellipsis cases, and that strings with different conjunct order can be regarded as candidates in an optimality theoretic competition.

In this chapter I will present the mechanisms that deliver the grammatical examples in elliptical coordination cases. After demonstrating how the system churns out the optional conjunct order in non-elliptical cases (4.1), I will define the "mop-up" cycle (4.2) and then discuss cases of argument ellipsis and gapping in English (4.3). Section 4.4 will focus on ellipsis phenomena in Hungarian, and demonstrate that the assumptions introduced for English can account for Hungarian shared topic ellipsis. In section 4.5 I will draw on the conclusions of Section 2.3.8 on the special status of initial verbs to discuss Hungarian gapping. The last section of this chapter will list some problematic cases, for which I have only speculative and informal answers (4.6).

\subsection{Conjunct order in full coordination}

The central claim of Newson and Gáspár (2001) was that the direction of ellipsis can be derived from the internal word order of the individual conjuncts, and as such, the 
direction of ellipsis does not have to be independently stipulated as in Wilder (1994, 1997) among others. I summarized the arguments in favour of this approach in Section 1.2, concluding that forward and backward ellipsis patterns are indeed complementary, cutting up the set of possibilities into three complementary sets:

(284) a. medial or left peripheral $\rightarrow$ forward

b. right peripheral argument $\rightarrow$ backward

c. right peripheral non-argument $\rightarrow$ no direction specified

Having argued that these are the only essential grammatical differences between ellipsis patterns it was concluded in Newson and Gáspár (2001) that from a grammatical point of view ellipsis is a unitary phenomenon and as such needs to be dealt with through a single grammatical mechanism. The OT framework adopted by Newson and Gáspár allowed this to be handled under the assumption that candidate expressions which differ with respect to the order of conjuncts compete and the winning candidate is determined by the constraints that determine basic word order.

Typically the order of the conjuncts in a coordinated expression makes no difference to its semantic interpretation: A\&B means the same as B\&A. This follows if both of the expressions are related to the same input, which can only be the case if: i) expressions in which the order of the conjuncts is reversed take part in the same competition and ii) they both have the same constraint violation profiles. That the two types of expression are part of the same candidate set follows from the assumption that there is no conjunct ordering in the input: each predicate is assigned to a functee slot of the conjunction but there is no priority given to either (see Section 2.2.1.3).

When there is no ellipsis, all orderings will emerge as optimal. Let me demonstrate this with a very simple example based on the following input:

$$
\left[\begin{array}{lll}
\& & & \\
\mathrm{x}= & \text { runs } & \\
& \mathrm{x}_{\mathrm{ag}, \text { sub }}= & \text { John } \\
\mathrm{y}= & \text { jumps } & \\
& \mathrm{x}_{\mathrm{ag}, \text { sub }}= & \text { Mary }
\end{array}\right]
$$


As there are four input elements (ignoring the coordination particle, which was placed between its functees in the previous cycle, as shown earlier), there are 24 possible orderings. However, the majority of these will be ruled out immediately as arguments will be too far from their respective predicates. In effect all we need to consider are the operations of the constraints on the relative ordering of related arguments and predicates. For simplicity's sake, I will represent this with a table for each conjunct, though in reality there is only one competition taking place per cycle.

\begin{tabular}{|c|c|c|c|c|}
\hline runs-jumps cycle & $\mathrm{Sp}$ & $\mathrm{fA}$ & $\mathrm{pS}$ & Af \\
\hline$\ldots$ John $_{\text {sub }}$ runs ... & & $\star$ & \multirow[t]{2}{*}{$\star$} & \\
\hline$\ldots$ runs $\mathrm{John}_{\mathrm{sub}} \ldots$ & $\star !$ & & & $\star$ \\
\hline John $_{\text {sub }} \ldots$ runs ... & *...! & $\star$ & \multirow{2}{*}{$\begin{array}{c}\star \\
* \ldots\end{array}$} & $* \ldots$ \\
\hline ... runs ...John $\mathrm{Jub}_{\text {sub }}$ & $\star !$ & $* \ldots$ & & $\star$ \\
\hline
\end{tabular}

(287)

\begin{tabular}{|c|c|c|c|c|}
\hline runs-jumps cycle & $\mathrm{Sp}$ & $\mathrm{fA}$ & $\mathrm{pS}$ & Af \\
\hline$\ldots$ Mary $_{\text {sub }}$ jumps ... & & $\bar{t} \star$ & \multirow[t]{2}{*}{$\star$} & \multirow[b]{2}{*}{$\star$} \\
\hline ... jumps Mary sub... & $\star !$ & & & \\
\hline Mary $_{\text {sub }} . .$. jumps ... & *...! & $\star$ & \multirow{2}{*}{$\begin{array}{l}\star \\
* \ldots\end{array}$} & *.. \\
\hline ... jumps ....Mary sub & $\star !$ & $* \ldots$ & & $\star$ \\
\hline
\end{tabular}

The order of these conjuncts relative to each other will be unfixed, in line with the data. This is demonstrated below:

(288)

\begin{tabular}{|c|c|c|c|c|}
\hline runs-jumps cycle & $\mathrm{Sp}$ & fA & $\mathrm{pS}$ & Af \\
\hline John $_{\text {sub }}$ runs and Mary sub $_{\text {jumps }}$ & & $\star \star$ & \multirow{2}{*}{\multicolumn{2}{|c|}{$\begin{array}{l}\star \star \star \\
\star \star\end{array}$}} \\
\hline Mary $_{\text {sub }}$ jumps and John sub $_{\text {runs }}$ & & $\star \star$ & & \\
\hline
\end{tabular}

\subsection{Argument ellipsis in English}

In cases of ellipsis, the order of the conjuncts matters: although both orderings are available in the candidate set, there is only one winner ${ }^{62}$. This is illustrated in (289):

(289) a. non-impoverished input

$$
\begin{array}{r}
\text { candidates: } \mathrm{A} \& \mathrm{~B} \\
\mathrm{~B} \& \mathrm{~A}
\end{array}
$$

\footnotetext{
${ }^{62}$ In a limited subset of cases, involving infinitival ellipsis, optionality in conjunct order is allowed:

i. John went shopping but Mary didn't want to

ii. Mary didn't want to but John went shopping

The development of a theory accounting for these cases is left for future research.
} 
b. impoverished input

candidates: * A \& B

$\leftrightarrow \mathrm{B} \& \mathrm{~A}$

I suggested in Section 1.2 that the position of the arguments of one predicate can be relevant for satisfying the alignment requirements of another. However, we would not want the arguments of any predicate to be able to satisfy the alignment conditions for any other predicate or else one input could be associated with several optimal outputs in which the arguments are aligned to different predicates:

(290) a. John said Bill saw Mary

b. Bill said John saw Mary

Given that (290a) and (290b) mean different things, as grammatical expressions they must be related to different inputs. When they are candidates of the same competition, only one of them will be optimal with respect to the particular input. I have introduced the mechanism of cyclicity (Section 2.2.2.4) to deal with such cases. In case of embedding each predicate cycle concentrates on a particular predicate, proceeding top down along the hierarchy presented in the input data structure. This will be relevant for coordination as well, where the first functor cycle places the conjunct functees (i.e. the predicates) in relation to the conjunction functor. The cycle of the conjunction functor determines (for English) only that one conjunct needs to license the conjunction from the right, while the rest of the conjuncts come to its left. Because none of the conjuncts is privileged as the licensor, the conjunction functor cycle will have nothing to say about the ordering of the conjuncts with respect to each other. All candidates in which the conjunction is in the second last slot will survive.

Next comes the cycle of the subordinate functors - i.e. the conjuncts themselves. Just like in cases of simple sentences, these attend to the requirements of individual predicates with specific reference to the elements assigned to them in the input. The effect of this will be to group together those arguments and predicates related in the input as though each conjunct were subject to a separate evaluation, though in reality there is just one evaluation of the entire candidate set. The end result of the cycle will be those candidates in which predicates and their arguments are properly aligned. 
There are, however, certain predicates whose arguments will be missing, and so the alignment constraints with respect to these predicates cannot be satisfied at this stage. Recall that in Section 2.2.2.1 I defined predicate-argument constraints from the point of view of the predicate: if the insertion of a predicate creates, say, two argument slots in the input data structure, the $\mathrm{pA}$ constraint, for instance, will require its two arguments to be right adjacent to the predicate. At the time it was inconsequential whether the $\mathrm{pA} / \mathrm{Ap}$ and $\mathrm{pS} / \mathrm{Sp}$ pairs of constraints are viewed from the position of the arguments (as in Newson 2000b) or from the position of the predicate. In case of argument ellipsis, however, the distinction is relevant.

The pA constraint, for instance, states that arguments must follow the verb. The violation in case of a missing argument is neither a side nor an edge violation: the argument is neither on the right nor on the wrong side - the constraint cannot be satisfied, owing to a third kind of violation. I will call this valence violation based on a similarity to chemical bonding between atoms ${ }^{63}$. A two-place predicate, for instance, has two argument valences, and - like every predicate - one subject valence.

When an atom cannot form a bond with the required number of other particles, its valences are not fully saturated - and it will "hang around" until there are other particles with which it can form its remaining bonds and saturate its free valences. The case is similar here: since the required element is neither on the wrong side nor is it too far, no final decision can be made about the violation of the constraint at this stage. To denote this suspended state for the violation I will use the time bomb symbol: (291) summarizes the types of alignment violations in the grammar.

(291) Yx: An element $\mathrm{x}$ must have an element $\mathrm{Y}$ to its left.

\begin{tabular}{lccc|} 
& violation & symbol & final? \\
side & $\mathrm{XY}$ & $\star$ & Yes \\
edge & $\mathrm{Y} \ldots \mathrm{x}$ & $*$ & Yes \\
valence & $\mathrm{x}$ & - & No \\
\hline
\end{tabular}

In case of argument ellipsis each candidate scores equally badly on the constraint related to this missing argument - since the item is missing from the input and so

\footnotetext{
${ }^{63}$ The two concepts are conceptually similar: a particular atom has a certain number of valences, and it needs all its valences satisfied by forming bonds with (aka becoming adjacent to) other atoms
} 
cannot be present in any candidate. By the end of the predicate functor cycle, however, the internal make-up of conjuncts has been "unfolded," so the arguments of the other conjunct are "visible" to the predicate of the elided conjunct. The satisfaction of the constraints with respect to the elided predicate can again be attempted in a new cycle. Only candidates surviving the previous cycles will compete in this "mop-up" cycle.

Deciding grammaticality will fall on the licensing constraints that could not be faithfully satisfied owing to the impoverished nature of the input - since the other constraints will be maximally satisfied by the elements that are related to them in the input. This is, after all, why these candidates survived to this point in the process. Only if there were any constraints that could not be locally satisfied due to the impoverished nature of the input (i.e. if there is a in the evaluation table) will the "mop-up" cycle have any impact on grammaticality. In other cases the constraint violation profile of the surviving candidates, which were the most harmonic with respect to the ranked constraints locally, will not be affected by the possibility of satisfying the constraints using the arguments of the other predicate. In these cases, a predicate's own argument will always be closer than the arguments in the other conjunct, as otherwise the candidate would not have survived this far in the process.

For the same reason only constraint satisfaction with respect to items that had unsaturated valences in the previous cycle will matter at this stage. Though the constraint violation profile of the full conjunct's predicate may be altered in the mopup cycle by aligning with the overt argument of the elided conjunct, this incremental improvement in constraint satisfaction will not be able to influence grammaticality. This will be clear in the examples of the next sections.

The conjunction will not be able to influence grammaticality either: since the arguments of its functees are "packed out" by this stage, any element that is the functee of either the conjunction or one of the predicates will be available to satisfy $\mathrm{f}_{\&} \mathrm{~A} / \mathrm{Af}_{\&}$ and $\mathrm{f}_{\&} \mathrm{~L} / \mathrm{Lf}_{\&}$. Since the conjunction is string medial in all candidates surviving the conjunction functor cycle, these constraints will always be maximally satisfied.

It is in the "mop-up" cycle that the order of the conjuncts will be determined, as a result of an attempt made to satisfy the open valances of the predicates with missing 
arguments using other input material. At this point, just like in other cases of cyclicity, order established in previous cycles cannot be undone.

The diagram below summarizes the focus of the different evaluation cycles, while the next sections will show how the mop-up cycle contributes to picking the grammatical candidate in different cases.

(292)

\section{Ciclicity schema}

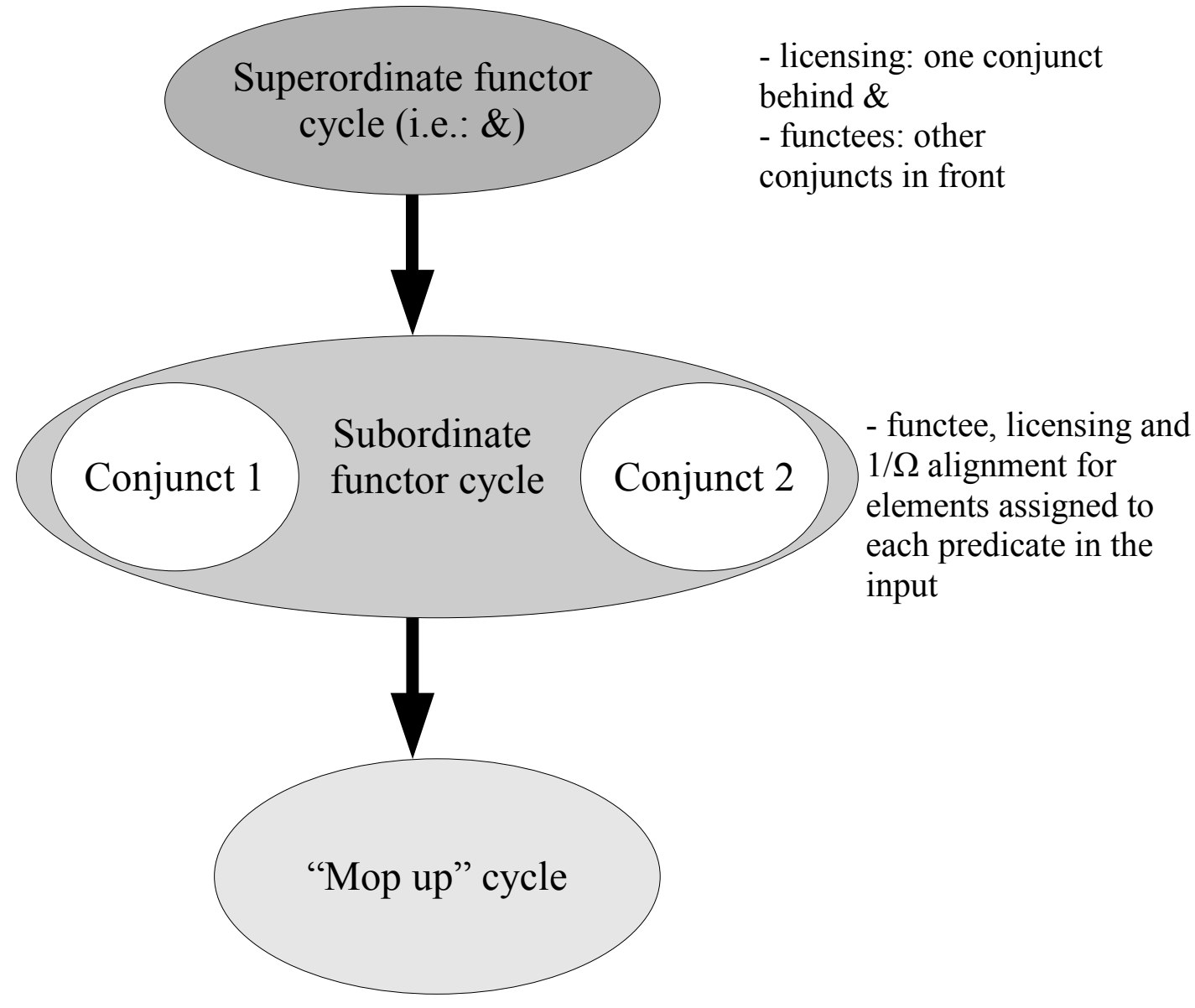

\subsubsection{Subject ellipsis}

As discussed in Section 2.2.1.4, the input of a sentence with an elliptical subject is impoverished, and looks like the input below: 
(293)

$$
\left[\begin{array}{lll}
\& & & \\
\mathrm{x}= & \text { loves } \\
& \mathrm{x}_{\text {exp, sub }}= & \text { John } \\
\mathrm{y}= & \text { Mary } \\
\text { hates } & \\
& \mathrm{x}_{\text {exp sub }}= & \\
& \mathrm{y}_{\text {th }}= & \text { Sue }
\end{array}\right]
$$

The cycle of the coordination predicate will place the coordination particle between the conjuncts, as discussed in detail in the previous chapter.

\begin{tabular}{|c|c|c|c|c|}
\hline \& cycle & $f_{\&} L$ & $\mathrm{Af}_{\&}$ & $\mathrm{Lf}_{\&}$ & $f_{\&} A$ \\
\hline$\&$ loves $_{[\text {John, Mary] }}$ hates ${ }_{[\text {Sue] }]}$ & & $\star \star !$ & $\star$ & $*$ \\
\hline$\&$ hates $_{[\text {Sue }]} \operatorname{loves}_{[\text {John, Mary] }}$ & & $\star \star !$ & $\star$ & $*$ \\
\hline $\operatorname{loves}_{[\mathrm{John}, \text { Mary }]} \&$ hates $[$ Sue] & & $\star$ & & $\star$ \\
\hline $\operatorname{loves}_{[\mathrm{John}, \text { Mary] }}$ hates $[\mathrm{Sue}]$ & $\star !$ & $*$ & & $\star \star$ \\
\hline hates $_{[\text {Sue] }} \&$ loves $_{[\text {John, Mary] }}$ & & $\star$ & & $\star$ \\
\hline $\operatorname{hates}_{[\text {Sue] }]} \operatorname{loves}_{[\text {John, Mary] }} \&$ & $\star !$ & $*$ & & $\star \star$ \\
\hline
\end{tabular}

Next comes the subordinate functor cycle, in which the internal make up of the conjuncts will be unfolded - i.e. the candidates whose shorthand candidates were compared in (294) will now compete with one another. Though there is only one evaluation taking place, it is easier to demonstrate the competition for the two conjuncts separately. The evaluation for the predicate loves and its arguments will be as for any subject-object sentence in English, discussed in Chapter 2.

\begin{tabular}{|c|c|c|c|c|c|}
\hline$(295)$ & loves-hates cycle & Sp & fA & $\mathrm{pS}$ & Af \\
\hline \multirow[t]{6}{*}{ 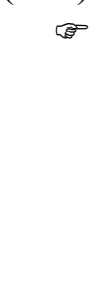 } & ....John sub $_{\text {loves Mary... }}$ & & $\star$ & $\star$ & $\bar{t} \star$ \\
\hline & ....John sub $_{\text {Mary loves... }}$ & $* !$ & $\star \star$ & $\star$ & $*$ \\
\hline & ...loves John sub $_{\text {Mary... }}$ & $\star !$ & $*$ & & $\star \star$ \\
\hline & ...loves Mary John ${ }_{\text {sub... }}$ & $\star !$ & $*$ & * & $\star \star$ \\
\hline & ...Mary John sub $_{\text {loves... }}$ & & $\star \star !$ & $\star$ & * \\
\hline & ...Mary loves John sub... & $\star !$ & $\star$ & & $\star$ \\
\hline
\end{tabular}

Hates, however, has no subject argument specified in the input. Thus the $\mathrm{Sp} / \mathrm{pS}$ cannot be satisfied with respect to hates in any way - and even the fA/Af constraints can only ever be partially satisfied at this stage, since the predicate has only one argument, not two as required by the number of data slots created for the predicate in the input. Despite the lack of subject argument, the candidates will score differently in the competition, and the fA constraint will pick the winning candidate: 


\begin{tabular}{|c|c|c|c|c|}
\hline loves-hates cycle & $\mathrm{Sp}$ & fA & $\mathrm{pS}$ & Af \\
\hline ... hates Sue ... & 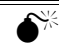 & $\sigma^{*}$ & \multirow{4}{*}{\multicolumn{2}{|c|}{ 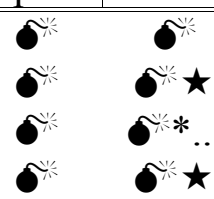 }} \\
\hline ... Sue hates ... & 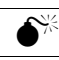 & $\boldsymbol{\theta}^{\prime \prime} \star !$ & & \\
\hline Sue ... hates ... & E & $\approx \star !$ & & \\
\hline ... hates ... Sue & 少 & - $* \ldots$ *..! & & \\
\hline
\end{tabular}

Once again, the order of the conjuncts is irrelevant at this stage, so both the following expressions are equally optimal:

\begin{tabular}{|c|c|c|c|c|}
\hline loves-hates cycle & Sp & fA & $\mathrm{pS}$ & Af \\
\hline John $_{\text {sub }}$ loves Mary and hates Sue & 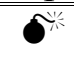 & $\overline{e * \star}$ & $\sigma \star$ & 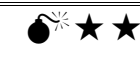 \\
\hline hates Sue and John sub $_{\text {loves Mary }}$ & 范 & $\boldsymbol{0} \star \star$ & $\boldsymbol{\sigma}^{\prime} \star$ & 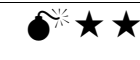 \\
\hline
\end{tabular}

However, unlike in the case of full clause coordination, one of the verbs has no subject and only one argument, so in the mop-up cycle an attempt can be made to align this with another subject. Given that there are only two candidates left, the choice is very limited. However, one of these does better than the other and will be selected as the optimal candidate. (To simplify the table, constraint satisfaction is tabulated only with respect to hates. Both candidates satisfy $\mathrm{Sp}$, the constraint that decides grammaticality with respect to loves, which has its own subject.)

\begin{tabular}{|c|c|c|c|c|}
\hline mop-up cycle & $\mathrm{Sp}$ & fA & $\mathrm{pS}$ & Af \\
\hline John $_{\text {sub }}$ loves Mary and hates Sue & $* * *$ & 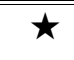 & $\star \star$ & $* * * \star$ \\
\hline hates Sue and John ${ }_{\text {sub }}$ loves Mary & $\star !$ & $* *$ & $* *$ & $\star \star$ \\
\hline
\end{tabular}

Thus, as required, the forward ellipsis version is selected as grammatical over the backward ellipsis pattern.

\subsubsection{Object ellipsis}

In the case of BWE the order of the conjuncts is determined by missing right edge elements, the complements. Let us take the input to be as below:

$$
\left[\begin{array}{lll}
\& & & \\
\mathrm{x}= & \text { loves } \\
& \mathrm{x}_{\text {exp, sub }}= & \text { John } \\
\mathrm{y}_{\text {th }}= & \text { Mary } \\
\mathrm{y}= & \text { hates } \\
& \mathrm{x}_{\text {exp, sub }}= & \text { Bill } \\
\mathrm{y}_{\text {th }}= &
\end{array}\right]
$$


The coordination cycle again has nothing to say about conjunct order, simply requiring that the coordination particle is sandwiched between them:

$(300)$

\begin{tabular}{|c|c|c|c|c|}
\hline \& cycle & $\mathrm{f}_{\&} \mathrm{~L}$ & $\mathrm{Af}_{\&}$ & $\mathrm{Lf}_{\&}$ & $f_{\&} A$ \\
\hline$\&$ loves $_{[\text {John, Mary] }}$ hates $_{[\text {[Bill] }}$ & & $\star \star \star !$ & $\star \star$ & $*$ \\
\hline$\&$ hates $_{[\text {Bill] }} \operatorname{loves}_{[\text {John, Mary] }}$ & & $\star \star !$ & $\star$ & $*$ \\
\hline loves $_{[\text {John, Mary] }} \&$ hates $[$ [Bill] & & $\star$ & & $\star$ \\
\hline $\operatorname{loves}_{[\text {John, Mary] }}$ hates $[$ Bill] $\&$ & $\star !$ & * & & $\star \star$ \\
\hline hates $_{[\text {Bill] }} \&$ loves $_{[\text {John, Mary] }}$ & & $\star$ & & $\star$ \\
\hline hates $_{[\mathrm{Billl}} \operatorname{loveS}_{\text {[John, Mary] }} \&$ & $\star !$ & $*$ & & $\star \star$ \\
\hline
\end{tabular}

The competition for the full conjunct will be as in (295).

Hates does have a subject this time, but it does not have an object. Thus while the $\mathrm{Sp} / \mathrm{pS}$ constraints can be satisfied with the elements available, the fA/Af constraints with respect to hates can only be partially satisfied: the input calls for two arguments to be aligned to the predicate, but there is only one argument available in the input.

\begin{tabular}{|c|c|c|c|c|}
\hline loves-hates cycle & $\mathrm{Sp}$ & fA & $\mathrm{pS}$ & Af \\
\hline$\ldots$ Bill $_{\text {sub }}$ hates ... & & $\star \sigma$ & $\star$ & $\approx$ \\
\hline ... hates Bill sub $\ldots$ & $\star !$ & 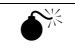 & & $\star \sigma^{\prime \prime}$ \\
\hline
\end{tabular}

The output of the predicate cycle will be the following candidates:

$\begin{aligned} \text { (302) a } & \text { John loves Mary and Bill hates } \\ \text { b } & \text { Bill hates and John loves Mary }\end{aligned}$

These two candidates enter the mop-up cycle, where the constraint to decide grammaticality will be fA with respect to hates. (The dominant subject constraint will be satisfied by the closest subject, which is hates' own subject.) The argument constraint will act to place the conjunct with the missing argument in front of the other conjunct so that the "shared" object can appear on the right side.

Here it is instructive to tabulate violations with respect to both predicates, as the constraint violation profile of loves improves in the mop-up cycle in comparison with the predicate cycle. This is because in the first candidate it can better satisfy fA by aligning with its own object and the other subject, since it incurs no side violations 
this way. To make the table easier to read, I am separating the violations belonging to the two verbs by commas: hates' violations follow loves' violations.

\begin{tabular}{|c|c|c|c|c|}
\hline mop-up cycle & $\mathrm{Sp}$ & $\mathrm{fA}$ & $\mathrm{pS}$ & Af \\
\hline John $_{\text {sub }}$ loves Mary and Bill sub hates & & $* *, \star \star !$ & 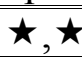 & $\star, * *$ \\
\hline Bill $_{\text {sub }}$ hates and John $n_{\text {sub }}$ loves Mary & & $\star * * * *$ & $\star, \star$ & $* *, \star$ \\
\hline
\end{tabular}

It is precisely because hates does not have an object that the first candidate fares worse. Thus even though the violations scored by the predicate of the full clause differ in the mop-up cycle in comparison with the predicate functor cycle, it will always be the violations of the predicate of the elided clause that determine grammaticality.

\subsubsection{Topic ellipsis}

Recall from Sections 2.2.2.2 and 2.2.2.3 that topic placement is governed by first/last constraints, not predicate alignment constraints.

Let us take the input to be the same as in the previous example, but this time with the topic feature marked on the object. Note that the only way in which (304a) below can be interpreted is that Mary is also the object and the topic of hates. This needs to be indicated in the input. (As I will discuss in Chapter 5, an input in which the object of hates is not marked for topic is not going to be interpretable, because the semantic component cannot reconstruct the missing object from one that is not sufficiently similar.) For now what is important is that the elided element needs to be marked for topic status as well, with its domain extending to its own predicate (Section 2.2.2.3).

(304) a. Mary, John loves and Bill hates

b.

$$
\left[\begin{array}{ccl}
\& & & \\
\mathrm{x}= & \operatorname{loves}_{(\alpha)} & \\
\mathrm{x}_{\exp , \text { sub }} & = & \text { John } \\
\mathrm{y}_{\text {th, top }}(\alpha) & = & \text { Mary } \\
\mathrm{y}= & \operatorname{hates}_{(\alpha)} \\
& \mathrm{x}_{\exp , \text { sub }}= & \text { Bill } \\
\mathrm{y}_{\text {th, top }}(\alpha) & =
\end{array}\right]
$$

Since the conjunction is not within the scope of the topic, the topic constraints will not be active in the conjunction functor cycle. Thus the competition illustrated in (300) will apply for the input above as well. 
The T1/T $\Omega$ constraint pair will be relevant in the evaluation of the loves conjunct, as it contains a functee marked for topic status.

\begin{tabular}{|c|c|c|c|c|c|c|}
\hline loves-hates cycle & $\mathrm{Sp}$ & $\mathrm{T} 1$ & fA & $\mathrm{pS}$ & $\mathrm{T} \Omega$ & Af \\
\hline$\ldots$ John $_{\text {sub }}$ loves Marytop ... & \multicolumn{2}{|r|}{$* *$} & $\star$ & \multicolumn{3}{|l|}{$\star$} \\
\hline$\ldots \mathrm{John}_{\text {sub }}$ Mary $_{\text {top }}$ loves ... & $* !$ & $*$ & $\star \star$ & \multirow[t]{2}{*}{$\star$} & $*$ & $*$ \\
\hline ... loves John ${ }_{\text {sub }}$ Mary ${ }_{\text {top }} .$. & $\star !$ & $* *$ & $*$ & & \multicolumn{2}{|r|}{$\star \star$} \\
\hline ... loves Mary lop $_{\text {John }}$ sub ... & $\star !$ & * & * & $*$ & $*$ & $\star \star$ \\
\hline$\ldots$ Mary $_{\text {top }} \mathrm{J}_{\mathrm{ohn}}$ sub loves ... & & * & $\star \star$ & $\star$ & $* *$ & $*$ \\
\hline ... Mary Mop $_{\text {toves }} \mathrm{John}_{\text {sub }} .$. & $\star !$ & & $\star$ & & $* *$ & $\star$ \\
\hline
\end{tabular}

For hates, given that its topicalized argument is missing, the evaluation will be the same as in the previous, object ellipsis case:

\begin{tabular}{|c|c|c|c|c|c|c|}
\hline loves-hates cycle & $\mathrm{Sp}$ & $\mathrm{T} 1$ & fA & $\mathrm{pS}$ & $\mathrm{T} \Omega$ & Af \\
\hline$\ldots$ Bill $_{\text {sub }}$ hates ... & & & $\star \sigma$ & $\star$ & & 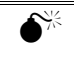 \\
\hline 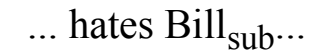 & $\star !$ & & $\widetilde{\sigma}$ & & & $\star \widetilde{\sigma}$ \\
\hline
\end{tabular}

The candidates contain no element marked as a topic, so the topic constraints are vacuously satisfied, just like in previous examples where they were left out of the optimality tables altogether.

Surviving to the next cycle we therefore have expressions containing two conjuncts, one with a missing object and the other with a topic object, in any order:

(307) a. Mary John loves and Bill hates

b. Bill hates and Mary John loves

Just like in the previous case the predicate hates has a missing object, which this time is topicalized. Since the topic constraint dominates the argument constraint, it will select the FWE expression over the BWE one. (The dominant subject constraint will be satisfied by hates' own subject as before.) This is illustrated below:

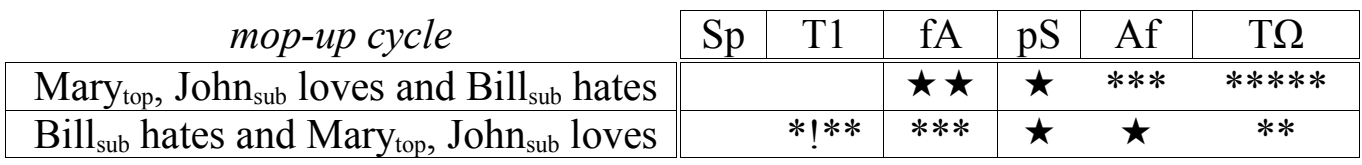




\subsubsection{Underparsing and valence violation}

It is important to note that valence violation may also occur during the underparsing of a feature or element. As I demonstrate in this section this, however, is of no consequence to the eventual outcome of the optimality competition - which allowed me to fudge this point, mentioning it only in a footnote when introducing the notion of underparsing in Section 2.2.2.1.

Let me illustrate the issue by providing a reanalysis of the basic Hungarian clause, originally discussed in Section 2.2.2.1. Underparsing the subject feature meant that the subject argument is no different from other arguments of the predicate, capturing the observation that Hungarian does not have a subject (É. Kiss 1994). I stated, following Newson (2000b), that underparsing of the feature means vacuous satisfaction of both the $\mathrm{Sp}$ and $\mathrm{pS}$ constraints at the expense of a PARSE violation. However, since unlike Newson, I view the satisfaction of the constraints from the point of view of the functor and its valences, underparsing the functee does not actually lead to constraint satisfaction: it leads to a valence violation. Example (104) is repeated here as (309) and the competition is provided in (310).

a. megverte Pétert János

PERF.beat-PST, 3SG Péter-ACC János

'John beat up Peter.'

b.

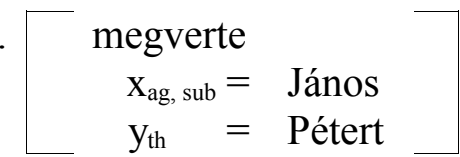

(310)

\begin{tabular}{|c|c|c|c|c|c|}
\hline Hungarian & $\mathrm{Sp}$ & $\mathrm{pS}$ & PARSE & $\mathrm{pA}$ & Ap \\
\hline János $_{\text {sub }}$ megverte Pétert & & $\star !$ & & $\star$ & 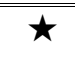 \\
\hline megverte János $_{\text {sub }}$ Pétert & $\star !$ & & & $\star$ & $\star$ \\
\hline János $_{<\text {sub }>}$ megverte Pétert & \% & 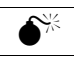 & $*$ & $\star$ & $\star$ \\
\hline János $>_{\text {sub }>}$ Pétert megverte & 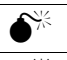 & 姃 & $*$ & $\star ! \star$ & $*$ \\
\hline megverte János $_{<\text {sub }>}$ Pétert & 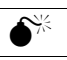 & 少 & $*$ & $*$ & $\star \star$ \\
\hline megverte Pétert János $_{<\text {sub }>}$ & $\%$ & $\tilde{\sigma}$ & $*$ & $*$ & $\star \star$ \\
\hline Pétert János $<$ sub $>$ megverte & $\%$ & 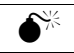 & $*$ & $\star ! \star$ & $*$ \\
\hline Pétert megverte János $<$ sub $>$ & $\%$ & $\mathbf{\sigma}^{\prime \prime}$ & $*$ & $\star !$ & $\star$ \\
\hline
\end{tabular}

The first two candidates will cause a definite side violation of a subject constraint each, while the valence violations incurred by the candidates with an underparsed 
subject feature can still hoped to be repaired at the mop-up cycle. As a result, it is the faithful candidates that are eliminated on the subject constraints. The candidates that satisfy pA are the winners of this cycle - and are passed on to the mop-up cycle. However, in this case there is no other subject in the input, alignment with which could salvage the valence violation. Both of the surviving candidates score equally, so they will be the shared winners of the competition. Thus the valence violation/mop-up cycle mechanism has no effect on the outcome of the grammaticality competition.

This concludes my discussion of argument ellipsis in the case of English and I will now move on to more complex cases of ellipsis, starting with gapping

\subsection{English gapping}

The analysis for argument ellipsis, in which predicate alignment constraints determined the order of the conjuncts in the mop-up cycle, cannot be simply carried over to cases of gapping, where the predicate is missing. Gapping phenomena raise the questions of what arguments are aligned to if there is no predicate in the output expressions and also what arguments are arguments of if there is no predicate in the input. In this section I will look at various cases of gapping and show that the OT alignment framework developed in Chapter 2 can extend to these phenomena.

\subsubsection{Verb-only gapping}

The arguments in the conjunct that lack a predicate are interpreted as related to each other as if they had a predicate to connect them. In (311) below not only is it clear that John is related to Mary, but also that Bill is related to Sue and Dennis to Rose. Also, Bill and Dennis are interpreted as experiencer, while Sue and Rose are themes.

(311) John loves Mary, Bill Sue, and Dennis Rose

If the input simply contained a list of 'floating' arguments, there would be no way to match up these aspects of the interpretation with the particular ordering in (311). For this reason, I take the inputs of gapping sentences to be impoverished inputs, in which the predicate is missing, but its data slot is present (see Section 2.2.1.4). The input needs to be parallel for reasons of interpretation that I will return to in Chapter 5. An input without a sufficiently parallel semantic structure would be uninterpretable, and 
hence the syntactically optimal candidate for that input would be anomalous. Note also that the theta-roles assigned to the missing predicates need to match the thetaroles of the overt predicate. This is again a semantic condition on what counts as an interpretable input: if different theta-roles were assigned, the recovery of the gapped predicates would be prevented and the input would be uninterpretable. I will discuss the semantic recovery mechanism, and the constraints it places on inputs in Chapter 5.

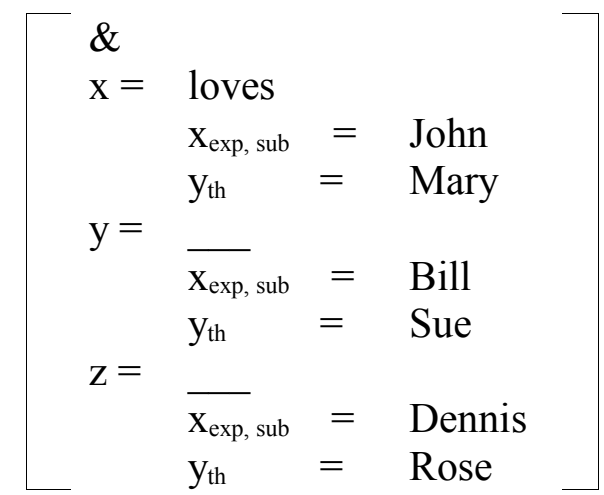

The predicate cycle delivers the SVO word order for the full conjunct as before. In the predicate cycle of the elliptical conjuncts the functor constraints will be vacuously satisfied in all candidates because the verbal arguments have no predicate to align to. Thus the constraints responsible for basic word order cannot be relied on to explain how the SO word order pattern is maintained even in the absence of the predicate.

In Chapter 2 I made use of the S1 constraint to account for SOV word order in the basic clause. If S1 exists for SVO languages it will exist in other languages as well, and we can make use of it to account for English verb-only gapping cases.

In normal English sentences we have no indication whether the $\mathrm{S} 1$ (or $\mathrm{S} \Omega$ ) constraint is prominent. As was shown in Chapter 2, the Sp constraint is sufficient to account for the placement of subjects in simple English sentences. If $\mathrm{Sp}$ is ranked higher than $\mathrm{pS}$, $\mathrm{S} 1$ and $\mathrm{S} \Omega, \mathrm{Sp}$ will determine the position of the subject. If a candidate satisfies $\mathrm{S} 1$ at the expense of an Sp violation, by placing the subject to the front of the string, further to the left than optimal with respect to the Sp constraint, the candidate will never be grammatical and the word order it would impose on input elements would never surface. In gapped constructions, however, the lack of a predicate means that $\mathrm{Sp}$ (and pS) are irrelevant in deciding grammaticality. Thus the otherwise hopelessly lowly ranked $\mathrm{S} 1$, if above $\mathrm{S} \Omega$, will get a chance to decide grammaticality. 
The fact that arguments of missing verbs are ordered with respect to each other suggests that the subject constraints are all relevant in the predicate functor cycle, even when the predicate is missing. The domain of the subject constraint will be local: the meaning of the input in (312) clearly shows that the subject arguments of the predicates do not extend their realm to the other predicates, which have subjects of their own. (Since the default scope domain for a scopal element is its own predicate, the scope domain of the subjects is not marked in the representation of the input.)

A hierarchy for English was adopted from Newson (2000b), and brought in line with the present assumptions in previous chapters. It is repeated here as (313):

(313) English: PARSE » Sp, T1» $\mathrm{fA} » \mathrm{pS}, \mathrm{T} \Omega, \mathrm{Af}$

$\mathrm{S} 1$ needs to be ranked below $\mathrm{Sp}$ and $\mathrm{T} 1$ to ensure that it does not interfere with the pre-verbal cluster in non-ellipsis cases. Its ranking in relation to the other constraints in (313) is irrelevant: it will never be in conflict with fA, because its relative ranking with respect to Sp will ensure that S1 is going to be active only in the absence of a predicate, in which case fA is going to be vacuously satisfied by all candidates anyway. pS, T $\Omega$ and Af are outranked by their respective counterparts, so their relative ranking with respect to $\mathrm{S} 1$ is not going to be important. S1 needs to be ranked above $S \Omega$, however. We arrive at the following ranking for English:

$$
\begin{aligned}
& \text { English: PARSE » } \mathrm{Sp}, \mathrm{T} 1 \text { » } \mathrm{fA} » \mathrm{pS}, \mathrm{T} \Omega, \mathrm{Af} \\
& \text { PARSE » } \mathrm{Sp}, \mathrm{T} 1 \text { » } \mathrm{S} 1 \text { » } \mathrm{S} \Omega
\end{aligned}
$$

Since first-last constraints exist for every type of input element, our inventory of argument alignment constraints also includes $A 1$ and $A \Omega$. Both of these need to be ranked below fA. For now, their ranking with respect to the other constraints is irrelevant. Their exact position will become relevant later, and I will specify it then.

\section{English: PARSE » $\mathrm{Sp}, \mathrm{T} 1$ » $\mathrm{A} \gg \mathrm{A} 1, \mathrm{~A} \Omega$}

None of the predicate constraints is relevant in the predicate cycle of a gapped verb, as they are vacuously satisfied. This leaves $\mathrm{S} 1 / \mathrm{S} \Omega$ and $\mathrm{A} 1 / \mathrm{A} \Omega$ to work out the optimal candidate. Since S1 dominates the others, an SO pattern will arise. The constraint interaction for the arguments of one of the gapped verbs in (312) is shown in (316). 


\begin{tabular}{|c|c|c|c|c|}
\hline loves cycle & S1 & $\mathrm{S} \Omega$ & A1 & $\mathrm{A} \Omega$ \\
\hline Bill $_{\text {sub }}$ Sue & & $*$ & $*$ & $*$ \\
\hline Sue Bill ${ }_{\text {sub }}$ & $* !$ & & $*$ & $*$ \\
\hline
\end{tabular}

The output of the predicate cycle will therefore be a number of groupings of the input elements, some aligned to a predicate, others aligned to each other. These groupings will be unordered with respect to each other. Because there are no unsatisfied predicate constraints, the mop-up cycle cannot decide grammaticality in this case $\mathrm{e}^{64}$.

Since the verb (or the predicate) is also an input element, our inventory of constraints includes a V1/V $\Omega$ pair of constraints as well. (In Section 2.3.8.3 I have already made use of the V1 constraint to account for Hungarian focal verbs.) This constraint is lowly ranked in English, so that it does not influence basic word order, but in cases of gapping will be relevant owing to the lack of influence of the predicate alignment constraints. (Note that though the candidates in the mop-up cycle in both (298) and (308) differ in terms of their satisfaction of V1, that will not disrupt conjunct ordering. In the superordinate functor cycle only the conjunction particle and the two verbs are placed. The internal make-up of the individual conjuncts and the possible ellipsis gaps they contain do not influence grammaticality. Once V1 would matter, it will be outranked by the licensing constraints.) Since the default domain of a first/last constraint is its predicate and all its dependents, in case of an input as in (312) the constraint will be relevant for the coordination cycle as well, as illustrated in (317).

\begin{tabular}{|c|c|c|c|c|c|c|}
\hline \& cycle & $f_{\&} L$ & $\mathrm{Af}_{\&}$ & $\mathrm{Lf}_{\&}$ & $f_{\&} \mathrm{~A}$ & V1 & $\mathrm{V} \Omega$ \\
\hline$\&$ loves $_{[\text {John, Mary] }[\text { Bill, Sue] }}{ }^{65}$ & & $\star \star !$ & $\star \star \star$ & * & "* & ** \\
\hline$\&_{[\mathrm{Bill}, \mathrm{Sue}]}$ loves $_{[\mathrm{John}, \mathrm{Mary}]}$ & & $\star \star !$ & $\star$ & $*$ & $* *$ & \\
\hline $\operatorname{loves}_{[J \mathrm{John}, \mathrm{Mary}]} \&_{[\mathrm{Bill}, \mathrm{Sue}]}$ & & $\star$ & & $\star$ & & $* *$ \\
\hline$\left[\right.$ Bill, Sue] $\&$ loves $_{[J o h n, ~ M a r y]}$ & & $\star$ & & $\star$ & $* ! *$ & \\
\hline 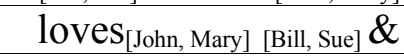 & $\star !$ & $*$ & & $\star \star$ & & $* *$ \\
\hline$\left[\right.$ Bill, Sue] $\operatorname{loves}_{[J o h n, \text { Mary }]} \&$ & $\star !$ & $*$ & & $\star \star$ & $*$ & $*$ \\
\hline
\end{tabular}

\footnotetext{
${ }^{64}$ The mop-up cycle would actually make the right prediction of conjunct ordering in case of two conjuncts, but not in case of three or more. The fA constraint could be better satisfied in the mop-up cycle than it was in the predicate cycle, because it would take one of the arguments of the elided conjunct as its second argument on the right side of the predicate. However, since it needs only one argument on top of its own object, the placement of the third conjunct in (311) could not be predicted. Thus even if we expanded on what could motivate a mop-up cycle, we would still not be able to explain multiple conjunction with gapping. (See also Section 4.3.2 for arguments concerning why an account of gapping based on predicate constraints would lead to the wrong cross-linguistic predictions.) As it becomes clear below, grammaticality can actually be decided before the mop-up cycle anyway.

${ }^{65} \mathrm{I}$ will take it that as long as there is material to the relevant side, the conjunction is licensed/has an argument. The representation [Bill, Sue] indicates that the exact positioning of these elements is not taken into consideration in this cycle, but one of them must appear behind the conjunction.
} 
Only those candidates survive into the next level in which the full conjunct is in initial position. Since conjunct order is already decided in the coordination cycle, once the predicate cycle determined the internal ordering of the conjuncts, the single optimal candidate will be identified. (The V1 constraint is not going to be relevant at this level, since in the case of the full conjunct the predicate constraint, while in case of the elided conjuncts the $\mathrm{S} 1 / \mathrm{S} \Omega$ constraints will be dominant.)

We have arrived at the following ranking for English:

(318) English: Parse » $\mathrm{Sp}, \mathrm{T} 1 » \mathrm{fA}, \mathrm{S} 1 » \mathrm{pS}, \mathrm{Af}, \mathrm{S} \Omega, \mathrm{A} 1, \mathrm{~A} \Omega » \mathrm{~V} 1 » \mathrm{~V} \Omega$

\subsubsection{Against Ross's generalization}

Before moving on to other cases of gapping, I would like to discuss an important prediction made by the grammar I have developed. It has been implicit in this analysis that the order of conjuncts in gapping may not be related to basic word order characteristics of a language - since it is the ranking of the first/last constraints, not the predicate alignment constraints that determine word order. This would contrast gapping with argument ellipsis, where conjunct order followed from basic word order facts, and would also contradict Ross' (1970) observation that conjunct order in gapping cases is directly related to the basic word order characteristics of a language.

Ross (1970) suggested that the direction of gapping could be used to test whether a language is underlyingly SVO, like English, or SOV like Japanese. He observed that in SVO languages gapping operates forward, and in SOV languages backward.

(319) a. I ate fish and Bill rice

b. * Bill rice and I ate fish

c. watakusi wa sakana o, Biru wa gohan o tabeta

I TOP fish OBJ Bill TOP rice OBJ ate

'I ate fish and Bill rice.'

d. * Biru wa gohan o tabeta, watakusi wa sakana o

(Ross 1970: 250-251)

Ross showed that the order in which gapping operates depends on the order of elements in the structure the gapping rule is applied to: if the identical elements are on 
the left branches of their respective structures gapping operates forwards. If they are on the right branches, gapping operates backwards. However, data from several verbfinal languages suggest that Ross's (1970) observation may not stand universally.

(320) Hindi

a. Mo:han ne Si:ta se aur Hari ne Gita se sa:di ki Mohan-ERG Sita-COMM and Hari-ERG Gita-INST marry-PST

'Mohan married Site and Hari Gita.'

(Sobha and Patnaik 2000: 9)

b. Mo:han ne Si:ta se sa:di ki aur Hari ne Gita se

(Aman Issar, p.c.)

(321) Malayalam

a. Raman Si:tayeyum Hari Ritayeyum kalyamam kaliccu.

Raman Sita-ACC-COORD Hari Rita-ACC-COORD marry do-PST

'Raman married Sita and Hari Rita.'

(Sobha and Patnaik 2000: 9)

b. Raman Si:tayeyum kalya:nam kaliccu Hari Ritayeyum

(Aman Issar, p.c.)

(322) Tundra Nenets

Xasawako xale ta0, many0 (nyanyih) nyany0m (taxd0m)

Xasawako fish brought, I (on the other hand) bread (brought)

'Xasawako brought fish, and I bread.'

(Salminen, 1995)

(323) Basque

a. Linda-k ardau eta Ander-ek esnea edaten dabez

Linda-ERG wine(ABS) and Ander-ERG milk(ABS) drink they.it

'Linda drinks wine and Ander milk.'

b. Linda-k ardau edaten du eta Ander-ek esnea

Linda-ERG wine(ABS) drink he.will and Ander-ERG milk(ABS)

'Linda drinks wine and Ander milk.'

(McCawley 1998: 286)

\footnotetext{
${ }^{66}$ Note also the difference in verbal agreement depending on the position of the shared verb. This further complicates matters.
} 
(324) Chuvash

a. Vasja KanaS-a kajaT Petja SupaSkar-a

Vasja Kanash-DAT go-PRS, 3SG Petya Cheboksary-DAT

'Vasja is going to Kanash and Petya to Cheboksary.'

b. Vasja KanaS-a Petja SupaSkar-a kajaT

Vasja Kanash-DAT Petya Cheboksary-DAT go-PRS, 3SG

'Vasja is going to Kanash and Petya to Cheboksary.'

(Kazenin 2001: 2)

Admittedly, the cases are not straight-forward: only in Nenets is the Ross pattern ungrammatical. In the other cases there is optionality between the pattern predicted by Ross and the opposite ordering. This, however, still contradicts his generalization.

Importantly, however, even where there is optionality in gapping, the directionality of argument ellipsis is strictly related to basic word order, as the data below illustrate. This suggests that the claim made in Newson and Gáspár (2001), and reviewed in Chapter 1, about the relationship between basic word order and the order of ellipsis can be maintained.

(325) Hindi

a. Si:ta ne ro:ti khayi aur cay pili

Sita-ERG roti eat-PST and tea drink-PST

'Sita ate roti and drank tea.'

(Sobha and Patnaik 2000: 9)

b. * ro:ti khayi aur Si:ta ne cay pili

(Aman Issar, p.c.)

(326) Malayalam

a. Sy:am kuttikale sne:hikkunnu pakse avanRe bha:rya verukkunnu

Syam children like-PRST but he-POSS wife hate-PRST

'Syam likes, but his wife hates children.'

(Sobha and Patnaik 2000: 9) 
I do not pretend to understand what is going on in these languages or why all the antiRoss examples found involved verb-final languages. The data, however, is compatible with the analysis of gapping and argument ellipsis provided here - whatever the details. Basic word order constraints are responsible for determining the order of the pre-formed conjuncts in case of argument ellipsis in the mop-up cycle: the functorfunctee constraint related to the verb with the missing argument survives into the coordination cycle because the verb's remaining valence needs to be satisfied. The same goes for topicalization, where the same $\mathrm{T} 1 / \mathrm{T} \Omega$ constraints that determine topic placement in basic sentences were relevant for topic ellipsis. The relative order of the $\mathrm{V} 1$ and $\mathrm{V} \Omega$ constraints, which may not be responsible for word order of the basic clause, determine the order of the conjuncts in case of gapping in the coordination cycle, because the predicate constraints for the elided clause are vacuously satisfied by all candidates and as such are irrelevant in determining grammaticality.

I will now move on to somewhat more complex examples of gapping, where the subject or the object is gapped along with the verb from one of the conjuncts. I will first discuss cases where the subject is gapped and the remnants are direct and indirect object and then present an analysis for cases with adjuncts in the remnant. Finally, I will look at the case when the object is gapped along with the verb.

\subsubsection{Subject-verb gapping: indirect object cases}

Sometimes verbs are not gapped alone. Subjects, for instance, can also go missing from one of the conjuncts. Even in this case the remnants of each missing predicate stick together in the internal order they would have in the presence of an overt predicate. (327) illustrates this for direct object-indirect object remnants ${ }^{67}$.

\footnotetext{
${ }^{67}$ The other reading of (327), in which Bill is the subject of the gapped verb, and its indirect object is missing is handled under the analysis established so far. V1 will account for the correct ordering of the conjuncts in the coordination cycle, while the subject and the direct object of the gapped conjunct will be ordered in the predicate cycle as discussed in the previous section.

The ambiguity between the two readings of (327) is due to the differing inputs associated with them. Note that the following sentence is only two ways ambiguous:

i. John showed Mary Bill and Dennis Rose

The object must be present in the elided conjunct - what is missing must be either the subject or the indirect object. This is in fact predicted by my theory: missing objects trigger backward ellipsis, so Bill cannot stand in as the object of the missing predicate. The correct construction for this meaning will be: ii. John showed Mary and Dennis Rose, Bill

This ordering is predicted by the theory here: the internal ordering of the remnants is handled as explained in this section, while the ordering of the conjuncts is determined by V1.
} 
In the second conjunct of (327) there is no predicate, so the fA constraint will be vacuously satisfied by all candidates. The evaluation is again left to the first-last constraints. $\mathrm{S} 1$ and $\mathrm{S} \Omega$ are not going to be relevant in the predicate cycle, because there is no subject. Recall from Section 2.2.2.2 that I have assumed that the indirect object - direct object ordering is accounted for by a universal ordering of the A1 (sub)constraints. Conjunct ordering is decided in the coordination cycle by $\mathrm{V} 1$ as before.

The ranking of the relevant constraints is the following:

$$
\begin{aligned}
& \text { English: } \mathrm{P}_{\mathrm{ARSE}} \text { » } \mathrm{Sp}, \mathrm{T} 1 \text { » } \mathrm{fA}, \mathrm{S} 1 » \mathrm{pS}, \mathrm{Af}, \mathrm{S} \Omega, \mathrm{A} 1 \text { » } \mathrm{A} \Omega, \mathrm{V} 1 \text { » } \Omega \\
& \mathrm{A} 1: \mathrm{A} 1_{\exp } \gg \mathrm{A} 1_{\text {th }} \\
& \mathrm{A} \Omega: \mathrm{A} \Omega_{\mathrm{th}} \text { 》 } \mathrm{A} \Omega_{\text {exp }}
\end{aligned}
$$

The account of gapping developed here is superior to the one in Newson and Gáspár (2001), because that theory could not handle the more complex cases of gapping in which the subject is elided along with the verb. Newson and Gáspár (2001) operated with predicate alignment constraints only, so could not use a constraint such as S1 and A1. Instead, it was argued that the subject of a gapped verb satisfies the Sp constraint in the predicate cycle by taking the object as a syntactic predicate, rather like a small clause arrangement. (In that paper the satisfaction of Sp was viewed from the position of the subject, not the predicate.) The need for the subject to take the object to align to ensured that floating arguments cluster together as 'clauses' and not drift apart. The availability of this approach hinges on the presence of a subject among the arguments of the missing verb. If, however, the subject is gapped along with the verb, as was the case in the examples in this section, this route is no longer available.

The present analysis does not face this problem: it can correctly predict cases where the subjects are gapped along with the verb. I have shown this in the case of direct object - indirect object remnants. In the following section I will show the same for cases when there is an adjunct in the remnant as well. 


\subsubsection{Subject-verb gapping: adjunct cases}

Not all gapping cases exclusively contain arguments. Subject-verb gapped conjuncts with an object and an adjunct stick together as well, and both follow the full conjunct. Our theory needs to predict (329) as well.

(329) John speaks English fluently, French impressively and Spanish badly

Though the development of a fully-fledged alignment analysis for adjunction is beyond the scope of this thesis, a rudimentary account can be provided based on the following standard adjunction observations:

- The internal ordering of adjuncts is optional when they are adjoined to the same element. Optionality is achieved if there there is only one $\mathrm{f}(\mathrm{Ad}) /(\mathrm{Ad}) \mathrm{f}$ constraint pair regulating the placement of all adjuncts with respect to their functor. Candidates [ $\mathrm{f} \mathrm{a} \mathrm{b}$ ] and [ $\mathrm{f} \mathrm{b}$ a], where $a$ and $b$ are adjuncts, will score equally on both constraints. For the first candidate, $\mathrm{f}(\mathrm{Ad})$ will be perfectly satisfied with respect to $a$ and will incur one edge violation with respect to $b$. The second candidate will occur an edge violation with respect to $a$ and will be satisfied perfectly with respect to $b$. Both candidates will incur two side violations on (Ad)f. Thus the total constraint violation profile of the two candidates will be the same, and the two orderings will emerge as equally optimal.

- When an internal adjunct ordering is found, it is due to the adjuncts modifying different elements (e.g. verbal versus sentential adjuncts). These adjuncts are likely placed in different cycles, though what exactly these adjuncts align to in terms of a theory that does not distinguish between clauses and phrases requires further investigation.

- Adjuncts follow/precede arguments, indicating that the ranking of $f(\operatorname{Ad}) /(\mathrm{Ad}) \mathrm{f}$ is universal with respect to predicate alignment: $f A » f(A d), A f » \operatorname{Ad}(f)$.

The kind of sentential adjuncts in (329) cannot interfere between the verb and its arguments (though they may interfere between the subject and the verb).

(330) a. John speaks English fluently

b. *John speaks fluently English 
c. John gave Mary a pen yesterday

d. *John gave Mary yesterday a pen

e. *John gave yesterday Mary a pen

f. John fluently speaks English

g. John yesterday gave a pen to Mary

If we claim that (330f) has a slightly different meaning from (330a), and (330g) from (330c) and hence they are related to different inputs, our makeshift adjunct theory needs to predict only (330a) versus (330b) and (330c) versus (330d-e). The adjunct in English is placed postverbally, which can be captured by the $\mathrm{f}(\mathrm{Ad})$ » $(\mathrm{Ad}) \mathrm{f}$ ordering ${ }^{68}$ - assuming that these are verbal/sentential adjuncts, so they need verbal licensing. Both of these constraints need to be outranked by fA, as was captured in the third point of the rudimentary adjunct theory.

Predicate and subject constraints are again irrelevant in the functor cycle of the gapped conjuncts, since these contain neither predicates nor subjects. By ranking Ad1 below A1, we predict the argument-adjunct ordering in these cases as well.

We have then arrived at the following ranking:

English: ParSe » $\mathrm{Sp}, \mathrm{T} 1$ » $\mathrm{fA}, \mathrm{S} 1$ » $\mathrm{pS}, \mathrm{Af}, \mathrm{f}(\mathrm{Ad}), \mathrm{S} \Omega, \mathrm{A} 1$ ( $\mathrm{Ad}) \mathrm{f}, \mathrm{A} \Omega, \mathrm{Ad} 1$ » $\mathrm{Ad} \Omega$ » $\mathrm{V} 1$ » $\mathrm{V} \Omega$

$$
\begin{aligned}
& \mathrm{A} 1: \mathrm{A} 1_{\exp } \gg \mathrm{A} 1_{\text {th }} \\
& \mathrm{A} \Omega: \mathrm{A} \Omega_{\text {th }} » \mathrm{~A} \Omega_{\exp }
\end{aligned}
$$

Similarly to the cases of gapping reviewed earlier, conjunct order is picked by V1 in the coordination functor cycle.

\subsubsection{Object-verb gapping}

It is not only the subject that can be gapped with the verb. As (332) illustrates, the object can also be elided, leaving behind a subject-adjunct remnant.

\footnotetext{
${ }^{68}$ Clearly this is a simplification. Yesterday and fluently are not the same type of adjuncts, and their ordering is fixed as the following examples illustrate:

i. John spoke English fluently yesterday

ii. *John spoke English yesterday fluently

These are the kind of details I do not intend to go into. What is required is an investigation of what sentential and verbal adjuncts are aligned to.
} 
(332) John speaks English fluently, Mary passionately and Bill vigorously

Everything I said about subject-verb gapping in the presence of adjuncts in the previous section will be relevant here as well - and sufficient for an account of the phenomenon. The functor-functee constraints will again be irrelevant in the case of the conjuncts with ellipsis, since they do not contain a predicate. The task to glue the remnants together will fall on the $1 / \Omega$ constraints in the predicate cycle, as before. S1 outranking Ad1 will yield the correct ordering in the rump conjuncts.

V1 will determine conjunct ordering in the coordination functor cycle.

This concludes my discussion on English gapping. I would now like to show that the mechanisms developed here can also handle Hungarian ellipsis phenomena.

\subsection{Hungarian shared topics}

I showed in Section 1.2 that Hungarian conforms to the general hypothesis that the basic word order of a language determines the order of conjuncts in argument ellipsis contexts. In what follows I would like to demonstrate how the grammatical mechanisms I have proposed can account for a range of Hungarian data. I will begin with the simplest case, shared topics.

The shared topic must appear in the first clause in Hungarian as well, yielding a forward ellipsis pattern similarly to English, discussed in Section 4.2.3:

$$
\begin{aligned}
& \text { a. *hámozza Mari és a krumplit vágja János } \\
& \text { peels Mari and the potatoes-ACC cuts János } \\
& \text { 'The potatoes, Mary is peeling and John is cutting' }
\end{aligned}
$$

b. a krumplit hámozza Mari és vágja János

The ranking of the constraints for Hungarian, justified in Section 2.2.2.3 and 2.3.3, is the following:

(334) Hungarian: $\mathrm{Sp}, \mathrm{pS} » \mathrm{P}$ ARSE » $\mathrm{T} 1 » \mathrm{fA} » \mathrm{Af}, \mathrm{T} \Omega$ 
The relatively high ranking of $\mathrm{T} 1$ forces the topic to the front of its conjunct, and it will also be this constraint which forces the FWE pattern. I will demonstrate this for the example in (333b), which has the input below. Note that the only way in which (333b) can be interpreted is that potatoes is also the object and the topic of the gapped conjunct. This needs to be indicated in the input by marking the topic status of the elided argument as well, as discussed for a similar English example in Section 4.2.3.

$$
\left[\begin{array}{lll}
\& & & \\
\mathrm{x}= & \text { hámozza }_{(\alpha)} & \\
& \mathrm{x}_{\mathrm{ag}, \text { sub }}= & \text { Mari } \\
\mathrm{y}_{\text {th, top }}{ }^{(\alpha)}= & \text { krumplit } \\
\mathrm{y}= & \text { vágja }_{(\alpha)}= \\
& \mathrm{x}_{\mathrm{ag}, \text { sub }}= & \text { János } \\
\mathrm{y}_{\text {th, top }}{ }^{(\alpha)}= &
\end{array}\right]
$$

Since the subject feature plays no role in determining the word order in Hungarian, and is underparsed at the expense of a faithfulness violation, I will omit the subject constraints from the tables below. T1, on the other hand, will be relevant in the evaluation of the peels conjunct, as it contains an item marked as topic.

\begin{tabular}{|c|c|c|c|c|}
\hline hámozza-vágja cycle & $\mathrm{T} 1$ & $\mathrm{fA}$ & Af & $T \Omega$ \\
\hline ... hámozza a krumplit ${ }_{\text {top }}$ Mari ... & $* !$ & * & $\star \star$ & * \\
\hline ... hámozza Mari a krumplit top... & $* ! *$ & * & $\star \star$ & \\
\hline ... a krumplit top Mari hámozza... & & $\star \star !$ & $\star$ & $* *$ \\
\hline ... a krumplit top hámozza Mari ... & & $\star$ & $\star$ & $* *$ \\
\hline ... Mari a krumplit top hámozza... & $* !$ & $\star \star !$ & $*$ & $*$ \\
\hline ... Mari hámozza a krumplit top ... & $* ! *$ & $\star$ & $*$ & \\
\hline
\end{tabular}

Since the candidates in case of the ellipsis conjunct contain no element marked as a topic, the topic constraints are vacuously satisfied, just like in previous examples where they were left out of the optimality tables altogether.

\begin{tabular}{|c|c|c|c|c|}
\hline hámozza-vágja cycle & $\mathrm{T} 1$ & fA & Af & $\mathrm{T} \Omega$ \\
\hline ... János vágja ... & & $\star ! ! 0$ & 必 & \\
\hline ... vágja János... & & $\sigma^{\prime \prime \prime}$ & $\star \sigma$ & \\
\hline
\end{tabular}

The following two candidates will survive at this stage:

(338) a. a krumplit hámozza Mari és vágja János

b. vágja János és a krumplit hámozza Mari 
T1 dominates the argument constraints, and since all input elements but the conjunction fall within its scope, it will select the FWE expression. This is illustrated in (339), where for expository purposes licensing constraint violations with respect to the two predicates are separated by a comma, with violations for vágja shown first.

\begin{tabular}{|c|c|c|c|c|}
\hline mор-ир cycle & T1 & fA & Af & $\mathrm{T} \Omega$ \\
\hline vágja János és a krumplit ${ }_{\text {top }} h$ & $* ! * *$ & $* * *, \star$ & $\star \star, \star$ & *** \\
\hline a krumplit top hámozza Mari és vágja János & & $\star, * * *$ & $* * * *, \star$ & $* * * * *$ \\
\hline
\end{tabular}

\subsection{Gapping in Hungarian}

In gapping, too, we find similarity with English as far as the ordering of the conjuncts is concerned: the full conjunct has to be initial.
a. SZERETI Mari Jánost
és Erzsi Ferit
loves Mari János-ACC and Erzsi Feri-ACC
'Mary loves John and Liz Frank'
b. * Erzsi Ferit és SzeRETi Mari Jánost

Since the subject feature plays no role in the syntactic organization of Hungarian, we cannot carry over the treatment of English gapping: the subject feature needs to be underparsed, which will cause a valence violation by all candidates with a realistic chance to win. Because the subject feature of both subjects is underparsed, this valence violation cannot be resolved in the mop-up cycle (see 4.2.4). Since the object and the subject are both arguments, $A 1 / A \Omega$ are going to be violated equally by both orderings, and so cannot be relied on to determine word order in the rump conjunct.

If there is no distinction between the arguments in each conjunct, the arguments should be able to align in any order. To some extent this is true, in that both nominative-accusative and accusative-nominative word orders can be found:
a. SZERETI Mari Jánost és Erzsi Ferit
b. SZERETI Jánost Mari és Ferit Erzsi

However, the theory developed so far would predict that either order of the arguments would be possible in each conjunct independently of the other. This is not the case: 

a. *? Szereti Mari Jánost és Ferit Erzsi
b. *? SZERETI Jánost Mari és Erzsi Ferit

There appears to be a further restriction on these examples forcing a parallel ordering of the arguments in each conjunct, so that if the nominative argument is first in the non-elided conjunct, the corresponding argument must be first in the gapped conjunct.

In order to account for these sentences, I will make use of the results of the investigation into verb-initial Hungarian constructions in Section 2.3.8. I concluded that verb-initial structures are not as neutral as argued by É. Kiss (1994). Instead, they contain a heavily stressed verb that needs to be in initial position, and a topic, which having been forced out of its pre-verbal spot - immediately follows the verb.

The discussion on the status of emphatic initial verbs has showed that the two sentences in (341), repeated here as (343a,c), have different input elements marked as topics: in (343a) the objects, while in (343c) the subjects are the topics. (343a) and (343c) must then belong to different inputs, and as such are never in competition. (Inputs in which subject and topic marking and thematic role assignment are not parallel this way will not be interpretable. I will return to this issue in Chapter 5.)

(343) a. szereti Jánost Mari és Ferit Erzsi

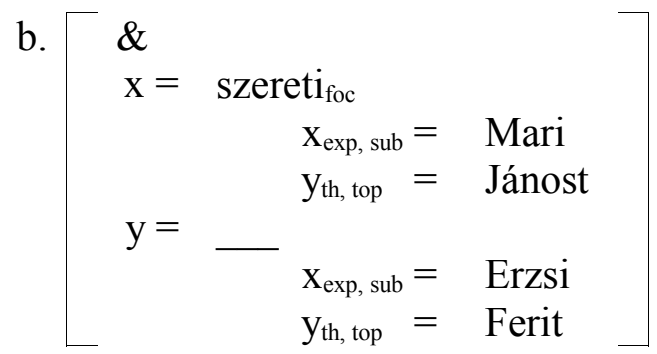

c. SZERETI Mari Jánost és Erzsi Ferit

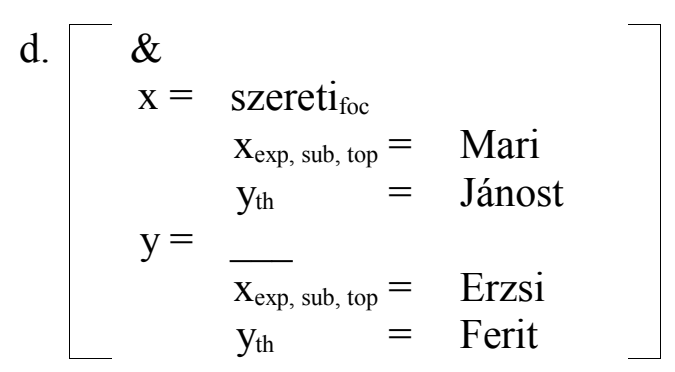


In Section 2.3.8.3 the following ranking was established:

(344) Hungarian: $\mathrm{Sp}, \mathrm{pS} » \mathrm{P}$ ARSE » $(\mathrm{V} 1 \& \mathrm{~F} 1) » \mathrm{~T} 1 » \mathrm{~F} 1 » \mathrm{fA} » \mathrm{Af}, \mathrm{T} \Omega, \mathrm{F} \Omega, \mathrm{V} 1$

The coordination functor cycle not only places the conjunction in the middle, but also determines conjunct order: the local conjunction (V1\&F1) is relevant here. Since the default domain of a $1 / \Omega$ constraint is its functor and the functor's dependents, in the current case that is going to mean the entire input. This places the full conjunct first.

The predicate cycle delivers the two conjuncts. The predicate cycle for the first conjunct of (343a) is the same as that of any verb-initial Hungarian clause, discussed in Chapter 2. The table below, including only the relevant constraints, illustrates how the interaction of the constraints in (344) yields the correct result for the full conjunct.

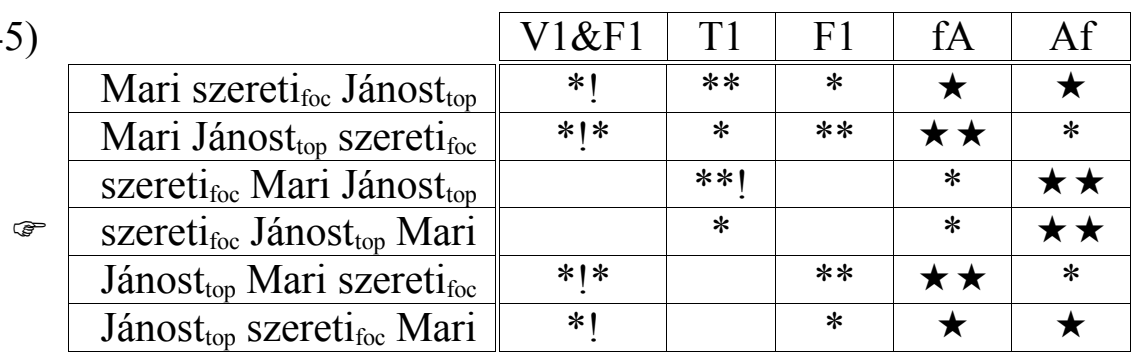

In case of the second conjunct, there is no predicate specified in the input, so V1 and the argument constraints are going to be vacuously satisfied by all faithful candidates. F1 is vacuously satisfied, since no element is marked for focus in this conjunct. The topic feature, however, is specified in the input, so it is relevant in the predicate cycle: the topicalized element will come first among the elements in the remnant.

\begin{tabular}{|c|c|c|c|c|c|}
\hline szereti cycle & V1\&F1 & $\mathrm{T} 1$ & F1 & fA & Af \\
\hline$\ldots$ Erzsi Ferit $_{\text {top }} \ldots$ & & $* !$ & & & \\
\hline$\ldots$ Ferit $_{\text {top }}$ Erzsi ... & & & & & \\
\hline
\end{tabular}

Gapped conjuncts in multiple coordination cases can also be explained this way: further verbless conjuncts will stick together in the grammatical order the same way as just described. This is illustrated in (347), this time with the experiencer marked as topic in the input.

a. SZERETI Mari Jánost, Erzsi Ferit és Juli Bélát

'Mary loves John, Liz Frank and Julia Béla.' 


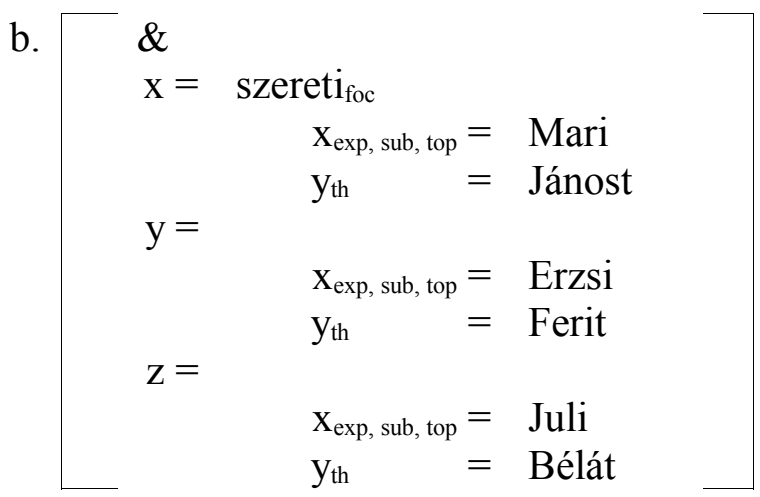

The predicate cycle for both verbless clauses will be as in (348). Though the subject feature of the subjects is underparsed, being topics, they will still come first.

\begin{tabular}{|c|c|c|c|c|c|}
\hline szereti cycle & $\mathrm{V} 1 \& \mathrm{~F} 1$ & T1 & F1 & fA & Af \\
\hline$\ldots$ Erzsi $_{\text {top }}$ Ferit & & $* !$ & & & \\
\hline$\ldots$ Ferit Erzsi $i_{\text {top }} \ldots$ & & & & & \\
\hline
\end{tabular}

Though I have provided an account for the examples in (341), the unacceptability of the non-parallel examples in (342) is yet to be explained. I will put this issue to the side for the time being, and will return to it in Chapter 5, where I will demonstrate that parallelism has semantic and not syntactic roots.

\subsection{Problematic Hungarian cases}

Though the analysis presented here is capable of explaining many coordination patterns, it faces problems. Some of these problems are enumerated in this section with only hypothetical and speculative solutions sketched out.

\subsubsection{Shared theme vs. shared agent}

The account developed here solves a problem in Newson and Gáspár (2001) related to the coordination of verb initial argument ellipsis, such as the examples in (349) ${ }^{69}$.

\footnotetext{
${ }^{69}$ The reason for the slight degradation of (349a) and (349b) is that the sentences are contrastive and therefore normally call for the presence of the contrastive marker pedig. However, this would interfere with the word order in that the contrasted element is moved to the left of this marker. In order to maintain the basic verb initial order I have excluded the contrastive marker, which causes degradation of grammaticality in (349a) and (349b). The important observation, however, is that (349c) and (349d) are much worse than (349a) and (349b).
} 

a. ?hámozza Mari és vágja János a krumplit peels Mari and cuts János the potato-ACC
'Mary is peeling and John is cutting the potatoes.'
b. ?hámozza Mari és vágja a krumplit János
c. *vágja János a krumplit és hámozza Mari
d. *vágja a krumplit János és hámozza Mari

The problem faced in Newson and Gáspár (2001) was that (349b) won in what in this thesis I call mop-up cycle over the other three structures - and (349a) was predicted to be ungrammatical, contrary to fact. This is because in the final cycle the object krumplit was further removed from the predicate of the first conjunct in (349a) than in (349b), which meant that (349a) contained an extra side violation compared to (349b).

Given the input assumptions developed in Chapter 2, (349a) and (349b) should not be viewed as competing candidates. In the input of (349a) it is the subject of the full conjunct that is marked for topic status, while in the input of (349b), it is the object. The verb is marked for emphasis in both, so the conjuncts will be verb initial. Whichever argument of the full conjunct's predicate is marked as topic will be verb adjacent in the winning candidate. In the case of the input when krumplit is marked as topic, (349b) will win over (349a). For the input with János marked as topic, (349b) will incur an extra T1 violation compared to optimal (349a). This will be decided in the predicate cycle. The mop-up cycle will eliminate candidates in which the conjuncts themselves are well formed, but where the shared argument is in the initial conjunct, such as $(349 \mathrm{c}, \mathrm{d})$. This is due to the fA constraint: when the full conjunct comes second, both verbs find two arguments to their right to align with, and so no side violation is incurred. When, on the other hand, the full conjunct comes first, fA registers a side violation with respect to the conjunct of the elided clause.

When the agent, and not the theme, is shared, however, problems arise.

For shared agents both word orders appear to be grammatical. This contradicts the theory developed here, since based on the discussion so far the post-verbal shared agent should follow both verbs - i.e. the FWE pattern (350a) and (350b). 
a. ? hámozza a krumplit és vágja a répát Mari peels the potato-ACC and cuts the carrot-ACC Mari

'Mary is peeling the potatoes and cutting the carrots.'

b. ? hámozza a krumplit és vágja Mari a répát

c. ? vágja a répát Mari és hámozza a krumplit

d. ? vágja Mari a répát és hámozza a krumplit

This difference in behavior between shared themes, where only the FWE pattern is grammatical and shared agents, where both ellipsis patterns are allowed, correlates with the asymmetry in the pro-drop nature of Hungarian: agents can be missing but objects of transitive verbs need to be present.

The subjectless conjuncts in (350) are grammatical on their own, and interpretable given the right context, while the objectless conjuncts of (349) are ruled out:

$$
\begin{aligned}
& \text { a. hámozza a krumplit } \\
& \text { peels the potato-ACC } \\
& \text { 'pro is peeling potatoes.' } \\
& \text { b. *hámozza Mari } \\
& \text { peels Mari } \\
& \text { 'Mari is peeling pro.' }
\end{aligned}
$$

To give a convincing explanation of this difference, a theory of empty categories within alignment OT would be required. What is needed is careful consideration of whether pro (or PRO) is an empty input element, whether empty categories are the (unfaithful) non-realisation of overt input material or whether the inputs are impoverished similarly to (coordinate) ellipsis, with recoverability based on the rest of the input. The development of such a theory is beyond the scope of this work.

Whatever the explanation for empty categories, the inputs of (350c) and (350d) then are not impoverished the way inputs of elliptical sentences are. (350a) and (350b) then can have two possible inputs. They can be the outcome of the optimality system of two full conjuncts with one of them containing an empty category. Since both conjuncts are 'full,' order does not matter, and the tie in (350) is predicted. 
Alternatively (350a) and (350b) can have impoverished, elliptical inputs, with the missing agent semantically reconstructed under identity with the overt agent. When the inputs are impoverished, FWE-patterned (350a) and (350b) are the only winning candidates, but when the inputs are full (350a) and (350c) are optional for an input with répát and krumplit marked for topic and (350b) and (350d) are joint winners when Mari and 'pro' are marked for topic.

\subsection{2 'Gapping' out of verb-final conjuncts}

In Hungarian verb final "gapping" cases we find unexpected optionality. This is illustrated in (352), an example where both conjuncts contain a topic and a focus marked argument. For the input to be interpretable, the arguments need to be parallel with the arguments of the overt predicate.

a. Feri Erzsit (és) János (pedig) Marit szereti

Feri Erzsi-ACC and János CONTR Mari-ACC loves

'As for Frank, (of all women) he loves Liz and as for John, Mary.'

b. János MARIT szereti (és) Feri (pedig) Erzsit

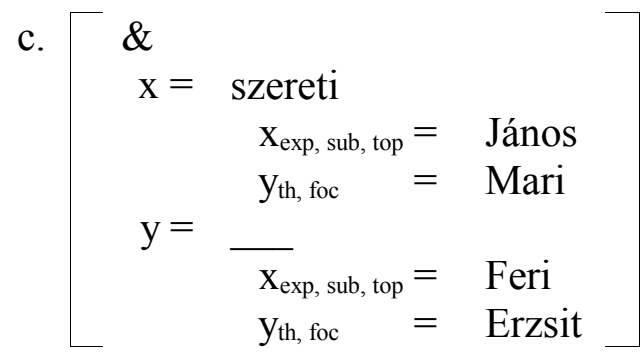

The verb-final status of the full conjunct suggests that the theme is in focus, while the experiencer is in topic position - as illustrated in the input in (352c). Due to parallelism, the corresponding arguments in the gapped conjuncts also need to carry the same information roles, and they will be ordered by the T1»F1 hierarchy.

Though the verb is not emphatic, and as such the highly ranked (F1\&V1) will not apply, there is nothing to stop the lowly ranked V1 from placing the full conjunct first in the coordination functor cycle: the domains of $\mathrm{F} 1$ and $\mathrm{T} 1$ will be the conjuncts, but the default domain of V1 will be its functor and its functor's dependents, i.e. the entire input. The full conjunct will be as in (352b), but contrary to (352a). 
A possible solution may be to rank V1 and V $\Omega$ equally at the bottom of the hierarchy for Hungarian. This would mean that the ordering of the conjuncts is not decided in the conjunction functor cycle, but both orderings of the conjuncts would proceed to the predicate functor cycles, predicting optionality.

The mop-up cycle, as currently defined, would undermine this optionality and pick (352b) over (352a), since fA can be better satisfied with respect to the predicate with the help of the arguments of the elided predicate. In this case the verb would align with its own arguments to satisfy the higher ranking T1 and F1 constraints, but it could still satisfy fA without incurring a side violation. This problem could actually be addressed by redefining the application of the mop-up cycle: if we assumed that the mop-up cycle takes place only when there is a valence violation during the normal cycles, this problem could be addressed and the optionality retained.

However, even in this case the explanation for optionality would actually undermine the account for cases in which only one of the verbal arguments is preverbal. As the examples below illustrate, in such cases the full conjunct must be initial - a prediction that is born out of the influence of lowly ranked V1 in the conjunction functor cycle.
a. János szereti Marit
(és) Feri (pedig) Erzsit

János loves Mari-ACC and Frank CONTR Liz

'As for John, he loves Mary and as for Frank, he loves Liz.'

b. * Feri Erzsit és János szereti Marit

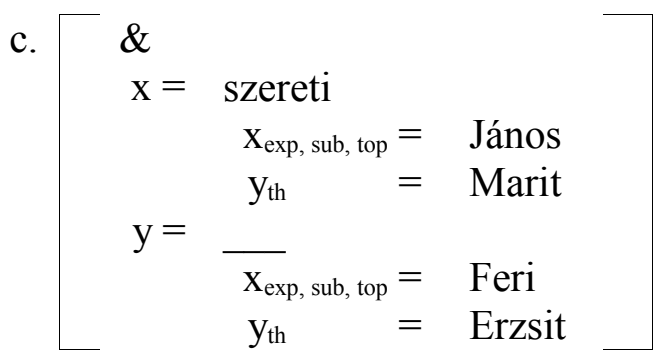

Finding solutions to these problematic cases is left for future work. 


\subsection{Conclusion}

In this chapter I have shown how the observation made in Chapter 1 on the directionality of ellipsis can be captured: the same principles that accounted for basic clause structure are used to predict the direction of argument ellipsis. This required the introduction of a third kind of constraint violation (valence violation) and the mop-up cycle, where alignment with elements not available in the functor cycles is attempted.

The system developed here also accounted for the asymmetry in the relationship between basic word order and ellipsis directionality: while argument ellipsis is related to basic word order, gapping directionality is not, contrary to the claim by Ross (1970). This empirical difference is predicted by the present theory, where licensing constraints are used to account for both basic word order and argument ellipsis, while first/last constraints are responsible for gapping.

The unacceptability of examples such as (342), repeated below, was not explained.

$$
\begin{aligned}
\text { (354) a } & \text { *? SZERETI Mari Jánost és Ferit Erzsi } \\
\text { b } & * \text { ? sZeretI Jánost Mari és Erzsi Ferit }
\end{aligned}
$$

I suggested that the unacceptability has semantic, not syntactic causes, a claim that has yet to be substantiated. This will be the topic of the next chapter.

Before concluding it is important to note that the introduction of valence violations and the mop-up cycle do not lend a helping hand to the vast majority of impoverished input cases. The problem with cases of impoverished inputs, in which there is no blueprint for the missing element to be recovered from, is semantic, not syntactic (see Section 2.2.1.4). Since these inputs are uninterpretable, no matter which candidate generated from the input emerges as optimal syntactically, it will still be anomalous, owing to semantic uninterpretability. The introduction of the mop-up cycle may influence which candidate from such an input emerges as optimal, but it will not change the uninterpretability of the grammatical candidate - as this uninterpretability is due to the input from which all of the competing candidates have been generated. 


\section{Unificational theory of semantic recovery}

A common theme running through earlier chapters has been that of parallelism, the apparent requirement that in coordinate ellipsis the gap be sufficiently parallel with its antecedent. Often syntactic theories of coordination take it upon themselves to explain this restriction. In contrast, I have taken the view that parallelism is semantic in nature, and is constrained by semantic recovery facts: for the gap to be assigned the intended interpretation, the elided element and the blueprint from which it is interpreted need to be sufficiently similar both in terms of features and positioning within their respective conjuncts. The previous chapters were syntactic in focus, so that hypothesis was enough to deal with the issues considered there. In the final chapter of the thesis I would like to substantiate this hypothesis, and give a semantic account of the parallelism requirement.

That syntax can even in principle be left out of the discussion on ellipsis recovery is due to the key assumption in the present framework that semantic interpretation is based on the input, not the output of the syntactic optimality system (Newson 1998a, 2000a). As such, meaning is not passed through syntax from the lexicon to semantics.

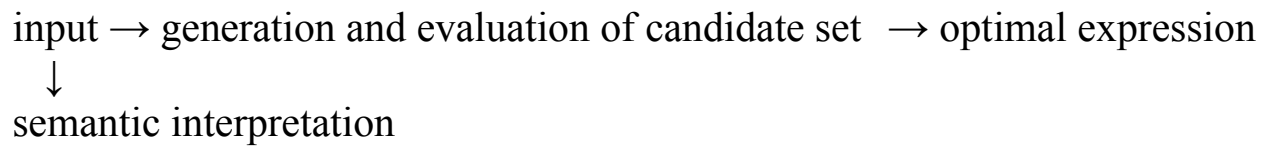

I have viewed ellipsis not as missing or unpronounced syntactic material, but as the faithful realization of missing input material, which needs reconstruction at the semantic level. The semantic operation takes place on the material in the input, which I have viewed as a data structure, organized around functors, whose subcategorization needs are responsible for the appearance of subsumed data slots in the template (Section 2.2.1.3). This is illustrated in (356) for full inputs, and in (357) for impoverished inputs.

$$
\left[\begin{array}{lll}
\& & & \\
\mathrm{x} & = & \text { came in } \\
\mathrm{y}= & \mathrm{x}_{\mathrm{ag}, \text { sub }}= & \text { John } \\
& \text { sat down } & \\
\mathrm{x}_{\mathrm{ag}, \text { sub }}= & \text { Mary }
\end{array}\right]
$$




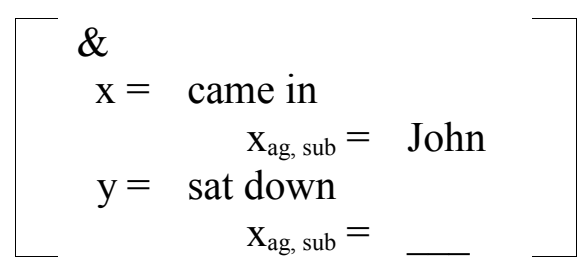

I have supposed that while the vast majority of inputs with unfilled data slots are uninterpretable, the kinds of impoverished inputs that are interpretable by the semantic component will give rise to ellipsis constructions. Though the syntactic optimality system does churn out a candidate for every input, this candidate input will often be semantically deviant and the resulting grammatical sentence unacceptable on semantic grounds. In this chapter I would like to define under what conditions impoverished inputs can receive an interpretation.

In the first section of the chapter I will discuss the apparent parallelism requirement in case of non-elliptical coordination and conclude that parallelism is a cognitive restriction (5.1). I will then review and round out the ellipsis parallelism observations that have arisen at various points in earlier chapters, showing that a stronger parallelism requirement is apparent in case of ellipsis than in full-clause coordination (5.2). Based on the data of the first two sections, I will develop a unificational theory for semantic recovery, which will consist of a two-step process: the pre-unificational competition that selects the most similar item from among the input items of the full conjunct to serve as the potential blueprint for the reconstruction of the ellipsis gap, followed by the unification procedure itself, during which it is established whether the selected item and the gap have feature sets that are non-conflicting enough for unification to take place. I will discuss the unification process first (5.3) and then motivate and introduce the pre-unification competition (5.4). I will conclude with a short section on conjunction recovery in cases of multiple coordination (5.5).

\subsection{Non-parallel full clause coordination}

Since in Chapter 4 I dealt with ellipsis, many of the apparent parallelism observations were made in terms of elided elements. For instance, while I established that gapping in Hungarian operates in a forward direction, the syntactic theory developed did not rule out the non-parallel structures in (358c-d). If in the input of (358a) Mari and Ferit - i.e. the experiencer of the full clause and the theme of the elided clause - are to be 
marked for topic status, the grammar should churn out $(358 \mathrm{c})$ as the optimal candidate, given the mechanisms introduced so far.

(358) a. SZERETI Mari Jánost és Erzsi Ferit

loves Mari János-ACC and Erzsi Feri-ACC

'(Of all the relevant feelings) it is love that Mary feels towards John and Liz towards Frank'

b. SZERETI Jánost Mari és Ferit Erzsi

c. *? SZERETI Mari Jánost és Ferit Erzsi

d. *? szereti Jánost Mari és Erzsi Ferit

I suggested that the unacceptability of these sentences has semantic roots.

Note, however, that the full versions of the sentences in (358c-d) are also odd, which suggests that the problems with $(358 \mathrm{c}-\mathrm{d})$ are related not to ellipsis, but to coordination in general.

(359) a. *? SZERETI Mari Jánost és SZERETI Ferit Erzsi

b. *? SZERETI Jánost Mari és SZERETI Erzsi Ferit

This oddity could be related to the unnatural presence of the second instance of the identical verb, so let us consider a case of verb-initial, emphatic coordination in which the verbs are not identical. As (360) shows, parallel structures are preferred even when there is no ellipsis.

a. ? SZERETI János Marit és UTÁLJA Feri Erzsit

loves János Mari-ACC and hates Feri Erzsi-ACC

'John loves Mary and Frank hates Liz.'

b. ?? SZERETI János Marit és UTÁLJA Erzsit Feri

loves János Mary-ACC and hates Erzsi-ACC Feri

'John loves Mary and Frank hates Liz.'

c. ?? SzERETI János Marit és/de Feri utálja Erzsit

loves János Mary-ACC and/but Feri hates Erzsi- ACC

'John loves Mary and/but Frank hates Liz.' 
While parallel structures are preferred, none of the examples are perfectly fine. The problem with (360a) seems to be that we are coordinating two clauses in which the verbs are emphasized, predicting a contrast of sort, but the conjuncts are full conjuncts, so they are not contrastive at all. Note that it is similarly odd, for reasons beyond grammaticality, to coordinate two full clauses with focal arguments ${ }^{70}$ :

(361) ? Mari A VIRÁGOKAT szereti esőben locsolni és János (pedig) a Mari the flowers-ACC likes rain.in water-INF and János (CONTR) the TEHENET utálja ködben fejni cow-ACC hates fog.in milk-INF '(Of all her plants in the garden) it is the flowers that Mari likes watering when it rains, and (of all the relevant animals) it is the cow that János hates to milk when there is fog.'

Non-parallel structures float in the grey area between simple weirdness and outright unacceptability in English as well.

(362) a. ?* I lent the axe to my uncle and to my nephew the saw

b. ? (I cannot go chop wood now.) I lent my uncle the axe and the saw to my nephew.

Coordinating two full interrogative clauses (363a) or two full declarative clauses (363b) is acceptable, but coordinating a declarative and an interrogative clause is unacceptable, regardless of their order (363c-d).

(363) a. who did you see and why did you meet them

b. John is a fool and Mary is an idiot

c. * who did you see and John is a fool

d. * John is a fool and who did you see

Since we are coordinating two full, grammatical clauses, this unacceptability cannot have anything to do with grammaticality. There must be a semantic/cognitive

\footnotetext{
${ }^{70}$ The example needs to be this complicated to avoid an unintended contrast being forced into the interpretation.
} 
constraint in operation. It seems that two sentences with different semantic/pragmatic functions cannot be coordinated. This is likely a case of parallelism forced on us by the way the mind works: it has either got to be dealing with statements or questions, but not both at the same time.

Placing a topic feature on one argument or another affects the semantic/pragmatic function of a sentence as well and hence non-parallel coordination constructions of this kind are also odd.

(364) ? it was John that I saw and in the park that I met Bill

The fact that (364), in contrast to (363c-d), is just odd and not outright unacceptable illustrates that the strength of the parallelism restriction depends on the type of nonparallel structures being coordinated. It seems that interpreting non-parallel topics in coordination causes a lesser cognitive burden for the mind than interpreting the conjunction of a declarative and an interrogative sentence.

Panenová (1974) also argues that semantic notions have a bearing on grammaticality in coordination. She observes that certain kinds of semantic functions are easier to coordinate even if syntactic conditions for their coordination are not met. Within the framework of the dependency grammar she adopts, coordination of unlike dependents is not possible, but if the syntactically unlike dependents are compatible semantically, coordination is salvaged. This is illustrated by the following Czech examples.

(365) a. udělán to kůvli ván a abych už měla konečně pokoj

'I'll do it because of you and to have some peace at last.'

b. ? přes svou naprostu vyčerpanost, ale pro své zdraví odjel na venkov už včera 'In spite of his total exhaustion but for the sake of his health he went to the country already yesterday.'

c. * při zvýšené opatrnosti v jízdě a pro dobrý stav komunikací se nemůže nic stát 'With an increased cautiousness in driving and because of the good state of the roads nothing can happen.'

(Panevová 1974: 14)

In (365a) the coordination of cause and aim is possible, because these are semantically related concepts in as much as they are the logical opposites of each other. Aim and 
concession in (365b) are harder to coordinate, and cause and condition are completely unrelated concepts, which is why they are impossible to coordinate as (365c) illustrates. Panenová (1974) does not, however, define in what sense these semantic notions are related or unrelated to each other.

Full clause parallelism is also apparent in cases of scope ambiguity. Where the full conjunct exhibits quantifier scoping ambiguities the scopes in the two conjuncts must be the same. Hirschbuehler (1982) noted that (366) is only two-way ambiguous:

(366) two European languages are spoken by many linguists, and two Asian ones too

The first conjunct of (366) is scope ambiguous between two readings, and so is the second conjunct. But a parallelism is forced on the ambiguities: either the interpretation is the wide scope existential one in both cases (i.e. two specific European languages and two specific Asian languages are spoken by many linguists) or it is the narrow scope existential one for both (i.e. that many linguists speak two European languages and many linguists speak two Asian languages). The interpretation that two specific European languages are spoken by many linguists who each speak two different Asian languages as well is not available and neither is the opposite interpretation, in which each linguist speaks two (random) European languages but they all speak the same two specific Asian ones.

Parallelism restrictions from other areas of cognitive science lend further support to the view that the unacceptability of the cases above is not grammatical but semantic/cognitive. Dutch graphic artist M. C. Escher (1898-1972) based his art on optical illusions - and on the limitations the mind places on interpreting what we see. In the drawing Concave and Convex, the left hand third of the drawing is convex, while the right hand third is concave. The middle section can be seen as either:

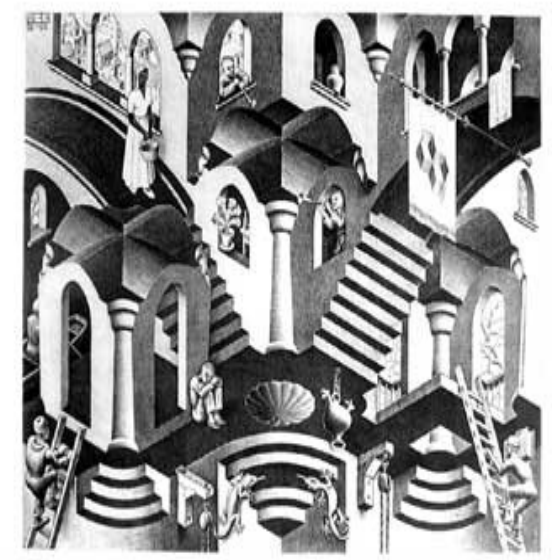

Illustration 1: M. C. Escher: Concave and Convex we either have an exterior or an interior view of the house with the crossvaulted roof in the middle. Significantly, depending on whether we view the middle section with the left or with the right, the house in the middle 
assumes the same view as the one with definite spacial interpretation next to it (Escher 1986: 68). Parallelism in visual perception is forced on the mind.

\subsection{Parallelism and ellipsis}

Let me now return to ellipsis where, as the examples at the beginning of this chapter showed, the parallelism requirement is stronger than in the case of full conjuncts. The cognitive restriction discussed in the previous section is likely amplified when the mind has to not only interpret but also reconstruct content missing from the input. (358), a case of elliptical, non-parallel coordination is repeated here as (367) and (360b), an example of non-parallel full coordination, as (368).

(367) a. *? SZERETI János Marit és Ferit Erzsi

b. *? szereti Marit János és Erzsi Ferit

$$
\begin{aligned}
& \text { ?? SZERETI János Marit és UTÁLJA Erzsit Feri } \\
& \text { loves János Mary-ACC and hates Erzsi-ACC Feri } \\
& \text { 'John loves Mary and Frank hates Liz.' }
\end{aligned}
$$

The subject of this section is to explore the causes of this stricter restriction. I will first review what has by now become the classic parallelism observation of Wilder (1997): the distinction between forward and backward (argument) ellipsis in terms of the differing strength of the parallelism requirement (5.2.1) and the empirical and theoretical problems faced by this account. In Section 5.2.2 I will discuss parallelism in case of gapping and propose that certain features that are typically seen as argument features can be thought of as being semantically marked on the predicate. This view can explain the parallelism. I will briefly discuss multiple topicalization in Hungarian, which provides support to the cognitive view of parallelism proposed (5.2.3). 


\subsubsection{Wilder (1997): BWE vs. FWE}

I discussed in Section 1.1.3 the distinction made by Wilder (1997) between forward and backward ellipsis. Though I argued that the distinction is not as rigid as Wilder (1997) claimed, and as such I viewed cases of FWE and BWE as competing word orders, the gist of the parallelism observations remains valid: The elided element needs to be in some sense parallel to its antecedent in the full conjunct.

Wilder (1997) argued that FWE requires a stronger kind of parallelism, which he termed structural parallelism: both the elided material and its overt counterpart must be in structurally identical positions within their own conjuncts:
a. Mary said John hit Bill and ran away
b. Mary said John hit Bill and ran away
c. * Mary said John hit Bill and ran away

The elided subject can only be recovered from a structurally parallel subject in the preceding clause. This can happen either from the main clause subject (Mary), in which case the clause of the elided subject is interpreted as non-embedded, or from the embedded clause subject (John), in which case the second clause is interpreted as embedded. What is not possible is for the elided subject to be recovered from the embedded subject AND for its clause to be interpreted as non-embedded.

String parallelism, relevant for BWE, imposes looser restrictions. The elided material must be in the same position as its overt counterpart, i.e. at the right edge of their respective conjuncts, but crucially the two do not have to be structurally parallel in that they may, for example, be related to elements at different levels of embedding.
a. John likes but I think Mary hates garlic
b. I think John likes but Mary certainly hates garlic

Wilder's argument is that these differences between FWE and BWE indicate that the two are due to different mechanisms: recovery in FWE is syntactically restricted to structurally parallel positions, while recovery in BWE is phonologically restricted to parallel positions in the phonological string. Under the view adopted in this thesis, 
recovery is a semantic process and so such restrictions seem better placed in the semantics rather than in the syntax.

I have noted in Section 1.2.1, following Newson and Gáspár (2001), that in fact not every case of FWE demonstrates strucutral parallelism, only those involving elided subjects - suggesting that it is the recovery of the subject that would force structural parallelism, not the FWE pattern. Thus the theory we develop needs to account for the special restrictions placed on the subject, not on all cases of FWE.

(371) Marmite, John hates but Mary said Peter loves

In the case of (371), it might be argued that the elided element is sitting in (a structurally parallel) topicalized position in the second conjunct. But (371) is also compatible with an account of parallelism under which the gap of the topicalized nonsubject is in a structurally non-equivalent topic position in the second conjunct. In one interpretation the elided topic has scope over te main clause and in the other it takes scope over the embedded clause. The two inputs are provided below - with the difference between them marked in terms of topic scope in the impoverished conjunct.

(372) a. Marmite, John hates but Mary said Peter loves

b. but

$$
\begin{aligned}
& \mathrm{x}=\text { hates } \\
& \mathrm{x}_{\text {exp, sub }}=\text { John }
\end{aligned}
$$$$
\mathrm{y}_{\mathrm{th}, \text { top }}=\text { Marmite }
$$$$
\mathrm{y}=\text { said }
$$

$$
\begin{array}{ll}
\mathrm{x}_{\mathrm{ag}, \text { sub }} & =\text { Mary } \\
\mathrm{y}_{\mathrm{th}(\alpha)}= & \text { loves }
\end{array}
$$

$\mathrm{X}_{\mathrm{exp}, \text { sub }}=$ Peter

$\mathrm{y}_{\mathrm{th}, \text { top }}{ }^{(\alpha)}=$

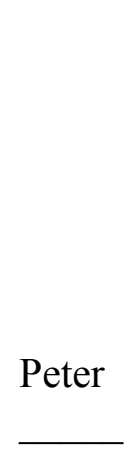

c. Marmite, John hates but Mary said Peter loves

b. $[$ but

$$
\mathrm{x}=\text { hates }
$$

$$
\mathrm{X}_{\mathrm{exp}, \mathrm{sub}}=\mathrm{John}
$$$$
\mathrm{y}_{\mathrm{th}, \text { top }}=\text { Marmite }
$$$$
\mathrm{y}_{(\alpha)}=\text { said }
$$$$
\mathrm{x}_{\mathrm{ag}, \text { sub }}=\text { Mary }
$$$$
\mathrm{y}_{\mathrm{th}}=\text { loves }
$$

$$
\begin{aligned}
& \mathrm{x}_{\text {exp, sub }}=\text { Peter } \\
& \mathrm{y}_{\text {th, top }}(\alpha)=
\end{aligned}
$$


Since both of these are legitimate inputs, possible to capture within the theory developed here, the data casts doubt on Wilder's (1997) observation. Consider also the following, anti-Wilder pattern.

(373) a. I think John will do the washing up but Mary certainly won't

b. John will do the washing up but I think Mary won't

Wilder (1997) discounts data such as those given in (373), as what is traditionally called VP deletion is not restricted to a forward direction. However, given that his account stipulates the relationship between the direction of ellipsis and the different types of parallelism rather than causally linking them, ignoring such data is tantamount to sweeping potential problems under the carpet.

Given the data above, what our theory needs to account for is the string parallelism in case of non-subject ellipsis and the stricter, structural parallelism in subject ellipsis.

\subsubsection{Gapping and predicate marking}

Clearly, not all information present in the input can be filled in from the full conjunct, even if all extralinguistic conditions are met for recoverability. In many languages only non-meaningful morpho-phonemic differences are allowed for the elided material to be recoverable (374). This is the case, even though (374b) should be perfectly interpretable due to the presence of the time adverbials.

$$
\begin{aligned}
& \text { a John drinks wine and his kids __ coke } \\
& \text { b * John arrives tomorrow but his wife __ yesterday }
\end{aligned}
$$

Under analogy with this example, where a verb in present tense cannot be recovered from the same verb in the past tense, it seems that in (367), repeated here as (375), the problem is that a verb with a subject topic cannot be recovered from another instance of the same verb whose topic is not the subject, i.e. the input constellation in (376). 
a. *? szereti János Marit és Ferit Erzsi

loves János Mari-ACC and Feri-ACC Erzsi

'(Of all the relevant feelings) it is love that John feels towards Mary and towards Frank, Liz.'

b. *? SZERETI Marit János és Erzsi Ferit

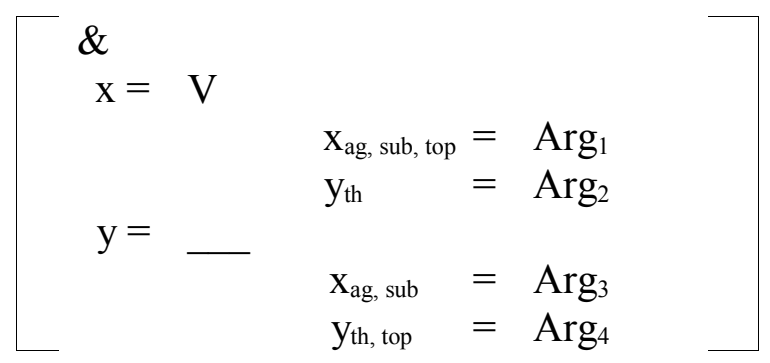

The same parallelism is apparent in English: (377) can only be grammatical with Bill as a topicalized object (with the appropriate pause following) - i.e. it cannot have an input as in (376).

(377) John, Mary hates and Bill Fred

The same would hold the other way round: a verb with a non-subject topic cannot be recovered from another instance of the same verb whose topic is the subject. Just as verbs with different morpho-syntactic features are not the same verbs as far as semantic recoverability is concerned, neither, it seems, are verbs with different arguments topicalized. In other words, two predicates with arguments bearing different semantically interpretable features (such as topic) are in fact two different predicates from a semantic point of view.

Certain semantic effects, such as topic, are typically not seen as being interpreted on the predicate. However, a predicate-based semantics for such notions is not inconceivable. For example, negation is usually seen as the semantic contribution of a negative operator which produces the opposite truth value to the proposition that it operates on. However, one could also produce the same effect by defining a negative predicate with its denotation being the complementary set to the denotation of the positive predicate. Thus John is not tall would be true if and only if the extension of John was in the complementary set defined as the extension of tall. A similar case can be made for the notion of a reflexive predicate, as opposed to a predicate which 
takes a reflexive argument, along similar lines to those proposed by Reinhart and Reuland (1993). Following Keenan (1988), we might take a reflexive predicate to be formed from a transitive predicate by a process which assigns both argument roles to a single argument, effectively making the predicate intransitive. In general then we could define topicalized predicates and focused predicates instead of predicates which have a topicalized or focused argument.

In what follows I would like to demonstrate that this idea of predicate-based semantics is plausible. If this is the case, the present suggestion of semantic topic marking is part of a general trend - and would explain why such semantically different predicates cannot be recovered from one another.

\subsubsection{Philippine predicates: overt argument feature marking}

In many Philippine languages affixation on the verb implies the role of the verbal arguments. Most typically, according to Reid and Liao (2004), verbs are considered to carry a semantic feature which implies the interpretation of the patient.

Mamanwa uses the -en ending to imply that the theme of the verb has been completely effected by the action (direct effect feature: $[+\mathrm{dfct}]$ ) and the -an ending to imply that it is only partially effected (local effect feature: $[+1 f c t]$ ). In the analysis of Reid and Liao (2004) -an and -en are manifestations of features that need to match the status of the theme (undergoer in their terminology).

(378) Mamanwa

a. direct effect feature

$$
\begin{aligned}
& \text { Bonalenmo ya baroy } \\
& {[+ \text { trns, }+ \text { dfct }]} \\
& \text { pound-EN-2SG,GEN DET leaf } \\
& \text { 'You will pound (completely) the leaf.' }
\end{aligned}
$$


b. local effect feature

Bonalanmo ya baroy
$[+$ trns, + lfct $]$
pound-AN-GEN.2S DET leaf
'You (sg) will pound (on) the leaf.'

(Miller 1964:90, quoted in Reid and Liao 2004: 460)

Maranao uses the -an ending on verbs, rather than word order, a preposition or an ending on the noun itself, to communicate that the argument is the beneficiary of the action (beneficary effect [ + bfct] feature):

(379) Maranao

Tabasan o bebai so dati sa dinis

$[+$ trns, + bfct $]$

cut-AN GEN woman DET chief OBL cloth

'The woman will cut cloth for the chief.'

(McKaughan and Macaraya 1967:xii, xxxii, quoted in Reid and Liao 2004: 462)

Southern Ivatan uses the $i$ - prefix to mark the same feature on the verb:

(380) Southern Ivatan

ipangamung ñi Kwan si Kusi

[+trns, +bfct]

I.catch.fish GEN Kwan DET Kusi

'John catches fish for José.'

(Hidalgo and Hidalgo 1971:180, quoted in Reid and Liao 2004: 462)

Guinaang Bontok uses a similar prefix, $2 i-$, to indicate instrument focus / manner affect feature - so that "please ?i-come coffee" in the example below means "please come with my coffee," i.e. "bring my coffee." 
(381) Guinaang Bontok

Piyálim man nan kapik
$[+$ trns, + mfct $]$
Pi-come-2SG, GEN please DET coffee-1SG, GEN
'Please bring my coffee.'

(Reid and Liao 2004: 462)

In these examples we have seen predicate marking as a way to express certain features that are typically thought of as being interpreted on the argument.

\subsubsection{Tundra Yukaghir: focus and topic marking on predicates}

The verb in Tundra Yukaghir, an Ugric language of North-eastern Siberia, reflects the information structure of its arguments, according to Maslova (2003). For instance, the information role and the illocutionary meaning of the subject are morphologically expressed on the intransitive verb. The paradigm, based on Maslova is provided in (382), followed by examples in (383). Note that in (383b), where the focused subject is third person, the focus marker is not present on the subject, only on the verb. Unfortunately, Maslova does not provide examples for subject topic cases.

(382) Tundra Yukaghir
a. -1
Subject Focus
b. $-\mathrm{j}(\mathrm{e})-$
Subject Topic and Indicative
c. $-\varnothing-$
Subject Topic and Interrogative

(Maslova 2003: 17)

(383) Tundra Yukaghir

a. te-n sarime-pe-len kelu-nu-l

PRXM-D $^{71}$ guest-PL-FOC come-PL-SFOC

'Guests have come!'

b. mit abut'ie joj-ā-l

1PL grandmother sick-INGRESSIVE-SFOC

'OUR GRANDMOTHER fell ill.'

(Maslova 2003: 8)

\footnotetext{
${ }^{71}$ Diectic presentative proximal marker, employed to refer to the following noun as spatially close to the speaker, but not yet visible. (Contrasts with visible and distal markers.) (Maslova 2003: 36)
} 
Maslova (2003) further reports that information role marking is apparent on transitive verbs as well - however the transitive paradigm is less transparent, as the encoding of the information roles interacts with encoding of person distinctions: whether the speaker himself is the sole or one of the active participants (loosely agent) of the verb.

\subsubsection{Hungarian: definite and indefinite agreement}

If we accept that predicates can carry semantic features normally associated with their arguents, we could view agreement as co-marking these features on both places: since both the predicate and the argument are capable of being marked, agreement is simply a special case of this phenomenon, with the feature being marked in both places.

Hungarian definite and indefinite agreement paradigms, for instance, could be thought of as an example of such co-marking. In Hungarian different verbal agreement forms are used on transitive verbs depending on whether the object of the verb is definite or indefinite - which is also indicated by the article of the object.

\section{(384) Hungarian}

a. Olvasok egy könyvet read-1SG, INDEF a book-ACC

'I am reading a book.'

b. Olvasom a könyvet

read-1SG, DEF the book-ACC

'I am reading the book.'

c. *Olvasok a könyvet

d. *Olvasom egy könyvet

Though the view of agreement as co-marking is not necessary, the option that it is available illustrates how the observations made in this section can be extended.

\subsubsection{Topic marking on predicates: first/last constraints revisited}

Under analogy with the above analyses, it is plausible to think of two predicates with arguments bearing different semantically interpretable features (such as topic) as in fact two different predicates from a semantic point of view. I.e. that the topic property, 
which is normally thought of as belonging to an argument, is in fact a property of the predicate that gets assigned to one of its arguments. Topic marking would be a hybrid between the Yukaghir phenomenon, where the information role of its arguments is marked on the predicate, and reflexive marking in the sense of Reinhart and Reuland (1993), where semantic marking takes place without a morphological correlate.

If the semantic make up of an empty slot and an otherwise parallel verbal slot in the input data structure of an impoverished input are not the same, the content of the empty slot cannot be reconstructed from the input verb. In other words, if we can distinguish between a subject-topic predicate and a non-subject-topic predicate, it seems plausible that they are not interchangeable and one cannot be recovered from the other. A formal semantic account of this will be provided in Section 5.3.4.

This view of predicate-based semantics allows me to finally substantiate what was introduced as an ad hoc notational device to indicate the scope domain of input elements in Section 2.2.2.3, when I defined the domain of first/last constraints.

I indicated the scope taking element with a bracketed Greek letter superscript on the scopally relevant feature of the element's data slot attributes and the scope domain with a subscript of the same Greek letter. The difference between the examples in (385) was explained in terms of a difference in scope domain, illustrated in (386a-b) for (385a-b), respectively.

(385) a. I believe Bill John hit

'It is my belief that as far as Bill is concerned, John hit him.'

b. Bill I believe John hit

'As far as Bill is concerned, my belief is that John hit him.'

$$
\text { a. }\left[\begin{array}{rll}
\text { believe } & & \\
\mathrm{x}= & \mathrm{I} \\
\mathrm{y}_{(\alpha)}= & \text { hit } \\
& \mathrm{x}_{\mathrm{ag}, \text { sub }}= & \text { John } \\
& \mathrm{y}_{\mathrm{th}, \text { top }}{ }^{(\alpha)}= & \text { Bill }
\end{array}\right]
$$


b. $\left[\begin{array}{rl}\text { believe }_{(\alpha)} & \\ \mathrm{x}= & \mathrm{I} \\ \mathrm{y}= & \text { hit } \\ & \mathrm{x}_{\mathrm{ag}, \mathrm{sub}}=\text { John } \\ & \mathrm{y}_{\mathrm{th}, \mathrm{top}}(\alpha)=\text { Bill }\end{array}\right]$

Having claimed that a topic-taking predicate is different from a normal predicate allows me to recast this formalism under predicate-based semantics. Thus the input of (385a) does not have a topicalized object with hit defining its scope domain, but instead has hit as a topic-object predicate. Semantically, a two-place predicate such as hit is standardly taken to be a function between a set of ordered pairs $<\mathrm{x}, \mathrm{y}>$ and truth values. A topic-object predicate is therefore a function between sets of ordered pairs, in which the second element conveys old information $<x, y_{\text {old }}>$, to truth values. The "scope" of the argument interpreted as topic is then the predicate which carries the feature and all of its dependents. (The item that will be the syntactic topic will be identified according to Grimshaw's (1990) argument prominence hierarchy: if the predicate is a topic-object predicate, for instance, it will be the lowest ranked argument that will be syntactically marked for topic status. This way we are introducing no new information by referring to grammatical functions of input items: these functions can be computed from what is already assumed to be in the input.)

I have argued that topic is a compulsory input feature, i.e. that when a predicate slot gets created in the input, a topic feature gets assigned to some dependent of a predicate or, if it cannot be assigned, it remains on the predicate itself (Sections 2.3.6.3 and 2.3.7). Translating that into predicate-based semantics, it means that every predicate is a topic predicate and the issue for a two place predicate is whether it is a topic-object predicate $\left(\mathrm{P}<\mathrm{x}, \mathrm{y}_{\text {old }}>\right)$, a topic-subject predicate $\left(\mathrm{P}<\mathrm{x}_{\text {old }}, \mathrm{y}>\right)$, or a topic predicate $\left(\mathrm{P}_{\text {old }}<\mathrm{x}, \mathrm{y}>\right)$. The constraints $\mathrm{T} 1 / \mathrm{T} \Omega$ will place the element marked on the predicate as its topic with respect to the predicate and all its dependents.

Other elements that were understood in terms of scope in earlier chapters can be similarly redefined: the difference between topic marking and focus marking on the predicate is that focus marking is not obligatory. The subject feature was also treated as a compulsory input feature - though what the semantic meaning of that is, if it has any, has been unclear. (A suggestion that the subject as well as the other grammatical functions do play a semantic role will be made in Section 5.3.3.5.) Every predicate is a 
subject-predicate, and the subject status is universally assigned to the most prominent argument, as defined by Grimshaw (1990).

The inputs for (385a-b) will then be as in (387a-b), respectively, with both the subject and topic features marked on the predicate. (The input for (385b) will actually be redefined once again below.)

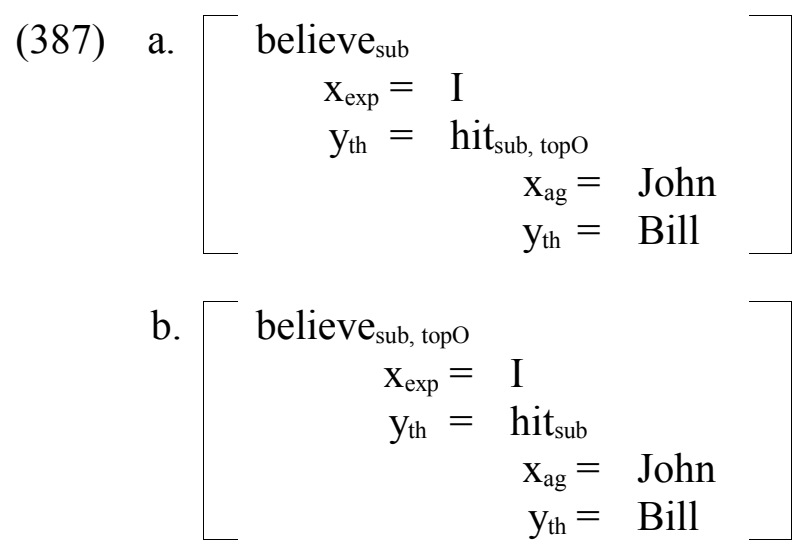

Sometimes, however, what input element fulfils the role of the feature marked on the verb is not obvious and needs to be defined. In (387b), for instance, although the matrix verb is marked for topic-object, it is not its own object, but the embedded object of its complement that gets interpreted as topic. The interpretation under which it is the lower verb itself that gets interpreted as topic is also available:

(388) hit Bill, I believe John did

The OT mechanism that can account for the stranded subject and the dummy did remains to be developed, but (388) is the sentence that the grammar would need to generate from the input in (387b). The input for (385b) needs to be a different one. Here the topic-object predicate is a function between a set of ordered pairs in which only part of the second element is old information: $\mathrm{P}<\mathrm{x}, \mathrm{y}_{\ldots \text {...ld } . . .}>$ and truth values. Thus the list of topic predicate types provided above appears to have been too simplistic: other types include topic-object(object) predicate and topic-object(subject) predicate. The input for both of these are illustrated below:

a. Bill, I believe John hit 
b.

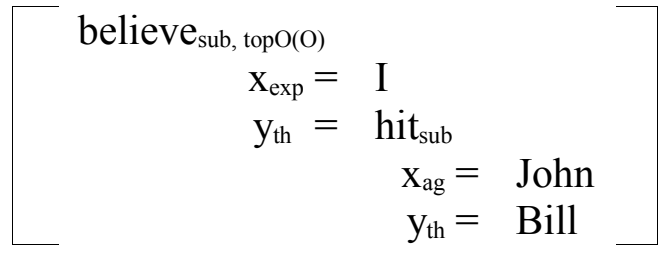

c. John, I believe hit Bill

d. $\quad$ believe $\mathrm{sub}_{\mathrm{s}, \mathrm{top}(\mathrm{S})}$

$$
\begin{aligned}
& \mathrm{X}_{\exp }=\mathrm{I} \\
& \mathrm{y}_{\text {th }}=\text { hit }_{\text {sub }} \\
& \mathrm{x}_{\mathrm{ag}}=\text { John } \\
& \mathrm{y}_{\mathrm{th}}=\text { Bill }
\end{aligned}
$$

Raising constructions would be another similar case: the subject feature of the predicate is satisfied by the most prominent argument of the embedded verb, an example of a subject-object(subject) predicate.

The $\mathrm{V} 1 / \mathrm{V} \Omega$ pair of constraints can also be reinterpreted in terms of predicate basedsemantics, or - rather - functor-based semantics. It is the (verbal) conjunction that is marked as a verbal coordinator, and as such defines the domain of the $1 / \Omega$ constraints.

\subsubsection{Multiple topics in Hungarian}

Cases with multiple topics lend further support to the view on parallelism that argues for a cognitive rather than a syntactic parallelism requirement.

In a transitive Hungarian sentence, both the subject and the object may become topicalised, with their preverbal order remaining free $(390)^{72}$.

a. János a bort megissza János the wine-ACC PERF.drinks

'John will have drunk the wine.'

b. a bort János megissza the wine-ACC János PERF.drinks

'John will have drunk the wine.'

\footnotetext{
${ }^{72}$ The usage of a verb with a preverbal verbal modifier $(m e g)$ guarantees that the preverbal subject and object are in topic, not focus position.
} 
When two such clauses are coordinated, parallel word order is preferred (391) ${ }^{73}$. This follows from the general preference for parallelism in coordination, discussed in 5.1.
a. Mari a sört kitöltötte és János a bort megitta
Mari the beer-ACC out.poured and János the wine-ACC PERF.drank
'Mary has poured the beer and John has drunk the wine.'
b. ? Mari a sört kitöltötte és a bort János megitta
c. ? a sört Mari kitöltötte és János a bort megitta
d. a sört Mari kitöltötte és a bort János megitta

When there is ellipsis, the shared topic must be in the first clause, as predicted, so that it precedes both verbs, and its pre-verbal word order with respect to the (contrastive) topic in its clause becomes completely optional (392). This is not surprising given the data we have seen so far: Since there is only one topic left in the other ellipsis clause, there is nothing to be parallel with and the parallelism requirement disappears.
a. Mari a bort kitöltötte és János megitta
b. A bort Mari kitöltötte és János megitta
c. * Mari kitöltötte és János a bort megitta
d. * Mari kitöltötte és a bort János megitta

Having reviewed the relevant data, in what follows I will develop a unificational account for semantic recovery, concentrating first on the semantic identity requirement between the overt and the elided element (5.3), and then on the apparent parallelism requirement between them (5.4). In both cases, I will be focusing on the examples raised during the discussion of the directionality of ellipsis in Section 1.2 and on the parallelism cases just discussed.

\subsection{Unification and feature identity}

In this section I will concentrate on the issue of whether a missing element can unify with its antecedent in the full clause. Of the examples raised in the previous sections,

\footnotetext{
${ }^{73}$ By including the contrastive marker pedig, the non-parallel sentences clearly improve. Presumably because the contrastive marker 'corrects' the non-parallel order of arguments by 'reminding' the hearer that there is a contrast. This would support the computational view of parallelism. The crucial contrast from our point of view is that the sentences with parallel order between the conjuncts are spotless even without the contrastive marker.
} 
this will provide an account for the contrast in (358) (later repeated as (367) and (375)) and (374). Analyses for the other examples, (369), (370), (371) and (373), will be provided in Section 5.4.

Unificational approaches to grammar provide a formal mechanism in which consistent information is put together: two pieces of data are unified if their feature sets contain non-conflicting values. If they contain conflicting information, the unification of a pair of feature structures fails. However, crucially for ellipsis, unification is also possible if one of the elements carries no value for a particular feature.

Since the input forms the basis for semantic interpretation, the unification procedure needs to operate on the input. The problem with standard unification, from our point of view, is that normally the feature sets of both items change during the unification process. This is different from what happens in case of ellipsis: here we have a oneway semantic process, in which missing information of the elided material is filled in from a parallel data slot in the other conjunct, but the content of the source data slot remains unchanged in the process. In the reconstruction of the simple input in (393), for instance, only one of the functees of the conjunction needs to undergo a change, the one that includes the unfilled data slot.

$$
\left[\begin{array}{lrl}
\& & & \\
\mathrm{x}= & \text { came in } \mathrm{in}_{\text {sub }} & \\
& \mathrm{x}_{\mathrm{ag}}= & \text { John } \\
\mathrm{y}= & \text { sat down } & \\
& \mathrm{x}_{\mathrm{ag}}=
\end{array}\right]
$$

The semantic make up of the conjunct John came in does not get altered during the semantic unification process, only the semantic make up of the input-impoverished sat down conjunct will ${ }^{74}$.

Dalrymple et al. (1991) present a unification-based method to account for the semantics of ellipsis structures. They focus on VP ellipsis, and show that various types of ambiguity such as scope follow from the process of interpreting the elided phrase

\footnotetext{
${ }^{74}$ This is true even in cases of ellipsis in which both clauses contain gaps:

i. John can and will run for president

In this case, John of the first clause needs to unify with the elided subject of the second clause, and run for predident in the second clause needs to unify with the missing verb of the first clause. The point is that in both cases something empty unifies with a full element.
} 
(target) on the basis of the unambiguous antecedent (source). Crucially for our purposes, in their system unification is a one-way process, in which the missing data in the target clause is filled in based on the characteristics of the element in the source clause. The task of ellipsis interpretation is to recover a property of the parallel element in the target that the missing material stands proxy for.

Let me illustrate the process through the following example, which is interpreted as meaning that both Dan and George like golf.

(394) Dan likes golf and George does too

In (394) the property $P$ being predicated of George is such that when $P$ is predicated of Dan it means that Dan likes golf. Dalrymple et al. (1991: 401) state this as follows:

$$
P(\text { dan })=\operatorname{like}(\underline{\text { dan }}, \text { golf })
$$

The underlined term is what is called the primary occurrence of the parallel element's interpretation - the one that cannot be present in the interpretation of the target clause. Dalrymple et al. (1991: 403) propose to solve this equation for the unknown $P$, to generate the relation that the resolution of the ellipsis requires, using Huet's (1975) higher-order unification algorithm. This is a unification algorithm based on higherorder logic. While in first-order logic quantification is permitted only over individuals, higher-order logic allows quantification over functions and predicates as well.

Under higher order unification two alternative substitutions exist for $P$ in (395):
a. $P \rightarrow \lambda x \cdot \operatorname{likes}(x$, golf $)$
b. $P \rightarrow \lambda x$.likes $(\underline{\text { dan }}$, golf $)$

The substitution in (396b) will be disregarded, because it leaves a primary occurrence (an underlined term) in the result. Primary occurrences cannot be present in the target clause, because there the parallel element needs to play the primary role in determining meaning. (The target clause is about George, not Dan.) The only remaining value for $P$ is (396a), and this needs to be applied as $P$ (george) to give the interpretation of the target clause. $P$ in (395) is thus replaced by the lambda value 
$\lambda x . l i k e(x$, golf $)$. Predicating this property of george, we get $[\lambda x . l i k e(x$, golf $)]($ george $)$, which reduces to like(george, golf).

The semantics of the whole sentence then is the following:

(397) likes (dan, golf) ^likes (george, golf)

The idea is to state the problem in terms of an equation based on the parallel structure of the two clauses and to solve the equation using higher-order unification - under the constraint requiring abstraction of the underlined primary occurrences.

In our case it is the input of the conjoined sentence that forms the basis for unification. The requirement for unification to operate is that the input of the complete clause and the elided clause be sufficiently similar. A problem with the mechanism developed by Dalrymple et al. (1991) is, as the authors themselves admit (Dalrymple et al. 1991: 407), a lack of explanation or even discussion of parallelism: what defines whether a clause can act as the source for another clause. Their chief focus is the higher-order unification procedure itself. In what follows, I will investigate the identity and parallelism requirements that are necessary to determine whether a (higher-order) unification mechanism of the kind introduced by Dalrymple et al. (1991) can even take place. For recovery to take place, the data structures that are to be unified have to be sufficiently equivalent, and it is on this basis that parallelism is to be accounted for. In this section I will discuss the identity requirement between the source and the target, and in Section 5.4 I will deal with the issue of structural equivalence.

\subsubsection{Asymmetrical mismatch and unary features}

Two items can unify if they do not contain conflicting features. This includes the possibility that a particular feature is null/unspecified. That this notion is relevant here is exemplified by the following sentences, which illustrate that a more specific predicate can be recovered from a more general one but not the other way round:

(398) a. John likes Bill and Mary herself

b. * John likes himself and Mary Bill

c. John likes Bill and Mary no one 


\section{d. * John likes no one and Mary Bill}

I will concentrate on the reflexive examples first and will return to the negative examples at the end of this section.

In (398a) the missing predicate is marked as reflexive by its arguments in the input, because the arguments are coreferential (see Section 5.2.2). This predicate includes reflexivity as one of its specified input features - even though most of its specifications are absent from the input. Non-conflicting information can be recovered from the predicate of the other conjunct. Unifying with the non-reflexive predicate will fill in the other specifications and hence the content will be recovered. This mechanism, however, is not possible the other way round, as (398b) illustrates. A predicate that is not marked for reflexivity cannot be recovered from one that is, as otherwise it would inherit the reflexivity feature incorrectly, presumably because of the restrictions imposed on the semantic recovery mechanism.

(399a) and (399b) - to be revised - represent a possible input representation for (398a) and (398b), respectively, with the reflexivity feature marked on the predicates as [+refl] and [-refl].

$$
\begin{aligned}
& \text { a. \& } \\
& \mathrm{x}=\text { likes-refl, sub }_{\text {sub }} \\
& \mathrm{X}_{\text {exp }}=\text { John } \\
& \mathrm{y}_{\text {th }}=\text { Bill } \\
& \mathrm{y}= \\
& { }_{\mathrm{p} \text {, sub }}^{\text {refl }}=\text { Mary } \\
& \mathrm{y}_{\mathrm{th}}=\text { herself }^{75}
\end{aligned}
$$

b.

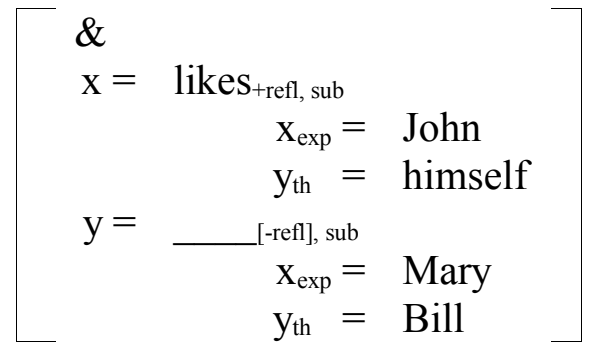

(400) illustrates an attempt at semantic unification for the two inputs.

\footnotetext{
${ }_{75}$ I will leave open the issue of how to represent reflexive pronouns in the input, as it is only tangentially relevant to the present discussion. Since the input is the interface with semantics, herself is presumably represented as another instance of Mary, or simply as $\mathrm{y}=\mathrm{x}$.
} 

a. likes-refl, sub $\cup$ ${ }_{+ \text {refl, sub }}=*$ likes $_{+ \text {reffl,-refl, sub }}$
b. likes ${ }_{+e f l, ~ s u b}$ -refl, sub $=*$ likeS $_{+ \text {refl,-refl, sub }}$

The unification attempts fail in the case of both inputs, as two conflicting features $([+\mathrm{refl}]$ and [-refl]) cannot unify. This contradicts the data presented in (398), which showed asymmetric recovery - i.e. that (400a) should unify, while (400b) should fail.

This problem can be solved, and the correct predictions made, if we assume that features are unary, not binary - i.e. that a feature is represented in the element's feature matrix only if it has the marked value. Thus the more features an element has, the more marked it is. Such underspecification captures the insight that two values of binary features are often in an asymmetrical relationship. While traditionally grammars operating with binary features have been more widespread, a system operating with unary features is able to capture the same contrasts as a binary feature system but more simply, as Szigetvári (1999: 7-11, 152-155) showed. This is the approach adopted in Government Phonology, in which unmarked, featureless sounds are the atomic building blocks making up complex sounds (Harris and Lindsey 1995).

If the non-reflexive predicate in the inputs for the sentences in (398) does not carry a [-refl] feature, but the specification for this feature is simply absent, unification of an empty predicate marked as [refl] with an overt non-reflexive predicate is possible. When the overt predicate is reflexive, on the other hand, the missing predicate cannot unify with a predicate marked with a [refl] feature, since it is not itself reflexively marked by a reflexive pronoun. This would explain the assymetric recovery exemplified in the contrast in (398).

(401a) represents the revised input for (398a) and (401b) for (398b).

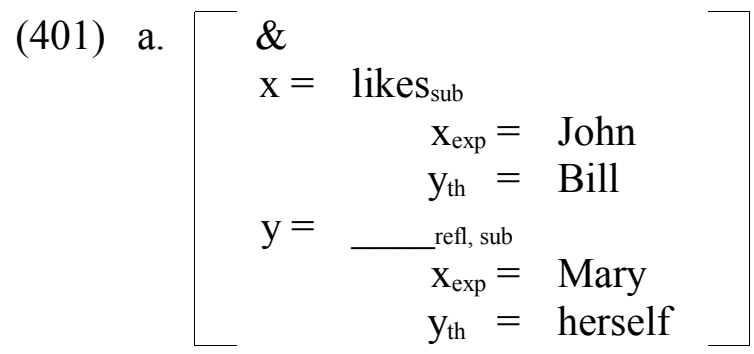




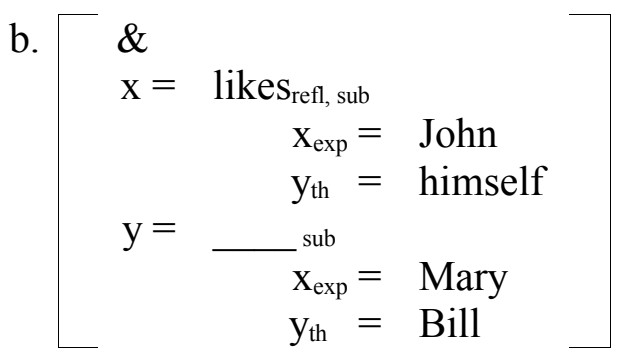

(402) illustrates the semantic unifications for the two inputs.

(402)
a. likes $_{\text {sub }} \cup$ refl, sub $=$ likes $_{\text {refl, sub }}$
$\left\{\text { Mary likes }_{\text {refl }} \text { herself }\right\}^{76}$
b. likes refl, sub $U \ldots$ sub $=$ likes $_{\text {refl, sub }}$
* $\left\{\right.$ Mary likes refl $_{\text {Bill }\}}$

The optimality syntax mechanism delivers the FWE sentences in (398) from their respective inputs in (401), as demonstrated in the analysis of gapping in Section 4.3.1, but (402b) will fail semantically, since a non-reflexive predicate cannot be reflexively marked, as discussed in Section 5.2.2.

The same assymetry in recoverability is apparent in case of predicates with different polarity, as was exemplified in (398c-d), repeated here as (403).
(403)
a. John likes Bill and Mary no one
b. * John likes no one and Mary Bill

In (403a) the missing predicate is marked as negative by dint of the fact that one of its arguments is negative. The rest of its content is recovered from the overt predicate, which is not specified for the negativity feature. However, if the overt predicate is specified for negativity, this will be erroneously recovered in the second example yieding a negative elided predicate.

(404a) represents the input for (403a) and (404b) for (403b).

\footnotetext{
${ }^{76}$ I denote (an informal description of) the semantic interpretation of the sentence with \{\} .
} 
(404) a.

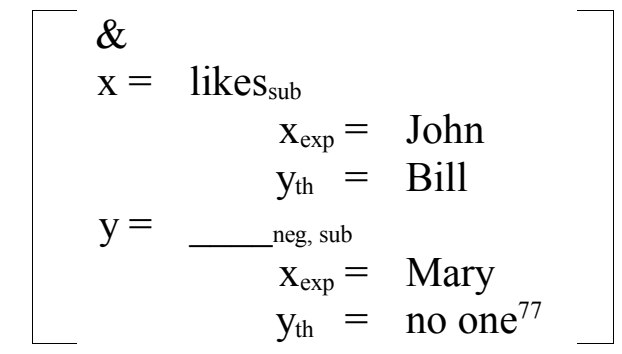

b.

$$
\begin{aligned}
& \text { \& } \\
& \mathrm{x}=\text { likes }_{\text {neg, sub }} \\
& \mathrm{x}_{\mathrm{exp}}=\mathrm{John} \\
& \mathrm{y}_{\mathrm{th}}=\text { no one } \\
& y=
\end{aligned}
$$

(405) illustrates the semantic unifications for the two inputs.

$(405)$
a. likes $_{\text {sub }} \cup$ ${ }_{\text {neg, sub }}=$ likes $_{\text {neg, sub }}$
\{Mary likes neg $_{\text {no one }}$
b. likes neg, sub $_{U}$ sub $=$ likes $_{\text {neg, sub }}$
* $\{\text { Mary likes } \text { neg Bill }\}^{2}$

The unacceptability again arises for semantic, not syntactic reasons. The syntax will churn out an optimal candidate for (404b), but the winning (403b) is uninterpretable because the elided predicate, which carries the [neg] feature, is not marked negative either by having a negative argument or by the appearance of a negative operator.

It is reasonable to assume then that parallelism is a recoverability requirement forced on the input by the semantic component. Inputs that are not sufficiently parallel - and thus are not interpretable - are not going to yield real sentences, so they are not very interesting to follow through the syntactic optimality pathway.

A crucial assumption in the discussion has been that the impoverished element is not totally absent from these sentences: its reflexivity or negative polarity feature is present even if the item itself is absent from the input. This is consistent with the assumptions developed in Section 2.2.1.4, where I assumed that argument structure is present even when the predicate is missing from the input of gapping sentences.

\footnotetext{
${ }^{77}$ Again, I will not speculate on how no one may be represented in the input.
} 


\subsubsection{Symmetrical match requirement}

In the previous section I introduced examples in which the feature mismatch relationship was assymetrical: a more specific predicate can be recovered from a more general one but not the other way round. This is, however, not always the case. Sometimes a mismatch is not tolerated in either direction.

(406) a. * John arrives tomorrow and his wife yesterday

b. * John arrived yesterday and his wife tomorrow

At first site this would contradict the unary feature theory developed for the asymmetrical cases. Note, however, that it is possible to retrieve the infinitival form of the verb from its tensed counterpart:

(407) a. John got up but Mary didn't want to

b. we told him not to but John still got up

The coordination of non-finite predicates with time adverbials is also possible.

(408) a. John wanted Mary to leave yesterday and Sue tomorrow

All of these examples are possible to explain if we assume that there are two unary semantic features, [pres] and [past]. In case of the examples in (407), the missing input element is infinitival, and so does not contain a specification for either tense feature (409). As such it can unify at the semantic level with a tensed element (410).

$$
\left[\begin{array}{rll}
\text { but } & & \\
\mathrm{x}= & \text { get up }_{\text {past, sub }} & \\
\mathrm{x}_{\mathrm{ag}} & = & \\
\mathrm{y}=\text { want }_{\text {neg, past, sub }} & \\
\mathrm{x}_{\mathrm{ag}} & = & \text { Mary } \\
\mathrm{y}_{\mathrm{th}} & =
\end{array}\right]
$$

(410) get up past, sub $U=$ get up past, sub

\{Mary didn't want to get up\} 
Though this means the infinitival verb ends up with a semantic [past] feature, this is not a problem: being infinitival is a grammatical feature, with no semantic repercussions. Stowell (1982) has in fact argued that tensed clauses contain a tense operator which fixes the understood time frame of the infinitival complement relative to the tense of the matrix - which means that certain infinitival constructions do have relevance in terms of tense. The examples below illustrate such a case:

(411) a. John tried to get up

b. John is trying to get up

c. John will try to get up

In terms of the semantic interpretation of the unification in (410), it means that the action of getting up can take place in the present or the past - and in our example the "non-getting up" took place in the past.

In (408) both clauses are infinitival, so neither carries a semantic tense feature. Unification can again take place.

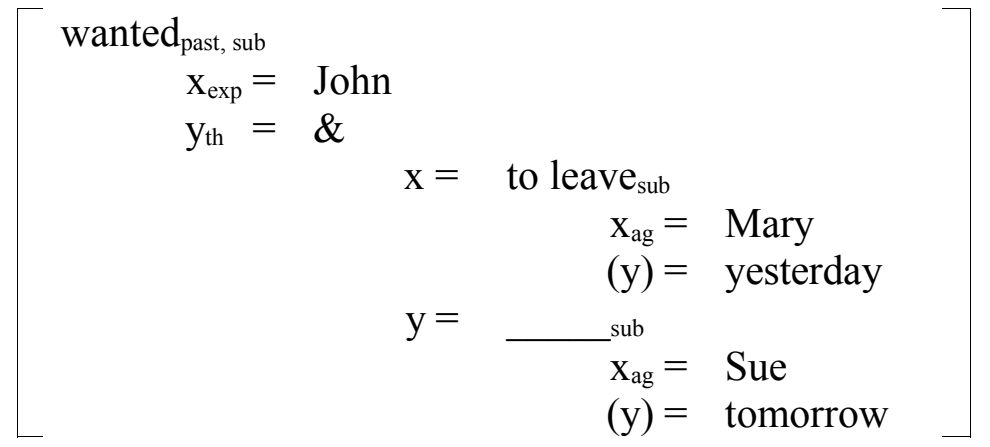

(413) to leave sub $_{\text {sub }}=$ to leave sub $_{\text {sub }}$

$\{\ldots$ Sue to leave tomorrow $\}$

Let me now return to (406) - and demonstrate that what could form the input for such sentences is uninterpretable. The missing input item is a finite verb, and as such it needs to bear a tense feature in the input. (This is similar to the examples in the previous section, where missing predicates carried features for reflexivity and negative polarity.) The tense feature can either be [past] or [pres]. In order for the conjunct to be interpretable the missing tense feature must match the tense feature of the adverbial 
(414). This is a plausible assumption since yesterday does force a past interpretation on the elided predicate: if (406a) were acceptable, it would mean that John's wife arrived in the past, i.e. yesterday. Though syntactically the winning candidates of (414), which are the sentences in (406), are well-formed, they fail at the semantic level, where a [pres] and a [past] feature cannot unify (415). When information is recovered from a source, everything from the source needs to recovered: the content of arrives cannot be split from its tense feature. (This conclusion will actually be slightly revised in the next section.)

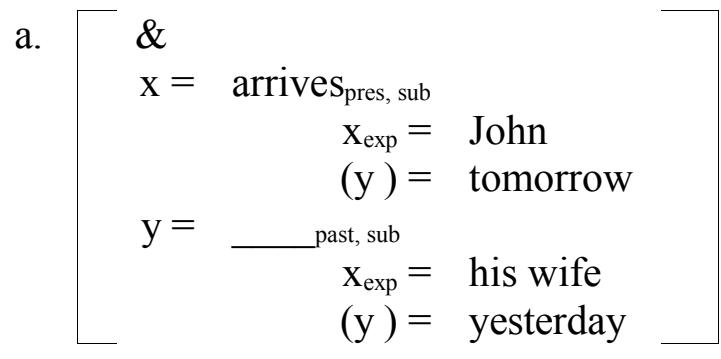

b. $\square$

$$
\begin{array}{lrl}
\& & & \\
\mathrm{x}= & \operatorname{arrived}_{\text {past, sub }} & \\
\mathrm{x}_{\text {exp }} & \text { John } \\
& (\mathrm{y})= & \text { yesterday } \\
\mathrm{y}=\quad \text { pres, sub } & \\
\mathrm{X}_{\exp }= & \text { his wife } \\
(\mathrm{y})= & \text { tomorrow }
\end{array}
$$

(415)
a. $\operatorname{arrives}_{\text {pres, sub }} \cup \ldots$ past, sub $=\varnothing$
b. $\operatorname{arrived}_{\text {past, sub }} \cup$
pres, sub $=\varnothing$

The question arises as to what happens to inputs that are like (414), but in which the missing verb does not have a tense feature, i.e. is infinitival.

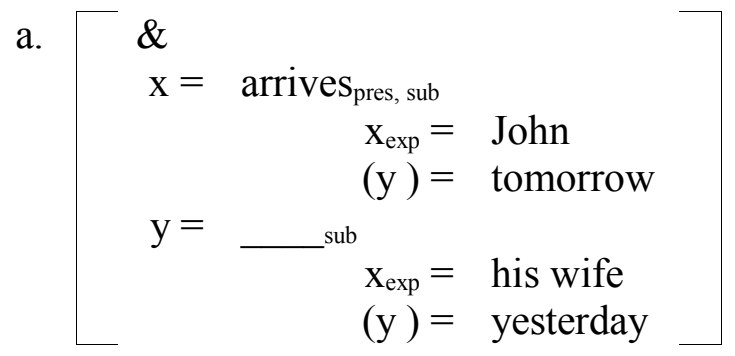




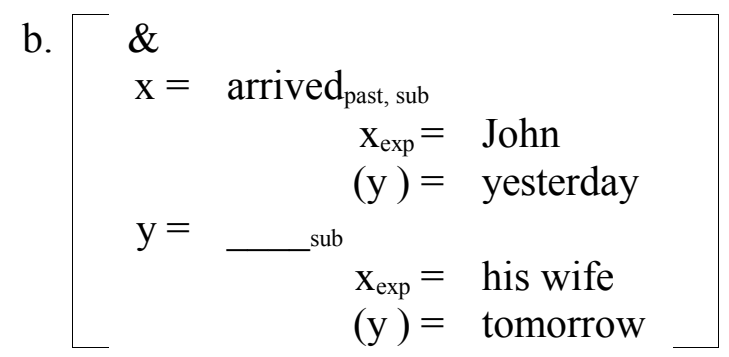

Semantic unification in these cases can take place between the missing verb and the overt predicate, as the following unificiation procedure illustrates for (416a).

$$
\text { arrives }_{\text {pres, sub }} \cup \ldots \text { sub }=\text { arrives }_{\text {pres, sub }}
$$

Though unification can take place, the tense feature that the infinitival, empty input verb has inherited clashes with the interpretation of the adverbial in its conjunct, yesterday. Thus this input is not going to be interpretable. This is compatible with all the above examples, where either the source for the missing infinitival predicate was another infinitival predicate, and so no tense feature got inherited and tense interpretation was left to the adverbial alone (412), or there was no adverbial to contradict the inherited tense feature (409). In the latter case, even if there is a time adverbial in the impoverished conjunct, it would act as a modifier to the matrix verb in the conjunct and not to the impoverished infinitival. This is illustrated below, where (418b) and (418d) are unacceptable because the adverbial clashes with want.

(418) a. John went shopping but Mary didn't want to yesterday

b. * John went shopping but Mary didn't want to tomorrow

c. John went shopping but Mary won't want to tomorrow

d. * John went shopping but Mary won't want to yesterday

More complex tense recovery cases support the view presented here.

(419) a. John went shopping but Mary wouldn't have even if she had the money

b. ? Mary wouldn't have even if she had the money but John went shopping

c. Mary wouldn't have gone shopping even if she had the money but John did

d. John did but Mary wouldn't have gone shopping even if she had the money

Tensed went shopping and tenseless gone shopping can be recovered from each other: 
a. go shopping past, sub $U \ldots$ sub $=$ go shopping past, sub $_{\text {sub }}$

\{Mary wouldn't have gone shopping\}

b. go shopping sub $\cup \ldots$ past, sub $=$ go shopping past, sub $_{\text {sub }}$

\{John went shopping\}

To sum up, it seems that tense recovery facts can be explained within the theory of recovery proposed here: unification of input items with unary features.

\subsection{3 'Strong' vs. 'weak' semantic features}

\subsubsection{Person and number features in English}

There are also well known cases when feature identity between the overt and the elided element are not required for recorvery. This is the case with person and number features in English. Consider (421).

(421) a. John drinks wine and the girls beer

b. the girls drink beer and John wine

In (421) number agreement differs between the overt and the elided verb, but ellipsis is still possible. Dalrymple et al. (1991) argued that such feature mismatches are allowed because despite the mismatch a parallelism still can be established between the conjuncts: the empty element plus its meaningful tense/aspect feature will be parallel with the overt element plus its meaningful tense/aspect feature. In their view as long as any relevant parallelism can be found, the sentence remains interpretable. They draw a similarity with the phenomena of non-parallel adjuncts.

(422) Jim couldn't open the door but Polly did with her blowtorch

(Dalrymple et al. 1991: 409)

Examples such as (422) suggest that not every element in the target clause must be analyzed as parallel to some element in the source clause in order for parallelism to be established. Adverbial phrases, for instance, may modify the target clause directly. 
Dalrymple et al. (1991) argue that the explanation for (422) can carry over to feature mismatches between the source and the target: as long as any relevant parallelism between the source and target can be found, the sentence will be interpretable. This explanation may suffice for the phenomena they are concerned with, VP ellipsis, but it would incorrectly predict that all the ill-formed examples in the previous sections are in fact acceptable. Thus we need to look for an alternative explanation for cases in which the identity requirement between source and target appears to be weaker.

One option would be to claim the person/number features actually do not need to unify: since unification is a semantic process, we could assume that it is blind to nonmeaningful elements. Thus the mismatch between the person/number features of the two verbs will be irrelevant during the unification process, and unification will proceed. This is illustrated in (423) for the semantic recovery of (421a). Note that person and number features do not even appear on the elements:

$$
\begin{aligned}
& \operatorname{drink}(\mathrm{s})_{\text {pres, sub }} \cup \ldots \text { pres, sub } \\
& \text { the } \operatorname{girls} \operatorname{drink}(\mathrm{s})_{\text {pres }} \text { beer }
\end{aligned}
$$

This is essentially the route adopted by Wilder (1997: 99-101). Following Minimalist assumptions, he focuses on the requirement of content identity at LF. Verbs contain phi-features on leaving the lexicon, and during the derivation these features are checked one by one, as the $\mathrm{V}$ raises to each Infl head. As a result, the features on the $\mathrm{V}$ and the functional head are elminiated, and by LF there is no difference left: $\mathrm{V}_{1}+$ $\operatorname{Agr}_{1}\left(\right.$ drinks) is identical to $\mathrm{V}_{2}+\operatorname{Agr}_{2}$ (drink). Tense features, on the other hand, are present at LF, where they are responsible for temporal interpretation. Since a gapped conjunct must contain a liniguistically equivalent V-Tense complex to that of its full conjunct counterpart, the requirement for tense match is predicted.

The problem with the assumption in (423), and its Minimalist equivalent, is that it incorrectly predicts the lack of person and number requirement to be a universal fact about semantic recovery. However, this is not so, as Hungarian examples in Section 1.2.2, repeated below, illustrated. In Hungarian it appears that third-person forms can be recovered from first person forms, but not the other way round. 
a. János bort és én pedig sört iszom

János wine-ACC and I contr beer-ACC drink-1SG

'John is drinking wine and I am drinking beer'

b. * én bort és János pedig sört iszik

If person features were (universally) irrelevant for semantic recovery, the unacceptability of (424b) would be left unexplained. The universal explanation, the semantic irrelevance of person and number features, is thus unavailable.

The input for (421a) is in (425), with the third-person singular feature marked on the overt verb and a plural feature ${ }^{78}$ marked on the elided predicate.

$$
\begin{aligned}
& \begin{array}{l}
\& \\
\mathrm{X}=\text { drinks }_{\text {pres, } 3 \mathrm{SG}, \text { sub }}
\end{array} \\
& \mathrm{X}_{\mathrm{ag}}=\mathrm{John} \\
& \mathrm{y}_{\text {th }}=\text { wine } \\
& y= \\
& \mathrm{x}_{\mathrm{ag}}=\text { the girls } \\
& \mathrm{y}_{\mathrm{th}}=\text { beer }
\end{aligned}
$$

During semantic recovery the plural feature cannot unify with the third-person singular feature. It is a language-specific property of English that the mismatch in person and number features does not stop the rest of the features from unifying, and the elided predicate is interpretable. I will mark such "weak" features with brackets, indicating that when they are on the source they do not participate in, but do not block, the unification procedure.

$$
\begin{aligned}
& \text { drinks }_{\text {pres, }(3 \mathrm{SG}) \text {, sub }} \cup \ldots \text { pres, PL, sub } \\
& \text { the girls drink beer }\}
\end{aligned}
$$

While the strong-weak distinction does not contradict any of the OT assumptions made so far, it is not in the spirit of the theory as it introduces an extra mechanism of language variation. An alternative would be to assume that languages such as English do not make use of the (universally available) person and number features in their inputs - i.e. that all input features are "strong," and cannot be peeled off the rest of the

\footnotetext{
${ }^{78}$ In English there is no morphological or agreement evidence of plural person features, so I am representing this is a single feature. This, however, is a simplification: in order to maintain that inputs are universal, plural number features would also need to be represented.
} 
input item when it acts as a source for semantic recovery of a gap. The English person and number features would under this view be inserted at Late Insertion - when the phonological item with the contextually most matching information is selected from among the Vocabulary Items of the language. (The contextually sensitive information cannot be thought of in terms of features of the Vocabulary Items due to the Subset Principle restriction of DM, discussed in 2.2.1.1.) The problem with this alternative view is that it would contradict the assumption that OT inputs are universal. One could assume that universally some inputs include verbs with no person and number features defined, while others include the same verbs with their person and number features. In the English case the inputs without the person and number features could receive interpretation - and so the grammaticality of (421) would be predicted. However, it is unclear why the same could not happen in a language like Hungarian, predicting the grammaticality of (424a) as well as (424b).

It appears that the only way for this alternative theory to work is to give up the requirement that OT inputs are universal. Once an ad hoc assumption needs to be introduced, it is better for that to be compatible with the rest of the grammar, so I will adopt the strong-weak feature distinction presented in this section.

\subsubsection{Person and number features in Hungarian}

Let me return to the Hungarian case in (424), presenting the full paradigm ${ }^{79}$ :
a. János bort
(és) én pedig sört
iszom
János wine-ACC and I contr beer-ACC drink-1SG
'John is drinking wine and I am drinking beer'
b. * én bort (és) János pedig sört iszik
c. János bort
(és) te pedig sört
iszol

János wine-ACC and you CONTR beer-ACC drink-2SG

'John is drinking wine and you are drinking beer'

d. * te bort (és) János pedig sört iszik

\footnotetext{
${ }^{79}$ Admittedly, judgments between individual speakers vary a great deal. To some speakers all the sentences are correct. For some other, more conservative, speakers all of the sentences are clearly unacceptable. The judgments indicated here are my own.
} 

e. ?* te bort
(és) én pedig sört
iszom
you wine-ACC and I CONTR beer-ACC drink-1SG
'you are drinking wine and I am drinking beer'
f. * én bort (és) te pedig sört iszol

Note that we could not claim, as we did in the case of reflexivity above, that 3SG is the default feature. While this would explain sufficiently why $1 \mathrm{SG}$ and 2SG cases cannot be recovered from each other (427e-f), it would predict that recovery when one of the predicates is $3 \mathrm{SG}$ is possible in both directions, contrary to fact.

Let us take the inputs for (427a) and (427b) as (428a) and (428b), respectively.

$$
\begin{aligned}
& \text { a. } \& \\
& \mathrm{X}=\text { iszom }_{\text {pres, }} 1 \mathrm{SG} \text {, sub, topS, topO } \\
& \mathrm{x}_{\mathrm{ag}}=\text { én } \\
& \mathrm{y}=\ldots \text { pres, 3SG, sub, tops, topO } \\
& \mathrm{y}_{\mathrm{th}}=\text { sört } \\
& \mathrm{x}_{\mathrm{ag}}=\text { János } \\
& \mathrm{y}_{\mathrm{th}}=\text { bort } \\
& \mathrm{X}=\text { iszik }_{\text {pres, } 3 \mathrm{SG}, \text { sub, topS, topO }} \\
& \mathrm{X}_{\mathrm{ag}}=\text { János } \\
& \mathrm{y}= \\
& \mathrm{y}_{\mathrm{th}}=\text { sört } \\
& \mathrm{x}_{\mathrm{ag}}=\text { én } \\
& \mathrm{y}_{\mathrm{th}}=\text { bort }
\end{aligned}
$$

Semantic unificiation can take place in the case of (428a), but not (428b). This is possible to capture if we assume that in Hungarian the person and number features other than [3SG] are weak: they neither participate in, nor block unification when they are a feature of the source.

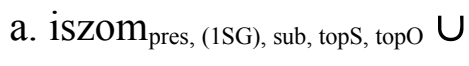

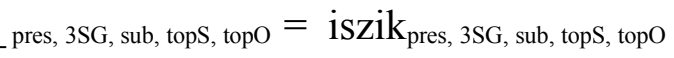 \{János bort iszik\}
b. iszik $_{\text {pres, } 3 \mathrm{SG}, \text { sub, tops, topO }}$ pres, $1 \mathrm{SG}$, sub, topS, topO $=\varnothing$

In footnote $79 \mathrm{I}$ mentioned that judgements on the sentences in (427) vary considerably between speakers. For some speakers, all the sentences were acceptable. 
For these speakers, all the person and number features are weak in Hungarian, similarly to the English case. For the more conservative speakers who judged all the examples unacceptable the opposite holds: all of the person and number features are strong, so unification is never allowed.

Admittedly, the introduction of the weak-strong feature distinction is a description, rather than an exaplanation. What actually makes a feature strong or weak is unclear though at the end of this section I will show that this assumption actually lends motivation to what until now has been an unmotivated stipulation in the theory. Whatever the reason behind the strong/weak distinction, it appears that crosslinguistically the distinction is a valid one in case of many different features. As such the theory presented here is already an improvement over previous accounts that claimed person and number features to be irrelevant for semantic recovery: my account can at least describe the attested data correctly.

\subsubsection{Assymetric tense recovery in Québec French}

I have shown the relevance of the strong/weak distinction for features that had hitherto been thought of as irrelevant for semantic recovery. Further support for the relevance of the distinction comes from observations that features that have been argued to matter for recovery may actually differ between the source and the target in some languages. Thus the distinction is applicable for features that had been thought of as universally strong as well as for features that had been treated as universally weak.

The tense feature in (informal) Québec French appears to be weak: ellipsis is possible under asymmetric tense interpretation between the predicates. Present tense is recoverable from past (430a), but this is not the case the other way round, as the ungrammaticality of (430b) illustrates.

a. Jean est arrivé hier et Marie demain

Jean is arrived yesterday and Marie tomorrow

'John arrived yesterday and Mary will arrive tomorrow.' 
b. * Jean arrive demain et Marie hier

Jean arrives tomorrow and Marie yesterday

'John will arrive tomorrow and Mary arrived yesterday.'

(Marie-Eve Sévigny, p.c.)

This is analogous to the Hungarian person and number case just discussed: mismatch is tolerated in only one direction. We can capture the data if we assume that in Québec French [past] is a weak feature, while [present] is strong. In (430a) the missing predicate receives a non-past interpretation from its time adverbial. The rest of the predicate's semantic content is recovered from the overt predicate, and the weak past feature neither participates in nor blocks semantic unification (431b).

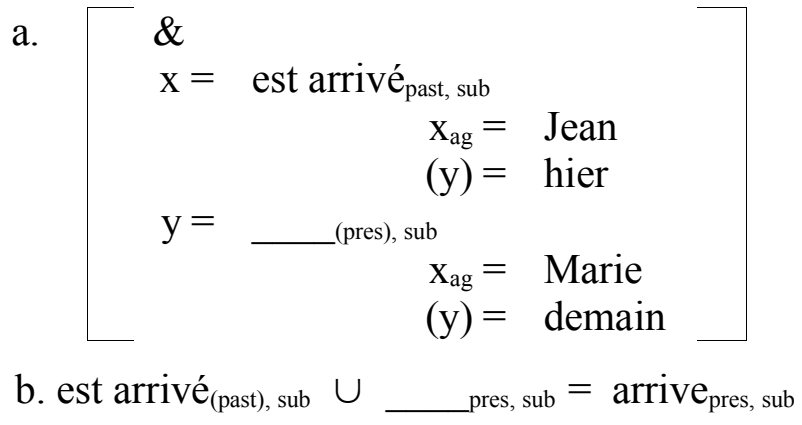

\{Marie arrive demain

However, when the overt predicate is specified for the present feature, and the elided one for past, the strong present feature will block semantic recovery, rendering the syntactically impeccable (430b) unacceptable. The input is presented in (432a) and the - failed - semantic unification process in (432b).

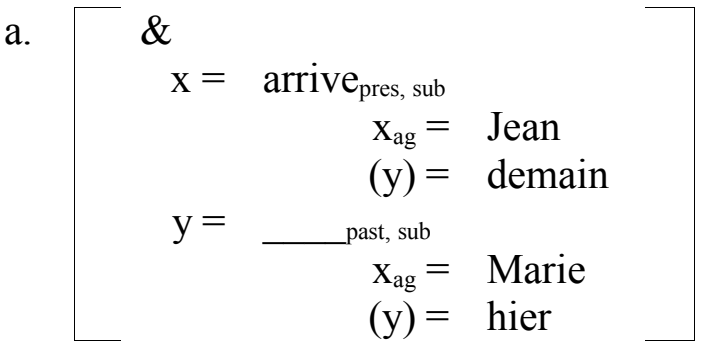

b. $\operatorname{arrive}_{\text {pres, sub }} \cup \ldots$ past, sub $=\varnothing$

The assumption of unary features and semantic recovery via unification can thus explain the difference between English and informal Québec French tense recovery. 


\subsubsection{Thematic features}

Thematic roles appear to be ignorable for semantic recovery, as the following ellipsis cases demonstrate for English, French and Hungarian, respectively:

(433) a. John ran and was killed

b. Jean a couru et a été tué

Jean has run and has been killed

'John ran and was killed.'

c. János futott és megölték

János ran and PERF-killed-PST-3PL, OBJ

'John ran and was killed.'

In the examples above the theme of the second predicate, passive in English and French but active in Hungarian, can be recovered from the agent of the active verb. (434a) is the input for (433a), and (434b) illustrates the unification mechanism.

(434)

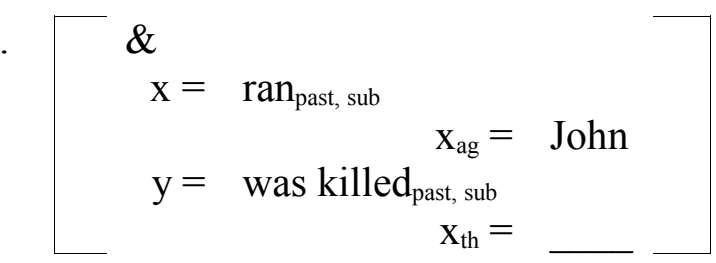

b. $\operatorname{John}_{(\mathrm{ag})} \cup{ }_{\text {(th) }}=\mathrm{John}_{\text {(th) }}$

The observation that arguments bearing different theta roles can unify means that theta roles are weak features - i.e. that they do not matter from a semantic point of view. If this view can be upheld universally, it would suggest that semantically the interpretation of a predication relationship is based on the verb alone and is consistent with the predicate-based semantics I argued for in earlier sections: features that are normally assumed to be marked on arguments are (semantically) marked on the verb. (Clearly, though, the view that features are marked on the predicate only cannot extend to syntax, where arguments do bear the features assigned to them.)

Predicate marking of theta roles is supported by the observation discussed in Section 4.3.1 that in case of gapping the argument theta roles of the missing predicate(s) must match those of the overt verb. Such an input is provided in (435), repeated from (312). 


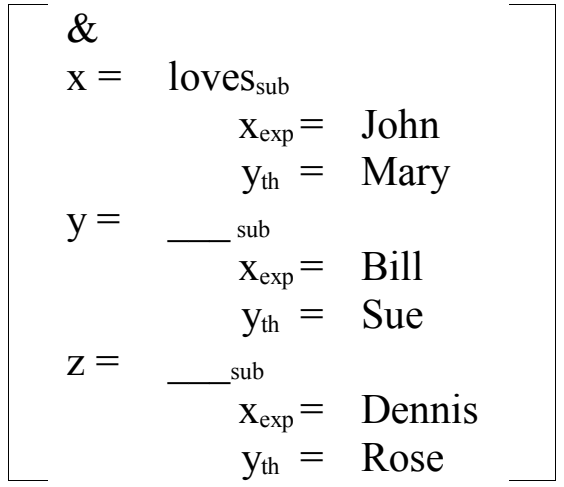

If we view thematic information as marked on the predicate and not on the arguments, this difference in parallelism between arguments and predicates is predicted.

\subsubsection{Grammatical roles}

What seems to matter for semantic recovery is not the thematic but the grammatical role of the argument. Even when the full conjunct has a theme, the interpretation of the sentences in (436) is that John, not Mary, gets killed:

(436) a. John kissed Mary and was killed

b. Jean a embrassé Marie et a été tué Jean has kissed Marie and has been killed

'John kissed Mary and was killed.'

c. János megcsókolta Marit és megölték

János PERF-kissed Mary-ACC and PERF-killed-3PL

'John kissed Mary and was killed.'

Further support for this view comes from examples like (437) below.

(437) a. * the book pleased John and loved it

Even though John in the first conjunct and the gap in the second conjunct are both experiencers, John cannot be understood as an argument of loved. This leads to ungrammaticality. Book could be the source for the gap, but that leads to a binding violation for $i t$, which would no longer be locally free. Indeed, replacing the pronoun with a reflexive yields a grammatical, though pragmatically strange sentence: 
The preceding discussion suggests not only that thematic roles are unimportant in terms of semantic recovery (i.e. are universally weak) but that grammatical roles matter (i.e. are strong) ${ }^{80}$. This is somewhat surprising, given that it suggests that grammatical roles have semantic relevance. The fact that thematic roles play no role in determining the recovery of missing arguments but are crutial in determining the recovery of gapped verbs has led me to conclude that $\theta$-role interpretation is a matter of interpreting predicates rather than their arguments. However, by the same argument if grammatical functions are relevant for the recovery of arguments, it follows that grammatical roles are part of the interpretation of arguments. It appears that a grammatical function is assigned to an argument in order to link it to the relevant part of the predicate's interpretation. In other words, while the grammatical function has no semantic interpretation on its own that can be isolated and defined, it does have the important semantic function to enable the bits of semantic interpretation to combine into one large interpretation of the predicate and its arguments.

This hypothesis lends support to the assumption introduced in Sections 2.2.1.2 and 2.2.2.1 that the subject feature is universally assigned in the input. Unlike the topic feature, which I also argued is universally assigned in every input, the subject feature did not appear to have any semantic role - and its compulsory assignment as an input feature was thus an unmotivated stipulation. Without the subject being assigned to the agents of the full conjuncts in (436), however, it would not be possible to specify that agent as the only possible source for the missing argument of the second clause. This observation motivates the compulsory assignment of the subject feature even in languages that do not have subjects, such as Hungarian.

While this in itself offers no independent motivation for the weak/strong distinction made between input features, at least the description allowed us to motivate what until now has been a stipulation in the OT framework that is being developed here.

\footnotetext{
${ }^{80}$ Comrie (1981) reports that in some ergative languages, which he terms ergative in terms of control, recovery of the gap in cases such as (436) takes place based on the object. One possible way to capture this, maintaining the assumptions made here, is to assume that the relevant grammatical roles in these languages are [erg] and [abs] for ergative and absolutive, respectively. However, an exact analysis of these languages is left for future research. If such recovery cases were to be attested also in non-ergative languages, the assumption that grammatical roles are universally strong would need to be revised.
} 


\subsubsection{Gapping of topic-marked predicates}

The requirement that the order of arguments in the gapped conjunct be parallel to the full conjunct, even though post-verbal word order in Hungarian is supposed to be free, can also receive an explanation under the feature-based approach developed in the preceding sections. The contrast is repeated from (358) as (439):

a. SZERETI Mari Jánost és Erzsi Ferit loves Mari János-ACC and Erzsi Feri-ACC

'(Of all the relevant feelings) it is love that Mary feels towards John and Liz towards Frank'

b. SZERETI Jánost Mari és Ferit Erzsi

c. *? SZERETI Mari Jánost és Ferit Erzsi

d. *? SZERETI Jánost Mari és Erzsi Ferit

In Section 4.5 I showed that (439a) and (439b) are optimal for different inputs, because in the case of verb-initial emphatic sentences, the topic needs to immediately follow the verb. Thus in the full clause of (439a) the experiencer/subject, while in (439b) the theme/object is marked for topic status in the input. In Section 5.2.2 I argued for the general notion of argument marking on predicates, and in Section 5.2.2.4 I proposed that the reason (439c) and (439d) are unacceptable is that the overt and the elided predicates are argument-marked differently, and thus the semantics of the elided predicate cannot be recovered from the predicate of the full conjunct. Now that I have developed a theory of semantic unification, I can present a more formal explanation for the unacceptability of these non-parallel coordination cases.

The inputs for $(439 c)$ and $(439 d)$ are presented in (440b) and (440d), respectively, with the semantic topic-marking provided on the predicates. 
(440) a. * SZERETI János Marit és Erzsit Feri

b.

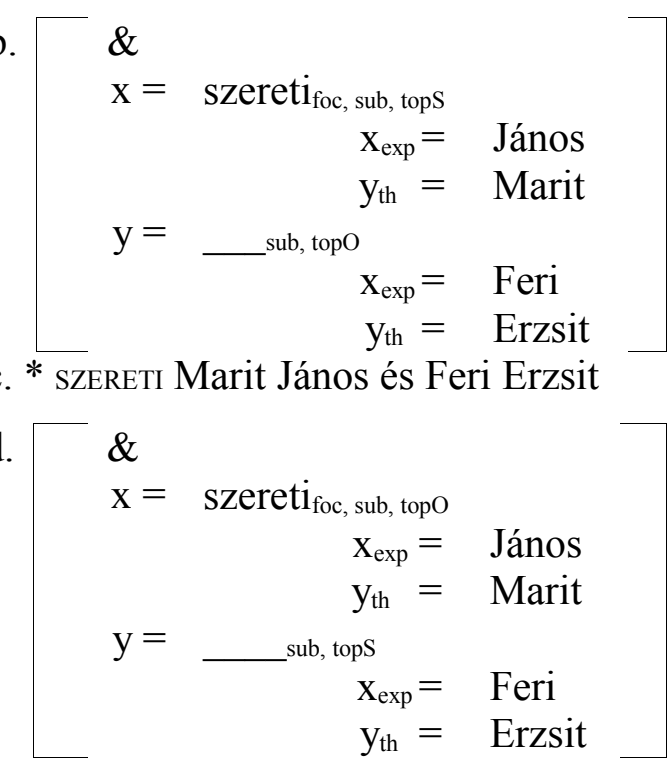

The topic-marking semantic features in Hungarian are strong features, and so semantic unification is impossible in both cases:
$(441)$
a. szereti sub, tops $\cup \ldots$ sub, topO $=\varnothing$
b. szereti $i_{\text {sub, topo }} \cup$ sub, tops $=\varnothing$

In the cases of (439a) and (439b) there will be no such semantic block on the syntactically well-formed sentences, because the semantic input features match, so unification can proceed.

(442) a. SZERETI János Marit és Feri Erzsit

b. $\quad \&$

$$
\begin{aligned}
\mathrm{x}=\text { szereti }_{\text {foc, sub, tops }} & \\
\mathrm{x}_{\mathrm{exp}}= & \text { János } \\
\mathrm{y}_{\mathrm{th}}= & \text { Marit } \\
\mathrm{y}=\quad \text { sub, tops } & \\
\mathrm{x}_{\mathrm{exp}}= & \text { Feri } \\
\mathrm{y}_{\text {th }}= & \text { Erzsit }
\end{aligned}
$$

c. SZERETI Marit János és Erzsit Feri

$$
\begin{aligned}
& \text { d. \& } \\
& \mathrm{x}=\text { szereti }_{\text {foc, sub, topO }} \\
& \mathrm{x}_{\mathrm{exp}}=\text { János } \\
& \mathrm{y}_{\mathrm{th}}=\text { Marit } \\
& y= \\
& \text { sub, topO } \\
& \mathrm{x}_{\mathrm{exp}}=\text { Feri } \\
& \mathrm{y}_{\mathrm{th}}=\text { Erzsit }
\end{aligned}
$$


a. szereti $_{\text {sub, tops }} \cup \ldots$ sub, tops $=$ szereti $_{\text {sub, tops }}$

\{szereti Feri Erzsit\}

b. szereti $_{\text {sub, topO }} \cup \ldots$ sub, topO $=$ szereti $_{\text {sub, topO }}$

\{szereti Erzsit Feri\}

This explanation is available in English as well, where a similar parallelism requirement is apparent, though the lack of morphological object marking means we can only force the non-parallel examples intonationally by omitting or including the pause which signifies the preceding topic. In (444a) it is clear that in the second conjunct Fred is the experiencer and Liz is the theme. The input is provided in (444b) and the unification in (444c).

(444) a. John loves Mary and Fred Liz

b. $\&$

$$
\begin{array}{rll}
\mathrm{x}=\text { loves }_{\text {sub, tops }} & \\
\mathrm{x}_{\exp }= & \text { John } \\
\mathrm{y}_{\mathrm{th}}= & \text { Mary } \\
\mathrm{y}=\quad \text { sub, tops } & \\
\mathrm{X}_{\exp }= & \text { Fred } \\
\mathrm{y}_{\mathrm{th}}= & \text { Liz }
\end{array}
$$

c. loves $_{\text {sub, tops }} \cup$ sub, tops $=$ loves $_{\text {sub, tops }}$

$\{$ Fred loves Liz $\}$

Let us now see what would happen to an input in which Fred is the theme of an object- topicalized missing predicate while Liz is its experiencer. Since English topics are fronted, the word order of the elided clause would be as in (445a), i.e. unchanged compared to (444a). This syntactically impeccable sentence would fail at the semantic level, since unification is not possible. This is illustrated in $(445 \mathrm{c})$.

(445) a. * John loves Mary and Fred ${ }_{\text {th }}$ Lizexp $_{\text {ex }}$

b.

$$
\left.\begin{array}{lrl}
\text { \& } & & \\
& & \\
& \text { loves }_{\text {sub, tops }} & \\
\mathrm{x}_{\mathrm{exp}}= & \text { John } \\
\mathrm{y}_{\text {th }}= & \text { Mary } \\
\mathrm{y}= & \text { sub, topO }_{\text {siz }}= & \text { Liz } \\
& \mathrm{x}_{\text {exp }}= & \text { Fred }
\end{array}\right]
$$


c. loves sub, tops $\cup \ldots$ sub, topO $=\varnothing$

As a result, the only meaning available for the sentence in (444a) is the one associated with the input of the parallel ordering in (444b).

This concludes my discussion on how semantic identity between source and target determine whether syntactically optimal sentences are interpretable in various cases of ellipsis. The unificational recovery theory operating with unary features can also account for the difference in identity requirement between languages, by introducing language-specific distinctions in the strengths of universal semantic features.

\subsection{Selection of the unification candidate}

So far I have focused on whether semantic unification can take place between two items - i.e. whether a particular item in the full conjunct can act as the source for semantic recovery. The focus was on the feature set of these items. What has not been dealt with is how that source item is chosen: which item or items in the full clause would undergo the unification procedure with the gap. The investigation of this issue will yield the analyses for the examples from Section 5.2 that were not dealt with in the preceding sections: (369), (370), (371) and (373).

One approach would be to claim that what unifies is not the gap with some element in the full conjunct, but the two entire conjuncts as input structures - one of which contains the gap that triggers the unification to occur in the first place. An advantage of taking this route is that if input structures are unified in full, parallelism follows from the very mechanism. On the other hand, if only the items are compared, the only requirement is for these items to bear sufficiently similar features, as was discussed in the previous sections. The requirement that the relevant structures containing these items be parallel does not follow automatically from a feature-based unification procedure and has to be added on top of the normal unification considerations. However, it seems to me that the potential problems with an account in which entire input structures unify outweigh the advantages.

Consider the input in (446): 


$$
\left[\begin{array}{lrl}
\& & & \\
\mathrm{x}= & \text { came in } \mathrm{inb}_{\text {sub }} & \\
& \mathrm{x}_{\mathrm{ag}}= & \text { John } \\
\mathrm{y}= & \text { sat down } & \\
& \mathrm{x}_{\mathrm{ag}}= &
\end{array}\right]
$$

If we wanted to unify the conjuncts, we would need a mechanism to ensure that only John gets unified with the gap, and there is no attempt made to unify came in with sat down, i.e. that certain material gets ignored. Under what is commonly termed unification, an attempt to unify two structures that include different lexical material in the same slot would fail.

$$
\text { came in } \operatorname{sub}_{\text {sub }}\left(\mathrm{John}_{\mathrm{ag}}\right) \cup \text { sat down } \text { sub }\left({ }_{\text {exp }}\right)=\text { ? }
$$

This complication is avoided if only the gap and its counterpart in the other conjunct are compared. What we then need is a mechanism that would match up the gap with another item in the input - and it is this mechanism that will account for parallelism. This is the focus of the present section.

\subsubsection{Pre-unification competition}

It has been clear from the examples so far that the source for an elided element is the equivalent, or parallel, element in the other conjunct. Semantic unification must "find" that relevant element. In a simple case such as the example in (446) the restriction appears to be that an argument can be recovered from an another argument, and, as the gapping examples in the previous section showed, a predicate from another predicate slot. This parallelism is captured as part of the semantic unification: an attempt to unify the elided element with one that is not sufficiently similar or parallel with it will fail, as demonstrated in (448) below.
a. $\operatorname{John}_{(\mathrm{ag})} \cup{ }_{(\mathrm{ag})}=\mathrm{John}_{\mathrm{ag}}$
\{John sat down\}
b. came in sub $_{\text {(ag) }}=\varnothing$

(449) presents a slightly more complex case - when there is more than one argument in the full conjunct. 
The sentence can only mean that it was John who left. As discussed before, it is not the thematic but the grammatical role of the elements in the full conjunct that determines whether they can act as a source. The input is provided in (450a) and the three potential semantic unification processes in $(450 \mathrm{~b}-\mathrm{d})$.

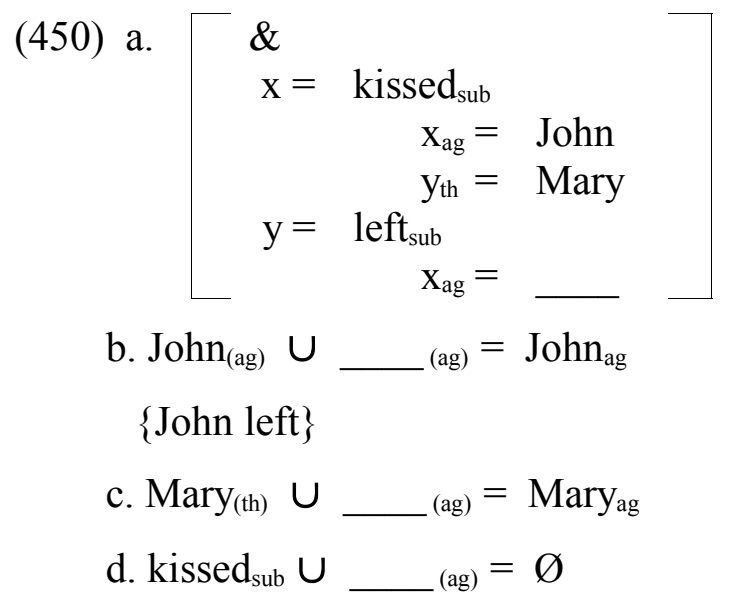

Given the behavior of unary features introduced in Section 5.3, both (450b) and (450c) are possible unifications: thematic roles do not matter for semantic recovery, while [sub] is a unary feature, so Mary $y_{\mathrm{ag}}$ should be a perfectly legal result for this unification attempt. It is clear, however, that in (449) only John, and not Mary, can be understood as the source of the gap, so the unification in (450c) needs to be ruled out.

We may view view the search for source as a competition: even if more than one unification would in theory be possible, i.e. non-conflicting, it is the element that is the closest match to the gap that will get the chance to attempt unification as the source. So even though Mary, too, could unify with the gap, John will act as the source, because its feature set more closely matches the feature set of the gap: both are subjects. I illustrate the pre-unification competition as in (451), where the top row represents the missing item's features, argument and subject. The unification candidates are the input items of the other conjunct, and mismatch is marked by *. 
$(451)$

\begin{tabular}{|r|c|c|}
\cline { 2 - 3 } \multicolumn{1}{c|}{} & arg & sub \\
\hline kissed & $* !$ & $*$ \\
\hline John & & \\
\hline Mary & & $* !$ \\
\hline
\end{tabular}

Like in OT, the features are organized hierarchically - though this is a semantic, and hence probably universal feature hierarchy. This competition differs from the syntactic optimality mechanism in one crucial respect: while under OT a winner is always generated for a given input, under the unification candidate competition, even the closest match may not be able to unify. The competition needs to be viewed as a preunification contest, establishing which input item from the other conjunct is the closest match to the missing element. Whether the closest match is close enough turns out during the unification procedure itself and is unrelated to the competition.

Let us see how this works for a case where unification failed in Section 5.3. One such example was the inability to recover a non-reflexive predicate from a reflexive one. (401b) is repeated here as (452).

$$
\left[\begin{array}{lrl}
\& & & \\
\mathrm{x}= & \text { likes }_{\text {refl, sub }} & \\
& \mathrm{x}_{\mathrm{exp}}= & \text { John } \\
& \mathrm{y}_{\mathrm{th}}= & \text { himself } \\
\mathrm{y}= & \mathrm{x}_{\mathrm{exp}}= & \text { Mary } \\
& \mathrm{y}_{\mathrm{th}}= & \text { Bill }
\end{array}\right]
$$

The pre-unification contest for (452) is provided below.

\begin{tabular}{|c|c|}
\cline { 2 - 2 } \multicolumn{1}{c|}{} & pred \\
\hline likes & \\
\hline John & $* !$ \\
\hline himself & $* !$ \\
\hline
\end{tabular}

It is not a very interesting competition, since only one item comes even close to matching the gap. The winning item can then attempt unification, which is repeated here from (402b). The unification fails, because the gap inherits the [refl] feature.

$$
\begin{aligned}
& \text { b. } \text { likes }_{\text {refl, sub }} \cup \underset{\text { sub }}{ }=\text { likes }_{\text {refl, sub }} \\
& \quad *\left\{\text { Mary likes }_{\text {refl }} \text { Bill }\right\}
\end{aligned}
$$


Simple competitions like the one in (453) precede all the unification attempts described in Section 5.3, but they will be as unexciting as (453). Where the preunification competition has relevance are cases in which more than one input item from the full conjunct could successfully unify with the missing element, which was the case in (450). In the following section I will discuss cases in which the preunification competition is relevant.

\subsubsection{Embedding}

In cases of embedding there is more than one potential source to recover the content of an elided argument, according to the unification rules established so far. This was the case with the examples in (369), repeated here as (455).
(455) a. Mary said John hit Bill and ran away
b. Mary said John hit Bill and ran away
c. * Mary said John hit Bill and ran away

Recall the observation by Wilder (1997: 95) that the elided subject can only be recovered from a structurally parallel subject in the preceding clause. This can happen either from the matrix subject (Mary), in which case the clause of the elided subject is interpreted as non-embedded or from the subject of the embedded clause (John), in which case the second clause, too, is interpreted as embedded. What is not possible is for the elided subject to be recovered from the embedded subject and for its clause to be interpreted as non-embedded.

In case of non-subjects the elided material must be in the same position as the source, i.e. at the right edge of their conjuncts, but the two do not have to be structurally parallel in that they may, for example, be related to elements at different levels of embedding within their conjuncts. The relevant examples are repeated from (370).
a. John likes but I think Mary hates garlic
b. I think John likes but Mary certainly hates garlic

In both of these cases recovery occurs from a structurally non-parallel source. (The certainly in (456b) is inserted to ensure that the second clause is non-embedded.) 
This difference between subject and non-subject recovery falls out from locality restrictions on recovery (Peters 1973, Salles 1995 and Pesetsky 1998 among others): the content of an elided element must be from the nearest parallel element (where parallelism is defined in terms of subject/non-subject arguments). As all clauses (and so conjuncts) have subjects, the nearest subjects in both conjuncts will always be the top-most ones in each. For non-prominent arguments, on the other hand, embedding occurs when the object is predicative, i.e. the nominal complement is embedded beneath a verbal complement. There is going to be only one nominal object to recover a missing object from, the lowest object in the embedding. In cases where embedding is asymmetric, the gap and the source will not be structurally parallel - even though this non-parallel element will still be the nearest potential non-subject argument.

Essentially the difference occurs because embedding never takes place in the subject, but always in the object, pushing the gap or the potential source further down. What we need is a formalism that captures this difference between subjects and non-subjects in terms of the pre-unification mechanism.

\subsubsection{Subjects: Structural parallelism}

Let me begin with the subject case. The two possible inputs for (455) are in (457).

(457) a. Mary said John hit Bill and ran away

b. said $_{\text {sub }}$

$$
\begin{aligned}
& \mathrm{x}_{\mathrm{ag}}=\text { Mary } \\
& \mathrm{y}_{\mathrm{th}}=\&
\end{aligned}
$$

$$
\mathrm{x}=\text { hit }_{\text {sub }}
$$$$
\mathrm{X}_{\mathrm{ag}}=\mathrm{John}
$$$$
\mathrm{y}_{\mathrm{th}}=\text { Bill }
$$

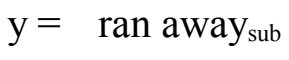

$$
\mathrm{x}_{\mathrm{ag}}=
$$


c. Mary said John hit Bill and ran away

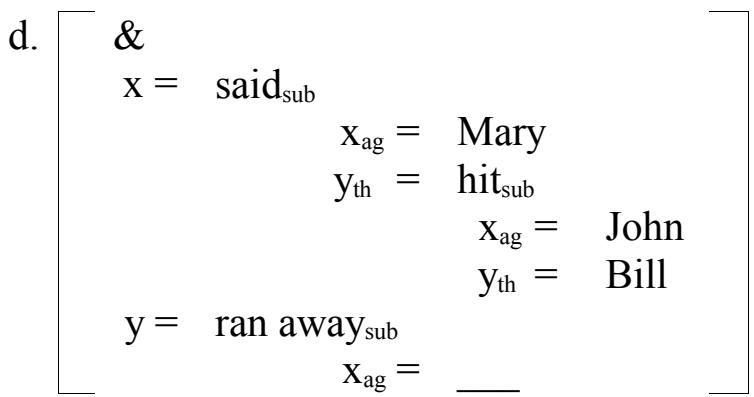

For (457d) there are two subjects in the full conjunct. In this case, however, only Mary, the structurally parallel subject can function as the source. We can capture this observation by introducing a formalism, where the input position of the missing element is another attribute that, if possible, needs to be matched by the source. This is represented in the final column of the table below, where the column header shows where the item the row represents stands with respect to the conjunction. \&2 means that the gap is two degrees of embedding down from the conjunction.

\begin{tabular}{|r|c|c|c|}
\cline { 2 - 4 } \multicolumn{1}{c|}{} & arg & sub & $\& 2$ \\
\hline said & $* !$ & $*$ & $*$ \\
\hline Mary & & & \\
\hline hit & $* !$ & $*$ & \\
\hline John & & & $* !$ \\
\hline Bill & & $* !$ & $*$ \\
\hline
\end{tabular}

The unification procedure for (457b) is similar. So far, as we did not deal with cases of embedding, the potential sources for interpretation were the input items of the other conjunct. This, however, does not need to be stated as an extra assumption, because the mechanism introduced here to capture parallelism will mean that unification will be attempted with an item of the other conjunct, whenever possible.

The unification competition is illustrated in (459).

(459)

\begin{tabular}{|r|c|c|c|}
\cline { 2 - 4 } \multicolumn{1}{c|}{} & arg & sub & $\& 2$ \\
\hline said & $* !$ & $*$ & $*$ \\
\hline Mary & & & $* !$ \\
\hline hit & $* !$ & $*$ & $*$ \\
\hline John & & & \\
\hline Bill & & $* !$ & \\
\hline
\end{tabular}

The unification procedures for the two inputs are provided in (460). 
(460)
a. $\operatorname{Mary}_{(\mathrm{ag}), \& 2} \cup$ (ag), $\& 2=$ Maryag $_{\mathrm{ag}}$

\{Mary ran away\}

b. $\operatorname{John}_{(\mathrm{ag}), \& 2} \cup$ (ag), \&2 $=\mathrm{John}_{\mathrm{ag}}$

\{John ran away\}

Note that the interpretation illustrated in $(455 \mathrm{c})$ is not available as the unification procedure for either inputs, which is the correct prediction.

\subsubsection{Objects: String parallelism}

The relevant inputs for (456) are provided below:

(461) a. John likes but I think Mary hates garlic

b. $\square$ but

$$
\begin{aligned}
& \mathrm{x}=\text { likes }_{\text {sub }} \\
& \mathrm{x}_{\mathrm{exp}}=\mathrm{John} \\
& \mathrm{y}_{\mathrm{th}}= \\
& \mathrm{y}=\text { think } \\
& \mathrm{x}_{\mathrm{exp}}=\mathrm{I} \\
& \mathrm{y}_{\mathrm{th}}=\text { hates }_{\text {sub }} \\
& \mathrm{x}_{\mathrm{exp}}=\text { Mary } \\
& \mathrm{y}_{\mathrm{th}}=\text { garlic }
\end{aligned}
$$

c. I think John likes but Mary certainly hates garlic

d. $\square$ but

$$
\begin{aligned}
\mathrm{x}=\text { hates }_{\text {sub }} & \\
\mathrm{x}_{\mathrm{exp}}= & \text { Mary } \\
\mathrm{y}_{\text {th }}= & \text { garlic } \\
(\mathrm{z})= & \text { certainly } \\
\mathrm{y}=\text { think }_{\text {sub }} &
\end{aligned}
$$

$$
\begin{aligned}
& \mathrm{x}_{\exp }=\mathrm{I} \\
& \mathrm{y}_{\text {th }}=\text { likes }_{\text {sub }} \\
& \mathrm{x}_{\text {exp }}=\mathrm{John} \\
& \mathrm{y}_{\mathrm{th}}=
\end{aligned}
$$

The pre-unification competition for (461b) is presented below. Though hates is an argument, it is predicative, so it is out of the race at the first feature. At the same time, it is the subject argument of the full conjunct that is structurally parallel, so it would incorrectly be predicted as the winner. 
(462)

\begin{tabular}{|r|c|c|}
\cline { 2 - 3 } \multicolumn{1}{c|}{} & arg & $\& 2$ \\
\hline think & $* !$ & $*$ \\
\hline I & & \\
\hline hates & $* !$ & \\
\hline Mary & & $* !$ \\
\hline garlic & & $* !$ \\
\hline
\end{tabular}

Since $I$ is a subject, and the gap is not, unification would fail - and the sentence would be incorrectly predicted as ungrammatical. This suggests that grammatical functions other than the subject are relevant for recovery, and so need to be marked in the input. In fact, this is less of a radical step than it may seem: implicitly these grammatical roles have already been assumed to be part of the input. When distinguishing between topic-object and topic-subject predicates, I had to introduce grammatical roles, since the data indicated that it is the grammatical function and not the thematic role of the topic that determines whether its gapped predicate can be recovered from a full predicate in the other conjunct (5.2.2.4). It also seems plausible that the grammatical functions can be auto-assigned to the thematic arguments, so the number of (independent) input features does not increase. The same way as the subject feature was assigned to the argument that is most prominent under Grimshaw's (1990) argument prominence hierarchy (2.2.1.2 and 2.2.2.1), the direct object feature can be assigned to the least prominent argument. The indirect object feature will be assigned to the argument in the middle.

The problem with turning the direct object and the indirect object ([ind]) grammatical functions into input features is that the asymmetrical relationship between the subject argument on the one hand and non-subject arguments on the other disappears. With the subject marked as the only special argument, the $\mathrm{pS} / \mathrm{Sp}$ pair of constraints could account for the special status of the subject in some languages. The subject is the only argument to appear on the other side of the predicate in languages that make a distinction between different types of arguments this way. The marking of the [obj] and [ind] features would mean that $\mathrm{pO} / \mathrm{Op}$ and $\mathrm{pI} / \mathrm{Ip}$ constraints also exist, predicting that there are languages that distinguish their direct or indirect object this way, contrary to fact. An answer to this issue will have to remain for future research ${ }^{81}$.

\footnotetext{
${ }^{81}$ One possibility is that it is not grammatical function that is important for unification, but input Case. On the assumption that different arguments get assigned different Cases in the input and that these to some degree reflect grammatical function, we can distinguish between subjects, objects and indirect objects in terms of the Case they bear. Furthermore, under the assumption of universal inputs, it follows that Case distinctions are universal, though they may not always show up at the surface in the same way.
} 
Once the object feature is introduced the winner to attempt unification is the closest such argument in the other conjunct, which is structurally non-parallel.

(463)

\begin{tabular}{|r|c|c|c|}
\cline { 2 - 4 } \multicolumn{1}{c|}{} & arg & obj & $\& 2$ \\
\hline think & $* !$ & $*$ & $*$ \\
\hline I & & $* !$ & \\
\hline hates & $* !$ & $*$ & \\
\hline Mary & & $* !$ & $*$ \\
\hline garlic & & & $*$ \\
\hline
\end{tabular}

Unification succeeds, so the sentence receives an interpretation, and so the syntactically optimal candidate of (461b), (461a), will be acceptable.

$(464)$

$$
\operatorname{garlic}_{(\mathrm{th}), \& 3} \cup \ldots{ }_{\text {(th), \&2 }}=\text { garlic }_{\text {th }}
$$

\{John hates garlic $\}$

(461d) is a simpler case, since there is only one non-subject argument in the full conjunct. None of the potential sources are at the same structural level, as the values in the third column of the table illustrate.

(465)

\begin{tabular}{|r|c|c|c|}
\cline { 2 - 4 } \multicolumn{1}{c|}{} & arg & obj & $\& 3$ \\
\hline hates & $* !$ & & $*$ \\
\hline Mary & & $* !$ & $*$ \\
\hline garlic & & & $*$ \\
\hline
\end{tabular}

The unification procedure is shown below.

$$
\operatorname{garlic}_{(\text {th) } \& 2} \cup \ldots \text { (th), \&3 }=\text { garlic }_{\text {th }}
$$

\{John hates garlic\}

The formalism introduced to capture the difference between structural and string parallelism may seem ad hoc, but all it did is to formalize the observation that the closest non-subject in the other clause is not necessarily structurally parallel. The subject is always nominal and therefore it will always be a possible source for a gapped subject, whereas complements are not always nominal and hence won't necessarily be a good source for the object.

Thus, we can still use Case to distinguish between input elements, even in languages like English where there are little or no Case distinctions visible at the surface. Newson (2003) assumes Case as an input feature along these lines. 
Let us test whether the present theory makes the correct prediction for non-subject FWE cases by deriving the semantic recovery procedure for (371), repeated below.

(467) Marmite, John hates but Mary said Peter loves

I discussed in Section 5.2.1 that there are two potential inputs that can form the basis for (467), depending on the input scope of the topicalized missing element.

(468) a. Marmite, John hates but Mary said Peter loves

b.

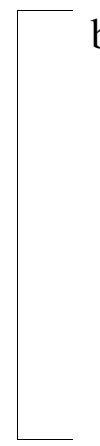

$$
\begin{array}{rll}
\text { but } & & \\
\mathrm{x}=\text { hates }_{\text {sub, topO }} & \\
\mathrm{x}_{\mathrm{exp}}= & \text { John } \\
\mathrm{y}_{\mathrm{th}}= & \text { Marmite } \\
\mathrm{y}=\text { said }_{\text {sub }} & \\
\mathrm{x}_{\mathrm{ag}}= & \text { Mary } \\
\mathrm{y}_{\mathrm{th}}= & \text { loves }_{\text {sub, topO }} \\
& \mathrm{x}_{\text {exp }}=\text { Peter } \\
& \mathrm{y}_{\mathrm{th}}= &
\end{array}
$$

c. Marmite, John hates but Mary said Peter loves

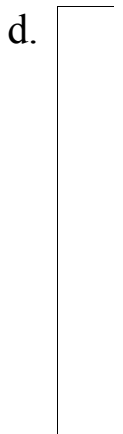

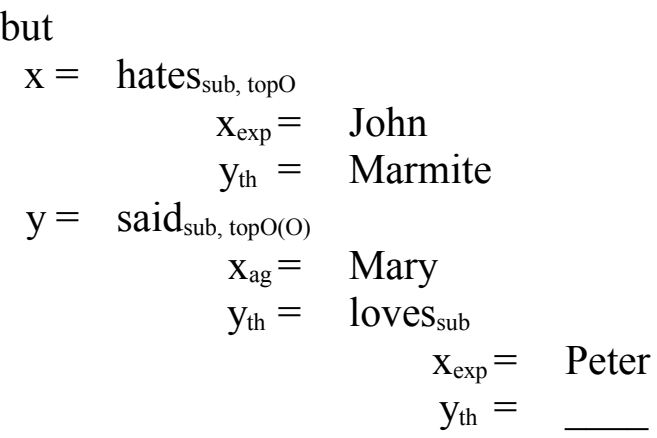

The pre-unification competition will be the same for both of these inputs:

(469)

\begin{tabular}{|r|c|c|c|c|}
\cline { 2 - 5 } \multicolumn{1}{c|}{} & arg & obj & top & $\& 3$ \\
\hline hates & $* !$ & $*$ & $*$ & $*$ \\
\hline John & & $* !$ & $*$ & $*$ \\
\hline Marmite & & & & $*$ \\
\hline
\end{tabular}

The unification is presented in (470a) below. The informal semantic representation for the elided conjunct of (468b) is in (470b), while that of (468d) is in (470c). 

a. Marmite $_{(\text {th }), \& 2} \cup$ (th), \&3 $=$ Marmite $_{\text {th }}$
b. \{Mary said Marmite Peter loves\}
c. $\{$ Marmite Mary said Peter loves $\}$

Marking grammatical features in the pre-unification competition is crucial in case of the example in (471) as well.

(471) a. John hates but Mary told Peter he likes garlic

b.

$$
\begin{aligned}
& \text { but } \\
& \mathrm{x}=\text { hates }_{\mathrm{sub}} \\
& \mathrm{X}_{\text {exp }}=\mathrm{John}_{\mathrm{i}} \\
& y=\operatorname{told}_{\text {sub }} \\
& \mathrm{y}_{\mathrm{th}}= \\
& \mathrm{x}_{\mathrm{ag}}=\text { Mary } \\
& \mathrm{y}_{\text {ben }}=\text { Peter } \\
& \mathrm{Z}_{\mathrm{th}}=\text { likes }_{\text {sub }} \\
& \mathrm{x}_{\exp }=\mathrm{he}_{\mathrm{i}} \\
& \mathrm{y}_{\mathrm{th}}=\text { garlic }
\end{aligned}
$$

The pre-unification competition will be the following:

\begin{tabular}{|r||c|c|c|}
\cline { 2 - 4 } \multicolumn{1}{c|}{} & arg & obj & $\& 2$ \\
\hline Mary & & $* !$ & \\
\hline Peter & & $* !$ & \\
\hline likes & $* !$ & & \\
\hline he & & $* !$ & $*$ \\
\hline garlic & & & $*$ \\
\hline
\end{tabular}

Without marking of the non-subject grammatical roles Peter and Mary, which are structurally parallel, could win the competition. Peter, as a non-subject could even unify with the gap, incorrectly yielding the meaning John hates Peter.

The unification based on the competition in (472) will succeed:

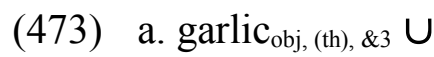
${ }_{\mathrm{obj},(\mathrm{th}), \& 2}=$ garlic $_{\mathrm{obj}}$, th

b. $\{$ John hates garlic $\}$ 


\subsubsection{3 "VP-deletion"}

The last examples from Section 5.2.1 whose semantic recovery needs to be accounted for are what are traditionally called VP-deletion cases, in which FWE and BWE patterns are both possible. (373) is repeated here as (474).

(474) a. I think John will do the washing up but Mary certainly won't

b. John will do the washing up but I think Mary won't

The relevant inputs are provided below:

(475) a. I think John will do the washing up but Mary certainly won't

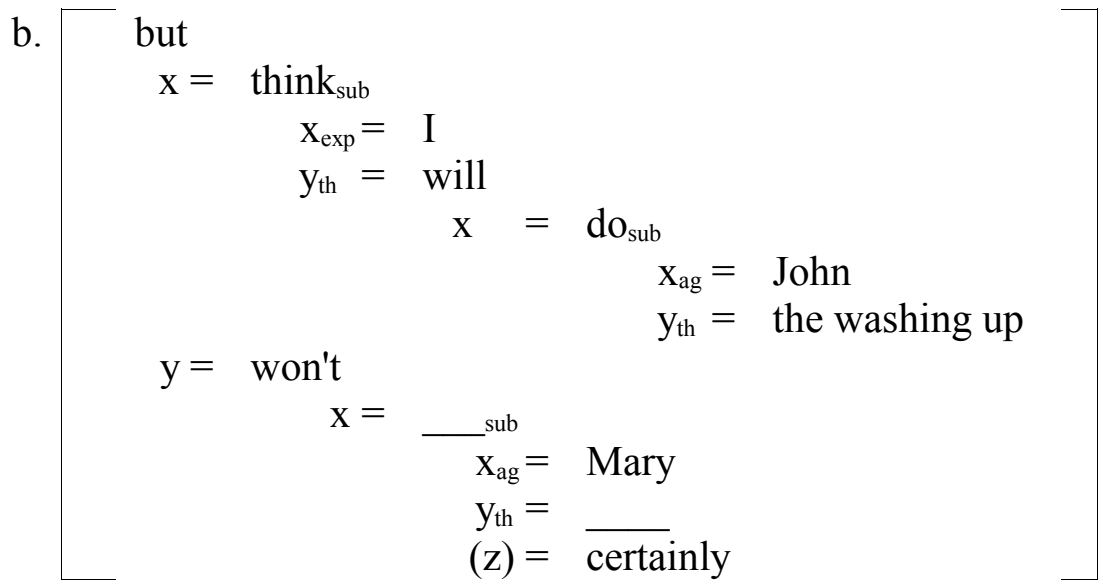

c. John will do the washing up but I think Mary won't

d. $\quad$ but

$\mathrm{y}=$ will

$\mathrm{x}=\mathrm{do}_{\mathrm{sub}}$

$\mathrm{X}_{\mathrm{ag}}=\mathrm{John}$

$\mathrm{x}=$ think $_{\text {sub }}$

$\mathrm{y}_{\mathrm{th}}=$ the washing up

$$
\begin{aligned}
& \mathrm{x}_{\text {exp }}=\mathrm{I} \\
& \mathrm{y}_{\text {th }}=\text { won't } \\
& \quad \mathrm{x}={ }^{\text {sub }} \quad \begin{array}{l} 
\\
\mathrm{x}_{\mathrm{ag}}=\text { Mary } \\
\mathrm{y}_{\text {th }}=
\end{array}
\end{aligned}
$$

The pre-unification competition for (475d) is as before: $d o$ is the closest match for the missing verb, as the only predicative element in the other conjunct. For the missing theme, the washing up will be the closest match. Unification succeeds for both gaps. 
As for (475b), the source for the theme gap again easily falls out: it is the only nominal, object argument in the full conjunct. The case of finding the source for the missing verbal element, on the other hand, is slightly more complex. The competition is illustrated in (476). Neither think nor do are structurally parallel to the gap.

(476)

\begin{tabular}{|r|c|c|c|}
\cline { 2 - 4 } \multicolumn{1}{c|}{} & pred & $\& 2$ & $\Omega 1$ \\
\hline think & & $*$ & $* !$ \\
\hline I & $* !$ & & $*$ \\
\hline will & $* !$ & & $*$ \\
\hline do & & $*$ & \\
\hline John & $* !$ & $*$ & $*$ \\
\hline the washing up & $* !$ & $*$ & $*$ \\
\hline
\end{tabular}

The more similar of the two verbs still in the running is the one that takes nominal arguments - just like the missing predicate. This can either be captured as a feature or as a structural characteristic of the item. I have chosen to illustrate the latter route in the competition table, marking that the gap is one level up from the bottom of the input structure $(\Omega 1)$. Looking at them from the bottom up, $d o$ and the missing item are positionally parallel. Once the elements to unify are chosen, unification will proceed and the impoverished input will receive an interpretation.

Let me conclude this section by returning to a structurally non-parallel unification case introduced in Section 5.3.2 on tense recovery. Here, too, we saw that when there is no structurally parallel matching element, another element with matching features can become the source. (409) is repeated here as (478), the input for (477), below.

(477) John got up but Mary didn't want to

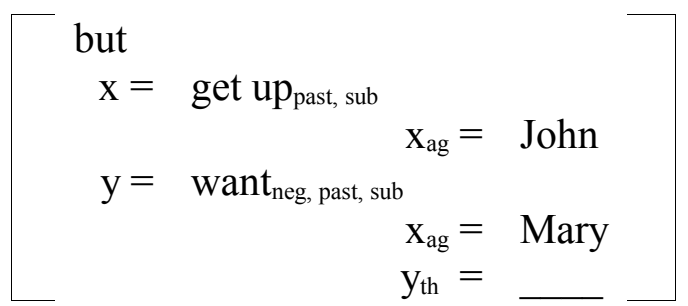

The competition is in (479), while the unification procedure is repeated from (410) in (480). The selectional properties of want require the gap to be predicative.

\begin{tabular}{|r|c|c|}
\cline { 2 - 3 } \multicolumn{1}{c|}{} & pred & $\& 2$ \\
\hline got up & & $*$ \\
\hline John & $*$ & \\
\hline
\end{tabular}


\{Mary didn't want to got up\}

Semantic recovery can tie the loose ends of the syntactic account: where the syntax would churn out a candidate, a failure for the missing element to unify can undermine the realization of the input in any semantic form. In the second half of the chapter, I provided an account of parallelism, and could maintain that BWE and FWE candidates compete in the syntax, because what were seen as fundamental differences in parallelism between them fell out from the semantic unification theory developed.

\subsection{Conjunction recovery}

In Section 3.6.2 I hypothesized that in cases such as (481) a missing and needs to be semantically recovered from but to achieve the intended interpretation that the third unit is contrasted with the conjunction of the first two.

(481) John likes coffee, Jim likes tea but Jane likes Horlicks

(Blakemore 1987: 135)

I would like to show that the analysis developed for recovery can be extended to generate the data. The input is provided in (482), with but represented as $\&_{\text {[contr]. }}$.

(482) input for (481) - to be revised

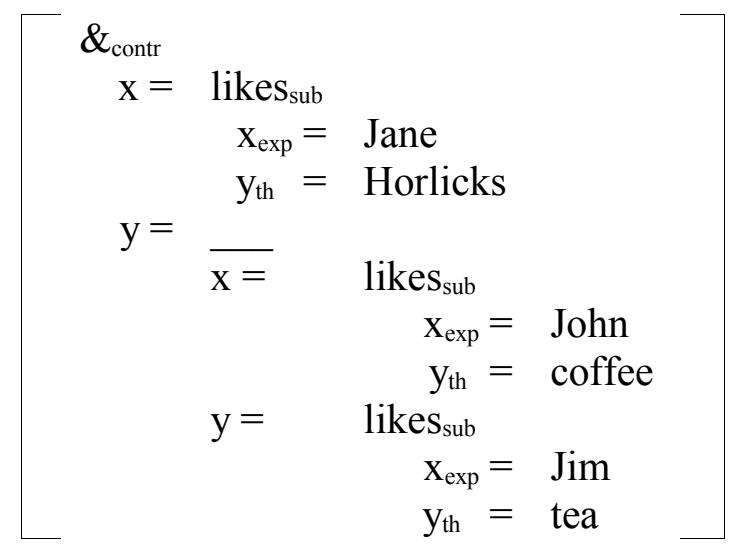

According to the theory developed so far, the pre-unification competition includes all the input items outside the conjunct containing the gap. So far I have not included the coordinative operator as a candidate in the competition, but there is nothing in the 
theory that would rule out its inclusion. In fact, while its inclusion is of no material consequence in the previous examples, the theory is simpler if we do not need to stipulate what elements outside the conjunct may act as potential sources for recovery.

The competition for (482) is illustrated below - with the operator feature added.

(483)

\begin{tabular}{|r||c|c|}
\cline { 2 - 3 } \multicolumn{1}{c|}{} & op & $\& 1$ \\
\hline but & & $*$ \\
\hline likes & $* !$ & \\
\hline Jane & $* !$ & $*$ \\
\hline Horlicks & $* !$ & $*$ \\
\hline
\end{tabular}

The unification procedure with but is then attempted:

$$
\&_{\text {funct, contr }} \cup \_ \text {funct }=\&_{\text {funct, contr }}
$$

\{John likes coffee but Jim likes tea but Jane likes Horlicks\}

Though unification does succeed, the outcome is semantically anomalous: there cannot be a three-way contrast - which is why in the first place it is and that we want to recover from the overt but. A possible way out of this problem is to assume that contrary to the traditional claim that but is like and plus something else, it is and which is like but plus something else. If the default coordination relationship is taken to be contrast, and may be seen as the default coordinator marked for conjunction (i.e. non-contrast). This is no more complex than the view under which but is seen as the default coordinator marked for contrast (i.e. non-conjunction). The Vocabulary Items of the coordination operators under the two approaches are contrasted below:

\begin{tabular}{|r|c|c|}
\cline { 2 - 3 } \multicolumn{1}{c|}{} & and-centric & but-centric \\
\hline and & and & but $_{[\text {conj] }}$ \\
\hline or & and $_{[\text {[isj] }}$ & but $_{[\text {disj] }}$ \\
\hline but & and $_{[\text {contr] }}$ & but \\
\hline
\end{tabular}

The revised input for (481) would then look like: 


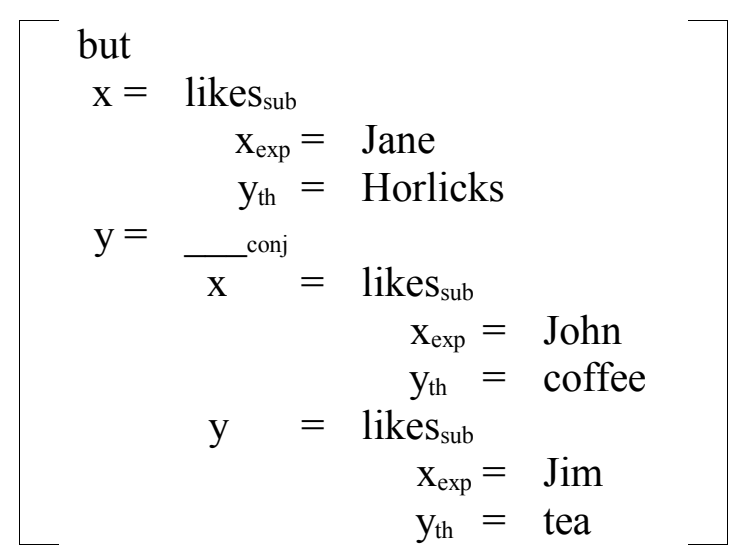

The pre-unification competition remains unchanged (see (483)), but the unification procedure will be the following:

$$
\begin{aligned}
& \text { (487) } \text { but funct } U \ldots \text { funct, conj }=\text { but funct, conj } \\
& \{\text { John likes coffee and Jim likes tea but Jane likes Horlicks }\}
\end{aligned}
$$

This theory correlates with other recovery facts as well: but can never be recovered from and. In an impoverished input that contains an and as well as a gap for but, this gap will lack a specification other than it being a coordinative functor, the vocabulary definition of but. When such an item would attempt to unify with and, the result will be another instance of and. This is illustrated in (488).

$$
\begin{aligned}
& \text { (488) } \text { but funct, conj } U \_ \text {funct }=\text { but }_{\text {funct, conj }} \\
& \{\mathrm{X} \text { and } \mathrm{Y} \text { and } \mathrm{Z}\}
\end{aligned}
$$

As such, an input of this kind will not be interpretable, which is the correct prediction.

A but cannot be recovered from another instance of but either. In (481) above, the missing coordinator cannot be a contrastive one, since three-way contrasts are impossible. If, however, the input contains a gap for a coordinative functor but without it being marked for conjunction, unification will succeed:

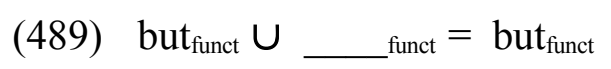

$\{\mathrm{X}$ but $\mathrm{Y}$ but $\mathrm{Z}$ \} 
Though unification succeeds, the resulting semantics will contrast with the meaning of but, which allows only two way contrasts. This will be similar to cases discussed in the previous sections of this chapter, such as the erroneous recovery from a reflexive predicate of a reflexivity feature for a predicate that is not reflexively marked by its arguments. Even though unification succeeded in that case, the result was a semantic anomaly, so the sentence did not receive an interpretation.

This concludes my discussion of the semantic recovery of ellipsis gaps in coordination. I hope to have demonstrated that the investigations of previous sections on the importance of parallelism in various ellipsis cases can receive a semantic explanation. As such the syntactic mechanisms responsible for ellipsis do not need to account for the parallelism facts, which in turn received semantic explanations. 


\section{Conclusion}

In what follows I will first briefly recapitulate the results of my investigation for the analysis of coordination and then summarize the observations made with respect to the wider body of OT alignment grammar.

\subsection{A structureless account of Coordination}

The starting point of this thesis was the observation that coordination has been problematic both for grammars that assume the existence of syntactic structure and for ones that do not. For accounts operating with phrase structure it has been a challenge to fit coordination into models developed to account for structures occurring elsewhere. Coordinate expressions either had to be treated as multi-headed structures or - even when an X-bar like, asymmetric phrase structure was argued for, exceptions to general X-bar rules had to be made to account for coordination data. Theories operating without the assumption of phrase structure faced problems of their own: the apparent notion that it is constituents larger than words that are coordinated was hard to capture in theories that do not assume the existence of syntactic phrases.

While many details remain to be worked out (nominal coordination, for one, was barely discussed), the grammar developed here has provided a framework that appears to be able to address the problems faced by both kinds of theories. The alignment version of Optimality Theory that was adopted as the framework to the thesis operates exclusively with faithfulness and alignment constraints, and treats syntactic structure as epiphenomenal. The key notion that allowed the grammar to solve the problem faced by other structureless theories in terms of coordination has been that of cyclicity. Under cyclicity, a functor is the focus of each evaluation cycle, and its arguments, or functees, are ordered in the cycle. Once a functor and its functees have been placed with respect to each other, a successive functor cycle cannot change their relative positions. This mechanism allows words to cluster together without the need for the grammar to resort to phrases. The key to this process is the assumption that the input to the syntactic apparatus is the sole interface between syntax and semantics, and as such it contains the complete semantic structure of the sentence. This semantic structure could be relied upon to restrict the attention of the grammar's evaluation component to a functor and its functees at a time. It was also demonstrated that in a 
theory working without phrases this approach is necessary not only to account for coordination but also for subordination facts.

The coordinative conjunction was treated as a functor, taking the predicates of its conjuncts as its functees. As the top functor, it came first in the evaluation procedure: Before the internal ordering of the conjuncts was attended to by the grammar, the coordinative conjunction was placed with respect to its predicate functees. Next came the functor cycle(s) responsible for the placement of the conjunct predicates with respect to their functees. A key assumption in terms of cyclicity has been that at each cycle the evaluation component of the grammar is "blind" to the position of the arguments of the functees placed in the cycle. In case of the coordination functor cycle this means that only one aspect of the the competition between possible word orders is decided at this stage: the position of the conjunction and the predicates. All candidates in which the relative position of these elements is the same will score equally during this cycle - and will not compete with each other until after the conjunction and the predicates have been placed with respect to one another.

Ellipsis is caused by missing input material, which the semantic system has to be able to reconstruct based on an antecedent in the other conjunct in order for the sentence to be interpretable. I have provided a theory for this reconstruction, based on higherorder unification, preceded by a pre-unification competition. In this competition the system identifies the best potential blueprint of the ellipsis gap from among the input elements outside the ellipsis conjunct. Unification is then attempted between this element and the gap. Only if unification succeeds will the semantic component be able to interpret the input. If unification fails, the result is a semantic anomaly no matter what ordering the syntactic apparatus places on the input items: since all competing candidates have the same interpretation, the optimal word order, too, will be anomalous.

While the syntax is powerless when an input is uninterpretable, it does have to deliver a grammatical candidate when semantic unification succeeds and the impoverished input can receive an interpretation. In cases of such impoverished inputs the licensing needs of certain input items in the conjunct with the input gap cannot be met. When an argument is elided, for instance, the predicate's requirement to be aligned to its 
required number of arguments cannot be satisfied as one of the arguments is missing. In such cases the arguments of the other conjunct can stand in to satisfy the argument alignment needs of the predicate with a missing argument. This is attempted after the alignment requirements of all items from among their functees has been maximally satisfied, as defined by the ordering of the alignment constraints in the language. The same constraint ordering is relevant in every cycle, including this final "mop-up" cycle, which is why the model developed here can account for the observation that cross-linguistically the direction of ellipsis can be derived from the internal word order of the individual conjuncts. In a language where the object must follow the verb, for instance, a clause with an elided object must precede the conjunct with the overt object, so that the object is on the right side of both verbs.

$$
\begin{aligned}
& \text { a. } Y_{-} \& \text { X Obj } \\
& \text { b. * X Obj \& Y }
\end{aligned}
$$

This match in directionality had to be independently stipulated in previous ellipsis accounts. In verbal deletion, or gapping, the relationship between the internal word order of the language and the directionality of ellipsis is looser. The theory presented here can account for this asymmetry. The mop-up cycle can influence the competition only when input items have unsatisfied alignment requirements. Since alignment is defined as a requirement on the predicate, when a predicate is missing there are no unsatisfied alignment relationships left to sort out. As such there is only one candidate left by the mop-up cycle, which will then not influence grammaticality. It is thus not the same constraints that account for basic word order that are responsible for gapping, predicting that the directionality of gapping does not need to be derivable from basic word order facts of the language.

\subsection{Additions to OT Alignment Syntax}

Besides providing an account for a number of coordination phenomena, the theory developed here has potential consequences for the wider research program to develop an OT grammar based solely on alignment and faithfulness constraints.

I have argued that the introduction of a second type of alignment constraints was necessary to explain relationships that were not related to the placement of arguments 
with respect to their predicates (or, more generally, functees with respect to their functors) but with respect to a number of other items in the input as well. These scopal constraints, which I termed first (X1) and last $(\mathrm{X} \Omega)$ constraints, also addressed a weakness in previous version of alignment OT: that the constraint system could not account for the basic word order of SOV languages, the second most commonly attested language type.

The grammar is a combination of functor-functee alignment and first/last constraints as well as the PARSE constraint, which sanctions against the underparsing of input material.

The ranking for English is repeated from (331) and for Hungarian from (206) $)^{82}$ :

(491) English: Parse » $\mathrm{Sp}, \mathrm{T} 1 » \mathrm{fA}, \mathrm{S} 1 » \mathrm{pS}, \mathrm{Af}, \mathrm{f}(\mathrm{Ad}), \mathrm{S} \Omega, \mathrm{A} 1 »(\mathrm{Ad}) \mathrm{f}, \mathrm{A} \Omega, \mathrm{Ad} 1 »$ $\mathrm{Ad} \Omega » \mathrm{~V} 1 » \mathrm{~V} \Omega$

(492) Hungarian: $\mathrm{Sp}, \mathrm{pS}, \mathrm{S} 1, \mathrm{~S} \Omega$ » $\mathrm{P}$ ARSE $»(\mathrm{~V} 1 \& \mathrm{~F} 1) » \mathrm{~T} 1 » \mathrm{~F} 1 » \mathrm{fA}, \mathrm{f}(\mathrm{Ad}) »(\mathrm{Ad}) \mathrm{f}$, $\mathrm{T} \Omega, \mathrm{F} \Omega, \mathrm{V} 1 » \mathrm{~A} 1, \mathrm{~A} \Omega, \mathrm{Ad} 1, \mathrm{Ad} \Omega, \mathrm{V} \Omega$

The definition of cyclicity provided here has also solved a problem in previous OT alignment accounts related to competition between strings of differing length. In alignment OT when an item is blocked from its desired position by another element, and so the constraint trying to place the item there is bound to be violated, the violation is smaller if the item is closer to its optimal position. The distance is measured as the number of intervening elements. This would predict that - all other factors being equal - elements consisting of more words (=longer) are placed further from their desired positions than elements consisting of fewer words (=shorter): when a long element is placed further, it is a short element intervening, so the alignment constraint with respect to the long element is violated less than the other way round. This is the wrong prediction, as in such cases the order of items is optional. If, on the

\footnotetext{
82 Some of the constraints, notably $\mathrm{S} 1, \mathrm{~S} \Omega, \mathrm{A} 1, \mathrm{~A} \Omega, \mathrm{Ad} 1, \mathrm{Ad} \Omega, \mathrm{f}(\mathrm{Ad})$, (Ad)f, were actually not discussed for Hungarian. Since Hungarian has no subjects, $S 1$ and $S \Omega$ may also be ranked above the faithfulness constraint. Just like in English, $A 1$ and $A \Omega$ would play a role in deciding grammaticality only when no predicate is present. However, as has been shown, in this case ordering is decided based on information structure, not the grammatical role of the arguments. As such A1 and $A \Omega$ are ranked equally, at the bottom of the constrain hierarchy. Since the default position of predicate functees is postverbal, $\mathrm{f}(\mathrm{Ad})$ » $(\mathrm{Ad}) \mathrm{f}$, and since the word order of non-topic post-verbal arguments is free, and no distinction is made between arguments and modifiers, the Ad constraints are placed along with the corresponding A constraints.
} 
other hand, when the items get placed, the evaluation system is "blind" to their internal make-up, items will always have the same constraint violation profiles.

\subsection{Final remarks}

The analysis of coordination provided here is not complete and several issues had to be left for future research.

Nominal coordination was not discussed, only mentioned in a footnote.

Certain Hungarian ellipsis constructions were problematic for the theory developed: unexpected optionality in conjunct order was found, contrary to the prediction made by the grammar. If this optionality can be related to independent considerations, the data do not contradict the basic premise that conjunct ordering is related to basic word order. If no such independent reasons can be identified to explain the unexpected conjunct order, the premise of this work - and along with it the analysis, which hinges on this premise - would need to be revised.

From a theory-internal standpoint the $\mathrm{pS} / \mathrm{Sp}$ pair of constraints lacked clear motivation, since argument constraints can already be argued to "license" the placement of the subject, while the predicate - unless it is the top predicate of the input - is licensed not by its subject but by virtue of being the functee of a higher functor, such as the conjunction in cases of coordination. An OT alignment account which can account for the same range of data without incorporating the $\mathrm{pS} / \mathrm{Sp}$ (or more generally Lf/fL) pair of constraints would be preferable.

On the whole, however, a very restricted Optimality Theoretic alignment approach, based on the interaction of violable alignment constraints, seems capable of accounting for a wide range of data. In terms of coordination and ellipsis it seems to offer a more principled approach than previous accounts either within the mainstream phrase structure tradition or within the diverse family of structureless theories. 


\section{References}

Alberti, G. (1999): 'The Grammar of Total Lexicalism,' Working Papers in the Theory of Grammar 6/1. Theoretical Linguistics Programme, Eötvös Loránd University, Budapest and Research Institute for Linguistics, Hungarian Academy of Sciences, Budapest.

Alberti, G. (2001): 'Indo-Germanic Word Order Phenomena in a Totally Lexicalist Grammar,' in Sprachtheorie und germanistische Linguistik 11.2, Kossuth University Publishing House, Debrecen, 135-193.

Anderson, S. R. (2000): 'An Optimal Account of Second Position Phenomena,' in J. Dekkers, F. van der Leeuw and J. van de Weijer (eds.) Optimality Theory - Phonology, Syntax, and Acquisition, Oxford University Press, 302-333.

Barry, G. and M. Pickering (1990): 'Dependency and constituency in categorical grammar,' in G. Barry and G. Morrill (eds.) Edinburgh Working Papers in Cognitive Science (5): Studies in categorical grammar, 23-45.

Bartos, H. (2001): 'Sound-form non-insertion and the direction of ellipsis,' Acta Linguistica Hungarica vol. 48 (1-3), pp. 3-24.

Belletti, A. and U. Shlonsky (1995): 'The order of verbal complements: a comparative study,' Natural Language and Linguistic Theory 13(3), 489-526.

Blakemore, D. (1987): Semantic Constraints on Relevance, Blackwell, Oxford.

Blakemore, D. (1989): 'Denial and contrast: a Relevance Theoretic account of but,' Linguistics and Philosophy 12, 15-37.

Blass, R. (1989): 'Pragmatic effects of coordination: The case of 'and' in Sissala,' UCL Working Papers in Limguistics 1, University College, University of London, 32-52.

Boas, F. (1901): Kathlamet Texts, Bureau of American Ethnology, Bulletin 26. Government Printing Office, Washington, DC.

Bogoras, W. (1922): 'Chukchee,' Handbook of American Indian Languages, Part 2, Bureau of American Ethnology Bulletin 40, 631-903.

Borsley, R. D. (1994): 'In Defence of Coordinate Structures,' Linguistic Analysis 24, 218246.

Bowe, H. J. (1990): Categories, Constituents and Constituent Order in Pitjantjatjara an Aboriginal Language of Australia, Routledge, London.

Bresnan, J. (1998): 'Morphology Competes with Syntax: Explaining Typological Variation in Weak Crossover Effects,' in P. Barabarosa, D. Fox, P. Hagstrom, M. McGinnis and D. Pesetsky (eds.) Is the Best Good Enough? Optimality and Competition in Syntax, MIT Press, Cambridge, Mass.

Bresnan, J. (2001): 'Explaining morphosyntactic competition,' in M. Baltin and C. Collins (eds.) Handbook of Contemporary Syntactic Theory, Blackwell, Oxford, 11-44. 
Bresnan, J. (2002): 'The Lexicon in Optimality Theory,' in S. Stevenson and P. Merlo (eds.) The Lexical Basis of Syntactic Processing: Formal, Computational and Experimental Issues, John Benjamins, Amsterdam, 39-58.

Choi, H-W. (1996): 'Optimizing Structure in Context: Scrambling and Information Structure,' Doctoral dissertation, Stanford University, Stanford, Calif.

Choi, H-W. (1999): Optimizing Structure in Context: Scrambling and Information Structure, CSLI Publications, Stanford, Calif.

Choi, H-W. (2001): 'Binding and Discourse Prominence: Reconstruction in "Focus" Scrambling,' in G. Legendre, J. Grimshaw and S. Vikner (eds.) Optimality-Theoretic Syntax, MIT Press, Cambridge, Mass., 143-169.

Chomsky, N. (1965): Aspects of the Theory of Syntax, MIT Press, Cambridge, Mass.

Chomsky, N. (1970): 'Remarks on nominalization,' in R. A. Jacobs and P. S. Rosenbaum (eds.) Readings in English transformational grammar, Ginn, Waltham, Mass., 184-221.

Chomsky, N. (1981): Lectures on Government and Binding, Foris, Dordrecht.

Chomsky, N. (1992): A minimalist program for linguistic theory. Occasional papers in linguistics 1, MIT Press, Cambridge, Mass.

Chung, D. (2001): '(A)symmetric Tense Interpretation of Asymmetrically Tense-marked -ko 'and' Coordinate Structures in Korean,' presentation given at the $4^{\text {th }}$ NWCL International Conference, University of Salford, Nov. 16-18.

Comrie, B. (1981): Language universals and linguistic typology: Syntax and morphology, University of Chicago Press.

Cook, E. (1984): A Sacree Grammar, University of British Columbia Press, Vancouver.

Craig, C. G. (1977): The Structure of Jacaltec, University of Texas Press, Austin.

Dalrymple M., S. M. Shieber and F. Pereira (1991): 'Ellipsis and higher-order unification,' Linguistics and Philosophy 14(4), 399-452.

Debusmann, R. (2000): An Introduction to Dependency Grammar, ms., University of the Saarland.

Dixon, R. M. W. (1972): The Dyirbal Language of North Queensland, Cambridge University Press.

Donati, C. (1999): 'Merge Copy,' presentation given at the $21^{\text {st }}$ Annual Meeting of the DGfS, University of Konstanz, Feb. 24-26.

Dowty, D. (1988): 'Type-raising, functional composition and non-constituent coordination,' in R. T. Oehrle, E. Bach and D. Wheeler (eds.) Categorial Grammars and Natural Language Structures, Reidel, Dordecht, 153-198.

Dowty, D. (1991): 'Thematic proto-roles and argument selection,' Language 67, 547-619.

É. Kiss, K. (1981): 'Structural relations in Hungarian, a 'free' word order language,' Linguistic Inquiry 12, 185-213. 
É. Kiss, K. (1987): Configurationality in Hungarian, Studies in Natural Language and Linguistic Theory, Reidel, Dordrecht.

É. Kiss, K. (1994): 'Sentence Structure and Word Order,' in F. Kiefer and K. É. Kiss (eds.) The syntactic Structure of Hungarian, Academic Press, San Diego \& New York, 1-90.

É. Kiss, K., F. Kiefer and P. Siptár (1998): Új magyar nyelvtan [New Hungarian Grammar], Osiris Kiadó, Budapest.

Escher, M. C. (1986): Escher on Escher, Harry N. Abrams, New York.

Gáspár, M. (1999): 'Coordination in Optimality Theory,' Nordic Journal of Linguistics 22, 157-182.

Gáspár, M. (2004): 'Topic Universality in OT inputs,' in L. Varga (ed.) The Even Yearbook 6, 60-73.

Glover, W. W. (1974): Semantic and Grammatical Structures in Gurung (Nepal), Summer Institute of Linguistics, University of Oklahoma Press, Norman.

Goodall, G. (1987): Parallel structures in syntax. Coordination, causatives and restructuring, Cambridge University Press.

Grimshaw, J. (1990): Argument Structure, MIT Press, Cambridge, Mass.

Grimshaw, J. (1991): 'Extended projection,' ms. Brandeis University.

Grimshaw, J. (1997): 'Projection, Heads and Optimality,' Linguistic Inquiry 28, 373-422.

Grimshaw, J. (1998): ‘Constraints on Constraints,' ms., Rutgers University, New Brunswick, New Jersey.

Grimshaw, J. and V. Samek-Lodovici (1995): 'Optimal subjects and subject universals,' University of Massachusetts Occasional Papers in Linguistics 18: 589-605.

Grimshaw, J. and V. Samek-Lodovici (1998): 'Optimal Subjects and Subject Universals,' in P. Barbosa, D. Fox, P. Hagstrom, M. McGinnis and D. Pesetsky (eds.) Is the Best Good Enough? Optimality and Competition in Syntax, MIT Press, Cambridge, Mass., 193-219.

Grønbech, K. (1979): The Structure of the Turkic Languages, Indiana University Altaic Series Vol. 136. Research Institute for Inner Asian Studies, Indiana University, Bloomington.

Haider, H. (in press): 'How to Turn German into Icelandic - And Derive the OV-VO Contrasts,' The Journal of Comparative Germanic Linguistics.

(http://www.sbg.ac.at/spr/people/hubert_haider/dl/turn.pdf)

Halle, M. (1997): 'Distributed morphology: impoverishment and fission,' in B. Bruening, Y. Kang and M. McGiniss (eds.) MIT Working Papers in Linguistics 30: Papers at the Interface, MIT Press, Cambridge, Mass., 425-449.

Halle, M. and A. Marantz (1993): 'Distributed morphology and the pieces of inflection,' in K. Hale and S. J. Keyser (eds.) The View from Building 20, MIT Press, Cambridge, Mass., 111-176. 
Hardegree, G. (in preparation): 'Introduction to Modal Logic,' ms., University of Massachusetts.

(http://www-unix.oit.umass.edu/ gmhwww/511/text.htm)

Harley, H. and R. Noyer (1998): 'Mixed nominalizations, short verb movement, and object shift in English,' in H. Harley (ed.) MIT Working Papers in Linguistics 32: Papers from the UPenn/MIT roundtable on Argument Structure and Aspect, MIT Press, Cambridge, Mass., 119-137.

Harris, J. and G. Lindsey (1995): 'The elements of phonological representation,' in J. Durand and F. Katamba (eds.) Frontiers on Phonology: Atoms, Structures, Derivations, Longman, Harlow, 34-79.

Hayward, R. J. and G. G. Corbett (1988): 'Resolution rules in Qafar,' Linguistics 26, 259279.

Hendriks, H. (1993): Studied Flexibility: Categories and Types is Syntax and Semantics, ILLC Dissertation Series 1993/5, University of Amsterdam.

Hidalgo, C. A. and A. C. Hidalgo (1971): A tagmemic grammar of Ivatan, University of the Philippines Press, Manila.

Hirschbueler, P. (1982): 'VP deletion and across the board quantifier scope,' in J. Pustejovsky and P. Selled (eds.) NELS 12, University of Massachusetts, Amherst.

Hockett, C. F. (1958): A Course in Modern Linguistics, Macmillan, New York.

Holmstedt, R. D. (2000): 'Dislocation and Topicalization in Biblical Hebrew: A Generative Syntactic-Pragmatic Analysis,' talk presented to the Midwest meeting of the Society of Biblical Literature, Chicago, Feb. 14.

Hordós, M. (2003): 'Gerunds in Optimality Theory,' Doctoral dissertation, Eötvös Loránd University, Budapest.

Huang, C-T. J. (1984): 'Phrase structure, lexical integrity and Chinese compounds,' Journal of Chinese Language Teachers Association 19.2, 53-78.

Huang, C.-T. J. (1982): 'Logical Relations in Chinese \& Theory of Grammar,' Doctoral Dissertation, MIT, Cambridge, Mass.

Huang, C.-T. J., Y.-H. A. Li and Y. Li (in preparation): 'Syntax of Chinese,' to be published by Cambridge University Press.

(http://www.courses.fas.harvard.edu/ ling171/HLL_2004_Chapters/)

Hudson, R. (1984): Word Grammar, Oxford: Blackwell.

Hudson, R. (1987): 'Zwicky on heads,' Journal of Linguistics 23, 109-132.

Hudson, R. (1990): English Word Grammar, Oxford: Blackwell.

Hudson, R. (1996): Sociolinguistics (2 ${ }^{\text {nd }}$ edition), Cambridge.

Hudson, R. (2002): 'Word Grammar - A brief introduction for graduate students,' ms., University College London. 
Hudson, R. (2003): 'An Encyclopedia of English Grammar and Word Grammar,' ms., University College London.

Huet, G. (1975): 'A Unification Algorithm for Typed $\lambda$-Calculus,' Theoretical Computer Science 1, 25-57.

Iten, C. (2001): 'But and and,' presentation given at the $4^{\text {th }}$ NWCL International Conference, University of Salford, Nov. 16-18.

Jackendoff, R. (1977): X'-Syntax: A Study of Phrase Structure, MIT Press, Cambridge, Mass. Jacobs, J. (1999): 'Informational autonomy,' in P. Bosch and R. van der Sandt (eds.), Focus: linguistic, cognitive and computational perspectives, Cambridge University Press, 5881.

Jacobs, J. (2001): 'The dimensions of topic-comment,' Linguistics 39(4), 641-681.

Johannessen, J. B. (1993): 'Coordination. A minimalist approach,' Doctoral dissertation, University of Oslo.

Johannessen, J. B. (1996): 'Partial agreement and coordination,' Linguistic Inquiry 27/4, 661676.

Johannessen, J. B. (1998): Coordination, Oxford University Press.

Kaplan, R. M. and J. Bresnan (1982): Lexical-functional grammar: a formal system for grammatical representation,' in J. Bresnan (ed.), The Mental Representation of Grammatical Relations, MIT Press, Cambridge, Mass., 173-281.

Kazenin, K. I. (2001): 'Can gapping always be constituent coordination?' ms. University of Tübingen.

www.sfb441.uni-tuebingen.de/b2/papers/chuvash.pdf

Keenan, E. (1988): 'On semantics and the binding theory,' in J. Hawkins (ed.) Explaining Language Universals, Blackwell, Oxford.

Kleene, S. (1935): 'A theory of positive integers in formal logic,' American Journal of Mathematics 57, 153-173, 219-244.

Klein, W. (1993): 'Ellipse,' in J. Jacobs, A. von Stechow, W. Sternefeld and T. Vennemann (eds.) Syntax: An international handbook of contemporary research 1, de Gruyter, Berlin, 763-799.

Koster, J. (1987): Domains and Dynasties. The Radical Autonomy of Syntax, Foris, Dordrecht.

Kroch, A. (2003): 'Syntactic change,' in M. Baltin and C. Collins (eds.) The Handbook of Contemporary Syntactic Theory, Blackwell, Oxford.

(Also available at: $\mathrm{ftp} / /$ babel.ling.upenn.edu/papers/faculty/tony_kroch/papers/diachronic-syntax-99.pdf) 
Kruijff, J-G. M. (2002): 'Formal and Computational Aspects of Dependency Grammar,' talk given at the 14th European Summer School in Logic, Language and Information, Trento, Italy, 5-16, August.

Kuno, S. (1973): The Structure of the Japanese Language, MIT Press, Cambridge, Mass.

Larson, R. (1985): 'On the Syntax of Disjunction Scope,' Natural Language and Linguistic Theory 3, 217-264.

Larson, R. (1988): 'On the Double Object Construction,' Linguistic Inquiry 19: 335-391.

Legendre, G., P. Smolensky and C. Wilson (1998): 'When is less more? Faithfulness and Minimal Links in wh-chains,' in P. Barbosa, D. Fox, P. Hagstrom, M. McGinnis and D. Pesetsky (eds.) Is the Best Good Enough? Optimality and Competition in Syntax, MIT Press, Cambridge, Mass., 249-289.

Martin, S. E. and Y-S. C. Lee (1986): Beginning Korean. Tuttle, Tokyo.

Maslova, E. (2003): Tundra Yukaghir, Lincom, München.

Also available at: www.stanford.edu/ emaslova/TundraYukaghir.pdf

McCawley, J. D. (1998): The syntactic phenomena of English, $2^{\text {nd }}$ ed., University of Chicago Press.

McKaughan, H. P. and B. A. Macaraya (1967): A Maranao dictionary, University of Hawai'i Press, Honolulu.

Mel'čuk (1988): Dependency Syntax: Theory and Practice, SUNY Press, Albany, New York.

Miller, J. (1964): 'The role of verb stems in the Mamanwa kernel verbal clauses,' Oceanic Linguistics 3.1: 87-100.

Mithun, M. (1988): 'The grammaticization of coordination,' in J. Haiman and S. A. Thompson (eds.) Clause combining grammar and discourse, John Benjamins Publishing, Amsterdam, 331-360.

Moreton, E. and P. Smolensky (2002): 'Typological Consequences of Local Constraint Conjunction,' in L. Mikkelsen and C. Potts (eds.) WCCFL 21 Proceedings, Cascadilla Press, Cambridge, Mass.

Munn, A. (1987): 'Coordinate structure and X-bar theory,' McGill Working Papers in Linguistics 4, McGill University, Montreal.

Munn, A. (1992): 'A null operator analysis of ATB gaps,' The Linguistic Review 9: 1-26.

Munn, A. (1993): 'Topics in the Syntax and Semantics of Coordinate Structures,' Doctoral dissertation, University of Maryland, College Park.

Munn, A. (2000): 'Three types of coordination asymmetries,' in K. Schwabe and N. Zhang (eds.) Ellipsis in Conjunction, Max Niemeyer Verlag, Tübingen, 1-22.

Newson, M. (1998a): 'Logical form,' ms., Eötvös Loránd University, Budapest.

Newson, M. (1998b): 'Thematic structure and optimality theory,' talk presented to the $2^{\text {nd }}$ Workshop on Optimality Theory Syntax, University of Stuttgart, Nov. 13-14. 
Newson, M. (2000a): 'The input in Optimality Theory,' course presented at Szeged University.

Newson, M. (2000b): 'A restrictive theory of alignment and some of its consequences,' ms., Eötvös Loránd University, Budapest.

Newson, M. (2002): 'The coordination particle,' in L. Varga (ed.) The Even Yearbook 5, Eötvös Loránd University, Budapest, 95-116.

Newson, M. (2003): 'Markedness in case systems without markedness constraints,' talk presented at the Seventh Workshop on Optimality theory Syntax, University of Nijmegen, Oct. 27-28.

Newson, M. and M. Gáspár (2001): 'Coordination, Ellipsis and Impoverished Inputs,' talk presented at the $4^{\text {th }}$ NWCL International Conference, University of Salford, Nov. 16-18.

van Oirsouw, R. R. (1987): The syntax of coordination, Croom Helm, London.

Panevová, J. (1974): 'On verbal frames in functional generative description I,' Prague Bulletin of Mathematical Linguistics 22: 3-40.

Pesetsky, D. (1998): 'Some Optimality Principles of Sentence Pronunciation,' in P. Barbosa, D. Fox, P. Hagstrom, M. McGinnis and D. Pesetsky (eds.), Is the Best Good Enough?, MIT Press, Cambridge, Mass.

Peters, S. (1973): 'On Restricting Deletion Transformations,' in M. Gross, M. Halle and M. Schutzenberger, (eds.), The Formal Analysis of Language, Mouton, The Hague, 372384.

Pickering, M. and G. Barry (1993): 'Dependency categorical grammar and coordination,' Linguistics 31: 855-902.

Prince, A. and P. Smolensky (1993): Optimality Theory: constraint iteraction in generative grammar, RuCCS Technical Report \#2, Rutgers University Center for Cognitive Science, Piscateway, New Jersey.

Radford, A. (1981): Transformational Grammar, Cambridge University Press.

Rakowski, A. (2001): 'Subject and Specificity: The Case of Tagalog,' in Mako Hirotani (ed.) Proceedings of NELS 32, GLSA, Amherst, Mass.

Reid, L. A. and H. Liao (2004): 'A brief syntactic typology of Philippine languages,' in E. Zeitoun (ed.) Linguistic Papers from the International Symposium on Austronesian Cultures: Issues Relating to Taiwan, Academia Sinica, Taipei. 433-490.

(Also

available

at:

http://www2.hawaii.edu/ hsiuchua/Brief\%20Syntactic\%20Typology\%20of\%20Philippi ne\%20Languages-final\%20version--\%2012-23-03.doc)

Reinhart, T. and E. Reuland (1993): 'Reflexivity,' Linguistic Inquiry 24. 657-720.

Rochemont, M. and P. Culicover (1990): English focus constructions and the theory of grammar, Cambridge University Press. 
Ross, J. R. (1970): 'Gapping and the Order of Constituents,' in M. Bierwisch and K. E. Heidolph (eds.) Progress in Linguistics, Mouton, The Hague, 249-259.

Rothstein, S. (1991): 'Heads, projections and category-determination,' in K. Leffel and D. Bouchard (eds.) Views on phrase structure, Kluwer, Dordrecht.

Rowlands, E. C. (1969): Yoruba, Hodder \& Stoughton, Sevenoaks, Kent.

Sag (1976): 'Deletion and Logical Form,' Doctoral dissertation, MIT, Cambridge, Mass.

Saito M. and H. Hoshi (2000): 'Japanese light verb constructions and the minimalist program,' in R. Martin, D. Michaels, and J. Uriagereka (eds.), Step by step: essays on minimalist syntax in honor of Howard Lasnik, MIT Press, Cambridge, Mass, 261-295.

Salles, H. M.-L. (1995) 'Preposition pied-piping and preposition stranding: a minimalist approach,' Research Papers in Linguistics 6, University of Wales, Bangor, 97-123.

Santorini, B. and A. Kroch (2000): 'The syntax of natural language: An online introduction using the Trees program,' University of Pennsylvania.

(http://www.ling.upenn.edu/ beatrice/syntax-textbook)

Schütz, A. J. (1969): Nguna Texts, Oceanic Linguistics Special Publication No. 4, University of Hawaii Press, Honolulu.

Schwarz, B. (1999): 'On the Syntax of Either... Or,' Natural Language and Linguistic Theory 17, 339-370.

Seuren, P. A. M. (1985): Discourse Semantics, Blackwell, Oxford

Smolensky, P. (1993): 'Harmony, markedness and phonological activity,' paper presented at Rutgers Optimality Workshop 1, Rutgers University, Oct. 23.

Sobha, L. and B. N. Patnaik (2000): 'Vasisth: An Anaphora Resolution System For Indian Languages,' presentation given at the International Conference on Artificial and Computational Intelligence for Decision, Control and Automation in Engineering and Industrial Applications, Monastir, Tunisia.

Speas, M. (1997): 'Optimality Theory and Syntax: Null pronouns and Control,' in D. Archangeli and D. T. Langendoen (eds.) Optimality Theory. An Overview, Blackwell, Malden, Mass., 171-199.

Stowell, T. (1981): 'Origins of phrase structure,' Doctoral dissertation, MIT, Cambridge, Mass.

Stowell, T. (1982): 'The tense of infinitivals,' Linguistic Inquiry 13, 561-570.

Szigetvári, P. (1999): 'VC Phonology: a theory of consonant lenition and phonotactics,' Doctoral dissertation, Eötvös Loránd University, Budapest.

Tateishi, K. (1994): The Syntax of 'Subjects', CSLI Publications, Stanford, Calif.

Tesnière, L. (1959): Eléments de Syntaxe Structurale [Elements of structural syntax], Klincksiek, Paris. 
Trávníček, F. (1949): Mluvnice spisovné češtiny, ii. Skladba [Czech registry grammar, ii. Syntax], Melantrich, Prague.

Welmers, W. E. (1973): African Language Structures, University of California Press, Berkeley.

Welmers, W. E. (1976): A Grammar of Vai, University of California Publications in Linguistics 84, University of California Press, Berkeley.

Wilder, C. (1994): 'Coordination, ATB and Ellipsis,' in Zwart, J.-W. (ed.), Minimalism and Kayne's Antisymmetry Hypothesis, Grönigen Arbeiten zur Germanistichen Linguistik vol. 37, 291-331.

Wilder, C. (1997): 'Some Properties of Ellipsis in Coordination,' in A. Alexiadou and T. A. Hall (eds.), Studies on Universal and Typological Grammar, Linguistik Aktuell vol. 13, pp. 59-107.

Williams, E, (1977): 'Discourse and Logical Form,' Linguistic Inquiry 8, 101-139.

Williams, E, (1978): ‘Across-the-board rule application,' Linguistic Inquiry 9, 31-43.

Williams, E. (1997): 'Blocking and anaphora,' Linguistic Inquiry 28, 577-628.

Worth, D. S. (1961): Kamchadal Texts Collected by W. Jochelson, Mouton, The Hague.

Zeevat, H. (1988): 'Combining Categorial Grammar and Unification,' in U. Reyle, C. Rohrer (eds.) Natural Language Parsing and Linguistic Theories, D. Reidel, Dordrecht, 202229.

Zeevat, H. (1991): 'Aspects of Discourse Semantics and Unification Grammar,' Doctoral dissertation, University of Amsterdam.

Zwart, J.-W. (1995): 'Review of Johannessen. B.: Coordiantion. A minimalist approach,' GLOT International 1. 